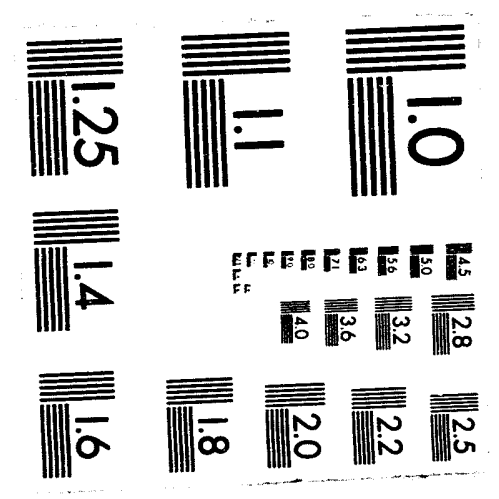



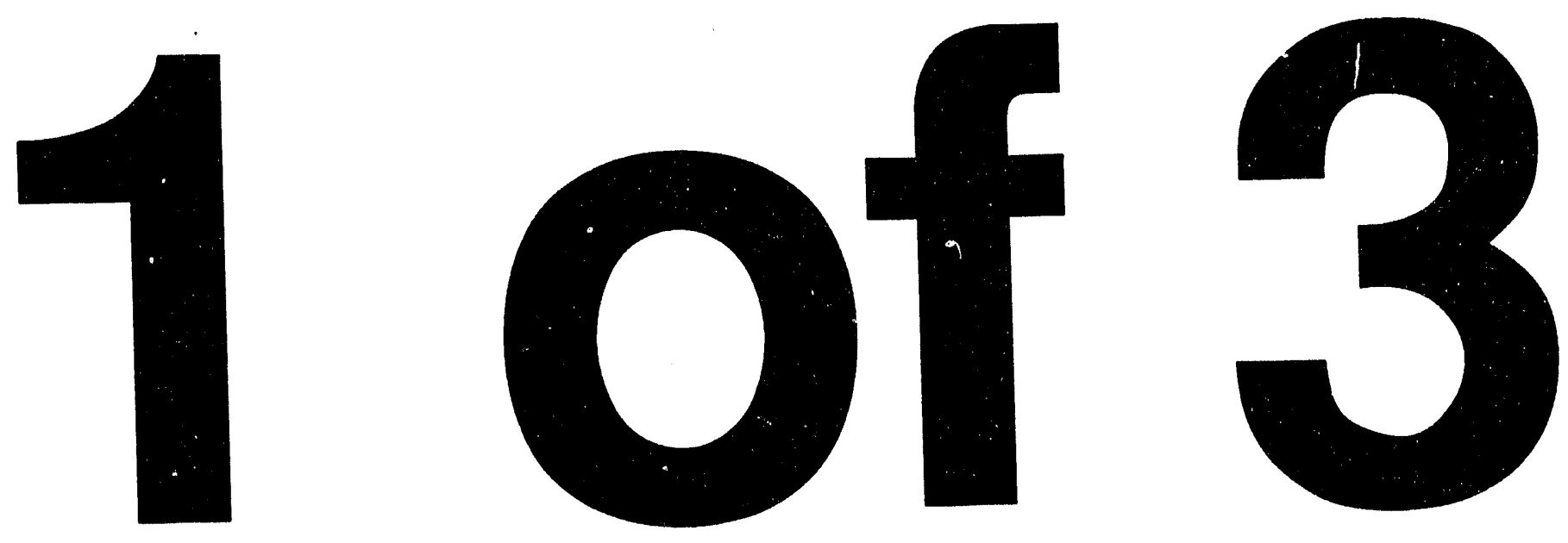


\title{
ASSESSMENT AND DEVELOPMENT OF AN INDUSTRIAL WET OXIDATION SYSTEM FOR BURNING WASTE AND LOW GRADE FUELS
}

\author{
CONTRACT No. DE-FC07-88m12711
}

FINAL REPORT - PHASE IIB

PILOT DEMONSTRATION OF THE MODAR SUPERCRITICAL WATER OXIDATION PROCESS

\author{
JANUARY 1994
}

DISCLAIMER

\begin{abstract}
This report was prepared as an account of work sponsored by an agency of the United States Government. Neither the United States Government nor any agency thereof, nor any of their employees, makes any warranty, express or implied, or assumes any legal liability or responsibility for the accuracy, completeness, or usefulness of any information, apparatus, product, or bility for the accuracy, completeness, or usefulness of any information, apparatus, product, or ence herein to any specific commercial product, process, or service by trade name, trademark, manufacturer, or otherwise does not necessarily constitute or imply its endorsement, recommendation, or favoring by the United States Government or any agency thereof. The views and opinions of authors expressed herein do not necessarily state or reflect those of the United States Government or any agency thereof.
\end{abstract}

Atone \& Webster Engineering Corporation 


\section{TABLE OF CONTENTS}

1.0 Summary, Conclusions, and Recommendations

$2.0 \quad$ Background

2.1 Introduction to SCWO

2.2 Previous Studies Completed in this Program

3.0 Engineering, Design and Design Studies

3.1 Design Basis/Concept

3.2 Process Description

3.3 Reactor System Flow Modeling

3.4 HAZOP Analysis

3.5 Health \& Safety Plan

4.0 Fabrication

$5.0 \quad$ Testing

5.1 Objectives

5.2 Approach

5.3 Overall Results

5.4 168-hour Performance Test

5.4.1 Conditions of Operation

5.4.2 Run Summary

5.4.3 Performance 


\subsection{Effluent Quality}

\subsubsection{Carbon Destruction}

5.5.3 Treatment of the Brine Solids

\subsection{Solids Handling}

5.6.1 System Performance

\subsubsection{Parameters Affecting Salt Removal}

5.7 Process Equipment and Operation

5.8 Materials Testing

5.9 Additional Studies

\subsubsection{Neutralization}

5.9.2 Supercritical Water Recycle

5.9.3 Reaction Initiators

Appendix A Materials Testing

A.1 Service Failures and NDE (April - June 1993)

A.2 Service Failures (August 1993)

A.3 Materials/Components Analyses

Appendix B 168-hour Performance Test Run Summary 


\subsection{BACKGROUND, CONCLUSIONS, AND RECOMMENDATIONS}

Stone \& Webster Engineering Corporation is Project Manager for the Development and Demonstration of an Industrial Wet Oxidation System for Burning Wastes and Low Grade Fuel. This program has been ongoing through a Cooperative Agreement sponsored by the Department of Energy, initiated in June 1988.

This report presents a comprehensive discussion of the results of the demonstration project conducted under this cooperative agreement with the overall goal of advancing the state-of-theart in the practice of Supercritical Water Oxidation (SCWO). In recognition of the Government's support of this project, we have endeavored to include all material and results that are not proprietary in as much detail as possible while still protecting MODAR's proprietary technology. A specific example is in the discussion of materials of construction where results are presented while, in some cases, the specific materials are not identified.

The report presents the results chronologically. Background material on the earlier phases (Section 2) provide an understanding of the evolution of the program, and bring all reviewers to a common starting point. Section 3 provides a discussion of activities from October 1991 through July 1992, during which the pilot plant was designed; and various studies including computational fluid dynamic modeling of the reactor vessel, and a process HAZOP analyses were conducted. Significant events during fabrication are presented in Section 4. The experimental results of the test program (December 1992 - August 1993) are discussed in Section 5.

\section{BACKGROUND}

Wet oxidation is a term commonly used to describe a chemical reaction occurring in the presence of water between oxygen and suspended or dissolved organic substances. Chemically these reactions are analogous to those occurring in simple burning, i.e. the amount of heat liberated and the primary end products formed are the same as when oxygen gas reacts directly with organic matter, but kinetically, they differ significantly. Although it is more difficult to initiate than conventional combustion, wet oxidation will proceed at much lower temperatures. Reaction rates are low, and the process is generally not self sustaining unless conducted at temperatures greater than $175^{\circ} \mathrm{C}$. Processes have been developed that oxidize dilute feeds at subcritical (less than $374^{\circ} \mathrm{C}$ and $3206 \mathrm{psi}$ ) and supercritical conditions (greater than $374^{\circ} \mathrm{C}$ and $3206 \mathrm{psi})$.

During reaction the heat liberated increases the reaction temperature. In current embodiments, the process is adiabatic - the heat of reaction is removed from the process as hot effluent. The reaction zone temperature is controlled by limiting the organic (fuel) concentration in the feed.

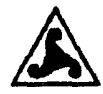


Current systems that achieve complete destruction of organic materials, and thereby generate the most heat per unit feed, are limited to feeds containing less than $1900 \mathrm{Btu} / \mathrm{lb}$ (approximately 15 $20 \%$ organic material in water) so as not to exceed a reaction temperature of $650^{\circ} \mathrm{C}$. During processing of organic materials, the heat of reaction may be recovered through heat exchange with the reactor effluent. This concept of energy recovery was the motivation behind the Department of Energy in initiating this project.

\section{SUMMARY}

As originally envisioned, the program consisted of four distinct phases:

Phase I Feasibility Evaluation

Phase II Proof of Concept

Phase III Pilot (Industrial) System Development

Phase IV Testing Under Industrial Conditions

To date, Stone \& Webster has completed Phases I and II. The result of Phase I, Feasibility Evaluation, was a report issued in September 1989. During the Phase I evaluations, Stone \& Webster concluded that energy could be recovered from wet oxidation systems. In addition, while subcritical processes were commercially mature, supercritical water oxidation (SCWO) was still under development. Furthermore, we concluded, through an industrial review panel, that commercial users wanted the complete destruction of hazardous or nuisance wastewaters that SCWO provided. A further conclusion was that the MODAR SCWO process was the most commercially mature, and therefore it became the focus of the development and demonstration project.

Based on the industrial interest shown in Phase I, Stone \& Webster began Phase IIA, which was an extensive review of the MODAR SCWO process to determine its readiness for commercial application, and develop a plan for future testing to prove the concept, or, if appropriate, proceed dirently to Phase III for commercial demonstration. In July 1990, the results of Phase IIA were presented. A project review meeting was held in lieu of publishing a final report to allow a free and open discussion of proprietary information related to the MODAR process. Key conclusions of Phase IIA $w^{\prime}$ e that the MODAR process, while supported by a solid background of laboratory and pilot scale testing, was not ready for commercial application, and several critical aspects needed to be demonstrated at a larger scale. These included demonstration of:

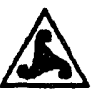


Continuous operation over extended periods;

Effective control of the solids generated during processing;

Complete destruction of the waste feed; and

Critical process equipment and procedures.

During Phase IIA, Stone \& Webster worked with MODAR to develop a cost effective plan to prove the critical concepts and equipment associated with the process through the refurbishment of MODAR's existing pilot plant. This project plan included extensive modifications to the existing reactor vessel, as well as upgrading the balance of plant to support the new process configuration. Since the goal of the project was demonstration of maximum energy recovery, the reactor and process were configured to produce a solid-free hot effluent from the reactor for heat recovery.

In the work reported here, Stone \& Webster and MODAR conducted the demonstration project to prove critical equipment and processes for the M DAR supercritical water oxidation concept. This was accomplished by refurbishing the existing MODAR pilot plant. The refurbishment was extensive and included reconfiguring most equipment and updating the control system. The project was designed to effectively "prove the concept" of supercritical water oxidation, and provide data necessary for scaleup to commercial units. Stone \& Webster, as Project Manazer, developed the performarice specifications for the pilot plant, and provided design oversight and assistance as required. Key to this demonstration was a pilot-scale design that effectively simulated full scale operations using commercially available equipment.

Key objectives of the pilot demonstration project included:

Characterization of the process effluent;

Continuous processing of a sticky solids feed;

Materials testing;

Equipment evaluation and testing; and

Measurement of heat/energy available for export.

During the pilot plant design, Stone \& Webster reviewed all designs and specifications developed by MODAR and provided actual design input for critical items that were beyond the capabilities of MODAR (for example the reactor vessel which required a National Board Certification). Stone \& Webster also performed a HAZOP (hazardous operations) analysis of the process, and assisted in the development of a comprehensive Health and Safety Plan for the pilot test project. 
The pilot plant was fabricated, and testing was initiated in December 1992. Stone \& Webster was responsible for setting experimental objectives and had one process engineer assisting as a Shift Supervisor during operations. MODAR provided the other staff to allow operations around the clock during experimental operation. Plant staffing included a Mechanical Operator, Computer Operator, and Shift Supervisor on each shift.

The test program included a series of tests of increasing duration and processing difficulty. Initially, the system was operated with a salt-free organic feed material for troubleshooting and debugging mechanical and control equipment. Once the system's operation was verified, the next series of tests focused on solids deposition and removal from the reactor. These shortduration tests were primarily to optimize nozzle performance.

It is critical to the commercialization of the SCWO process to demonstrate the capability to treat materials that contain/generate sticky solids. MODAR's approach to controlling these materials is two-fold. First, the solids generated are directed into the liquid brine within the vessel reactor. Secondly, any entrained material is removed through mechanical filtration. It was anticipated that the filter would remove virtually all entrained particulate matter in the reactor effluent and eventually accumulate enough particulate to require cleaning. A unique feature of the MODAR design was that the filter could be cleaned without shutting the unit down. This is a significant advantage over other systems that shutdown, cooldown and redissolve the solids or use mechanical techniques to remove the accumulated salts. The test program evaluated the process' ability to maintain continuous operations without plugging the downstream lines or the filter.

The next series of tests used a simulated hazardous waste feed material (a simulated waste is being used because of permitting limitations) and proceeded stepwise from 24 to 168 hour performance tests. During each test, data were gathered regarding organic destruction, inorganic solids distribution, available energy for recovery, and general system operation. Each test was evaluated and equipment or procedures adjusted prior to proceeding. These tests concluded with a 7-day (168 hour) continuous system test processing the simulated hazardous waste containing $2 \%$ (by weight of the total feed) sticky solids.

The process performance test was completed on August 30, 1993.

\section{CONCLUSIONS}

As expected, tests have shown that scale-up of a SCWO process designed to process a sticky solid feed, was not a trivial task. Our work to date has been valuable in evaluating the mechanical integrity, operation, and limitations of the process. Much of the plant exceeded performance goals. While we processed more sticky solids during this test program than all other projects to date combined (1180 pounds), the primary objective of demonstrating effective control of sticky solids was not achieved. This was due in large part to the limitations imposed on the process (specifically the reactor system) by the configuration that was required to meet

Stone \& Webster

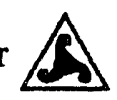


the programmatic goal of producing a hot effluent for energy recovery. The details of this will be discussed further in this report.

Overall, the major conclusions of this deveiopment and demonstration project were:

- The MODAR SCWO process effectively destroys organic materials - at steady state, organic carbon destruction efficiencies of greater than $99.999 \%$ are obtainable and easily maintained.

- The process in its current configuration (filter reactor) processing a sticky solid feedstock, is not ready for commercial application. Limitations and additional developmental efforts are required to control the deposition of sticky solids within the reactor, while effectively neutralizing acid-forming anions in the feed.

However, an alternative embodiment of the MODAR process (quench reactor) shows promise for effective operation with sticky solid feedstocks by neutralizing the acids produced by quenching the reactor effluent.

- Effective control of the sticky solids appears to be strongly dependent on the size/geometry of the reactor system and the flow regime generated by the feed nozzle.

- $\quad$ Corrosion in all zones of the SCWO process can be severe, and requires a variety of materials and fabrication techniques for effective control.

- While special materials are required for some components, commercially available equipment can be used for the majority of a SCWO process.

- The recovery of energy from the SCWO process through heat exchange in the process effluent is possible at the current state-of-the-art with non-sticky feeds. It does not appear likely when processing feedstocks that contain or generate sticky solids without further development.

Each of these conclusions is discussed below. A further discussion is found in Section $\mathbf{5}$ of this report.

\section{Organic Destruction}

Three streams make up the effluent of the MODAR SCWO process: 1) the largest effluent constists of the aqueous stream (mainly water contained in the feed and any generated by oxidation), 2) the gas which consists of $\mathrm{CO}_{2}$, excess oxygen and any nitrogen, 3) and the brine

Stone \& Webster 
which is removed from the reactor and contains the inorganic salts and any ash formed. All three streams are potential pathways for organic material to escape, and were monitored to determine the organic destruction efficiency of the process.

During the test project, the organic material exiting the process was monitored in several ways. Firstly, total organic carbon (TOC) was used to monitor gross carbon destruction. This was monitored and calculated by wet analyses on the brine and liquid effluent and carbon monoxide in the vent gas. Using the available equipment, this technique could validate destruction efficiencies of up to $99.996 \%$ of total carbon. The limitation was due to the detection limit of the liquid TOC analyses.

Destruction of the specific organic constituent (perchloroethylene) was determined by gas chromatographic/mass spectroscopic (GC/MS) analyses of the three effluent streams. In all tests perchloroethylene destruction was in excess of $99.999 \%$.

\section{Processing of Sticky Solids/Nozzle Performance}

This configuration of the MODAR process was developed to produce a hot solid-free effluent that could be used to recover heat from the process. In order to achieve this end, the process design incorporated a feed nozzle that would both provide sufficient mixing to ensure complete chemical reaction (oxidation and neutralization) as well as effectively direct the solids generated through neutralization into the brine. In addition, filters were installed on the vessel effluent lines to capture any solid material that might plug the effluent lines.

The filters performed well. During all tests, there were no indications that any solids passed into the downstream lines. On-line cleaning of the filters was accomplished using liquid water and a backwashing procedure. Physical examinations of the filters were conducted several times during the test program, and the media showed no deterioration even after repeated backwashing.

As testing progressed it became apparent that the nozzle design was critical to efficient operation of this process configuration. The nozzle performed two functions -to provide sufficient mixing to achieve organic destruction and neutralization, and to direct any solids formed or precipitated into the liquid brine at the bottom of the reactor. These objectives tend to be in opposition in that to minimize solids deposition on the vessel walls, a quiescent reactor is needed, while the chemical reactions (oxidation and neutralization) required a highly turbulent environment. During nearly all tests salt deposits on the vessel walls were unacceptably high. Organic destruction was simply accomplished using a variety of nozzles, neutralization of the acidforming anions was very difficult, and required the use of high energy nozzles and acceptance of their increased salt deposition within the reactor.

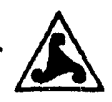


An alternative of operating without neutralization and its associated sticky solids, was not considered since it has been observed that corrosion is highly dependent on the $\mathrm{pH}$ in the system. When acid-forming anions in the feedstock are processed without neutralization, the resultant acid can be extremely corrosive. This was confirmed during testing by increased concentrations of metal cations ( $\mathrm{Cr}$ and $\mathrm{Ni}$ ) in the effluent at $\mathrm{pH}$ levels below 2 .

While we have made significant progress in our understanding of the scaleup of the SCWO process, it is apparent that achieving the original objective of generating a hot solids-free effluent for maximum energy recovery from a sticky solids feedstock is a difficult objective. The complexities of the relationship between nozzle performance and solids deposition in the reactor are not clearly understood, and further work is required to attain a better understanding. This is not to say that the MODAR SCWO process has a fundamental flaw. Our testing has shown and validated the performance of the process destruction efficiencies and the filter's ability to produce a solids-free effluent. This capability is critical to eventual power production with SCWO through use of an expansion turbine. At this time, however, the option of power production may be limited to feedstocks such as sewage sludge or coal wastes which do not produce sticky solids.

MODAR has developed and patented an alternative process reactor configuration in which the effluent is quenched. While this configuration will produce a cooled reactor effluent that is not suitable for energy recovery, it has definite advantages in that it removes a degree of constraint from the nozzle by allowing some neutralization and associated salt formation to occur in the quench area of the reactor effluent. This affords the nozzle a larger window of success in its objectives of mixing and solids control. Although this design will be better suited for processing sticky solids feedstocks, energy recovery from the effluent will be limited.

\section{Materials of Construction}

The SCWO process presents unique material challenges. Within the process one encounters high and low temperatures, basic and acidic $\mathrm{pH}$, free oxygen, and various inorganic materials. In addition, since the process operates at high pressures the same materials are subjected to high sustained stresses, and fabrication techniques may introduce tensile residual stresses which exacerbate the corrosion problem.

The project represents one of the most comprehensive materials test efforts in this field to date. The size of the pilot unit afforded the opportunity to test not only coupon samples but evaluate materials, components and fabrication techniques in actual service equipment. The MODAR SCWO process is made up of four zones or chemical environments: the area where the subcritical fluid mixture is cooled to liquid water, the hot supercritical fluid reaction zone, the liquid effluent zone where final cooldown and gas/liquid separation occurs, and the liquid brine zone. Each of these areas is a unique chemical and thermal environment. Temperatures range from 40 to $600^{\circ} \mathrm{C}, \mathrm{pH}$ from 2 to 8 , oxygen concentration from ppm to percent levels, and salt $\left(\mathrm{NaCl}, \mathrm{Na}_{2} \mathrm{SO}_{4}, \mathrm{Na}_{2} \mathrm{CO}_{3}\right)$ concentrations from ppm levels to nearly saturated. 
This test program has verified that controlling corrosion to acceptable levels is one of the greatest challenges to commercial application of the process. The critical control parameter to limit corrosion is maintaining the effluent $\mathrm{pH}$. In this project it was observed that corrosion increased significantly at effluent $\mathrm{pH}$ levels below 2 .

Most metals and alloys were susceptible to corrosion of varying degrees. Many of the highnickel alloys also experienced stress corrosion cracking in some environments. At this time we have not identified a single metal/alloy that can be used in all zones of the process, however several ceramics show promise. Stone \& Webster and MODAR have identified materials (metals/alloys and ceramics) that are appropriate for each of the zones, and are confident that they are can be used in commercial applications with acceptable corrosion rates. Materials of choice include high-nickel alloys, as well as specialized grades of other materials (Ti for example). In addition, several ceramic materials have been identified that show excellent corrosion resistance. However their use may be limited due to mechanical limitations in strength and fabrication techniques.

Based on the results of the recent test program, the most appropriate materials for fabrication of a MODAR based SCWO process at this time are those shown in the following table. Note that testing has been limited to conventional, commercially available, materials of construction in the process industries, exotic materials (e.g. noble metals) have not been extensively evaluated. Additional candidate materials have been identified and are being tested independently by MODAR. In addition, while this table addresses the suitability of materials to resist corrosion, it is not implied that all these materials in themselves are mechanically suitable for pressure containment.

\begin{tabular}{||c|c|c||}
\hline ZONE & CONDITIONS & MATERIAL \\
\hline 1 & $\begin{array}{c}\text { SUBCRITICAL (acidic) } \\
350^{\circ} \mathrm{C} \geq \mathrm{T} \geq 250^{\circ} \mathrm{C}\end{array}$ & $\begin{array}{c}\mathrm{Ti} \\
\text { (Grades 2 and 12) }\end{array}$ \\
\hline 2 & $\begin{array}{c}\text { SUPERCRITICAL (acid/base) } \\
650^{\circ} \mathrm{C} \geq \mathrm{T} \geq 350^{\circ} \mathrm{C}\end{array}$ & $\begin{array}{c}\text { Proprietary } \\
\text { (alloy and ceramic) }\end{array}$ \\
\hline 3 & $\begin{array}{c}\text { LIQUID EFFLUENT (acidic) } \\
250^{\circ} \mathrm{C} \geq \mathrm{T}\end{array}$ & $\begin{array}{c}\mathrm{Ti} \\
\text { (Grades 2 and 12) }\end{array}$ \\
\hline 4 & $\begin{array}{c}\text { LIQUID BRINE (basic) } \\
350^{\circ} \mathrm{C} \geq \mathrm{T}\end{array}$ & $\begin{array}{c}\mathrm{Ti} \\
\text { (Various Grades) }\end{array}$ \\
\hline
\end{tabular}

\section{Use of Standard Equipment}

The test program verified that commercially available equipment can be used in the MODAR SCWO process. The pilot plant was fabricated using catalog items - albeit sometimes with special materials - for all items but the reactor vessel. During operations all of the ancillary 
equipment performed to meet or surpass expectations. Specifically the liquid effluent pressure control valves, feed pumping modules, and brine pressure reduction system operated without incident throughout the project. In addition, a commercial distributed computer control system was used that controlled the plant effectively and efficiently. In virtually all experimental runs, the balance of plant operated without incident.

A problem area was the hot valves used to isolate the hot reactor effluent during filter cleaning. The ball valves were problematic in operation and suffered damage in at least three runs. The major problems were that the packing could not survive in the process environment and leaked after as little as one cycle, and the ball and seat were very fragile.

In the model used for this application, the stem packing was located adjacent to the valve seat and operated at the process temperature $\left(600^{\circ} \mathrm{C}\right)$. None of the packing materials used were able to survive at these conditions. A single operation of the valve could result in a complete failure of the packing and shutdown of the system. It is anticipated that an alternative design using an extended bonnet where the packing could remain cool, would improve performance and reliability of the component.

Physical damage to the ball and seat were also encountered. The valves while designed to provide hydraulic isolation, were not designed to provide pressure isolation in excess of $400 \mathrm{psi}$ (differential). The inlet and outlet lines had to be monitored constantly to ensure that the operating limits were not exceeded. It is believed that the ceramic ball and seats were damaged due to pressure or temperature transients in the system. Corrosion of the metal parts occurred that compromised the ball and seat seals due to a manufacturing process that coated the Inconel 625 ball with a carbide material eroded in the process. A ceramic ball exhibited excellent corrosion resistance, however it appeared to be physically more fragile.

\section{Energy Recovery}

The recovery of useful energy from a SCWO plant will probably be limited, in the foreseeable future, to units processing non-sticky feedstocks in a pipe reactor. This is due to the current state-of-the-art's inability to effectively control the deposition of sticky solids.

The project did demonstrate that the SCWO process is reliable in that it can effectively process a waste material and produce a hot solid-free effluent. The system operated well and all problems were associated with the acids and sticky solids generated during neutralization. Therefore, it appears that energy recovery will be limited for the near term to non-sticky-solid feedstocks. This result is still significant in that there exist numerous materials that may be processed to this end.

\section{RECOMMENDATIONS}

At this time the future of SCWO can proceed along two paths. The direction is most dependent on whether one perceives the process as a waste destruction technique, or an alternate combustion technique. There is enough evidence to support either conclusion. 
The embodiment of the MODAR SCWO process tested in this project focused on demonstrating the ultimate SCWO process. It attempted to not only demonstrate the destruction of industrial and hazardous wastes containing sticky solids - it also had to demonstrate such effective control of the sticky solids that the effluent could be used for energy recovery. In retrospect it appears that this project goal is beyond the current technology, and that development in the near term should focus on more specific process applications/markets.

Recommendation 1 - A commercial demonstration of SCWO to destroy sewage sludge while recovering energy through heat exchange with the process effluent should be conducted.

When considered as an alternative combustion technique with the ultimate goal of producing energy while processing a fuel or waste material, the focus of further development should be directed towards the design and demonstration of processes and reactor systems that process feedstocks that do not generate sticky solids. At the present time the most promising feedstocks appear to be sewage sludge and coal waste. Heat recovery techniques include the generation of steam or high temperature water through heat exchange, or expansion of the hot high-pressure effluent through an expansion turbine. The former (heat exchange) is well understood and can be implemented with current technology, while t.e latter (expansion turbine) would require development of a turbine capable of processing the effluent at process conditions.

Once the process is limited to feedstocks that do not contain appreciable amounts of acid-forming anions, the problems associated with sticky solids are eliminated, and corrosion is significantly reduced. The only areas requiring development are associated with feeding slurry materials into the high pressure process.

Based on the system performance demonstrated in this project, the SCWO process is ready for commercial demonstration of this application. The challenge lies in the economics of the application. So long as inexpensive alternatives for materials like sewage sludge and coal wastes exist, there is no incentive for SCWO. However all indications are that the inexpensive disposal alternatives including landfilling, ponding, land application, and stockpiling may soon end, and SCWO can provide a viable alternative.

Recommendation 2 - A project to demonstrate the MODAR quench reactor system should be initiated.

Considering SCWO as a technique to destroy industrial wastes is also appropriate. SCWO is unique in that it is a process that has demonstrated the ability to effectively destroy organic material contained in an aqueous matrix. When compared with alternative techniques such as incineration, solvent recovery, and landfilling, SCWO has distinct advantages. These include SCWO's complete indiscriminate, non selective destruction of material, as well as a perceived safeguard against process upsets and accidental releases since the major process effluents are liquid and easily contained to verify destruction prior to discharge.

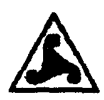


Throughout the United States, and even the world, the disposal of industrial wastes is becoming increasingly difficult. Public opinion is driving legislatures to regulate what are acceptable waste processing techniques. In many cases these regulations are outright bans against specific processes including incineration. A tremendous market exists for any process that can effectively destroy a hazardous waste. Its ability to be permitted is almost as important as the process performance.

Any survey of industrial wastes that are amenable to treatment by SCWO would reveal that the majority contain appreciable amounts of chlorine or sulfur. Processing these materials in a SCWO process results in the generation of hydrochloric and sulfuric acids, or in the presence of cations, formation of salts. As discussed previously, operating a SCWO process under extremely acidic conditions ( $\mathrm{pH}$ less than 2 ) results in an extremely aggressive environment that degrades most high nickel alloys. At the current time only certain ceramics, alloys, and noble metals have shown appreciable resistance. The MODAR SCWO process relies on in-siiu neutralization of acids formed. However, this generates the sticky solids that can potentially plug the system.

MODAR has developed an alternative configuration in the quench reactor that should be more effective in its ability to control the problems associated with acid-forming anions in the feed. This patented reactor is designed to immediately quench the reactor effluent. This concept has several advantages over the filter reactor in that it provides more latitude in the nozzle performance by allowing a portion of the neutralization to occur in the quench system and thereby reduce the demands on the nozzle. This test program clearly indicated a direct relationship between neutralization efficiency and solids deposition on the vessel wall (at high neutralization efficiencies there was increased solids deposition). While some degree of neutralization will be required in the reaction zone, the new design allows the quenching of the effluent with a dilute caustic to neutralize acids in the process effluent.

While the MODAR quench reactor system relies on the same balance of plant as the filter system, there are several concepts that must be demonstrated prior to commercial application of the process. They include:

- Fabrication and operation of the quench reactor

- Demonstration of solids control in the reactor

- Control of corrosion in the reactor and quench system 


\subsection{BACKGROUND}

\subsection{SUPERCRITICAL WATER OXIDATION}

Supercritical Water Oxidation (SCWO) is an aqueous oxidation process. It is similar to wet oxidation processes in that oxidation of organic substances occurs in the presence of water at moderate temperatures. The major difference is that while subcritical systems are operated to maintain water in the liquid state and are called 'wet,' supercritical systems are operated above the critical point of water. Within the reaction zone, the water is not present as a conventional vapor (steam) or liquid. It exists as a supercritical fluid phase that is a hybrid with properties of both liquid and vapor. The supercritical fluid has unique solubility properties in that organic materials and gases are completely miscible, while inorganic materials are only slightly soluble. These properties remove the mass transfer limitations, and associated lower destruction efficiencies, of subcritical (wet) systems. This enhanced mass transfer combined with a moderate temperature of operation $\left(374-600^{\circ} \mathrm{C}\right)$ results in a system capable of virtually complete destruction $(99.99+\%)$ of organic materials, while providing a means of separating and concentrating inorganic compounds.

A significant advantage of SCWO is that there are minimal air pollution problems compared with conventional incineration. The oxidation occurs in water, and acid gas formers (anions of $S$, $\mathrm{P}$, and $\mathrm{Cl}$ ) are soluble and exit the process as solutions, or in the case of nitrogen, as inert gases. $\mathrm{NO}_{\mathrm{x}}$ is routinely less than $1 \mathrm{mg} / \mathrm{m}^{3}$ in the gaseous effluent of any existing test unit. A significant advantage is that the main effluent streams are liquid and can be contained and tested prior to discharge.

Supercritical water oxidation systems have a solid history of bench scale testing, and have been shown to be capable of complete destruction of a variety of organic compounds. To date more than 175 materials have been oxidized with continuous bench scale units. However, previous pilot scale demonstrations of this technology have experienced limited success.

The basic process flow is shown in Figure 2.1-1. Feed material and an oxidant (air or oxygen) are pressurized to $3400 \mathrm{psi}$ and fed into a reaction vessel. The reaction vessel may be an actual vessel, or in the simplest embodiment, a long pipe. At the present time the reactors are all operated adiabatically, and temperature is controlled by limiting the heating value of the feed material. Without preheating, the maximum feed heating value that can be tolerated is 1900 $\mathrm{Btu} / \mathrm{lb}$. With feed preheating, feeds as low as 400-500 Btu/lb can be used. In many cases, the preferred option is to add fuel to the feed to bring it up to $1900 \mathrm{Btu} / \mathrm{lb}$.

In the reaction zone, the organic material is oxidized at $600^{\circ} \mathrm{C}$. Metals tend to precipitate as their oxides, while inorganic anions of $\mathrm{Cl}, \mathrm{S}$, and $\mathrm{P}$ form their respective acids. In the event these materials are present in quantities sufficient to effect corrosion through lowering $\mathrm{pH}$, they

Stone \& Webster

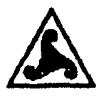


Figure 2.1-1

ScWO Process Block Flow

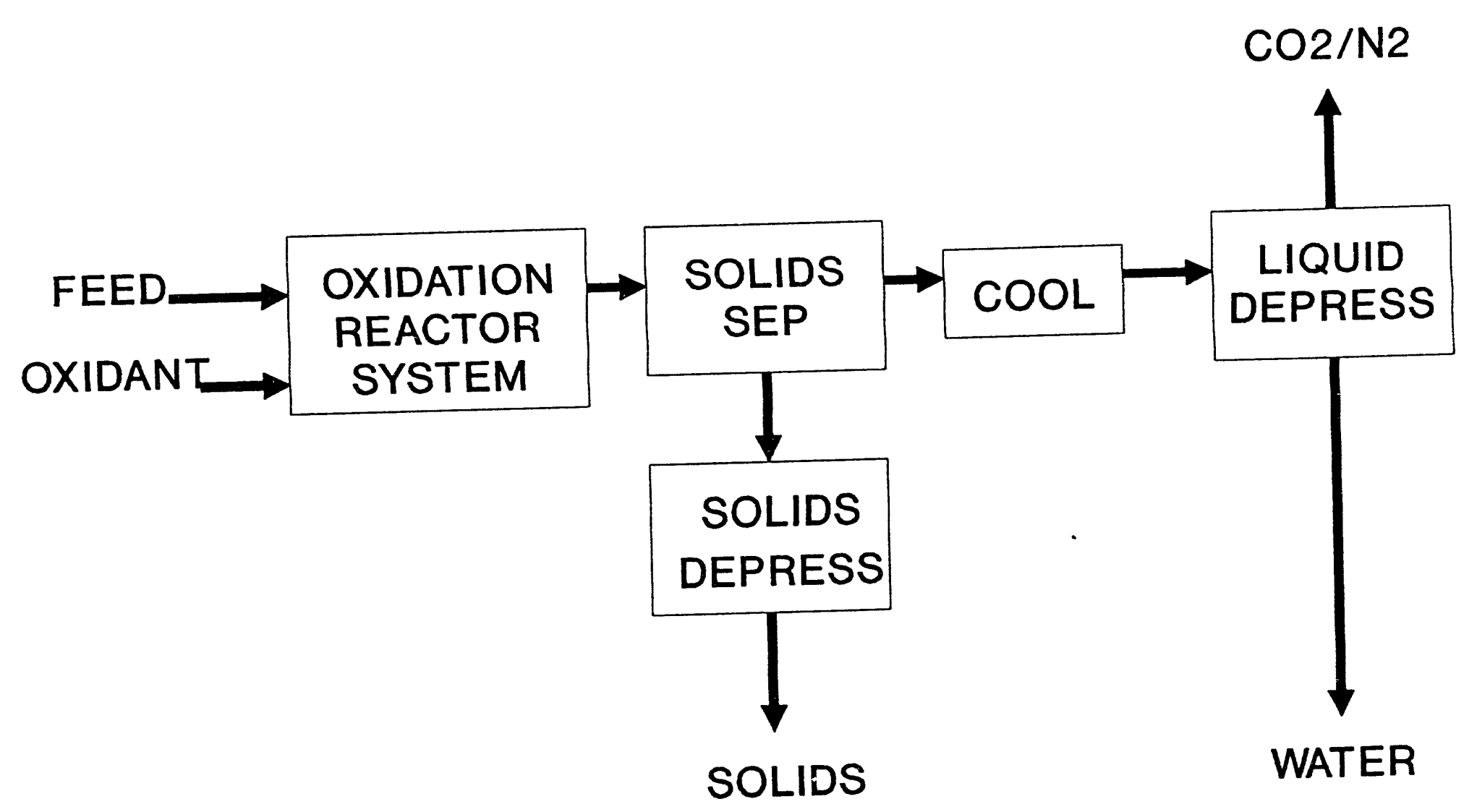


are neutralized by the addition of $\mathrm{NaOH}$. Experience has shown that reactor effluent $\mathrm{pH}$ should be maintained above 2 to minimize corrosion and potential failure of high pressure components. The anions present are neutralized to their corresponding salt form which is insoluble in the supercritical fluid. These precipitated salts are separated from the clean supercritical fluid and removed at process conditions. Pipe reactors use hot cyclones, while the vessel design performs the separation and oxidation in one unit.

The major hurdle for the technology is handling inorganic solids that are present or generated during processing. In the mid-1980's, MODAR engineers observed that when processing a chlorinated waste that required neutralization, the resulting sodium salts plugged the reactor (sodium hydroxide vas used as a neutralizing agent). Subsequent investigations have shown that any feedstock that contains moderate amounts of halogens or acid precursors $(\mathrm{Cl}, \mathrm{S}, \mathrm{P})$ must be neutralized to iinit corrosion. To date the most effective neutralization technique has been insitu through the addition of $\mathrm{NaOH}$ or $\mathrm{Ca}(\mathrm{OH})_{2}$. However, while the neutralization is effective in minimizing corrosion, the resulting salts formed $\left(\mathrm{NaCl}, \mathrm{Na}_{2} \mathrm{SO}_{4}\right)$ are virtually insoluble in the supercritical fluid, and are "sticky," depositing on the walls of the reactor or piping and eventually plugging the system. It has been observed that even when these sticky salts $(\mathrm{NaCl}$, $\mathrm{Na}_{2} \mathrm{SO}_{4}, \mathrm{Na}_{2} \mathrm{CO}_{3}$ ) are introduced into the reactor in their dissolved form (not generated in-situ), they are still sticky.

Currently there are three major commercial proponents of supercritical water oxidation; MODAR, Inc. of Natick, Massachusetts, Modell Development Corporation (MODEC) of Framingham, Massachusetts, and Eco-Waste of Austin, Texas. Eco-Waste is teamed with General Atomics on two SCWO development programs. Several other players are involved in the technology including independents that are advocating the former Oxidyne and VerTech deep well technologies. At this time, the deep well technologies will most likely be limited to subcritical conditions due to fabrication and solids handling problems. All of the technologies apply a similar process flow. Differences among the technologies are mainly in reactor design and techniques to handle acid-forming ions and any inorganic solids generated. They also have slightly different operating conditions to prevent patent infringement, although no litigation has occurred as of this date.

Since the majority of potential SCWO feedstocks are chlorinated hazardous materials, the plugging problem had to be solved. The technology developers have spent considerable time and money trying to deal with this problem. MODAR has developed a vessel reactor system in which oxidation, precipitation, and collection of the sticky solids occurs in one unit. Another developer uses a pipe reactor to process more dilute concentrations of sticky salts to delay plugging and routinely shuts down and fills the system with liquid water to redissolve the salts (this approach may be limited to certain feeds). While operationally effective, the disadvantage of this technique is that, depending on the feed, cleaning shutdowns may be required more than once-a-day. This could prove costly in a high temperature water system. Another developer is focusing on less complex wastes that do not generate "sticky solids," however the industrial market for this approach is limited. Still another approach is to develop systems that are highly corrosion resistant, and can tolerate strongly acidic systems. If one doesn't neutralize the acids 
formed, however, sticky solids may still be formed if sufficient cations are present in the feed. At the present time, these corrosion resistant materials are rather exotic and include both metallic and ceramic options.

\subsection{Previous Studies completed in This Program}

Stone \& Webster Engineering Corporation is Project Manager for the Development and Demonstration of an Industrial Wet Oxidation System for Burning Wastes and Low Grade Fuel. This program has been ongoing through a Cooperative Agreement sponsored by the Department of Energy, initiated in June 1988.

As originally envisioned, the program consisted of four distinct phases:

Phase I Feasibility Evaluation

Phase II Proof of Concept

Phase III Pilot (Industrial) System Development

Phase IV Testing Under Industrial Conditions

To date, Stone \& Webster has completed Phase I and II. The result of Phase I activities was a report issued in September 1989. Phase II is the subject of this report. During the Phase I evaluations, Stone \& Webster concluded that energy could be recovered from wet oxidation systems. Furthermore, we concluded that the first commercial applications would be to destroy hazardous wastes.

\section{Phase I - Feasibility Evaluation}

During Phase I, Stone \& Webster conducted technical and economic feasibility analyses of suband supercritical systems applied to five waste streams representing typical compositions for pulp and paper; food processing; pharmaceutical; chemical manufacturing; and coal cleaning industries. These analyses along with a general discussion of the sub- and supercritical technologies were presented to a twelve member Industrial Review Panel for comment and recommendations on the program direction.

The panel was unanimous in its recommendation to demonstrate supercritical water oxidation. This was based on their understanding that the subcritical systems were commercially mature. In addition, they favored the complete destruction offered by the SCWO system over the limited efficiency of the subcritical systems. 
Following the Review Panel's recommendation, Stone \& Webster focused further evaluations on developing a SCWO demonstration unit conceptual design for an application at Northeastern Products Company (a subsidiary of Campbell's Soup) in Plainfield, New Jersey. This facility generated approximately 20,000 gallons-per-day of a brewer's yeast waste that was amenable to SCWO treatment. The owner of the facility was a member of the Industrial Review Panel, and had expressed an interest in hosting a demonstration. At that time, the SCWO process under development by MODAR, Inc., of Natick, Massachusetts was the most commercially mature.

Stone \& Webster proceeded with the conceptual design of a demonstration facility. The design effort also included an in-depth evaluation of the MODAR SCWO technology (process fundamentals and mechanical designs), as well as a study of the feasibility of incorporating a turbine to generate mechanical energy (and electricity) by expanding the supercritical fluid exiting the reactor at $600^{\circ} \mathrm{C}$ and $3600 \mathrm{psi}$.

As the design proceeded, Stone \& Webster identified several process elements of the MODAR process as areas of critical concern, and potentially not ready for full scale demonstration. The MODAR process had been thoroughly tested at the bench $(10 \mathrm{gpd}) \mathrm{scale}$. In the mid-1980's, tests were conducted on a variety of organic wastes including hazardous materials. However, problems were encountered when processing materials that contained moderate amounts of acid precursors (organic compounds containing $\mathrm{Cl}, \mathrm{S}$, or $\mathrm{P}$ ). These materials form acids ( $\mathrm{HCl}$, $\mathrm{H}_{2} \mathrm{SO}_{4}, \mathrm{H}_{2} \mathrm{PO}_{4}$ ) which require in-situ neutralization to limit corrosion. Upon neutralization with $\mathrm{NaOH}$, the corresponding salts formed $\left(\mathrm{NaCl}, \mathrm{Na}_{2} \mathrm{SO}_{4}, \mathrm{Na}_{2} \mathrm{PO}_{4}\right)$ were insoluble in the supercritical fluid, and were observed to be "sticky" and would agglomerate and eventually plug the pipe reactor system.

MODAR then developed a patented reactor vessel design that operated with three water phases present. This design concept is shown in Figure 2.2-1. In the top supercritical region, the feed is oxidized and resulting acids neutralized. The lower region of the reactor contains liquid water which dissolves the salts precipitated from the supercritical region. In the middle of the reactor, there is a transition zone where liquid water, steam and supercritical water are commingled. In 1986 this reactinr concept was tested at a pharmaceutical facility (SmithKline Chemicals in Conshohocken, Pennsylvania). The concept was demonstrated to be capable of complete destruction of the organic constituents, but less than adequate in the area of solids handling. When processing feeds that contained or generated moderate amounts of acid precursors or chloride or sulfate salts, the reactor exit lines plugged.

MODAR responded to this challenge by developing a design that 1) more effectively directed the generated solids into the lower liquid portion of the reactor, and 2) protected the smaller effluent piping from contact with the sticky solids using a filtration technique. Stone \& Webster performed a review of the proprietary reactor system designed by MODAR and found that item 1 had been thoroughly tested using system mockups and was ready for demonstration. However regarding the filtration technique, while the fundamental concept had been tested on the bench

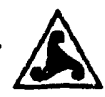




\section{MODAR VESSEL REACTOR CONCEPT}

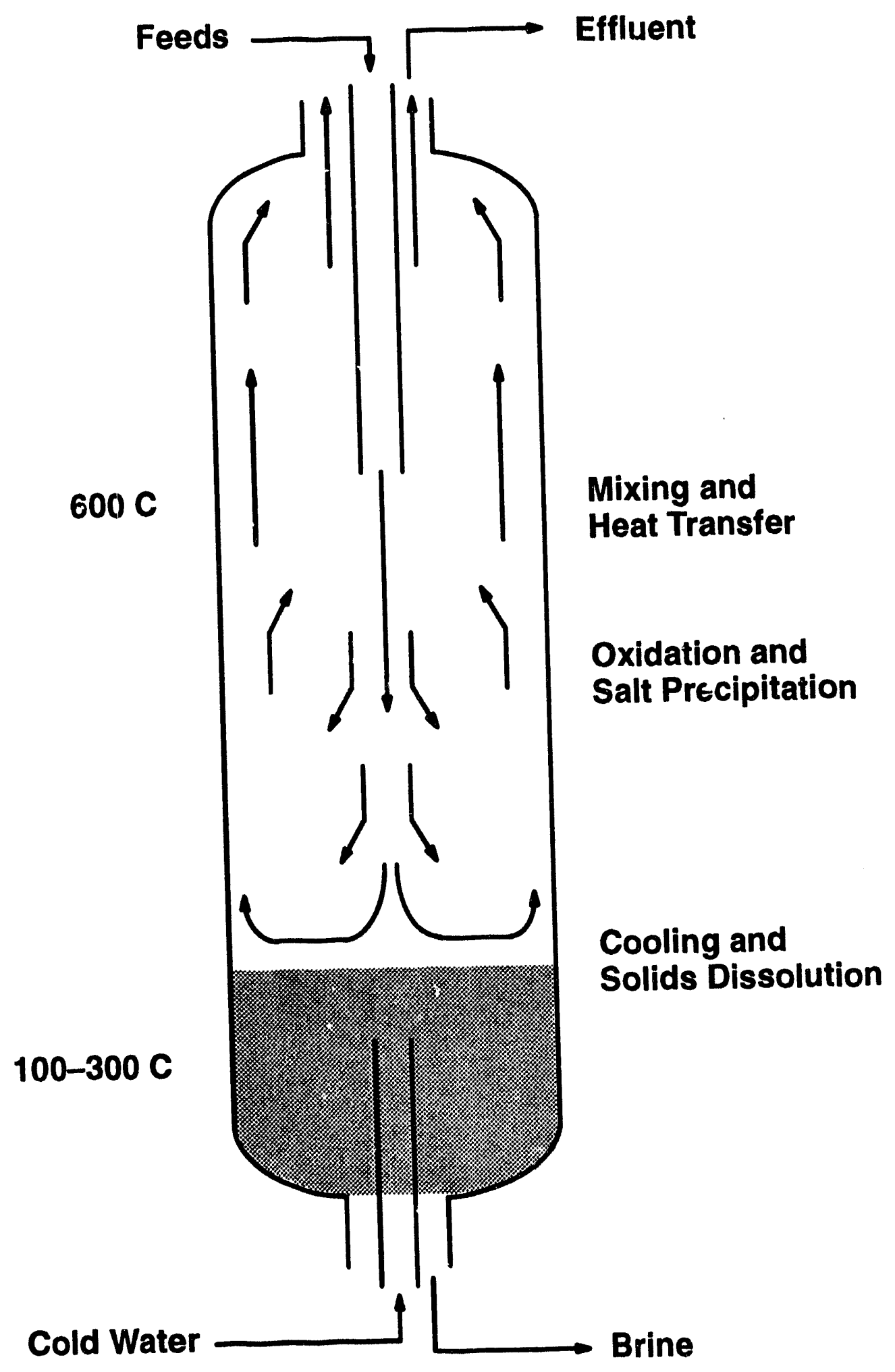

Figure 2.2-1 MODAR Vessel Reactor Concept 
scale, the mechanical design had not been tested. Stone \& Webster concluded that while the system may work, the full-scale design was mechanically complex and could be problematic during operation.

Stone \& Webster concluded that while the concept was proven from a process point of view, the mechanical design was not. We recommended that the Phase II activities be initiated to prove the concept of the MODAR process prior to full-scale design. In addition, Phase I raised several questions related to the commercial potential for energy recovery from the process.

\section{Phase II - Proof of Concept}

In September 1989, Stone \& Webster proposed to initiate Phase II - Proof of Concept. The approach was to divide this phase into two distinct activities. Phase IIA was to concentrate on additional analyses to determine the commercial viability of energy recovery/production using SCWO. In addition, the conceptual design of a research unit suitable to demonstrate the process' ability to handle sticky solids would be developed. Following this, Phase IIB would be initiated in which the research unit would be fabricated and tested, thereby proving the MODAR concept.

\section{Phase IIA Activities}

The major activities of Phase IIA were to:

Evaluate the commercial viability of large-scale power production based on SCWO;

Conduct further tests of candidate wastes to determine the process effluent's suitability for expansion in a power recovery turbine;

Develop a concept for the control and handling of sticky solids generated during operations (included would be a plan to demonstrate/validate the design concept).

In January 1990, Stone \& Webster initiated activities under Phase IIA. In July 1990, a review meeting was held in Stone \& Webster's Boston office where the results were presented to the DOE. This review meeting was held in lieu of a final report to allow a free and open discussion of proprietary information related to the MODAR process. Key conclusions/products of the Phase IIA efforts included:

Supercritical water oxidation has the potential for power production at large scales (>100,000 gpd). The most probable fuels for these applications are raw coal, coal cleaning plant waste, and sewage sludge.

The development of a revised, simpler mechanical design for sticky solids control in a reactor system. 
Identification of the key steps in developing/demonstrating SCWO eventually leading to the ultimate system producing exportable energy. The next step would be pilot scale proof of the system's ability to process feedstocks that contain or generate sticky solids.

Development of a conceptual design and test plan for renovating the existing MODAR pilot plant to demonstrate critical aspects of the technology.

Regarding the SCWO development/demonstration plan, Stone \& Webster believes while the ultimate system to produce exportable power will probably not process hazardous wastes, and may not even encounter sticky solids, it is critical to the commercialization of SCWO that the process demonstrate the ability to process materials that do generate sticky solids. The capability to handle sticky solids is critical to treating hazardous wastes since the vast majority of these materials are chlorinated hydrocarbons. It is not realistic to expect that the SCWO process will be ready for application at the 100,000 gpd level necessary for power export based on this 500 gpd demonstration. Even with the successful demonstration of the process at this pilot level, an intermediate step is required to establish a track record/operating history for the process. At this time it appears that this intermediate level will be industrial applications in the range of $20,000 \mathrm{gpd}$. Through the extended operation of these units, valuable data on materials as well as operation will be generated that will set design requirements for the eventual larger units. In addition, the expansion turbine to effectively recover energy from the supercritical process effluent is necessary for the large-scale applications, but will require a significant developmental effort. This work would only be justified if the process was shown to be reliable and operationally available at a rate that could support power production. In the marketplace, only the destruction of hazardous wastes provides the economic incentive to construct a new capital-intensive process such as SCWO. The demonstration of SCWO as a hazardous waste treatment is therefore a logical, necessary step in the development process.

Based on the positive results of Phase IIA, Stone \& Webster, in conjunction with MODAR, proposed the initiation of Phase IIB to provide pilot scale proof of the MODAR reactor vessel's ability to process feedstocks that produce sticky solids. In October 1991, activities in Phase IIB were initiated. 


\subsection{ENGINEERING, DESIGN, AND DESIGN STUDIES}

In October 1991, Stone \& Webster and MODAR began design activities to support refurbishment of the pilot plant. The refurbishment was extensive and included reconfiguring most equipment and a complete replacement of the control system. The project was designed to effectively "prove the concept" of supercritical water oxidation, and provide data necessary for scaleup to commercial units. Stone \& Webster, as Project Manager, developed the performance specifications for the pilot plant, and provided design oversight and assistance as required. A pilot-scale design that effectively simulated full scale operations using commercially available equipment was fundamental to the demonstration.

Key objectives of the pilot demonstration project included:

Continuous processing of a sticky solids feed;

Characterization of the process effluent;

Materials testing;

Measurement of heat/energy available for export;

Equipment testing;

Feed nozzles,

Brine/slurry pressure reduction valves,

Hot isolation valves.

During the pilot plant design, Stone \& Webster reviewed all designs and specifications developed by MODAR (the technology developer) and provided actual design input for critical items that were beyond the capabilities of MODAR (for example the reactor vessel required a National Board Certification). Stone \& Webster also performed a HAZOP analysis of the process, and assisted in the development of a Health and Safety Plan for the pilot test program.

\subsection{DESIGN BASIS/CONCEPT}

The pilot plant design was based on the existing unit as far as possible. Capacity was determined by evaluating the critical components - the existing reactor and air compressor which together set the design plant capacity of 500 gallons-per-day of aqueous $(1900 \mathrm{Btu} / \mathrm{lb})$ feed material. Initially a target of processing feeds containing the equivalent of up to $5 \%$ by weight of sticky solids was set. A surrogate waste was used for all testing due to permit limitations at MODAR's laboratory. 
Actual composition of the surrogate feed was determined by MODAR based on a survey of industrial inquiries over their 13 year history. The surrogate feed was a mixture of organic solvent (isopropyl alcohol), organic chlorine (perchloroethylene), inorganic chlorine $(\mathrm{NaCl})$, inorganic sulfur $\left(\mathrm{Na}_{2} \mathrm{SO}_{4}\right)$, and caustic $(\mathrm{NaOH})$. Over the test period, the feed was varied using these compounds depending on the experimental objectives. Generally speaking the organic chlorine concentration was set by the neutralization efficiency of the particular nozzle to maintain system pH. Caustic was added in a stoichiometric proportion to neutralize acids formed, and the balance of salt content was provided by the inorganic materials.

The system was configured to maximize production of a hot solid-free effluent from the reactor. To accomplish this, filters were incorporated in the reactor effluent path to remove any particulate matter. The goal was to characterize the effluent and determine its suitability for expansion across a turbine.

Sticky solids were controlled in two ways. The bulk of solids generated were collected in the brine located in the lower portion of the reactor. This was accomplished by selecting a nozzle that maintained a sufficient velocity to propel solids into the brine and prevent their entrainment and carryover in the major effluent flow as it reversed direction in lower portions of the reactor.

The nozzle was designed and fabricated by MODAR based on previous data. Made up of concentric tubes, the aqueous feed and any additives (caustic) are injected at ambient temperature through a nozzle head in the center tube. Air and additional water are introduced through the annulus at reaction conditions $\left(600^{\circ} \mathrm{C}\right)$.

The filter was installed as a final polishing device that would capture any solid material remaining in the effluent. Previous work had shown that even small arnounts of solid carryover could eventually agglomerate and plug the effluent lines. Two filters were installed in parallel allowing one to be cleaned (by flushing with liquid water to dissolve any salt deposits) without impacting operations. Critical to the on-line cleaning was the ability to control the reactor effluent and direct flow between the filters. To accomplish this, ball valves were installed downstream of the filters. Valving the filter effluent was done since any constriction on the filter inlet such as a valve, would provide a site for plugging.

The pilot plant was designed within two material balance cases. The first, designated Case 5, had no supercritical water introduced through the annulus. This case had been predicted by computer simulations, and demonstrated on the bench scale. While not previously demonstrated on the pilot plant, operation without recycle is highly desirable since the elimination of the additional supercritical water would have a positive impact on system economics. In a commercial facility, this stream would probably be accommodated by recycling a portion of the effluent. However, at the present time, a pump capable of boosting the $600^{\circ} \mathrm{C}, 3400$ psi stream for reinjection is not commercially available. The alternatives of using an eductor or heating a stream of cold water are not considered as desirable. 
The second extreme of the material balance was designated Case 6 in which supercritical water was introduced in the annulus at three times the aqueous feed flow. This was based on MODAR's previous pilot plant operations at SmithKline.

\subsection{Process Description}

The pilot plant process flow diagram is included as Figure 3.2-1. This design is based on processing a feed that contains or generates sticky solids and controls their deposition to produce a hot solid-free effluent suitable for energy recovery through heat exchange with an expansion turbine (when available). The pilot plant consists of the following major subsystems:

\section{Feed Preparation and Pressurization}

Within the feed subsystem, the organic waste material, oxidant, neutralizing agent, auxiliary fuel, and water are raised from atmospheric pressure to approximately 3400 psig for injection into the reactor system. For flexibility, the pilot plant has been designed such that the individual components of the feed are contained in separate tanks and conveyed in separate pumps and blended prior to entering the feed nozzle.

The liquid feeds are pressurized in their respective pumps and enter the reactor through the core of a concentric nozzle at near room temperature. This cold feed arrangement allows the system to process higher concentrations of organic materials, and hence destroy more material. In addition, the operational problems of feed/effluent heat exchange (control and fouling) are avoided. The oxidant, in this case air, is compressed, and heated electrically to reaction temperature $\left(600^{\circ} \mathrm{C}\right)$ and combined with a supercritical water stream (to simulate a recycle) which has been heated through regenerative exchange with the process effluent and supplemental electric heaters. This combined hot stream enters the reactor through the annulus of the feed nozzle and aids in reaction initiation.

\section{REACTION}

The feeds enter the reactor through a nozzle and are instantaneously brought to supercritical conditions and the reactions proceeds. At the nozzle tip several things are occurring: the entire mixture is becoming miscible in a single phase; the oxygen is combining with organic carbon and hydrogen to form $\mathrm{CO}_{2}$ and $\mathrm{H}_{2} \mathrm{O}$; inorganic materials are being oxidized to form insoluble salts; and the acid-forming anions $\left(\mathrm{Cl}^{-}, \mathrm{S}^{-}\right)$are being neutralized.

The reactor is a vessel that operates like a continually stirred tank reactor with the nozzle providing the mixing force. Within the reactor three distinct fluids exist as well as transition zones. In the upper portion of the vessel the temperature is maintained at near $600^{\circ} \mathrm{C}$ by the heat liberated during reaction. This supercritical zone is maintained in the reactor and through the filters into the second stage reactor which is essentially a small pipe with the provision for injecting fuel to raise the mix temperature $30-50^{\circ} \mathrm{C}$ to ensure complete destruction of organics. 
Just below the nozzle tip, the inorganic materials (metal oxides and salts) are precipitated from the supercritical mixture. These materials may be simple metal oxides like $\mathrm{Fe}_{2} \mathrm{O}_{3}$, and fall into the bottom of the reactor or are entrained in the flow and captured in the effluent filters. Ir. the case where organic compounds containing chloride or sulfur are processed, the $\mathrm{Cl}^{-}$and $\mathrm{S}^{-}$that are liberated in reaction are neutralized by the addition of a caustic material (in our case $\mathrm{NaOH}$ ) to form their respective sodium salts. These salts present the challenges in operating the system because they are very sticky. Sodium carbonate is also formed by caustic reacting with the excess $\mathrm{CO}_{2}$ and is also sticky. Ideally, these sticky salts are projected straight down into the brine at the bottom of the reactor where they dissolve and are removed.

The bottom portion of the reactor vessel is cooled by the injection of cold water to maintain a pool of liquid water at approximately $200^{\circ} \mathrm{C}$. This liquid water is maintained in the bottom of the reactor due to the extreme density difference between the hot supercritical fluid above and the cooler liquid water phase. The sticky solids that fall into the brine are immediately dissolved in the cool water and can be removed.

At the reactor exit, filters have been installed to effect complete removal of the sticky solids. This prevents plugging of downstream components due to the presence of sticky solids. The filters are installed directly onto the reactor and parallel trains are used to facilitate cleaning without system shutdown. The specific design and material of construction is proprietary to MODAR.

Following the filter is a second stage reactor and material test chamber \#1. The material test chamber is a one liter pressure vessel. When the second stage reactor is on-line, this area represents the hottest temperature in the system.

\section{EFFuUent CoOLNG AND LETDOWN}

Upon exiting material test chamber $\# 1$, the effluent is cooled through regenerative heat exchange with the process air and simulated recycle. A second material test chamber ( $\# 2)$ is installed to represent subcritical water at high pressure. The effluent is further cooled and enters the first of two pressure letdown stages. This is the point at which the system pressure is controlled. In the first liquid-gas separator, pressure is reduced from 3400 to 1500 psig through a control valve. The gases $\left(\mathrm{N}_{2}, \mathrm{CO}_{2}\right.$, and excess $\mathrm{O}_{2}$ ) exit through a carbon trap (to capture any organics), while the liquid is transferred into a second liquid-gas separator where system pressure is reduced to atmospheric. The $\mathrm{CO}_{2}$ evolved joins the other gases from the first separator and exits via the carbon trap, and the liquid water is saved for subsequent analyses and discharge. The gas effluent is continuously monitored for $\mathrm{CO}, \mathrm{CO}_{2}, \mathrm{NO}_{\mathrm{x}}, \mathrm{O}_{2}$, and $\mathrm{N}_{2}$. 


\section{BRINE LETDOWN}

The liquid brine exiting the reactor is brought to atmospheric pressure in the same manner as the liquid effluent. This is a two step process across conventional control valves. The liquid brine is collected for treatment (precipitation of heavy metals if required) and disposal. The gas is combined with the main effluent gas and discharged.

A design option exists whereby the brine could be letdown through a series of "lockhoppers" whereby the pressure reduction would be accomplished by control of the gas stream. This system would be appropriate when handling brine that contain appreciable concentrations of suspended solids which would cause excessive erosion of liquid control valves.

\section{Filter BaCkWaSh}

The filters are designed to be periodically cleaned by dissolving the accumulated solids in liquid water. The backwash water is heated to prevent thermal shock to the system, and injected onto the off-line filter. Removal of the liquid water is accomplished using a process identical to the brine letdown system.

\section{COMPUTER CONTROL}

The pilot plant is capable of complete computer control. The control hardware is from Leeds and Northrup, and controls both MODAR's bench and pilot unit. It is based on the MicroMax II control systems combining data acquisition/storage, proportional-integral-derivative control (PID), and programmable logic control (PLC) into a single package.

The single CPU supports both the bench and pilot unit. The pilot unit is configured to monitor 150 analog inputs (temperatures, pressures, levels, etc.), read 29 digital inputs (level switches, pressure switches, etc.), manipulate 24 analog outputs (control valves, pump stroke adjusts, proportional heaters, etc.), and activate 106 digital outputs (on/off valves, on/off heaters, pump power, etc.). The bench unit is configured with 68 analog inputs, 15 digital inputs, 8 analog outputs and 30 digital outputs.

The control unit monitors all inputs and outputs in real time. Analog inputs and associated calculations are trended, printed out and stored to electronic media. Digital outputs are activated either manually or via the PLC and drum sequencers. System temperatures, pressures, flow rates and liquid levels are controlled by either PID loops or on/off loops. Cascade temperature and pressure control loops have also been implemented.

In addition the system has a comprehensive series of safety interlocks that have been designed and debugged. All critical parameters have been alarmed at two levels (warning and corrective action required) and the system is programmed for automatic shutdown in the case of preselected safety parameters (system pressure and temperature). In addition, an operator-initiated emergency shutdown switch is included in the system. 
Supporting the control hardware and software, a complete operating manual detailing procedures for start-up and shutdown, normal operation, and emergency procedures has been developed. This manual, which has been used extensively, has been verified through operations, and incorporates many lessons learned during the current project.

\subsection{Reactor System FLow MOdeLING}

During the design efforts, a computational fluid dynamic model was used to simulate the reactor environment. The purpose was to determine if a correlation could be determined that would aid in design of the feed nozzle. The work was performed by ABB Lummus-Crest (Lummus) under subcontract to Stone \& Webster.

In earlier work, Lummus had used the PHOENICS Software Code developed by CHAM of North America. This work was done to predict flows and reaction rates for commercial applications with larger diameter vessels ( $3-4$ feet). During this project, the simulation was modified to model both the bench and pilot reactor systems. The goal was to evaluate the model against actual performance observed in recent bench experiments as well as previous pilot plant work performed in 1986 during a demonstration at a SmithKline \& French pharmaceutical manufacturing facility in Pennsylvania.

The modeling was completed in March 1993. The results of the simulation were a series of data that modeled flow velocities, temperature profiles, and organic conversions (based on the destruction of ethanol). The simulation was limited in that it was two-dimensional and assumed a flat bottomed cylinder - the actual process is three-dimensional and the bottom is a denser layer of brine, and probably concave in shape. In addition, the simulation did not include the generation of solids nor include any modeling of trajectories or the solids effect on flow velocities. The prediction of solids behavior within the system was conducted based on the velocity profiles using numerical techniques.

The CHAM-generated simulations indicated that the fluid flow fields, and hence the expected thermal gradients and residence times would be similar for reactor vessels of different sizes if they are geometrically similar. The analyses was based on actual flow and size data from the earlier bench and pilot scale runs and confirmed that the bench scale destruction efficiencies translate into larger systems that were geometrically similar. The critical ratios included vessel length to diameter; jet diameter to vessel diameter; and the mass throughput to vessel cross sectional area. Verification of this relationship was desired since the process configuration in this project, specifically the nozzle design and flow rates, had not been tested beyond the bench scale.

The CHAM model did predict that material balance Case 5 (no supercritical water recycle) was achievable in the pilot system. This was verified during operations. 
The solids behavior predictions based on the model were ambiguous. As mentioned earlier, the simulation predicted velocity profiles which were then used to develop particle trajectories. In our analyses, a single spherical particle was introduced into the CHAM calculated flow fields. A drag force, calculated from the relative differences between the fluid and particle velocities, was combined with gravity in order to determine the particle's radial and axial acceleration at a given position. These accelerations were then integrated, over a suitable time increment, to obtain the particle's new velocity and position. The procedure was repeated until the particle was either caught in the recirculation loop, hit the wall, or fell into the brine. The relationship between the drag coefficient and Reynolds number was used to produce a plot of particle diameter versus settling velocity.

Three particle generation points were selected to evaluate the impact of physical location on the deposition. At this time, we do not know where the solid particles are actually generated, nor their size or shape. At each generation point the critical spherical particle diameter was determined that would result in a) a particle in the recirculation loop; b) a particle impacting the wall; and c) a particle dropping into the brine.

While we did not have sufficient data from earlier pilot scale tests to validate any solids deposition projections, the model did predict conditions that would favor conveyance of solids into the brine. Based on the model, we tried to develop a nozzle that would:

1) Maintain flows as near to the centerline of the vessel as possible;

2) Generate solids low in the reactor without compromising destruction;

3) Have sufficient energy (velocities) for good mixing, but in general encourage a quiescent reactor environment with a well established flow pattern.

Pilot plant operations verified that the simulation did a reasonable job of modeling the system destruction efficiency. Through all tests with low and high energy nozzles, we were able to achieve good destruction. However it should be noted that the model only predicted that good destruction would occur, and it was not used to determine the boundary conditions at which the destruction efficiencies would degrade. In addition, while the model predicted that Case 5 (no supercritical water recycle) was achievable, actual operation at Case 5 conditions proved difficult to achieve, and required several attempts using different nozzle designs. This could be due in part to the differences in reaction rates between the feeds (the model assumed an ethanol feed while the pilot plant used isopropyl alcohol). However, Case 5 was achieved with one nozzle design. Following demonstration of those conditions, subsequent operations of the system were conducted using a supercritical water recycle to aqueous feed ratio of 1 , to simplify operations, and focus on evaluation of other operating parameters. 
The simulation results and subsequent analyses did not correlate with observed solids deposition. This was probably more due to the complexities of the system than any specific failure of the simulation. Our approach of simply applying solids models on the CHAM predicted velocity profiles probably did not address the complexities of the actual environment. Any model used to predict solids behavior in this system would need to have the capability to generate the solids within the actual simulation, and then evaluate their interactions and impact on the system.

\subsection{HAZOP ANALYSIS}

In July 1992, at approximately $80 \%$ design completion, a HAZard and OPerability (HAZOP) review of the process was conducted. This evaluation was led by independent experts from Stone \& Webster who were assisted by the project team. This effort was a comprehensive analysis of every piece of equipment and system associated with the process. The analysis was conducted using Stone \& Webster's PC HAZOP program which facilitates review of the system and equipment against a standard set of operating deviations. For this review the plant was subdivided into 24 process subsystems. Each subsystem was then evaluated against a variety of failure and accident modes postulating worst case events. Whenever a system, procedure, or piece of equipment was identified that could potentially experience an incident, it was noted, and both the potential frequency and severity were identified with an adjective (high, moderate, and low). Based on the severity and frequency, a risk code was assigned based on the following matrix:

\begin{tabular}{|c|c|c|c|}
\hline $\begin{array}{c}\text { SEVERITY } \rightarrow \\
\text { FREQUENCY } \downarrow\end{array}$ & HIGH & MODERATE & LOW \\
\hline HIGH & 1 & 1 & 2 \\
\hline MODERATE & 1 & 2 & 3 \\
\hline LOW & 2 & 3 & 3 \\
\hline
\end{tabular}

Corrective action was required for all items that had an assigned risk code of 1 or 2 . These could include control interlocks. procedural guidelines, or even reconfiguration to reduce the risk code to 3. The review indicated 5 potential deviations with a risk code of 1 or 2 , as well as several other items that would improve plant safety and operations. Corrective actions were developed for all items, and the necessary modifications were completed prior to operation.

In April 1993, the plant was in an extended shutdown while repairs to the vessel were being conducted. The plant had already logged 9 experimental test runs and nearly 350 hours at process conditions. During this period, a second HAZOP was conducted. The purpose was to review any plant modifications as well as revisit the previous work to determine how well the plant had responded during any upsets. 
The HAZOP team reviewed the current plant configuration and operating logs and confirmed that the safety systems in place performed as intended. In addition, two other incidents which occurred due to operator error were evaluated, and it was determined that the corrective actions, (training and revised preoperational checklists) were proper and would prevent recurrence.

MODAR's personnel were trained in the use of Stone \& Webster's PC HAZOP program and its associated database and a copy was left with MODAR. It is intended that MODAR will use these materials to evaluate any modifications that may be implemented in the pilot plant throughout its life.

\subsection{Health and Safety Plan/Site Permits}

Since this project included a significant experimental component, it was determined that a formal Health and Safety Program needed to be developed and implemented prior to any operations. In October 1992, MODAR published a Health and Safety Plan that addressed operations at their Natick, Massachusetts facility associated with this project. This project is comprehensive and was prepared with the guidance of Stone \& Webster, and represents a formal approach to employee and public health and safety. Included are administrative policies and procedures as well as programs for medical monitoring, hazard communication, and hearing conservation. In addition, standard operating procedures for general safety; chemical handling and disposal; and laboratory experiments were published, and an emergency response plan was developed.

The plan established training programs as well as minimal requirements for operational personnel. In addition it contained a summary of the existing permits and approvals that regulated operations at the Natick facility. The applicable permits and jurisdiction are summarized below:

\section{$\underline{\text { Air Permit }}$}

Regulating Authority: Massachusetts Department of Environmental Protection

Issued in 1985. Permit states "For Air Quality Control Purposes, an Environmental Notification Form is not required to be submitted for this project since it is exempt under the Environmental Protection Regulations of the Executive Office of Environmental Affairs, and the project has been determined to cause no significant damage to the environment." MODAR monitors all discharges for Carbon Monoxide to be in compliance with the Clean Air Act.

MODAR refiled its Source Registration Forms in January 1993. 
Sewer Permit

Regulating Authority: Massachusetts Water Resources Authority

MODAR's current permit contains no volume limitation, however in September 1992 , MODAR notified the regulating authority that discharges would be increasing to support pilot plant operations. In addition, MODAR is required to sample all effluent for concentrations of various compounds and system $\mathrm{pH}$ in accordance with the MWRA's Sewer Use and Enforcement Regulations.

\section{Treatability Studies Permit}

Regulating Authority: Massachusetts Department of Environmental Protection

Operation of the pilot unit in Natick was addressed in the permit approval of April 1989. The regulatory authority's only stipulation regarding specific operation was that the unit must be installed within the confines of a building.

In addition, the overall Natick facility permit states that "No more than a total of $250 \mathrm{~kg}$ of "as received" hazardous waste is subject to the initiation of treatment in all treatability studies in any single day. "As received" waste refers to the waste as received in the shipment from the generator or sample collector." The rated capacity of the pilot unit is 500 gallons-per-day or $1900 \mathrm{~kg} /$ day. Consequently we chose to conduct the tests with surrogate wastes formulated from purchased industrial chemicals. Such a surrogate waste is not a hazardous waste.

\section{Fire Permit}

Regulating Authority: Natick Fire Department

MODAR's permit for the storage of Class A flammable fluids is limited to 150 gallons. Since isopropyl alcohol is a Class A material, and the pilot plant consumption is a maximum of 98 gallons-per-day, MODAR contracted with local suppliers for a preferred delivery schedule. 


\subsection{FABRICATION}

The pilot plant fabrication effort was completed on November 13, 1992 - essentially on schedule and without incident. 


\subsection{TESTING}

The demonstration program was a series of tests of increasing duration and complexity. The original plan was to optimize the process for organic destruction, then evaluate the system performance and ability to operate when handling sticky solids. A fundamental concept was that the process had to demonstrate an ability to operate for exterided periods of time while processing a sticky solids feed. At the outset of this project, it was agreed that the goal was a demonstration of the MODAR process with a 168 hour performance test. The results of this performance test are summarized in Section 5.3.

\subsection{OBJECTIVES}

The ultimate objectives of the test program were to demonstrate the ability of the MODAR process in this configuration (filter reactor) to process a simulated industrial feed with sticky solids. The test program was focused on demonstration of the existing process as opposed to fundamental research on the phenomenon of SCWO. It was anticipated that, based on a successful demonstration project, the next application of the MODAR process would be a commercial-scale demonstration. Inherent in this test program were the goals of advancing the current state-of-the-art and furthering the understanding of the limitations of the SCWO process especially related to the treatment of salt-containing and salt-forming feeds.

Based on the project objectives, the following goals were established for this demonstration testing program:

- Organic Destruction: Demonstrate the ability to achieve greater than 99.99 percent destruction of all organics processed.

- Solids Handling: Demonstrate effective control and handling of inorganic salts present in the waste feed and salts formed by reaction.

- Energy Recovery: Demonstrate the ability to operate and produce a hot solids-free effluent suitable for energy recovery.

- Materials and Equipment Testing: Evaluate equipment and materials for their suitability for commercial use in a SCWO process. 
- Process Scale-Up: Obtain data from the pilot plant to be used for process scale-up.

- 168-Hour Performance Test: Complete the project with a 168-hour continuous test to demonstrate this embodiment of the MODAR SCWO process.

\subsection{APPROACH}

The test program included a series of tests of increasing duration and processing difficulty to demonstrate the process. The capability to treat materials that contain/generate sticky solids, is critical to the commercialization of the SCWO process. MODAR's approach to controlling these materials is two-fold. First, the solids generated are directed into the liquid brine within the vessel reactor. Secondly, any entrained material is removed through mechanical filtration. It was anticipated that the filter would remove virtually all entrained particulate matter in the reactor effluent and eventually accumulate enough material to require cleaning. A unique feature of the MODAR design was that the filter could be cleaned without shutting the unit down. This is a significant advantage over other systems that shutdown, cooldown and redissolve the solids or use mechanical techniques to remove the accumulated salts. The test program evaluated the process' ability to maintain continuous operations without plugging the downstream lines or the filter.

Following fabrication, the system was subjected to a series of cold tests. These were primarily mechanical and hydrostatic tests of the entire system. During the cold pressure tests, all mechanical equipment was operated to verify operation. Upon successful completion of the mechanical tests, the Stone \& Webster/MODAR team began testing the unit by using the simplest feed material first: adding isopropyl alcohol (IPA) and supercritical water. As the desired process flows were developed, and the conditions optimized, the complexity of the feeds and the run duration were increased.

During the test program, Stone \& Webster was responsible for setting experimental objectives and had one process engineer assisting as a Shift Supervisor during operations. MODAR provided the other staff to allow operations around the clock during experiments. Plant staffing included a Mechanical Operator, Computer Operator, and Shift Supervisor on each shift.

Testing progressed with increasing complexity and ultimately led to a feed containing a chlorinated organic, IPA, and a simulated salt mixture containing four weight percent salt. Caustic soda $(\mathrm{NaOH})$ was also added to neutralize the acid formed from the chloride, which formed sodium chloride. The focus shifted from increasing feed complexity to understanding the process parameters which affected the salt deposition within the reactor and the neutralization of the chlorinated organic feed. 
The knowledge was then used to formulate the configuration for the 168-hour run. This run demonstrated the capabilities of the current configuration and benchmarked the progress of the MODAR unit to date.

Each decision made during testing was to meet the final objective, which was to run for 168 hours at the best achievable conditions. This project was not a research program - it was driven by a goal of demonstrating the technology. To this end, the primary objective was to find the best process conditions and configuration for the 168-hour run. A secondary objective was to yield information on parameters affecting salt deposition and neutralization as well as corrosion at supercritical conditions. This information will be critical to development and refinement of the MODAR process.

Each test was planned with a specific set of objectives. A formal test plan was developed that included specific objectives, procedures, sampling and analytical requirements, safety precautions, and a logic diagram of the process and hardware evolutions to direct the operators during the test. A pre-run meeting was attended by all operations personnel. The experimental procedures and objectives, as well as results of the previous experiments were reviewed.

Data were obtained through automated data acquisition as well as manual logkeeping. Samples were obtained at least hourly and at any significant event. In addition, composite samples were collected. Real time analyses and material balance calculations may have been conducted hourly when required.

Following each experiment, the results were evaluated. Data sources included instrument data, laboratory analyses, and in the case of salt deposition, visual observations. A run analysis was prepared for each run which includes the objectives, results, conclusions, and recommendations for the next series of experiments.

A typical experiment (run) consists of four periods; the startup, experimental, steady state, and shutdown. The system is started up from a cold condition. Startup consists of bringing the system up to pressure and recirculating water that is heated electrically until the system is hot enough to sustain oxidation. Fuel is then introduced and the flow is slowly increased to allow the heat of oxidation to bring the system to steady state operating conditions. Upon reaching stable operating conditions the experiment begins. Startup generally takes 6 to 8 hours.

It was determined early in the experimental phase that the major factor that impacted process performance was the nozzle. Unfortunately, the nozzle was a fixed item for each run. That is, once the nozzle is fabricated and installed, the system must be shutdown and opened to effect any change. Given this constraint, a test program was developed that attempted to evaluate nozzle performance in the areas of destruction efficiency, solids deposition, and neutralization. It was evident that for each nozzle tested, we could achieve acceptable organic destruction, and had to limit the chlorinated organic feed to a level that maintained an acceptable effluent $\mathrm{pH}(2)$, 
to minimize corrosion. Based on the initial tests, the vessel was rinsed and process operated at the optimum condition (highest allowable organic chloride feed) and solids deposition associated with the nozzle design was observed.

During the experimental period of most runs, the system dc ss not reach a sustained steady state condition. Experience has shown that for the system to completely stabilize could require 4 to 6 hours once acceptable operating conditions are achieved. During most experiments, selective indicators of system performance (brine quality, temperatures, $\mathrm{pH}$ ) were used to evaluate the systems sensitivity to changing parameters. Most runs were conducted with a series of parametric evaluations to determine the optimum operating conditions for the given nozzle and configuration.

Following the experimental portion of the run, the system was rinsed, in a rapid-turn-around procedure. During turnaround, the fuel and feeds are shut off, and the reactor allowed to fill with warm liquid water to dissolve any salt that may have been deposited during the parametric experiments. The operators were able to consistently perform the rinse and have the system at steady conditions ready for organic feed introduction (back at $600^{\circ} \mathrm{C}$ ) within 8 hours.

The steady state operations were to evaluate solids deposition pattern for the particular nozzle. In general the plant was operated for 6 to 12 hours at full salt flow, then shut down by cutting off all feeds (a hot dry shutdown). The system was then depressurized, and salt observations made.

\subsection{SUMMARY OF RESULTS}

Our work evaluated the mechanical integrity, operation, and limitations of the process. Several of our primary objectives have been satisfied. Specifically, the brine let-down system and effluent filters (operation and cleaning), have met or exceeded performance goals. In addition, we have debugged and tested our computer control system, and confirmed the critical parameters to monitor and control the process effectively.

Additional accomplishments to date include demonstration of complete destruction of organic feeds, and the ability to operate over extended periods (more than 850 hours at supercritical conditions have been logged with one continuous run portion in excess of 100 hours). We have also shown the ability to operate for extended periods processing between 2 and $4 \%$ "sticky solids" feed mixtures of organic and inorganic chlorides. Over the test period, more than 1180 pounds of sticky solids were processed in the pilot plant.

The test program was rigorous. Twenty test runs were completed ranging from 15 to more than 100 hours of operation at supercritical conditions. Table 5.3-1 is a summary of tests conducted. Initially tests focused on system debugging and developing an understanding of critical control parameters for the system. In addition, significant work was done to evaluate the destruction efficiency of the process. During these early tests it was observed that virtually complete 
destruction of organic materials occurred during operation at process conditions. The results shown in Table 5.3-1 generally reflect the detection limits of the analytical techniques. For consistency, all destruction efficiency calculations assumed residuals present at the detection limit of the analytical technique. Variations in destruction efficiencies are generally related to the run duration, and amount of material processed.

The test program culminated in a 168 -hour performance test. Due to a system leak, the test was completed in two segments. During all portions of the test, destruction efficiency was in excess of $99.99 \%$ (based on total carbon analyses). In addition, energy balances conducted during the performance test indicated that nearly $75 \%$ of the total energy input to the system was available for recovery in the hot effluent.

As testing progressed it became apparent that the nozzle design was critical to efficient operation of this process configuration. The nozzle was required to perform two functions; to provide sufficient mixing to achieve organic destruction and neutralization, and to direct any solids formed or precipitated into the liquid brine at the bottom of the reactor. One can see that these objectives tend to be in opposition in that to minimize solids deposition on the vessel walls, one needs a quiescent reactor, while the chemical reactions (especially neutralization) required a highly turbulent environment. Testing focused on analyzing a series of nozzle designs and flow conditions to develop an understanding of the system. In addition, tests were conducted to evaluate the effect of external systems (i.e. feed additives and pretreatment methods), alternate configurations, and even salt composition on the process performance.

While we have made significant progress in our understanding of the scaleup of the SCWO process, it has become apparent that the original objective of achieving a hot solids-free effluent for maximum energy recovery from a feed containing/generating sticky solids is a difficult objective. The complexities of the relationship between nozzle performance and solids deposition in the reactor are not clearly understood. This is not to say that the process configuration is not sound. Our testing has shown and validated the performance of the process destruction efficiencies and the filters ability to produce a solids-free effluent. This capability is critical to eventual power production with SCWO through use of an expansion turbine. At this time, however, the option of power production may be limited to feedstocks free of sticky solids such as sewage sludge or coal wastes. MODAR has developed and patented an alternative process reactor configuration in which the effluent is quenched. While this design will be better suited for processing sticky solids feedstocks, it will not have the capability for energy recovery.

Another significant result is in the system metallurgy. We experienced several failures in components fabricated of high nickel alloys (alloy 625 and C-276). Based on these failures, our metallurgical evaluation programs were expanded to include additional testing of the system using non-destructive and metallographic techniques, as well as the inclusion of a variety of additional samples. One significant item to note is that the pilot plant, by virtue of its size and that it reused existing equipment, included a variety of fabrication methods and materials. This variety proved to be valuable in analyzing the effect on materials during operation. Portions of the pilot plant have been in service for nearly 2000 hours at process conditions. 
Table 5.3-1

Test Program Summary

\begin{tabular}{|c|c|c|c|c|c|c|c|c|c|}
\hline \multirow[t]{2}{*}{ RUN } & \multirow[t]{2}{*}{ DATE } & & FroD & & \multirow[t]{2}{*}{ Gours } & \multirow[t]{2}{*}{ Nozale } & \multirow{2}{*}{$\begin{array}{l}\text { DEsTRUCTION } \\
\text { (carbon) }\end{array}$} & \multirow[t]{2}{*}{ SALT } & \multirow{2}{*}{$\begin{array}{c}\text { OAJECTIVESTESTS } \\
\text { REMURKS }\end{array}$} \\
\hline & & $\begin{array}{l}\text { now } \\
\text { (epd) }\end{array}$ & $\begin{array}{l}\text { soums } \\
(x)\end{array}$ & TYTE & & & & & \\
\hline 914 & $12 / 22 / 92$ & 508 & 0 & IPA & 27 & IA-9 & $>99.99$ & & SYSTEM DEBUCONO \\
\hline 915 & $1 / 20193$ & 547 & 2 & NOR-CI & 38 & $1 A-9$ & $>99.99$ & 3 & $\begin{array}{l}\text { FLRST SALT } \\
\text { OROANIC DESTRUCTION }\end{array}$ \\
\hline 916 & $1 / 28 / 93$ & 589 & 2 & NOR+OR CI & 27 & $1 A-9$ & $>99.99$ & 11 & $\begin{array}{l}\text { ANALYTICAL TEST } \\
\text { OROANC DESTRUCTION }\end{array}$ \\
\hline 917 & $2 / 5 / 93$ & 450 & 2 & INOR-CI & 41 & IA-9 & $>99.99$ & 6 & $\begin{array}{l}\text { OROANIC DESTRUCTION } \\
\text { RATE ENHANCER } \\
\text { TESTED }\end{array}$ \\
\hline 918 & $2 / 17 / 93$ & 531 & 2 & NOR-CI & 29 & $2 A-9$ & $>99.99$ & 16 & $\begin{array}{l}\text { OROANIC DESTRUCTION } \\
\text { RATE ENHANCER } \\
\text { TESTED } \\
\text { NEW NOZZLE } \\
\end{array}$ \\
\hline 919 & $3 / 4 / 93$ & $\mathbf{5 2 7}$ & 2 & NOR+OR Cl & 46 & 3D-9 & $>99.99$ & 11 & $\begin{array}{l}\text { NEW NOZZLEE } \\
\text { OROANIC DESTRUCTION } \\
\text { SALT DEPOSITION }\end{array}$ \\
\hline 920 & $3 / 10 / 93$ & 512 & 2 & $\begin{array}{l}\text { DNOR+OR CI } \\
\text { INOR SOA }\end{array}$ & s1 & 3D-9 & $>99.99$ & 53 & $\begin{array}{l}\text { NEUTRALIZATION } \\
\text { SALT DEPOSTION } \\
\text { NEW NOZZLE } \\
\end{array}$ \\
\hline 921 & $3 / 23 / 93$ & 450 & 4 & $\begin{array}{l}\text { DNOR + OR CI } \\
\text { INGR SO4 }\end{array}$ & so & 3B-5 & $>99.7$ & $n$ & $\begin{array}{l}\text { NEUTRALIZATION } \\
\text { SALT DEPOSTION } \\
\text { FLTER CLEANINO }\end{array}$ \\
\hline 922 & $47 / 93$ & 520 & 4 & $\begin{array}{l}\text { INOR+OR CI } \\
\text { INOR SO4 }\end{array}$ & 40 & 3D-15 & $>99.99$ & 2 & $\begin{array}{l}\text { NEUTRALIZATION } \\
\text { SALT DEPOSTION } \\
\text { LEAK N SYSTEM }\end{array}$ \\
\hline 924 & $5 / 7 / 93$ & 497 & 4 & $\begin{array}{c}\text { INOR + ORCI } \\
\text { NOR SO4 } \\
\end{array}$ & 44 & 3D-26 & $>99.99$ & 40 & $\begin{array}{l}\text { NEUTRALIZATION } \\
\text { SALT DEPOSTTION }\end{array}$ \\
\hline 925 & $6 / 23 / 93$ & 512 & 4 & $\begin{array}{c}\text { WNOR + OR CI } \\
\text { NOR SO4 } \\
\text { HI CO3 } \\
\end{array}$ & 41 & 3D-7 & $>99.99$ & 23 & $\begin{array}{l}\text { SALT COMPOSTIION } \\
\text { SALT DEPOSTION } \\
\text { NEUTRALIZATION } \\
\end{array}$ \\
\hline 926 & $6 / 29 / 93$ & 525 & 4 & $\begin{array}{l}\text { NOR + OR CI } \\
\text { INOR SO4 } \\
\text { HI } \mathrm{CO}^{2}\end{array}$ & 37 & $2 A-8$ & $>99.99$ & 25 & $\begin{array}{l}\text { SALT COMPOSITION } \\
\text { SALT DLSPOSITION } \\
\text { NEUTRALIZATION } \\
\text { FEED CONFIGURATION } \\
\text { PEED ADDITIVE }\end{array}$ \\
\hline 927 & $711 / 93$ & 495 & 4 & $\begin{array}{l}\text { WNOR + OR C1 } \\
\text { INOR SO4 } \\
\text { HI CO3 }\end{array}$ & 38 & $2 A-6$ & $>99.99$ & 25 & $\begin{array}{l}\text { SALT COMPOSTIION } \\
\text { SALT DISPOSITION } \\
\text { NEUTRALIZATION } \\
\text { FEED CONFIOURATION }\end{array}$ \\
\hline
\end{tabular}




\begin{tabular}{|c|c|c|c|c|c|c|c|c|c|}
\hline \multirow[t]{2}{*}{ RUN } & \multirow[t]{2}{*}{ DATE } & & FESD & & \multirow[t]{2}{*}{ HOURS } & \multirow[t]{2}{*}{ NozzLE } & \multirow{2}{*}{$\begin{array}{c}\text { DESTRUCTION } \\
(\%)\end{array}$} & \multirow{2}{*}{ SALT } & \multirow[t]{2}{*}{$\begin{array}{l}\text { OALCTIVES/TESTS/ } \\
\text { REMARKS }\end{array}$} \\
\hline & & $\begin{array}{l}\text { FLow } \\
\text { (cpd) }\end{array}$ & $\begin{array}{c}\text { soums } \\
(\%)\end{array}$ & TYFE & & & & & \\
\hline 928 & $7 / 13 / 93$ & 650 & 4 & $\begin{array}{l}\text { WOR + OR CI } \\
\text { NOR SO4 } \\
\text { HI } \mathrm{CO}^{3}\end{array}$ & 54 & 3B-27 & $>99.99$ & 16 & $\begin{array}{l}\text { SALT COMPOSITION } \\
\text { SALT DISPOSITION } \\
\text { NEUTRALIZATION } \\
\text { RX CONFIGURATION }\end{array}$ \\
\hline 929 & $7 / 22 / 93$ & $500+$ & 4 & $\begin{array}{l}\text { ROR + OR Cl } \\
\text { WOR SO4 } \\
\text { HI CO3 }\end{array}$ & 35 & $3 B-25$ & $>99.99$ & 15 & $\begin{array}{l}\text { SALT COMPOSITION } \\
\text { SALT DISPOSITION } \\
\text { NEUTRALIZATION } \\
\text { RX CONFIOURATION }\end{array}$ \\
\hline 930 & $7 / 30 / 93$ & 300 & 2 & $\begin{array}{l}\text { NOR + OR CI } \\
\text { NOR SO4 } \\
\text { HI CO3 }\end{array}$ & 15 & 3B-27 & $>99.99$ & 9 & $\begin{array}{l}\text { SYSTEM FLOW } \\
\text { SALT COMPOSITION } \\
\text { SALT DISPOSITION } \\
\text { NEUTRALIZATION }\end{array}$ \\
\hline 931 & 8/8/93 & 300 & 2 & $\begin{array}{l}\text { INOR + OR Cl } \\
\text { INOR SO4 }\end{array}$ & 40 & $3 C-6$ & $>99.99$ & 22 & $\begin{array}{l}\text { SALT COMPOSTION } \\
\text { SALT DISPOSITION } \\
\text { NEUTRALIZATION } \\
\end{array}$ \\
\hline 932A & $8 / 17 / 93$ & 313 & 2 & $\begin{array}{l}\text { DNOR + OR CI } \\
\text { NOR SO4 }\end{array}$ & 87 & $3 \mathrm{~B}-6$ & $>99.99$ & 74 & PERFORMANCE TEST \\
\hline 932B & $8 / 17 / 93$ & 313 & 2 & $\begin{array}{l}\text { NOR + OR Cl } \\
\text { NOR SO4 }\end{array}$ & 102 & $3 \mathrm{~B}-6$ & $>99.99$ & 89 & PERFORMANCE TEST \\
\hline 933 & $8 / 29 / 93$ & 300 & 4 & $\begin{array}{l}\text { NOR + OR Cl } \\
\text { NOR SO4 }\end{array}$ & 28 & $3 C-6$ & $>99.99$ & 22 & $\begin{array}{l}\text { SALT CONCENTRATION } \\
\text { SALT DISPOSITION } \\
\text { REPEAT OF 931 } \\
\text { CONDITIONS }\end{array}$ \\
\hline
\end{tabular}

One key metallurgical result is that the severity of corrosion was most dependent on system pH. Even when using high nickel alloys, corrosion is greatly accelerated when system pH falls below 2 , which can occur with chloride-bearing feeds and inadequate neutralization. In addition, preliminary results indicate that a variety of materials are required for process plant fabrication. The SCWO process can be broken down into several zones each characterized by their physical (temperature, pressure) and chemical ( $\mathrm{pH}$, chloride, and oxygen concentration) environment, and material requirements. Based on the preliminary results of this project, Stone \& WebsterlMODAR have identified the specific materials, fabrication techniques, and post fabrication treatment methods best suited for commercial applications.

\subsection{8-HOUR PERFORMANCE TEST}

A key objective of this project was demonstrating the MODAR SCWO process's ability to continously produce a hot-solids-free effluent suitable for energy recovery over a prolonged period. In order for the energy recovery to have a significant impact on the overall energy consumption of an industrial facility, the process unit must operate nearly constantly. For example, if the SCWO process cannot demonstrate continuous availability, then the industrial facility cannot depend on the energy it produces as a replacement for existing sources. During

Stone \& Webster 
negotiation of the scope of work for Phase IIB, a demonstration of 168 continuous hours of operation processing a sticky solids feed was chosen.

The specific composition of the feed for the 168 hour performance test was not set at the beginning of the project. It was understood that we would make all efforts to ensure that the test was an accurate demonstration of an industrial waste, and include as a minimum both organic and inorganic chloride sources, as well as a significant amount of total sticky solids. During the test program, we tested sticky solids concentrations in the range of 0 to 4 weight percent of the feed. In the end, a value of 2 weight percent sticky solids was used for the 168 hour performance test.

The 168-hour performance test was conducted from August 20 to August 28, 1993. The saltprocessing portion of the run was divided into two segments:

\section{Segment I: $\quad$ August 20 2:26 - August 23 7:31}

Segment II: $\quad$ August $2414: 25$ - August 28 10:00

Salt-bearing feeds were processed for 77.1 hours during segment I. A thermowell failure shut the plant down at this time. Based on the amount of salt in the reactor, the filter, and nozzle (indicated by differential pressures), the system would likely have been forced down for a vessel rinse within twenty-four hours of the shutdown.

The thermowell was repaired, and the vessel was rinsed between the first and second segments of the run to remove any salt which had accumulated in the reactor.

The system was restarted, and upon reaching steady-state, the simulated waste was processed. Salt-bearing feeds were processed for 91.6 hours during segment II. The plant was shut down voluntarily when the required 168 hours of processing salt had been achieved. The length of time the plant could have continued running is unknown. The most probable cause of shutdown would have been salt accumulating within the reactor.

To our knowledge, this is the first time that a SCWO unit of any size was operated for prolonged periods while processing this level of sticky solids. The project goal of 168 hours of continuous operation was ambitious, and not fully achieved. Based on the project results, we estimated a $95 \%$ availability of the process over the 168 hour period. However, we believe that an alternate configuration of the MODAR process (the quench reactor described previously) will show improved operation and availability.

The following section discusses Run 932, the 168 hour performance test. It includes discussion of the conditions of operation, a summary of the run, and analyses of the results. A detailed summary of Run 932 is included as Appendix B. 


\subsubsection{CONDITIONS OF OPERATION}

The system was run at an average simulated waste feed capacity of 313 gallons-per-day. The waste composition was 0.3 weight percent Perchloroethylene (organic chloride), 89.1 weight percent aqueous waste (salt water), and 10.6 weight percent isopropyl alcohol (non-halogenated solvent waste). The feed was autogenic.

The total system waste feed was established at approximately 300 gallons-per-day of waste feed. During the experimental program, we initially operated at 500 gallons-per-day, however since we were having difficulties controlling the deposition of solids in the reactor, experiments were conducted at a lower overall capacity, and solids control improved. This indicated that the solids control is probably highly dependent on the size and geometry of the reactor.

The amount of perchloroethylene was set by the neutralization efficiency attained with the feed nozzle used. It was determined at a mid-point of the experimental program that neutralization of the organic chloride in the feed was the limiting factor that determined the maximum allowable organic chloride-containing feed. We could achieve low solids deposition with low energy nozzles, however we could only achieve good neutralization with high energy nozzles. For the 168 hour performance test, a decision was made to maximize the solids loading on the system, and base the organic chloride feed rate on the observed neutralization efficiency. The perchloroethylene feed rate was controlled to maintain the process effluent at a $\mathrm{pH}$ greater than 2.

The aqueous waste was the mixture of salts and water that contained most of the sticky solids. For this run, the feed contained 2.0 weight percent salt. It was made up of dissolved salts $\left(\mathrm{NaCl}, \mathrm{Na}_{2} \mathrm{SO}_{4}\right)$ as well as the $\mathrm{NaCl}$ generated by neutralization of the perchloroethylene. The actual sticky solids were 15.7 percent from the neutralization of perchloroethylene, 67.3 percent from dissolved $\mathrm{NaCl}$, and 17.0 percent from the dissolved $\mathrm{Na}_{2} \mathrm{SO}_{4}$.

The fuel was isopropyl alcohol. This was added to bring the heating value of the feed to maintain the reactor temperature.

In addition to the feed flows mentioned above, caustic $(6.25 \% \mathrm{NaOH})$ was added at $95 \%$ the calculated stoichiometric amount. Earlier experiments indicated that addition of caustic above this level did not enhance neutralization, and in fact, generated additional sticky solids $\left(\mathrm{Na}_{2} \mathrm{CO}_{3}\right)$.

Other flows into the reactor included supercritical water (simulated recycle), air, liquid water to maintain the brine level, and several purge streams in the liner annulus and filters.

The supercritical water was added in a 1.2 to 1 ratio with the feeds. The air was heated to reactor temperature and metered to ensure a 3 to 5 percent residual oxygen concentration in the effluent gas. The brine water was added at two points to eliminate stratification of the brine

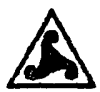


layer. The flow was monitored and controlled to maintain level at an prespecified length to diameter (L/D) ratio from the nozzle tip. This flow varied as run time rinse procedures (RTRPs) were conducted.

The liner purge was minimal and consisted of cool water introduced in a lower portion of the annular area and prevented the accumulation of process effluent and salts in the annular space. The filter purges were used to maintain and control temperatures in this area of the reactor.

A summary of the flows into the reactor is included in Table 5.4.1-1:

Table 5.4.1-1

168-hour PERFORMANCE TEST FEED FLOWS

\begin{tabular}{||l|c|c|}
\hline \multicolumn{1}{|c|}{ STREAM } & $\begin{array}{c}\text { SEGMENT I } \\
\mathbf{8 / 2 0 - 2 3 / 1 9 9 3}\end{array}$ & $\begin{array}{c}\text { SEGMENT II } \\
\mathbf{8 / 2 4 - 2 8 / 1 9 9 3}\end{array}$ \\
\hline Aqueous Feed (mL/min) & 722 & 708 \\
\hline Perchloroethylene (mL/min) & 1.4 & 1.3 \\
\hline Caustic (mL/min) & 26 & 26 \\
\hline IPA (mL/min) & 112 & 109 \\
\hline TOTAL FEEDS (mL/min) & 861 & 844 \\
\hline Supercritical Water (mL/min) & 1050 & 1010 \\
\hline Air (NLPM) & 930 & 930 \\
\hline $\begin{array}{l}\text { Brine Water Addition } \\
\text { (mL/min) }\end{array}$ & 228 & 122 \\
\hline Purges (mL/min) & 144 & 129 \\
\hline
\end{tabular}

The reactor did not have the hot valves in place for this run. The packing of the AV $410 \mathrm{~B}$ hot valve had leaked during a previous attempt at initiating the 168 -hour run. With the hot valves removed, the filter arms still performed their function as a finishing stage of salt removal from the hot effluent, but the filters could no longer be backwashed. Both filters were used in parallel for Run 932.

A titanium liner was in the reactor during this run. It was installed earlier to limit the reactor vessel wall's exposure to the processing environment and to minimize corrosion. A purge between the reactor wall and the liner was used to rinse any salt away which may have accumulated behind the liner. 
A low energy nozzle was installed for this run. It duplicated that used during an earlier experiment. As in previous tests, the aqueous, organic, and caustic feeds were introduced at room temperature. The supercritical water and air were preheated to approximately $600^{\circ} \mathrm{C}$ and entered through the nozzle annulus.

The run objective was to complete the 168 hour demonstration and characterize the effluents. No experimenta' activities were scheduled.

\subsubsection{Run Chronology}

Run 932 was initiated on August 17 at 12:49. At 16:30 a leak at thermowell 4014 caused a shutdown. The thermowell nozzle was plugged and the system was started approximately twenty minutes later. At 19:22 IPA and pure water were sent to the system. A momentary CO spike of $100 \mathrm{ppm}$ occurred in the process effluent at this time.

Once stabilized at process temperature, salt precursors and salt-bearing aqueous waste were sent to the system on August 18 at 1:43. At 6:39 the fifth stage rupture disk in the air compressor blew and required a system shutdown. The disk was replaced and the system was restarted. At 13:46 salt precursors and aqueous waste were again sent to the system.

After nearly 24 hours of running aqueous waste and salt precursors, the filter differential pressures were nearly $10 \mathrm{psi}$. In preparation for a backwash, the hot valve, AV 410A, was closed to isolate filter $\Lambda$ from the reactor so it could be backwashed. Daily filter backwashes had been planned. The packing of the open valve, AV 410B, started to leak . A controlled shutdown was performed and both hot valves removed from the system. With the hot valves removed, the filters would still perform their function as a finishing stage of salt removal from the effluent, but the filters could no longer be backwashed. Both filters were used in parallel for the remainder of the run.

The system was restarted. Aqueous waste and salt precursors were sent to the system at 2:26 on August 20. The salt-bearing feeds were processed continuously for 77.1 hours, until 7:31 on August 23, when a leak at thermowell 4008 forced an operator controlled shutdown. During segment I, seven run time rinse procedures were completed.

During this segment the feed nozzle core and annular differential pressures $(\Delta p)$ had increased steadily. After about 60 hours the core $\Delta \mathrm{p}$ was as high as $125 \mathrm{psi}$. In previous runs, the nozzle $\Delta p$ were reduced by momentarily switching off aqueous waste, perchloroethylene, and caustic. To clear the nozzle, the perchloroethylene and caustic feeds were put in recycle as the first step of switching off all salt feeds. Within a few minutes (with the aqueous waste feed still on) the core, annular, and filter $\Delta \mathrm{ps}$ were drastically reduced. 
At this intermediate (77 hour) shutdown, it was estimated that $13 \mathrm{~kg}$ of salt were in the reactor. The filter $\Delta$ ps were about $40 \mathrm{psi}$, and feed nozzle core and annular $\Delta$ ps were 11 psi and 30 psi respectively. Based on these data, and the relatively constant salt accumulation rate, it was estimated that the system would probably have forced a shutdown within 24 to 48 hours, so the decision was made to rinse the reactor vessel prior to resumption of the test.

On August 24, with the reactor and filters rinsed, the system was restarted. Aqueous waste and salt precursors were sent to the system at 14:25.

During Segment II salt was processed through the system for 91.6 continuous hours. The system was shut down on August 28 at 10:00, after operating a total of 168 hours in two segments. Seven run-time-rinse-procedures (RTRPs) were completed during this portion of the run. A RTRP is a segment where the brine level is increased to rinse the vessel walls of accumulated salt. These are conducted while maintaining full feed flow, and have been found to be effective in removing accumulated salt in the lower portions of the vessel. The perchloroethylene and caustic feeds were switched off two times (for less than 30 minutes each) to reduce the core, annular, and filter $\Delta \mathrm{ps}$. The $\Delta \mathrm{ps}$ were lower in this second segment of the run than they had been in the first segment. The cause for this is not known.

\subsubsection{Performance}

The 168-hour run provided a benchmark of the MODAR process. The results are discussed below.

\section{ORganic Destruction}

Greater than 99.99 percent of the organic carbon was destroyed and converted to $\mathrm{CO}_{2}$ during this run. This is based on mass balances conducted during the performance test. Table 5.4.3-1 is a summary of these balances. Greater than 99.9998 percent of the perchloroethylene feed to the system was destroyed. The destruction efficiency was not affected by salt accumulation within the reactor or the RTRPs, wherein the brine level was raised within the reactor. The desired destruction efficiency was achieved. Carbon destruction was consistently durable - that is, the destruction efficiency was maintained throughout the run and did not decrease with variations in process conditions.

During the 168 hour performance test (Run 932), the analytical program was increased. The performance test was to represent the benchmark of the process, and would represent the closest simulation of actual commercial operation. During the test, liquid (brine and effluent) samples were collected hourly, and composited for later analysis by GC/MS. The results are shown in Table 5.4.3-2. As the analyses indicate, no organic contaminants were detected in the main effluent. 
Table 5.4.3-1

Mass Balances/Destruction Calculations

\begin{tabular}{|c|c|c|c|}
\hline Mass Balance & Date & $\begin{array}{l}\text { Closure } \\
(\%)\end{array}$ & $\begin{array}{l}\text { Destruction } \\
(\%)\end{array}$ \\
\hline Water & $8 / 20 / 9311: 00-8 / 23 / 933: 00$ & 99.2 & -- \\
\hline Water & $8 / 24 / 9323: 00-8 / 28 / 9310: 00$ & 97.6 & -- \\
\hline $\begin{array}{l}\text { Salt } \\
\text { (based on Cr, and so:n) }\end{array}$ & 8/24/93 23:00 - 8/28/93 10:00 & 95.7 & --- \\
\hline Carbon & 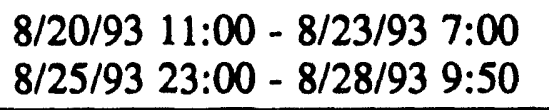 & 98.8 & $>99.99$ \\
\hline Perchloroethylene & $8 / 22 / 933: 15-21: 05$ & --- & $>99.9998$ \\
\hline
\end{tabular}

The gaseous effluent was monitored continuously for $\mathrm{NO}_{\mathrm{x}}, \mathrm{CO}, \mathrm{CO}_{2}$, and $\mathrm{O}_{2}$. In addition, the entire gaseous effluent was passed through an activated carbon filter to remove any residual contaminants that may be present. The samples were taken prior to the carbon filter, and represent the feed to the filter, not actual discharges.

In addition to the continuous samples, the gaseous effluent was also sampled using concentrating techniques (solid and liquid gas traps) to later analyze for volatile organics (collected on Tenax), and $\mathrm{HCl}, \mathrm{Cl}_{2}$, and $\mathrm{SO}_{2}$ (collected in aqueous solutions). Table 5.4.3-3 indicates that only trace amounts of tetrachloroethene (perchloroethylene) were detected. This was the result of concentrating the gas effluent in a Tenax trap over a 200 minute period. These results are consistent with what was observed through the test period. In most experiments where perchloroethylene was run, trace amounts were detected in the gas effluent at comparable levels.

It is interesting to note that since this analysis is based on a concentrating technique (that is the sample is collected over a 16.7 hour period), the actual perchloroethylene detected is less than $0.000027 \%$ of the feed. In all cases, the limit of destruction efficiency claimed is based on the minimum detectable concentration in the liquid effluents. 
Table 5.4.3-2

Performance Test Brine and Emuent Composite Volatile Organic Analyses Composites were taken from 8/20/93 11:00 - 8/23/93 7:00, and from 8/25/93 23:00 - 8/28/93 9:50.

\begin{tabular}{|c|c|c|c|}
\hline Yolatile Orranice bre GCMMS & Emuent & Brine & RDLL/(na/h) \\
\hline Methylene Chloride & ND & ND & 5.0 \\
\hline 1,1-Dichloroethane & ND & ND & 1.5 \\
\hline Chloroform & ND & ND & 1.5 \\
\hline Carbon Tetrachloride & ND & ND & 1.0 \\
\hline 1,2-Dichloropropane & ND & ND & 3.5 \\
\hline Dibromochloromethane & ND & ND & 1.0 \\
\hline 1,1,2-Trichloroethane & ND & ND & 1.5 \\
\hline 2-Chloroethylvinyl ether & ND & ND & 10 \\
\hline Tetrachloroethene & ND & ND & 1.5 \\
\hline Chlorobenzene & ND & ND & 3.5 \\
\hline Trichlorofluoromethane & ND & ND & 5.0 \\
\hline 1,2-Dichloroethane & ND & ND & 1.5 \\
\hline 1,1,1-Trichloromethane & ND & ND & 1.0 \\
\hline Bromodichloromethane & ND & ND & 1.0 \\
\hline trans-1,3-Dichloropropene & ND & ND & 1.5 \\
\hline cis-1,3-Dichloropropene & ND & ND & 1.0 \\
\hline Bromoform & ND & ND & 1.0 \\
\hline 1,1,2,2-Tetrichloroethane & ND & ND & 1.0 \\
\hline Benzene & ND & ND & 1.0 \\
\hline Toluene & ND & ND & 1.5 \\
\hline Ethylbenzene & ND & ND & 1.0 \\
\hline Chloromethane & ND & ND & 10 \\
\hline Bromomethane & ND & ND & 2.0 \\
\hline Vinyl Chloride & ND & ND & 3.5 \\
\hline Chloroethane & ND & ND & 2.0 \\
\hline 1,1-Dichloroethene & ND & ND & 1.5 \\
\hline trans-1,2-Dichloroethene & ND & ND & 1.5 \\
\hline Trichloroethene & ND & ND & 1.0 \\
\hline
\end{tabular}

1 RDL $=$ Reportable Detection Limit

Stone \& Webster 


\begin{tabular}{||l|c|c|c|}
\hline Volatile Organics by GCMMS & Emuent & Brine & RDL (uag) \\
\hline 1,2-Dichlorobonzene & ND & ND & 10 \\
\hline 1,3-Dichlorobenzene & ND & ND & 10 \\
\hline 1,4-Dichlorobutane & ND & ND & 10 \\
\hline Methyl tert butyl ether & ND & ND & 10 \\
\hline Xylenes & ND & ND & 1.0 \\
\hline cis-1,2-Dichloroethene & ND & ND & 1.0 \\
\hline Dibromomethane & ND & ND & 10 \\
\hline 1,4-Dichlorobutane & ND & ND & 10 \\
\hline Iodemethane & ND & ND & 10 \\
\hline 1,2,3-Trichloropropane & ND & ND & 10 \\
\hline Styrene & ND & ND & 1.0 \\
\hline Dichlorodifluoromethane & ND & ND & 10 \\
\hline Acetone & ND & ND & 10 \\
\hline Carbon disulfide & ND & ND & 10 \\
\hline 2-Butanone & ND & ND & 4.5 \\
\hline Vinyl Acetate & ND & ND & 10 \\
\hline 4-Methyl-2-pentanone & ND & ND & 10 \\
\hline 2-Hexanone & ND & ND & 10 \\
\hline Ethyl methacrylate & ND & ND & 10 \\
\hline Acrolein & ND & ND & 25 \\
\hline Acrylonitrile & ND & ND & 10 \\
\hline
\end{tabular}

Stone \& Webster 
' $S$ ' $S$ uo!̣ว

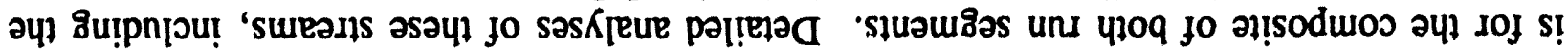

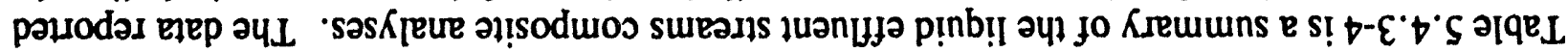

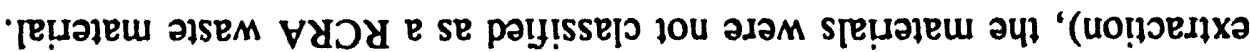

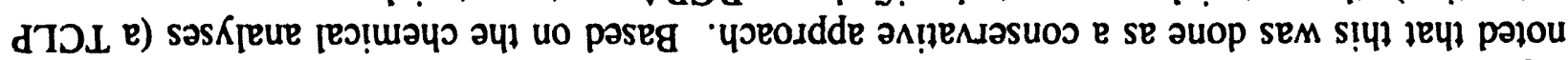

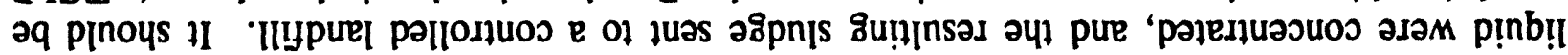

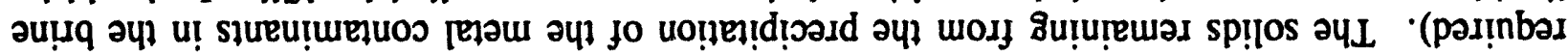
иәчм uo!̣e!!

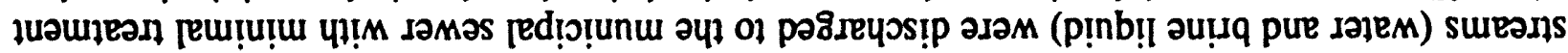

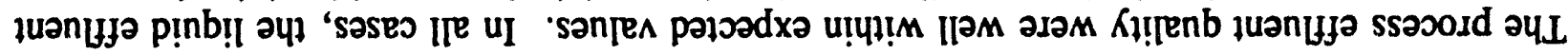

MLITVחO INanTudG

\begin{tabular}{|c|c|c|}
\hline os & aN & euəzueqowodg \\
\hline OS & aN & 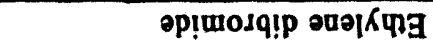 \\
\hline osz & aN & wsojowosg \\
\hline OS & aN & อUezueqOAO|qว \\
\hline OS & $\mathbf{a N}$ & 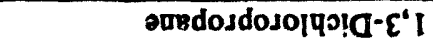 \\
\hline OS & aN & จuвdosdoso|पว!Q-乙'। \\
\hline 02 & aN & 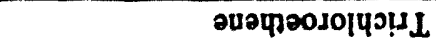 \\
\hline 02 & OII & 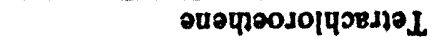 \\
\hline OS & aN & 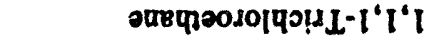 \\
\hline OS & aN & 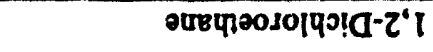 \\
\hline OS & aN & op!solqoeneI uoqreכ \\
\hline or & $\mathbf{a N}$ & 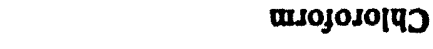 \\
\hline (cqe 80) Tad & (sqe 8d) भined & 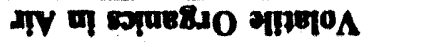 \\
\hline
\end{tabular}

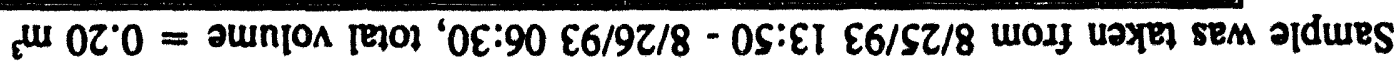

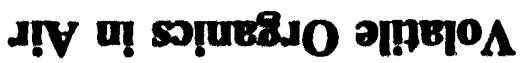

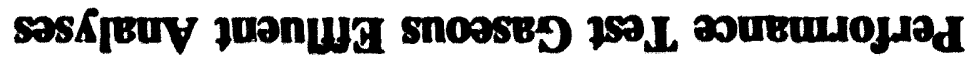

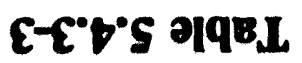


Table 5.4.3-4

Brine and Emuent Composite Analyses

\begin{tabular}{|l|c|c|c|c|c|c|c|c|}
\hline SAMPLE & pH & $\begin{array}{c}\mathrm{Cr} \\
(\mathrm{ppm})\end{array}$ & $\begin{array}{c}\mathrm{Na}^{+} \\
(\mathrm{ppm})\end{array}$ & $\begin{array}{c}\text { SO } \\
(\mathrm{ppm})\end{array}$ & $\begin{array}{c}\text { TOC } \\
(\mathrm{ppm})\end{array}$ & $\begin{array}{c}\mathrm{Cr} \\
(\mathrm{ppm})\end{array}$ & $\begin{array}{c}\mathrm{Ni} \\
(\mathrm{ppm})\end{array}$ & $\begin{array}{c}\mathrm{Fe} \\
(\mathrm{ppm})\end{array}$ \\
\hline $\begin{array}{l}\text { Effluent Composite: } \\
\text { Segment I: } \\
\text { 8/20/93 11:00 - 8/23/93 7:00 } \\
\text { Segment II: } \\
\text { 8/25/93 23:00 - 8/28/93 9:50 }\end{array}$ & 2.3 & 270 & 6 & $<1$ & $<1$ & 3.3 & 11 & $<0.1$ \\
\hline $\begin{array}{l}\text { Brine Composite: } \\
\text { Sogment I: } \\
\text { 8/20/93 11:00 - 8/23/93 7:00 } \\
\text { Segment II: } \\
\text { 8/25/93 23:00-8/28/93 9:50 }\end{array}$ & 6.7 & 12500 & 10000 & 3680 & 2 & 1.5 & 0.8 & 0.7 \\
\hline
\end{tabular}

Conductivity: Brine composite (Segment I and II) 17,400 umhos/cm

Acidity: $\quad$ Effluent composite (Segment I and II) $340 \mathrm{mg} \mathrm{CaCO}^{3} / \mathrm{L}$ equivalent

The nickel and chromium levels in both the brine and the effluent were consistent during Segment I of the run. In the beginning of Segment II, the observed chromium levels were higher, and then decreased with time. The nickel concentrations from Segment II appeared consistent with those from Segment I. Based on post run observations, the nickel and chromium were most likely from the corrosion of the Alloy C-276 filter housing end plates and nozzle centering plate.

The gaseous effluent was monitored continuously for $\mathrm{NO}_{\mathrm{x}}, \mathrm{CO}, \mathrm{CO}_{2}$, and $\mathrm{O}_{2}$. In addition, the entire gaseous effluent was passed through an activated carbon filter to remove any residual contaminants that may be present. The samples were taken prior to the carbon filter, and represent the feed to the filter, not actual discharges.

During operation, no $\mathrm{NO}_{\mathrm{x}}$ was detected in the effluent. SCWO operates below the temperature at which $\mathrm{NO}_{\mathbf{x}}$ is formed. Carbon monoxide was formed and discharged through the stack. The level averaged approximately $2 \mathrm{ppm}$ for both segments of the test. At no time did the CO level exceed $15 \mathrm{ppm}$.

In addition to the continuous samples, the gaseous effluent was also sampled using concentrating techniques (solid and liquid gas traps) to later analyze for volatile organics (collected on Tenax), and $\mathrm{HCl}, \mathrm{Cl}_{2}$, and $\mathrm{SO}_{2}$ (collected in aqueous solutions). The results of the Tenax columns were discussed previously (Table 5.4.3-3). The liquid trap analyses $\left(\mathrm{HCl}, \mathrm{Cl}_{2}\right.$, and $\mathrm{SO}_{2}$ ) are contained in Table 5.4.3-5. 
Table 5.4.3-5

\section{Effuent Gas Sampling Bottle Results}

\begin{tabular}{|l|c|c|}
\hline \multicolumn{1}{|c|}{ GAS } & $\begin{array}{c}\text { RESULT } \\
\left(\mathrm{mg}^{\prime} \mathbf{m}^{3}\right)\end{array}$ & $\begin{array}{c}\text { DETECTION LIMIT } \\
\left(\mathrm{mg}^{\mathbf{3}}\right)\end{array}$ \\
\hline Hydrochloric Acid & ND & 10 \\
\hline Sulfur Dioxide & ND & 2.5 \\
\hline Chlorine & ND & 1.5 \\
\hline
\end{tabular}

\section{STICKY SOLIDS CONTROL}

A total of 164 kilograms of salt was processed over the 168-hour test period. Based on material balances, 75 percent of the salt in the feed was removed in the brine during Segment I, and 83 percent in Segment II.

RTRPs improved the salt removal from the reactor by effectively rinsing accumulated salt from the lower section of the reactor wall. It is not clear whether RTRPs significantly impact the online time of the system. At this time it is not clear if the limiting on-line factor for this configuration is plugging the filter inlet; bridging and plugging the upper part of the reactor with salt; or in the absence of RTRPs, formation of a salt block in the lower part of the reactor.

As salt accumulated in the reactor, the brine level could be raised higher during RTRPs without reducing the destruction efficiency. In Run 931 , which had the same nozzle configuration, a response (increase) in CO levels was noted during a RTRP where the L/D was 3.4. During this test, the RTRPs routinely reached an L/D of 3 . This may have been due to the salt deposits reducing the effective diameter within the reactor and increasing the flow velocities (both downward and upward).

\section{SALt DEPOSITION}

The salt deposition was visually observed at the completion of Segment II of the test. Observations were not made at the end of Segment I so that the system could be brought back into operation as quickly as possible. However, a salt balance of Segment I operations including the vessel rinse was conducted to verify the amount of salt that was retained in the vessel. The Segment I salt balance had a closure of 98 percent.

Table 5.4.3-6 is a summary of the salt distribution within the process for Segment II of the 168hour performance test. Following this tabulation is a description of the salt deposits (qualitative and quantitative) that remained in the system. The salt balance was calculated by assuming all Chloride formed $\mathrm{NaCl}$, and all Sulfur formed $\mathrm{Na}_{2} \mathrm{SO}_{4}$. The salt balance had $95.7 \%$ closure. Filter $\mathrm{A}$ was removed and analyzed. It was assumed that Filter B had similar deposits.

Stone \& Webster 
Table 5.4.3-6

Salt Deposition Within the Reactor System

\begin{tabular}{|l|c|c|}
\hline LOCATION & $\begin{array}{c}\text { SALT } \\
\text { (kg) }\end{array}$ & $\begin{array}{c}\text { SALT } \\
\text { (\% of tota) }\end{array}$ \\
\hline Reactor & 13 & 16 \\
\hline Filter Arms & 0.5 & 0.6 \\
\hline Nozzle & 0.2 & 0.2 \\
\hline Brine & 70 & 83 \\
\hline
\end{tabular}

\section{Reactor}

Based on visual observations, the majority of the salt was deposited in the supercritical region of the reactor. This salt layer was consistent, and approximately 1.5 inches thick. A second deposit, located in the transition zone from supercritical fluid to liquid brine, was approximately 0.5 inches thick. Assuming these two areas account for all of the salt in the reactor, and assuming uniform salt density, $69 \%$ of the observed salt was found in the supercritical reaction area, and $31 \%$ in the transition area.

A small sample of the salt deposit from the supercritical reaction zone of the reactor was analyzed. The $\mathrm{pH}$ of a solution made by dissolving the salt in distilled water, was slightly higher than that of deposits taken from the nozzle tip and deposits from near the entrance of Filter $\mathrm{A}$. The latter two area salt deposits had neutral $\mathrm{pH}$ 's by similar analysis. The deposited salt had a $\mathrm{NaCl}: \mathrm{Na}_{2} \mathrm{SO}_{4}$ ratio was 7.5 , while the ratio in the feed was 4.9.

No salt deposits were observed in the lower portion of the reactor where the liquid brine existed.

Filters

Nearly 250 grams of salt were found on Filter $\mathrm{A}$. The $\mathrm{pH}$ of a dissolved sample was 7.7. The $\mathrm{pH}$ implies that carbonate was present in appreciable amounts. Assuming an identical amount of salt on Filter B, $0.6 \%$ of the total salt processed was deposited on the filters. This value compares well with Run 931 where $1 \%$ of the total salt processed was found on the filters. 
Filter A was removed from the reactor for visual analysis. The first nine inches of the filter (measuring from the reactor outboard), had solid salt deposits. This layer was approxiniately 0.6 inches thick closest to the reactor but tapered off to a thin layer about 9 inches from the reactor. From 9 inches to 21 inches, there was a consistent dusting of salt. From 21 inches to 29 inches there was no observable salt.

The entrance to Filter B was observed by looking into the reactor. The entrance to the filter arm appeared to be nearly blocked by salt with no visible holes. The salt appeared to be approximately 0.5 inches thick above the filter housing endplate. The salt covering the filter housing endplate was uniform with the wall salt deposit which was estimated to be 1.5 inches thick.

\section{Nozzle}

Solids collected on the nozzle itself. This was probable the result of recirculating flows within the vessel.

\section{FILTERS}

The design objectives of the filters were met. Salt entrained in the hot, supercritical effluent stream was effectively removed. This prevented down-stream plugging. However, the failure of the hot valves (AV 410A and B) limited the testing of repeated backwashing of the filters. Since the backwashes had been completed successfuily in several previous runs, and an alternative mechanical design for the hot valves exists, the filter operation was considered successful.

\section{NEUTRALIZATION}

The overall neutralization efficiency for this run was 80 percent. As stated previously, this limited the total organic chloride processed. The perchloroethylene feed flow was set to maintain the system effluent $\mathrm{pH}$ above 2 . The neutralization appeared to improve and reached a maximum of 85 percent as more salt accumulated in the reactor.

The neutralization efficiency was determined every thirty minutes during the test while perchloroethylene was being processed. The neutralization efficiency was approximately $70 \%$ at the beginning of Segment I. As the run continued, the neutralization did improve. During Segment I, the neutralization efficiency increased from 70 to 85 percent. In Segment II the neutralization efficiency started at 72 and again increased to 85 percent.

At this time the cause of the increase in neutralization efficiency is not completely understood. However, as salt accumulated in the vessel, the effective diameter did decrease which would cause higher flow velocities and turbulence in the reactor. This increase in mixing may have contributed to better neutralization. 


\section{Process avallability (ON-LINE TIME)}

Originally, it was anticipated that the process would operate continuously during the 168 hour test. However, a thermowell failure caused a shutdown after 77 hours. While this shutdown was caused by a mechanical failure, the rate of salt accumulation in the reactor was such that a shutdown was expected within 24 hours of the forced shutdown, due to the accumulation of salts in the reactor. One alternative to deal with the sticky solids is intermittent rinsing of the reactor as solids accumulate. While MODAR's intent is to develop a process that is continuously available, an estimate of a rinses impact on the process availability was made.

Earlier in the project, several runs were conducted in which the reactor vessel was rinsed in the middle of an experiment. This was part of a series of experiments to parametricly evaluate various nozzle configurations, then rinse the vessel and operate at steady state to evaluate salt deposition. This evolution was completed during Runs 925 and 928 . During these experiments, the system was rinsed and aqueous waste was processed within eight hours. Since repairs were conducted, the actual downtime of Run 932 was not used. Based on this analysis, the on-line time of the plant would be 93 percent. While the 8 hour rinse has been conducted several times in the project, the actual run time of the plant between rinses has never been evaluated. For example the plant operated for nearly 100 hours in the second segment. However, it did not appear that the process would have gone the full 168 hours without a shutdown and rinse. The $93 \%$ prediction was based on one shutdown occurring during the 168 hour period. The plant certainly has the potential to exceed this availability - for example if one 8 hour rinse is required over a 200 hour period as demonstrated during Seginent II, the process availability could be $96 \%$.

A degree of caution must be used when interpreting this process availability factor. This is not meant to be a prediction of the long-term (annual) availability of the process. Commercial processes require regular maintenance and repair. On line factors of 85 to 90 percent are not uncommon for commercial processes. The availability factor calculated based on this 168 hour snapshot would be considered as an indication of availability during the normal operation of the process - not as an overall on-line factor.

\section{ENERGY BALANCE}

The pilot plant was not very efficient. Heat losses to the st:iounding environment were relatively high. This is typical of pilot applications of high temperature processes. However minimizing heat loss was not a high priority of the project, and the primary focus was to demonstrate the process. Efficiency can always be built into the process at a later date. However, it is interesting to note that at higher capacities, the system was significantly more efficient.

Energy balances from Run 932 and Run 928 are presented in Table 5.4.3-7. These two balances show to impact of plant capacity on the overall energy balance.

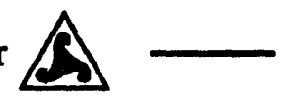


Table 5.4.3-7

OVERALL ENERGY BALANCE

\begin{tabular}{||l|c|c|c|c||}
\hline Energy Source & \multicolumn{2}{|c|}{$\begin{array}{c}\text { Run 932 } \\
\text { (300 gpd) }\end{array}$} & \multicolumn{2}{c|}{$\begin{array}{c}\text { Run 928 } \\
\text { (500 gpd) }\end{array}$} \\
\hline & (kJ/s) & $(\%)$ & (kJ/s) & (\%) \\
\hline ENERGY IN & & & & \\
\hline Electrical Power & & & & \\
\hline Air Compressor & 32 & 21 & 33 & 19 \\
\hline All other motors & 22 & 14 & 21 & 12 \\
\hline Electric heaters & 52 & 34 & 45 & 26 \\
\hline Computer control & 1.7 & 1 & 1.7 & 1 \\
\hline Chemical Energy & 47 & 30 & 73 & 42 \\
\hline TOTAL ENERGY IN & 154 & 100 & 174 & 100 \\
\hline & & & & \\
\hline $\begin{array}{l}\text { Rejected to Cooling } \\
\text { Water (Available for } \\
\text { Recovery) }\end{array}$ & 80 & 52 & 127 & 73 \\
\hline & & & & \\
\hline $\begin{array}{l}\text { ESTIMATED HEAT } \\
\text { LOSS (to evirons) }\end{array}$ & 74 & 48 & 48 & 27 \\
\hline
\end{tabular}

\subsection{EFFLUENT QUaLITY}

A primary goal of the project was to validate that the SCWO process achieved complete destruction of organic materials. While a significant amount of work had been done at the bench scale, and limited tests at the pilot scale, this particular configuration (filter reactor) of the process plant had not demonstrated organic destruction. In addition, since the process would eventually be used to treat hazardous wastes, the composition of the effluent should be such that little or no post treatment is required prior to disposal of any residuals.

Stone \& Webster 


\section{Effluent Characterization}

Early in testing, the process was evaluated to determine both the most reliable parameter to monitor destruction, as well as the relative sensitivity of the process to transients that may result in reduced destruction efficiencies. It was confirmed that the level of carbon monoxide (CO) released in the liquid gas separators for both the brine and effluent was the most sensitive parameter available. In addition, it was determined that, in most cases, organic breakthrough would occur first in the brine. This appeared to be a result of organic material falling directly into the liquid brine which essentially "quenched" the oxidation reaction. However, this was easily mitigated by maintaining the brine level lower in the vessel and thus controlling the effective reactor volume. Good destruction (99.99\%) was maintained at effective reactor length to diameter ratios of 3.5 and higher.

During most operations, hourly samples of the brine and liquid effluent were taken once the system was started up and reactor temperatures had stabilized. The gaseous effluent was monitored continuously. The hourly samples were saved and analyzed if specific occurrences during the run needed to be reconstructed or to obtain the results of specific experiments. These hourly samples were also to make up composites of both the brine and liquid effluent that were used for subsequent dc:ailed analysis. To validate destruction during the 168 hour performance test, additional sampling using Tenax traps was conducted.

During the individual runs, the liquid effluent and brine samples were analyzed in-house for Total Organic Carbon (TOC). When the system was operating with organic chloride feeds (perchloroethylene), the composite samples were sent to an outside laboratory during most runs to verify the carbon destruction by testirig for volatile organics by GC/MS via reference method 8260 or 624 . The samples were tested in-house for $\mathrm{pH}$, sodium, chloride, sulfate, chromium, nickel, iron, total organic carbon, acidity and conductivity. As mentioned previously, the effluent gas stream was also sampled for volatile organics by running a Tenax trap for several hours and also analyzed by standard methods for hydrochloric acid, sulfur dioxide, and chlorine.

\section{Organic Destruction - Overall}

Based on the detection limit of the in-house TOC analyses, up to $99.996 \%$ carbon destruction could be validated. The limitation was due to the difficulty in detecting low levels of carbon in a brine matrix. A better method of analyses was to send the composite samples to a commercial analytical laboratory where more sophisticated instruments could detect levels of organic contaninants to validate organic destruction efficiencies in excess of $95.9999 \%$.

For this report, destruction efficiencies based on analyses of the effluent composites for each of the runs are reported. The results are presented in Table 5.4-1. During every run with the exception of one (Run 921), the carbon destruction efficiency was greater than 99.99 percent. The efficiency can easily be maintained at greater than 99.99 percent. Testing was completed during each of the experimental runs which included gross variations in feed flows attempting to reach material balance case 5; variations in nozzle types and energies (exit velocities);

Stone \& Webster

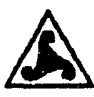


varying salt compositions; and changing the reactor internal configurations. The high destruction efficiencies during each of the runs demonstrates the effectiveness of the MODAR SCWO reactor vessel. Even with wide variations in conditions, the destruction efficiency was not compromised.

\section{Effluent and Residual Characterization and Treatment}

The test program conducted at MODAR's Natick, Massachusetts facility was a series of experiments conducted on a surrogate waste. The surrogate waste was made up of pure chemicals to simulate an industrial feed. Based on the policies of the Massachusetts Department of Environmental Protection, these "treatability studies," when conducted with pure chemicals and not actual RCRA wastes, are not a priori considered to generate a RCRA waste. When verified as not exceeding discharge limitations, the effluents may be discharged to the atmosphere or sewer.

\section{Liquid Effluents (Water and Brine)}

During operations, the water effluent from the process was collected in a discharge holding tank. This tank was sampled, and tested for total organic carbon, metal contaminants ( $\mathrm{Cr}$ and $\mathrm{Ni}$ ), and pH. In all cases, the water effluent could be discharged to the municipal sewer with minimal treatment - neutralization of the acidic $\mathrm{pH}$ and mixed bed ion exchange.

The brine which was collected in the bottom of the reactor, is a stream that concentrates the inorganic material. In addition, it also contains the bulk of the corrosion products from the system. Within the reactor, there are several regimes that are very corrosive: temperatures range from 200 to $600^{\circ} \mathrm{C}$; there are liquid, gas and supercritical phases present; pH ranges from neutral to basic in the brine to acidic in the supercritical fluid; and in all areas there is an excess of oxygen.

The brine quality varied during the test program. It also varied as specific tests progressed. This was probably the result of passivation within the system. In general, the brine contained ppm levels of $\mathrm{Cr}$ and $\mathrm{Ni}$ which had to be removed by chemical precipitation. This was a straightforward process that was accomplished through normal water treatment methods (chemical precipitation). Following precipitation of the heavy metals, the supernatant was sampled and discharged to the sewer. 
Table 5.5-1

Organic Destruction Efficiency

Entire Program

\begin{tabular}{|c|c|c|c|}
\hline Run & Feed (1) & $\begin{array}{l}\text { Destruction Ericlency } \\
\text { of Carbon (\%) }\end{array}$ & $\begin{array}{l}\text { Destruction Efriciency of } \\
\text { Perchloroethylene } \\
\text { (\%) }\end{array}$ \\
\hline 914 & IPA & $>99.99$ & $=$ \\
\hline 915 & IPA, $1.8 \%$ Salt & $>99.99$ & $=$ \\
\hline 916 & IPA, $1.4 \%$ Salt & $>99.99$ & $>99.999$ \\
\hline 917 & IPA, 1.7\% Salt & $>99.99$ & $\cdots$ \\
\hline 918 & IPA, $1.8 \%$ Salt & $>99.99$ & - \\
\hline 919 & IPA, $1.75 \%$ Salt & $>99.99$ & $>99.9995$ \\
\hline 920 & IPA, Perc, $4.1 \%$ Salt & $>99.99$ & $>99.9999$ \\
\hline 921 & IPA, Perc, 3.5\% Salt & 99.66 & $\cdots$ \\
\hline 922 & IPA, Perc, Salt & $>99.99$ & -- \\
\hline 924 & IPA, Perc, $4.9 \%$ Salt & $>99.99$ & $>99.9999$ \\
\hline 925 & IPA, Perc, 3.4\% Salt & $>99.99$ & $>99.9999$ \\
\hline 926 & IPA, Perc, $3.3 \%$ Salt & $>99.99$ & $>99.9999$ \\
\hline 927 & IPA, Perc, 3.6\% Salt & $>99.99$ & $>99.9999$ \\
\hline 928 & IPA, Perc, $4.5 \%$ Salt & $>99.99$ & $>99.999$ \\
\hline 929 & IPA, Perc, $1.7 \%$ Salt & $>99.99$ & $\cdots$ \\
\hline 930 & IPA, lerc, $2.0 \%$ Salt & $>99.99$ & -- \\
\hline 931 & IPA, Perc, $2.0 \%$ Salt & $>99.99$ & $>99.999$ \\
\hline 932 & IPA, Perc, $2.0 \%$ Salt & $>99.99$ & $>99.9998$ \\
\hline 933 & IPA, Perc, $3.9 \%$ Salt & $>99.99$ & -- \\
\hline
\end{tabular}

--- = Not Analyzed

(1) Feed made up of Perchloroethylene (Perc), and mixture of $\mathrm{NaCl}$, and $\mathrm{Na}_{2} \mathrm{SO}_{4}$ (Salt)

Stone \& Webster 
The residual precipitate was reduced to a sludge and disposed to a controlled landfill. It should be noted that over the entire project (nearly 1000 hours of operation including startups), only two drums of sludge were generated. Over the 168 hour performance test, the precipitate collected from the brine treatment process was sampled and analyzed in accordance with standard methods to determine if it was a waste controlled under the RCRA. The results of the TCLP analyses are contained in Table 5.5-4. Although the TCLP results presented in Table 5.54 indicate that the material does not require special controls, the two drums of sludge were sent to a controlled facility.

\subsection{SOLIDS HANDLING}

MODAR has developed a process approach and patented reactor design for the treatment of saltcontaining and salt-forming feeds. Key to this approach is using the chemical and physical properties of the supercritical fluid to both, destroy any organic material and separate the inorganic solids formed. The destruction of the organic material is straightforward. At the operating temperatures, sufficient residence time is available to permit the reaction to proceed. At first, solids control appears as easy. The MODAR patented reactor concept simultaneously maintains a supercritical reaction zone in the top and liquid water in the bottom of the reactor. Since inorganic materials (salts and metal oxides) have a low solubility in supercritical water, they simply precipitate and fall into the liquid water in the bottom of the reactor. Since most of the solid materials are soluble inorganic salts $\left(\mathrm{NaCl}, \mathrm{Na}_{2} \mathrm{SO}_{4}\right)$, they readily dissolve in the liquid water and are removed from the process as a concentrated brine. Figure 5.6-1 illustrates this concept.

Early in the development of the MODAR process, it was discovered that some of these solids, particularly the inorganic salts, tended to be very sticky, and would agglomerate and even plug the reactor effluent lines. This phenomenon has been observed by every researcher in the field, and is the biggest developmental hurdle to be overcome for commercial use. It should be noted that not all feedstocks contain sticky solids. Sticky solids are either contained in the feed as dissolved salts, or generated while neutralizing acids formed by organic compounds containing $\mathrm{Cl}, \mathrm{S}$, or P. However, the largest market for SCWO is to process sticky solid feeds. For that reason this project has focused on developing and demonstrating a process capable of handling these materials.

As mentioned previously, the MODAR process uses the unique properties of the supercritical fluid to effect separation and control of the sticky solids. During operation, the feed material is injected into the reactor through a nozzle. This nozzle performs several functions. It provides sufficient mixing of the feeds (organic, water, and oxidant). In addition, it establishes a downward velocity in the area where solids are being precipitated. This is critical in that by directing the solids down, they will impact and dissolve in the liquid brine and not become entrained and carried up in the reactor where they may deposit on the walls.

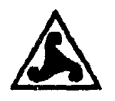


Table 5.5-4

Performance Test Brine Sludge TCLP Results

\begin{tabular}{|c|c|c|}
\hline Compound & Results (mo/l) & $\mathrm{RDL}(\mathrm{mo} / \mathrm{ll})$ \\
\hline \multicolumn{3}{|l|}{ Thom } \\
\hline Arsenic & ND & 1.0 \\
\hline Barium & ND & 0.50 \\
\hline Cadmium & ND & 0.10 \\
\hline Chromium & ND & 0.20 \\
\hline Lead & ND & 0.50 \\
\hline Mercury & ND & 0.005 \\
\hline Selenium & ND & 0.50 \\
\hline Silver & ND & 0.10 \\
\hline 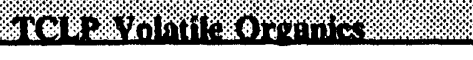 & 18.8. & 2 \\
\hline Benzene & ND & 0.005 \\
\hline Carbon Tetrachloride & ND & 0.005 \\
\hline Chlorobenzene & ND & 0.018 \\
\hline Chloroform & ND & 0.0075 \\
\hline 1.4-Dichlorobenzene & ND & 0.05 \\
\hline 1.2-Dichloroethane & $\mathrm{ND}$ & 0.0075 \\
\hline 1.Dichloroethane & ND & 0.0075 \\
\hline Tetrachloroethane & ND & 0.0075 \\
\hline Trichloroethene & ND & 0.005 \\
\hline Vinyl Chloride & ND & 0.018 \\
\hline Methyl ethyl ketone & ND & 0.05 \\
\hline \multicolumn{3}{|l|}{ 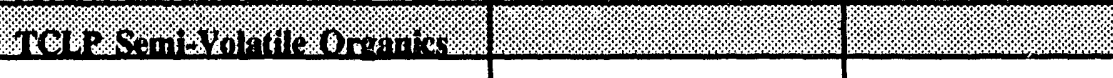 } \\
\hline Cresol_total & ND & 0.058 \\
\hline 2.4-Dinitrotolvene & ND & 0.030 \\
\hline Hexachlorobenzene & ND & 0.022 \\
\hline Hexachlore-1.3-butadiene & ND & 0.064 \\
\hline Hexachloroethane & ND & 0.040 \\
\hline Nitrobenzene & ND & 0.0152 \\
\hline Pentachlorophenol & ND & 0.0736 \\
\hline 2.4.5-Trichlorophenol & ND & 0.038 \\
\hline 2.4.6-Trichlorophenol & ND & 0.022 \\
\hline Pyridine & $N D$ & 0.20 \\
\hline
\end{tabular}

Stone \& Webster 
In support of this project, MODAR developed an additional solids control device - an effluent filter. This design effort was specifically directed to producing a hot solid-free effluent suitable for energy recovery by either heat exchange or expansion through a turbine. The filter was developed, designed and tested on the bench scale and found to adequately remove any entrained solids from the reactor effluent. However, as stated previously, the majority of the solids control was provided by the nozzle (directing the solids into the brine) within the geometry of the reactor.

\subsubsection{System Performance}

This demonstration project tested the solids control concepts of the MODAR process at the pilot scale. While the reactor had two solids control methods (nozzle and filter) it was realized that the nozzle was critical to achieving effective solids control. If enough solids were entrained to cause significant fouling of the filters it was thought that the wall deposits would be significant and become the controlling parameter.

During testing, the plan was to evaluate several nozzles and determine the relative influence of the nozzle design on the observed salt deposition. This was accomplished by installing a nozzle that was designed with a specific "energy" and outlet configuration. The term "energy" refers to the relative velocity that the nozzle imparts to the fluid as it exits. Nozzles were used that were high, medium, and low velocity. Three basic configurations were used, the differences being essentially in the design of the diffusion element at the extreme tip. Both in-house and commercial designs were used.

Since the nozzle characteristics were fixed mechanically, an experimental run would evaluate performance and evaluate operational efficiencies online (organic destruction and neutralization), then perform a steady state salt deposition experiment. Following the steady state period, the unit was shutdown, and visual observations of the salt deposition were made.

Table 5.6.1-1 is a summary of the experimental results. Initially, the focus of experiments was to find the nozzle that provided the least salt deposition on the reactor walls. This was conducted using only dissolved salts in the feed. The additional complexity of effecting neutralization was not considered.

As testing progressed it became apparent that the nozzle design was critical to efficient operation of this process configuration. We also observed that even with similar energy nozzles, the destruction efficiencies and solids deposition could vary. Our initial focus was to verify destruction efficiency, and optimize the process flows. The benchmark for destruction efficiency was to be achieving material balance case 5 (no supercritical water recycle) conditions. Nozzle configurations 1 and 2 could not achieve case 5, whereas nozzle 3, achieved case 5 operation. Nozzle 2 performed better than nozzle 1, based on its performance with minimal simulated recycle flow. Based on this performance, further work focused on using nozzles 2 and 3. 
The nozzle was required to perform two functions - to provide sufficient mixing to achieve organic destruction and neutralization, and to direct any solids formed or precipitated into the liquid brine at the bottom of the reactor. These objectives tend to be in opposition. Minimizing solids deposition on the vessel walls requires a quiescent reactor, while complete chemical reactions (oxidation and neutralization) requires a highly turbulent environment. While the requirements of these objectives may seem in opposition, we speculated there is most likely a window at which both are satisfied. Finding this window or optimum was the initial focus of testing.

As performance goals, we were looking for conditions where complete destruction $(99.999+\%$ of the specific organic constituent measured by GC/MS), good neutralization ( $95 \%$ with $2 \%$ perchloroethylene feed), and $95 \%$ of the solids were collected in the brine.

During nearly all tests salt deposits on the vessel walls were too high. While obtaining and maintaining organic destruction was simply accomplished using a variety of nozzles, neutralization of the acid-forming anions was very difficult, and required the use of high energy nozzles and acceptance of their increased salt deposition within the reactor. Upon observing this, subsequent testing focused on analyzing a series of nozzle designs and flow conditions to develop an understanding of the system. In addition, a series of tests were conducted to evaluate the effect of external systems (i.e. feed additives and pretreatment methods), alternate reactor configurations, and even salt composition on the process performance. Some of this testing is discussed in Section 5.6.2.

On the positive side, the filters performed well. During all tests, there were no indications that any solids passed into the downstream lines. On-line cleaning of the filters was accomplished using liquid water and a backwashing procedure. Physical examinations of the filters were conducted several times during the project, and the media showed no deterioration even after repeated backwashing.

The filters were designed to prevent downstream plugging and to reduce the fouling of downstream equipment. Dual filters allowed for on-line cleaning of the filters. To facilitate cleaning of each filter, the effluent was isolated using a valve resistant to the high temperature, high pressure, and low pH conditions. These were called the "hot valves." The salt accumulation on the filter was monitored by measuring the differential pressure across the filter (the filter $\Delta p$ ). As the salt accumulated on the filter, the filter $\Delta p$ increased. At an established setpoint, the filter was isolated and cleaned by introducing a backflow of high pressure liquid water. Temperatures within the filter were monitored, and once they reached $350^{\circ} \mathrm{C}$, a series of soaks were initiated to dissolve the salt. The backwash liquid was monitored by specific gravity periodically to evaluate removal. When the salt removal rate lessened, the backwash was ended. The total backwash liquid was retained and analyzed to determine the backwash efficiency. 
Table 5.6.1-1

Salt Deposition Results

\begin{tabular}{|c|c|c|c|c|c|c|c|c|}
\hline ron & $\begin{array}{l}\text { Woment } \\
\text { relowit }\end{array}$ & (n) & 18 & 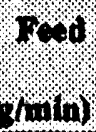 & $\begin{array}{l}\text { sort } \\
\text { (type) }\end{array}$ & Srin & 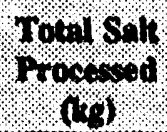 & 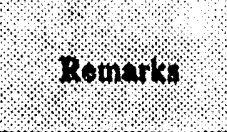 \\
\hline 915 & 1-A-MED & 1.8 & 1.8 & 25.5 & inor & $\ldots$ & 2.7 & \\
\hline 916 & 1-A-MED & 1.4 & 1.4 & 20.0 & inor tor & 92 & 11 & $\begin{array}{l}\text { Hi Brine Take- } \\
\text { off }\end{array}$ \\
\hline 917 & 1-A-MED & 3.3 & 1.7 & 16.1 & inor & 99 & 3.3 & \\
\hline 918 & 2-A-MED & 9 & 1.8 & 25.5 & inor & 45.7 & 15.6 & \\
\hline 919 & 3-D-MED & 9 & 1.8 & 20 & inor & 39 & 12.5 & $\begin{array}{l}\text { Best } \\
\text { Destruction }\end{array}$ \\
\hline 920 & 3-D-MED & 20.5 & 4.1 & 52.6 & inor tor & 69 & 50.8 & \\
\hline 921 & 3-B-LOW & 30.7 & 3.5 & 42 & inor +or & 95.3 & 77.3 & \\
\hline 922 & 3-D-MED & 2 & 2.4 & 36.6 & inor tor & $\cdots$ & 4.0 & \\
\hline 924 & 3-D-HIGH & 10.5 & 4.9 & 63.5 & inortor & 48 & 40 & $\begin{array}{l}\text { Best } \\
\text { neutralized }\end{array}$ \\
\hline 925 & 3-D-LOW & 9 & 3.4 & 45.4 & inor tor & 37.8 & 24.5 & \\
\hline 926 & 2-A-LOW & 8 & 3.3 & 44.0 & inortor & 57.6 & 21.1 & \\
\hline 927 & 2-A-LOW & 7.9 & 3.6 & 41.7 & inor tor & 76.9 & 22.1 & \\
\hline 928 & 3-B-HIGH & 4 & 4.5 & 71.7 & inor tor & 7.1 & 17.6 & \\
\hline 929 & 3-B-HIGH & 3.8 & 4.8 & 66 & inor tor & 32 & 14.5 & \\
\hline 930 & 3-B-HIGH & 8.7 & 1.7 & 14 & inortor & 29 & 8.5 & \\
\hline 931 & 3-C-LOW & 24 & 2.0 & 15 & inor tor & 78.5 & 21.6 & \\
\hline 932 & 3-B-LOW & 168.7 & 2.0 & 16.2 & inor tor & 83.4 & 163.7 & $\begin{array}{l}\text { Performance } \\
\text { Test }\end{array}$ \\
\hline 933 & 3-C-LOW & 12 & 3.9 & 31.7 & inor tor & 75.5 & 22.7 & \\
\hline
\end{tabular}

Note: "Salt in Brine" refers to the percentage of the total salt that was removed continously via the brine. The remaining salt was deposited within the vessel or collected in the filters.

Stone \& Webster 
There were several items which were crucial to the operation of the filters:

Removal of salt as the hot reactor effluent flowed through the filter;

General robustness/stability of the filter under thermal transients in the reactor environment;

Effective isolation of the filter being cleaned using the hot valve; and

Removal of the salt during the backwash procedure.

While the filters demonstrated that they could capture the salt on-line, and be cleaned off-line, the hot valves caused some problems and limited the usefulness of the filter arms during the project. The hot valves were used for only eight of the nineteen runs. Problems with the sealing, stem packing, and wear of the balls and seats required maintenance. For repairs, the valves had to be shipped to the manufacturer requiring four to six weeks. As configured, the hot valves have proven to be unreliable. However, the major problem appears to be mechanical in that the packing material was subjected to the full temperature of the process $\left(600^{\circ} \mathrm{C}\right)$, and failed to hold up. The valve manufacturer has a similar valve with an extended bonnet that would allow cooling of the packing material, and should prove more reliable in that respect.

The filters were cleaned during three separate runs of this project. The most recent procedure was tested in Run 931. The system capacity during this run was 298 gallons per day. The feed was 1.7 weight percent salt. After running on both filters for twenty-four hours, the pressure differential across each of the filters was 4 psi. The post run analysis indicated that eighty percent of the salt was removed during a filter backwash. The salt which accumulated on the filter arms is estimated to be approximately one percent of the salt processed. At such a slow rate, the filters would not require cleaning on a daily basis. The salt removal during filter cleaning is considered to be 80 percent or greater. As the salt load on the filter increased, it is likely that a greater percentage of salt would be removed during successive cleanings.

\subsubsection{Parameters Affecting Salt Removal}

During the test program, it became apparent that salt behavior in the reactor was complex. While the initial scope of the project was to conduct a demonstration of the process, it was recognized that additional work was required to further understand the factors that influenced the solids deposition within the system. Since the reactor was a set piece of equipment, evaluations focused on studying the items that could be varied including nozzle energy and tip configuration, overall salt loading, and the configuration within the reactor. In addition, tests were also conducted in which the brine level was allowed to "float" " $\mathrm{p}$ and effectively rinse the vessel walls, without compromising destruction efficiency. These "run time rinse procedures" (RTRP's) were used effectively in subsequent tests.

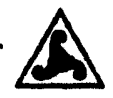


While the tests were not a pure parametric study of solids behavior in a SCWO reactor, several conclusions can be drawn from the experimental program.

\section{Nozzle Design}

The nozzle projects the feed, supercritical water, air, and caustic into the reactor. The nozzle must provide enough mixing for the oxidation of organics and neutralization of acids while directing the salt downward. To determine which nozzle design best suited this purpose, the nozzle design was changed slightly from one run to the next. A comparison with the previous run would identify whether or not the most recent change was beneficial to both salt removal and neutralization. Three different nozzle tips were tested at varying velocities. The process conditions were changed throughout the run to learn more about the effect they had on salt deposition as well.

The projection of the feed downward was best accomplished with a low velocity nozzle. This minimized turbulence and short-circuit flows which directed salt toward the wall. The nozzle design (energy and configuration) was one of the strongest factors affecting salt removal. The nozzle also appears to be the most important factor in neutralization.

\section{BRINE TAKEOFF}

The rate at which water was removed from the bottom of the reactor influenced the flow dynamics within the reactor. Removing water from the bottom of the reactor pulled the flow through the reactor, reducing the contact of solids with the reactor wall. Though this was recognized as a factor which affected salt removal, it was not pursued because an increased brine flow rate and a reduced effluent flow would result in reduced energy recovery and also result in more brine which must be subsequently treated and disposed of.

\section{SALT COMPOSITION}

Varying the salt composition appears to alter the stickiness of the salt. Within the test program, two compositions were studied: a mixture of sodium chloride and sodium sulfate (approximately $80 \%$ and $20 \%$, respectively), and the third contained sodium chloride, sodium sulfate, and sodium carbonate. The relative stickiness and removal rates of the different salts varied with each composition.

From Run 925 through Run 930, a sodium chloride, sodium sulfate, and sodium carbonate mixture (approximately 15\%, 65\%, and 20\%, respectively) was tested. Work previously completed by MODAR indicated that salt did not stick to the walls at certain compositions. In Runs 925 and 926, up to 58 percent of the salt was removed via the brine. However it was observed that this low recovery resulted from salt accumulating toward the bottom of the reactor above the brine water. As the salt began to accumulate, it provided additional surface area for more salt to accumulate. The salt was not sticky in the upper regions of the reactor, but quickly accumulated in the lower region of the reactor. In Run 927 the nozzle was modified to better 
direct the salt into the brine. During this run, 77 percent of the salt was removed via the brine. Although this was an improvement, the new nozzle design was abandoned because it did not provide the desired neutralization or salt removal efficiencies. In Runs 928, 929, and 930 the same salt mixture was run, but the reactor configuration was changed in hopes of enhancing removal. In each run, the revised configuration resulted in poorer salt recovery in the brine. In addition, analyses of the effluents and observations in the reactor indicated that this salt mixture was significantly more corrosive than those used earlier. All subsequent runs were conducted with the original sodium chloride/sodium sulfate mixture.

\section{Process Condritons}

The reactor temperatures, process flows, and brine level in the reactor are process conditions which affected the salt removal. With certain salt compositions, maintaining the reactor wall at temperatures above $600^{\circ} \mathrm{C}$ minimized the salt deposits in that region.

In other instances, minimizing the supercritical zone by raising the brine level in the reactor minimized the zone of precipitation. Salt was rinsed off of the reactor wall as the brine level was raised. This process was referred to as a run-time rinse procedure (RTRP). It is difficult to assess the usefuiness of the RTRPs. Based on mass balances conducted during Run 932, the percent of salt removed from the reactor increased after an RTRP. The RTRP may have prevented a salt block from forming in the lower region of the reactor. The RTRP should not be considered a stand alone solution for achieving complete salt removal/control, but at this stage of development, the RTRP was an effective tool for reducing the amount of salt in the reactor and potentially increasing the on-line time of the plant.

\section{Reactor Configuration}

Modifying the internals of the reactor can affect salt removal by changing the flow patterns. Several internal configurations were tried during the project, with little success. During Run 928, a "can" was inserted in the reactor to effectively direct the flows downward. The effluent had to flow out of the can and up around the outside to exit the reactor. It was thought that by forcing a more controlled flow, more of the salt would fall into the brine. In addition, the can also allowed higher temperature operation which along with increasing reaction rates, appeared to minimize salt deposition on hot walls.

During Run 928, it was found that the reaction was harder to control. The temperatures were significantly more sensitive to minor changes in flow, and the operators had to watch the system closely. After operation, it was observed that the majority of the salt accumulated toward the bottom of the reactor, with poor $(7 \%)$ recovery in the brine. The operational difficulties encountered combined with the apparent lack of improvement, and lack of time remaining in the project were cause to abandon this concept. 
An impinger device was used in Run 929. The impinger was a salt collection device which was located in the lower part of the reactor. The intent was for the salt to accumulate on the device. a cool water feed on the bottom plate would rinse the accumulated salt into the brine. The design did not appear to increase salt removal.

\section{Salt Concentration}

Two runs were completed to determine if the percent of salt in the feed affected the amount of salt which accumulated on the reactor walls. In Run 931, the feed was two weight percent salt, while in Run 933 the feed was four weight percent salt. For each run the same nozzle was used and the same process conditions were met. Salt on the walls did not increase with the doubling of the salt load. Although this was only tested in one case, the results indicate that salt deposition depends only on the total amount fed and is independent of the feed rate (with this particular configuration). Further work in evaluating this relationship is required.

\subsection{PROCESS EQUIPMENT AND OPERATIONS RESULTS}

The pilot unit operated well during the project. With the exception of the hot valves, all mechanical equipment met or exceeded all performance goals. This is exceptional considering that the bulk of the pilot plant was over ten years old. This is an important result. The balance of plant equipment used in the MODAR pilot plant were all catalog items and configured in a way that truly duplicated a commercial plant. A common criticism of pilot plant demonstrations is that they too often are more laboratory curiosities than actual plants. In all systems, the MODAR SCWO duplicated full scale operations. This verifies that the supporting infrastructure of a SCWO unit can operate reliably. Looking back on the recent test program, the only problems encountered were associated with neutralization of acid-forming anions and control of the sticky solids associated with them. In a system that was free of sticky inorganic solids, and acid-forming anions, corrosion rates would probably be significantly lower since the process would operate at a more moderate $\mathrm{pH}$, and obviously, no sticky solids would be present. Based on the results of this project, SCWO processing feeds that do not contain or generate sticky solids is ready for commercial demonstration.

The following discussion provides details of the operations of the balance of plant equipment.

\section{Feed Preparation and Pressurization}

The simulated waste components, air and caustic are pumped from atmospheric pressure to approximately 3400 psi. In most cases, three-head positive displacement pumps are used. The pumps were operated such that two heads were set manually while the third was controlled by the computer control system. During this project both the new and older pumps remained in calibration, and required no extraordinary maintenance. On several occasions air compressor components failed resulting in temporary plant shutdowns. However considering the age of the 
compressor (over 10 years), and the fact that it was continuously operated in excess of $95 \%$ capacity, the operators at MODAR are to be commended for its availability.

\section{REACTION}

The air and organic feed mix with supercritical water initiating oxidation of the organic material. The exothermic reaction provided additional heat to the process. The reaction mixture was between approximately $580^{\circ} \mathrm{C}$ and $600^{\circ} \mathrm{C}$ at steady-state. A second stage reactor for the effluent stream was available but was not required. During the earlier runs the second stage reactor was used during start-up to help heat up the system and to ensure complete oxidation. It was found unnecessary and was no longer used. The reaction was successfully initiated and the desired temperatures were easily maintained. The only temperature control problems were during Run 928 when the internal can was used. This concept was not used after this run.

During the experiments with the alternative salt mixture (sodium chloride, sodium sulfate, and sodium carbonate), corrosion within the reactor seemed to increase. To prevent excessive corrosion of the reactor vessel, a liner was installed. This liner was placed in the reactor prior to Run 928, and used in all subsequent runs. Provision was made to allow a purge between the liner and the reactor wall. While the liner did reduce the effective diameter of the vessel, this factor did not appear to impact operations or salt deposition. During the runs with the liner, a variety of purge configurations were tried in an attempt to develop a steeper temperature transition between the supercritical reaction and brine zones. Purge streams of hot air, hot water, and even supercritical water were used with little effect on the salt deposition. In the end, warm water was used as a purge simply to prevent reaction fluids from entering the annular space.

The filters performed well. They did remove essentially all solids and did not plug. The backwash system did meet expectations and removed more than $80 \%$ of the accumulated salt during a rinse. The filter material proved to be robust, and appeared to be unchanged from repeated thermal transients and exposure to low $\mathrm{pH}$ and high salt environments.

The hot valves did not perform as expected. This is discussed in some detail in previous sections.

One of the modifications to the vessel was the installation of several ReFLANGE fittings. These quick connect high pressure flanges were used repeatably during the test program. In every case the connection was separated and reconnected without incident or leakage. These connectors, manufactured by ReFLANGE of Houston, Texas, allowed the replacement of nozzles and evaluation of solids deposition without removal of the vessel head. Using the ReFLANGE connectors, a nozzle change could be accomplished in 8 hours. Allowing the vessel to cool, then remove and reinstall the main pressure head required 5 days.

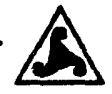




\section{Effluent Coolng AND LetdoWn}

Mechanically the effluent cooling and letdown systems worked well. The only problem encountered was icing on the gas lines, which was eliminated by controlling the cooling water flow such that the two phase effluent's temperature was maintained greater than $35^{\circ} \mathrm{C}$ prior to pressure letdown. The pressure reduction valves worked throughout the project, and did a good job of controlling system pressure. Although redundant systems (pressure control valves) were installed, they were not necessary in this project; however, a commercial design would definitely incorporate parallel control valves.

The effluent system did experience corrosion-related problems. This was mainly isolated to the regenerative heat exchanger and materials test chamber 2 . Within this zone the supercritical fluid condenses to liquid water, and isolated areas of concentrated materials such as $\mathrm{HCl}$ may exist. The system was fabricated mainly of high nickel alloys (625 and C-276), and was found to experience stress corrosion cracking in this area. Section 5.8 contains detailed discussions of these observations.

\section{BRINE LETDOWN}

The brine and backwash letdown systems performed without incident.

\section{COMPUTER CONTROL}

The computer was used to control approximately eighty percent of the plant. A Leeds \& Northrop Micromax II Controls system was used. Although complete computer control could have been implemented, several key process parameters were left under operator control to allow testing of different variables, and to minimize the time spent debugging control loops which were not necessary for the experimental unit. However, feed and effluent tank level controls were completely computer controlled

Early in the test program, the computer control system was debugged, and operations verified. Several problems were encountered with one portion of the system resulting in a "black out" of the control screens. The control system continued to function, having only cut out the operator. With replacement of a faulty card in the CPU, the system performed reliably.

\subsection{MATERIALS TESTING}

The SCWO process presents unique material challenges. Within the process one encounters high and low temperatures, basic to acidic $\mathrm{pH}$, free oxygen, and various inorganic materials. In addition, since the process operates at high pressures the same materials are subjected to high sustained tensile stresses, and fabrication techniques impart residual stresses which can exacerbate the corrosion problem.

Stone \& Webster 
The test program represents one of the most comprehensive materials test efforts in this field to date. The size of the pilot unit afforded the opportunity to test not only coupon samples but evaluate materials, components and fabrication techniques in actual service equipment.

The following section presents the overall results of the materials testing. Detailed discussion of metallurgical observations and analyses are contained in Appendix A.

\section{OVERALl APPROACH AND ResUlts}

Initially the metallurgical effort for this project was limited to the evaluation of materials coupons contained in the two materials test chambers, as well as physical observations of the reactor vessel at three times during the project: initially, approximately halfway through the test program, and finally at the conclusion of the 168 hour performance test. The results of this portion of the materials test program are discussed in Section A.3 of Appendix A.

When this project was initiated in 1992, the preferred materials of fabrication for SCWO processes were high nickel alloys, primarily 625 and C-276. The bulk of the high-temperature, high-pressure portions of the pilot plant was fabricated of these materials. MODAR had identified some ceramic materials that appeared to be corrosion resistant, however suitable techniques to fabricate pressure containing components were not sufficiently developed to permit their use in the pilot plant. Within this project, the use of ceramic materials was limited, and included further evaluation of potential materials and fabrication methods.

During operation, our appreciation of the corrosive nature of the process environment was increased through experiencing several system failures due to corrosion. The first failure occurred after the system had run for approximately 400 hours. The initial failure was in a tube in the regenerative heat exchanger. The failure occurred during Run 920 in which the system $\mathrm{pH}$ was inadvertently allowed to fall to approximately 1.3. This was an older piece of equipment, and the inside surface appeared severely pitted. It was not known if the bulk of the pitting occurred during this project, or was a result of earlier use of the equipment. It was assumed that the failure was a result of previous pitting that was exacerbated by the low pH run. The tube was repaired, and the project continued.

During Run 922, a leak developed at the outlet of material test chamber 2 (MTC-2). The material was severely pitted. Since this was a new piece of equipment, a further investigation was conducted. This included nondestructive examinations (ultrasonic testing) as well as metallographic analyses in Stone \& Webster's laboratories. This testing was to assess the condition of the pilot plant, and reevaluate the materials program to gain further insight into the corrosion mechanisms observed. The goal was to develop a revised metallurgical program that would aid in determining the appropriate materials of construction and fabrication techniques for a commercial application of SCWO.

The MODAR SCWO process can be classified into four zones: the hot subcritical zone where the process effluent is cooled prior to pressure letdown (Zone 1), the hot supercritical fluid 
reaction zone (Zone 2), the liquid effluent zone where final cooldown and gas liquid separation occurs (Zone 3), and the liquid brine zone (Zone 4). Each of these areas is a different chemical and thermal environment. Temperatures range from 40 to $600^{\circ} \mathrm{C}, \mathrm{pH}$ from 2 to 8, oxygen concentration from ppm to percent levels, and salt $\left(\mathrm{NaCl}, \mathrm{Na}_{2} \mathrm{SO}_{4}, \mathrm{Na}_{2} \mathrm{CO}_{3}\right)$ concentrations from ppm levels to nearly saturated.

Our approach was to evaluate equipment from each of the zones and determine the extent of corrosion in each system. To accomplish this, pieces were removed from each zone for analyses in the metallurgical laboratory. In addition, the reactor vessel was examined using an ultrasonic NDE technique to evaluate its condition. Detailed results of these analyses are contained in Section A.1 of Appendix A. Based on the successful operating history at MODAR, and from similar commercial applications, no testing was conducted on the cool effluent zone (Zone 3).

The analyses showed that the most severe corrosion occurs in Zone 1 - the region where hot subcritical fluid is being cooled. The fluid in this area is hot $\left(250\right.$ to $\left.350^{\circ} \mathrm{C}\right)$, and typically at an acidic $\mathrm{pH}$ (depending on the feed, $\mathrm{pH}$ can range from 2 to 6). Within this region, the most severe corrosion was observed. Analyses of Zone 1 components revealed pitting in virtually all pieces, and stress corrosion cracking in heat affected zones of welds. However, the base material did not appear to be experiencing stress corrosion cracking. This led us to postulate that heat treatment would eliminate the problem of stress corrosion cracking in this zone. Subsequently, all components included in Zone 1 of the process were heat treated.

Examinations (NDE and metallographic) of components in Zone 2 (the supercritical environment) indicated some pitting, but no stress corrosion cracking.

Examination of Zone 4 revealed that while both Alloy 625 and Alloy C-276 experienced pitting, only Alloy 625 appeared susceptible to stress corrosion cracking. Based on these results Alloy 625 was eliminated in the brine system as much as practical. The only portion of the brine section that remained Alloy 625 was the reactor vessel and nozzles.

As mentioned previously, the major corrective action was to repair the leaks and heat treat all equipment in Zone 1 . In addition, our metallurgical program was reevaluated, and additional samples were placed in the materials test chambers.

Following the heat treatment, the system was reassembled and placed in service. Two runs later (in Run 924), a leak was detected in a reactor thermowell nozzle in the brine zone. Since these thermowells, and other nozzles in the brine section of the reactor were Alloy 625 , it was decided to replace them with Alloy C-276 components. The results of these analyses are again contained in Section A.1 of Appendix A.

This was a major undertaking since the vessel was registered with the National Board of Boiler and Pressure Vessel Inspectors, and any work had to be done to specific standards and inspected by an authorized inspector. Since ine incremental cost was not great, it was decided to replace all Alloy 625 fittings in the brine section of the reactor. This effectively eliminated all Alloy 
625 from Zone 4 with the exception of the reactor. The reactor was also inspected for signs of stress corrosion cracking.

The system was again placed in operation and tests conducted for several hundred hours without major incident until the 168 hour performance test. During the performance test one leak occurred at a reactor thermowell inner tube. This required interrupting the performance test to depressurize and replace the tube. It should be noted that the leak was not in the reactor body, but rather in an insert that was contained within the thermowell nozzle to prevent contact between the fluid and the thermocouple wire. It is believed that this failure was mainly due to a flaw introduced during fabrication of the tube. Once this insert was replaced, the 168 hour performance test was concluded.

Following the performance test, one additional run was conducted to evaluate the effect of feed salt concentration on the salt deposition. During this run, two leaks were observed. The first occurred in the heat affected zone of a coupling on the filter A backwash exit tubing. The tubing was replaced. The second leak occurred in a ten-year old section of the regenerative heat exchanger. The failure was due to stress corrosion cracking. Section A.2 of Appendix A contains further discussion of these failures.

This test program has verified that controlling corrosion to acceptable levels is one of the greatest challenges to commercial application of the process. The critical control parameter to minimize corrosion is maintaining the effluent $\mathrm{pH}$. In this project it was observed that corrosion increased significantly at effluent $\mathrm{pH}$ levels below 2 .

Based on metallurgical analyses of the coupons and reactor componets, most metals were susceptible to localized corrosion of varying degrees. The high-nickel alloys also experienced stress corrosion cracking in some environments. At this time we have not identified a single metal/alloy that can be used in all zones of the process. However, several ceramics show promise. Stone \& Webster and MODAR have identified materials (metals/alloys and ceramics) that are appropriate for each of the zones, and are confident that they can be used in commercial applications with acceptable corrosion rates. Materials of choice include high-nickel alloys, as well as specialized grades of other materials ( $\mathrm{Ti}$ for example). In addition, several ceramic materials have been identified that show excellent corrosion resistance. However their use may be limited due to mechanical limitations in strength and fabrication techniques.

Based on the results of the recent test program, the most appropriate materials for fabrication of a MODAR based SCWO process at this time are those shown in the following table. Note that testing has been limited to conventional, commercially available, materials of construction in the process industries, exotic materials (e.g. noble metals) have not been extensively evaluated. In addition, while this table addresses the suitability of materials to resist corrosion, it is not implied that all these materials in themselves are mechanically suitable for pressure containment. 


\begin{tabular}{|c|c|c||}
\hline ZONE & CONDITIONS & MATERIAL \\
\hline 1 & $\begin{array}{c}\text { SUBCRITICAL (acidic) } \\
350^{\circ} \mathrm{C} \geq \mathrm{T} \geq 250^{\circ} \mathrm{C}\end{array}$ & $\begin{array}{c}\mathrm{Ti} \\
\text { (Grade 2 and 12) }\end{array}$ \\
\hline 2 & $\begin{array}{c}\text { SUPERCRITICAL (acid/base) } \\
650^{\circ} \mathrm{C} \geq \mathrm{T} \geq 350^{\circ} \mathrm{C}\end{array}$ & $\begin{array}{c}\text { Proprietary } \\
\text { (alloy and ceramic) }\end{array}$ \\
\hline 3 & $\begin{array}{c}\text { LIQUID EFFLUENT (acidic) } \\
250^{\circ} \mathrm{C} \geq \mathrm{T}\end{array}$ & $\begin{array}{c}\mathrm{Ti} \\
\text { (Grade 2 and 12) }\end{array}$ \\
\hline 4 & $\begin{array}{c}\text { LIQUID BRINE (basic) } \\
350^{\circ} \mathrm{C} \geq \mathrm{T}\end{array}$ & $\begin{array}{c}\mathrm{Ti} \\
\text { (Various Grades) }\end{array}$ \\
\hline
\end{tabular}

\subsection{ADDITIONAL STUDIES}

Over the course of the test program, several sub-studies were conducted in the process of demonstrating the system. These were mainly in response to problems encountered in the demonstration. The following section presents a summary of these studies and their results.

\subsubsection{NeUtralization}

As discussed previously, when significant amounts of organic chloride were introduced in the feed, the extent of the neutralization reaction depended on the nozzle design. Ineffective neutralization could not be tolerated since the resultant acidic environment was observed to cause excessive corrosion.

Once neutralization was identified as a key process parameter, a series of experiments were conducted to identify the variables affecting the reaction efficiency. Neutralization experiments were conducted from Run 919 through Run 933. The testing can be grouped into three segments:

Segment A (Run 919 - 922):

During this period the process was operated with low levels of organic chloride feed. Testing was to validate analytical procedures and confirm chlorinated organic destruction efficiency. During this time, it was observed that the low to medium velocity nozzles were not providing sufficient neutralization. 
Segment B (Run 924 - 930):

During this period, the strong interrelation between neutralization and salt removal was observed. A series of experiments were conducted to study neutralization as the primary objective. In addition, once it was identified that nozzles that achieved high neutralization efficiencies had poor solids performance, tests were conducted to evaluate the solids behavior in the reactor. These experiments focused on varying the system configuration and salt composition in an attempt to improve salt removal and to shift away from the dependency of salt removal on the nozzle design.

Segment C (Run 931 - 933):

During this portion of the test program, the best achievable conditions were established for the 168 hour performance test.

The majority of the neutralization experiments were conducted during Segment B. Based on the results from both Segment A and previous MODAR bench-scale testing, two factors were identified as significantly affecting the neutralization efficiency: the nature of the aqueous feed and nozzle energy. The former is related to the characteristics of the feed material (solubility, etc), while the latter is an indication of the mixing at the nozzle tip. The relative impact the two parameters had on neutralization was evaluated in a limited experimental program. The results are not to be interpreted as a true parametric study of the phenomenon. Rather conclusions were drawn from the tests to set the conditions for the performance test.

\section{Feed Characteristics}

Solubility

In Run 922, a di-chloro acetic acid (DCAA) feed was neutralized with an efficiency of $99 \%$. The neutralization efficiency was 15 to 20 percent higher than the neutralization efficiency of Perchloroethylene at identical conditions. DCAA is a water soluble organic while perchloroethylene is insoluble. The solubility of DCAA was considered as the reason for the difference in the neutralization efficiencies.

Based on this observed neutralization efficiency, a series of experiments to determine if feed homogenization would increase neutralization was conducted.

Feed Homogenization

The dependence of the neutralization efficiency on the homogeneity of the feed was tested in Runs 924 and 925 . A high energy mixer was used to homogenize the perchloroethylene-containing feed in Run 924. In addition, Triton, a surfactant, was added to decrease the surface tension of water facilitating better dispersion of the 
perchloroethylene in water. Based on the results of Runs 924 and 925, the use of both the mixer and the surfactant did not increase the neutralization efficiency.

\section{Nozzle Energy}

The nozzle's relative energy (annular velocity) was varied over a range of low to high. The neutralization efficiency increased as the annular velocity was increased. The type of nozzle tip from which the feeds were dispersed may have contributed to the neutralization efficiency as well but the effect was not as evident. The higher annular velocities increased the turbulent flows within the reactor, and provided better mixing and therefore, higher neutralization efficiencies.

\subsubsection{SUPERCritical Water Recycle Flow}

From Run 914 to Run 921, achieving what is known as the "Case 5" material balance condition was one of the primary objectives. Case 5 refers to process conditions where no supercritical water is used. In this process configuration, the supercritical water serves two functions: it provides additional mixing and additional heat for kicking off the oxidation of the organic. To successfully reach Case 5 , complete oxidation of the organic feed must be attained without the addition of supercritical water.

Successful operation (organic destruction) at Case 5 conditions eliminate the need for a supercritical water recycle pump. The incentive for reaching this condition is the elimination of the cost of such a pump. The suction and discharge conditions are severe. Stone \& Webster believes that the recycle pump can be successfully built and operated. However, if the expense of such a pump could be avoided, it would reduce the cost of the overall process.

During the pilot plant test program a recycle pump was not used. Recycle was simulated by heating a pressurized stream of fresh water to reactor temperature and feeding it to the reactor inlet. The engineering team was successful in designing a nozzle which reached Case 5 conditions. In Run 920 the system was started up with a 1:1 supercritical water to feed ratio. Upon reaching steady-state, the supercritical water was slowly decreased. The CO levels in the effluent gas were carefully monitored to ensure the destruction efficiency was not compromised. The supercritical water was eventually shut off and the process maintained in steady state at Case 5 conditions for approximately 5 hours.

After successfully achieving Case 5 conditions in Run 920, this condition was no longer pursued. The team had demonstrated that Case 5 could be achieved. The refinement of this condition was not within the scope of this project. Such refinement would have to be studied in conjunction with neutralization and salt removal. 


\subsubsection{REACTION INITIATORS}

Two compounds were studied as reaction rate enhancers/initiators. Based on previous bench scale studies completed by MODAR, certain compounds enhanced oxidation reaction rates, and caused more efficient operation. These initiators were used in two experiments as part of demonstrating "Case 5" conditions. In Runs 917 and 918 initiators were used to enhance the reaction sufficiently to overcome the temperature deficit caused by the lack of supercritical water recycle. In both cases, the initiators did not appear to enhance the reaction rates enough to achieve case 5 conditions. 


\section{APPENDIX A}

\section{MATERIALS TESTING}

The SCWO process presents unique material challenges. Within the process one encounters high and low temperatures, basic to acidic $\mathrm{pH}$, free oxygen, and various inorganic materials. In addition, since the process operates at high pressures the same materials are subjected to high sustained tensile stresses, and fabrication techniques impart residual stresses which can exacerbate the corrosion problem.

The test program represents one of the most comprehensive materials test efforts in this field to date. The size of the pilot unit afforded the opportunity to test not only coupon samples but evaluate materials, components and fabrication techniques in actual service equipment.

The following sections present the detailed results of the materials testing that support the summary contained in report Section 5.8. Section A.1 and A.2 presents the results of observations, metallurigical analyses, and conclusions based on the evaluations of several components that failed during the test program. Section A.3 is a discussion of the analyses and conclusions of the materials test program based on the coupon samples included in the process.

\section{A.1 SERVICE FAILURES AND NONDESTRUCTIVE EXAMINATIONS APRIL - JUNE 1993}

By April 1993, the pilot plant had accumulated approximately 400 service hours. During the three-month (April - June 1993) period, leaks were detected in several components as mentioned above. Examinations were performed at the Stone \& Webster Materials Laboratory to establish the mode of each failure. This section summarizes the findings of the metallurgical and nondestructive examinations. The observations, analyses, and corrective actions are presented chronologically.

\section{Laboratory Examination Methods}

The laboratory examinations were limited to:

- examination of the I.D. and O.D. surfaces at low magnifications (up to 20X) in an optical stereomicroscope and

- metallography 
Due to budget constraints, no fractographic examinations either in a stereomicroscope or in a scanning electron microscope have been done. Likewise, no microprobe analysis or energy dispersive spectroscopy has been performed.

\section{Regenerattve Heat Exchanger (HX-210)}

A leak in the regenerative heat exchanger (HX-210) occurred during Run 920 (March 1993). The leak was located in tube No. 23, i.e., in the second row of tubes from the bottom, at the toe of the weld, 1.25-in. upstream of the tube U-bend. In this area the fluid was subcritical water at approximately 250 to $300^{\circ} \mathrm{C}$. The leak occurred near the 7 o'clock position looking along the flow. Based on observations by MODAR, the opening through which the leak occurred was elongated and its length on the outside diameter surface did not exceed 1/16 in. No record of its orientation relative to the tube axis (longitudinal, transverse, or at an angle) was made. When MODAR was removing the tube section, a cut was apparently made through the location of the leak. The tube material was Alloy C-276.

\section{Observations}

We did not have a chance to examine the leak area in the heat exchanger tube because it was destroyed during removal of the tube.

\section{Corrective Action}

Since this heat exchanger was ten years old, and the exact mechanism of failure could not be determined, the failed tube was replaced and testing continued.

\section{Material Test Chamber 2 (MTC-2) OUTLet NiPPle}

During Run 922 (April 1993), a leak developed at the outlet of MTC-2. The system was shutdown, and after cooling, MTC-2 was delivered for a laboratory examination of the failure mode.

\section{Observations - Initial}

The leak occurred through a wide-open crack in the Alloy 625 nipple material, in close proximity to the weld. At least a portion of the crack was in the heat affected zone (HAZ) of the weld. The crack was oriented at an angle to the nipple axis and to the weld. A metallographic examination of a cross section at the weld revealed a number of transgranular stress corrosion cracks which initiated in the heat-affected zone at the inside diameter surface of the nipple. The stress corrosion cracking pattern is similar to one typically observed in austenitic materials exposed to chloride-bearing aqueous environments. No local chemical analysis of the fracture surfaces was performed. However, the known chemistry of the environment strongly suggests chloride induced stress corrosion cracking.

\footnotetext{
FINAL REPORT PHASE UB
} 
Since this was the first failure of new equipment, a thorough investigation was conducted. As a matter of convenience, designations of the zones in the SCWO unit were assigned as shown in Table A.1-1 (it should be noted that the boundaries between zones are not clearly identified in the system, and may vary depending on the process configuration):

Table A.1-1

Description of Zones in the MODAR Pilot Plant

\begin{tabular}{|c|l|l|}
\hline ZONE & \multicolumn{1}{|c|}{ DESCRIPTION } & \multicolumn{1}{|c|}{ COMPONENTS } \\
\hline 1 & $\begin{array}{l}\text { Process main effluent } \\
250 \text { to } 350^{\circ} \mathrm{C} \\
\text { Hot subcritical liquid and gas } \\
\text { Acid pH }\end{array}$ & $\begin{array}{l}\text { Lower part of the } \\
\text { regenerative heat } \\
\text { exchanger (HX-210) } \\
\text { and MTC-2 }\end{array}$ \\
\hline 2 & $\begin{array}{l}\text { Main reaction zone and effluent } \\
>350^{\circ} \mathrm{C} \\
\text { Supercritical fluid } \\
\text { Acid pH }\end{array}$ & $\begin{array}{l}\text { Top of the pressure } \\
\text { vessel, MTC-1, and top } \\
\text { portion of the regenerative } \\
\text { heat exchanger (HX-210) }\end{array}$ \\
\hline 3 & $\begin{array}{l}\text { Process main effluent } \\
25 \text { to } 250^{\circ} \mathrm{C} \\
\text { Subcritical liquid and gas } \\
\text { Acid pH }\end{array}$ & $\begin{array}{l}\text { Final cooldown and } \\
\text { letdown system }\end{array}$ \\
\hline 4 & $\begin{array}{l}\text { Reactor brine } \\
<250^{\circ} \mathrm{C} \\
\text { Subcritical liquid } \\
\text { Basic pH }\end{array}$ & $\begin{array}{l}\text { Bottom of the pressure } \\
\text { vessel and brine letdown } \\
\text { system }\end{array}$ \\
\hline
\end{tabular}

The boundary between Zones 1 and 3 , i.e., $250^{\circ} \mathrm{C}$ is arbitrary and may be changed in the future. A transition zone between the main reaction and liquid brine zones is not explicitly included in the above classification because it only occurs in the reactor vessel. However, this transition zone would probably be corrosive, and material integrity in this area is crucial to successful operation of the SCWO unit.

Subsequently, Zone 2 was subdivided into three subzones:

Zone 2a Main reaction zone

Zone $2 \mathrm{~b} \quad$ Filter arms

Zone $2 c \quad$ Downstream of the filters.

While all three zones are exposed to the supercritical fluid, the following differences can be identified. In Zones $2 \mathrm{a}$ and $2 \mathrm{~b}$, salts are present, including sodium chloride, sodium sulfate, and 
sodium carbonate. The relative amount of each salt varies. In Zone $2 a$, the salt deposits are relatively richer in sodium carbonate, while in Zone $2 b$, they are rich in sodium chloride.

\section{System Evaluation - Laboratory Analyses}

To evaluate the integrity of the system, a number of components were selected for a laboratory examination. Results of the examination (visual, low magnification stereomicroscopy, and metallography) are summarized below. They are grouped by the zones as defined earlier.

Zone 1 - Subcritical $\left(250\right.$ to $350^{\circ} \mathrm{C}$ and acidic $\left.\mathrm{pH}\right)$

The following Zone 1 components were examined:

- $\quad$ MTC-2 inlet nipple

- Inlet and outlet tubes at the tee downstream of valve AV-290

- $\quad$ Regenerative heat exchanger (HX-210) tubes adjacent to previous failure

The first three components were made of Alloy 625 while HX-210 was fabricated of Alloy C276. None of the components were heat treated after welding. The results are summarized in Table A.1-2.

As shown in the above summary, the inlet to MTC-2 had suffered stress corrosion cracking and pitting to a similar extent of the outlet. Stress corrosion cracks in the base metal under thread in the inlet tube at the tee downstream of valve AV-290 are shown in Figures A.1-1. Typical pits in the base metal of the outlet tube at the tee downstream of valve AV-290 are shown in Fig. A.1-2. Transgranular stress corrosion cracks were found in the heat-affected zone and in the base metal under a thread. The common factor, other than the environment and stresses due to pressure, in both cases is the presence of residual stresses from welding and thread forming operations, respectively. No cracks were detected in base metal away from threaded area. However, extensive pitting was found in all examined areas. The maximum pit depth in the examined sections was approximately 0.015 in. 
Table A.1-2

Summary of Zone 1 Component Metallographic Analyses

\begin{tabular}{|l|l|l|}
\hline \multicolumn{1}{|c|}{ COMPONENT } & EXAMINED AREA & \multicolumn{1}{|c|}{ FINDINGS } \\
\hline MTC-2 inlet & Heat affected zone & $\begin{array}{l}\text { Multiple deep } \\
\text { transgranular (TG) } \\
\text { cracks; extensive pitting }\end{array}$ \\
\hline $\begin{array}{l}\text { Inlet tube at tee } \\
\text { downstream of } \\
\text { AV-290 }\end{array}$ & Heat affected zone & $\begin{array}{l}\text { Shallow TG cracks; } \\
\text { extensive pitting } \\
\text { Deep TG cracks; } \\
\text { extensive pitting }\end{array}$ \\
\hline $\begin{array}{l}\text { Outlet tube at tee } \\
\text { downstream of } \\
\text { AV-290 }\end{array}$ & Base metal (2 sections) & $\begin{array}{l}\text { No cracks; extensive } \\
\text { pitting }\end{array}$ \\
\hline \hline $\begin{array}{l}\text { HX cracks; extensive } \\
\text { pitting }\end{array}$ \\
\hline
\end{tabular}

Since HX-210 had failed in an earlier run, a .

be, adjacent to the failed member, was examined. A longitudinally sectioned bend fron .... bottom row of tubes was examined in an optical stereomicroscope. The examination revealed numerous pits (Figures A.1-3) and, in the bend proper, a number of longitudinally oriented trenchlike grooves (Fig. A.1-4). No grooves were found in the straight sections of the tube. The diameter of the larger pits was in the range of 0.015 to 0.02 in. ( 0.4 to $0.5 \mathrm{~mm}$ ). Some of these pits appear to be almost as deep. The width of the wider grooves is in the same range, i.e., between 0.015 and 0.02 in. The formation of grooves is quite unusual in high-nickel alloys. At least some of them appear to interconnect previously formed pits. New pits are evident at the bottom of some of the grooves. The mechanism of their formation requires an additional and more detailed evaluation including metallography and energy-dispersive or wave-dispersive spectroscopy.

Based on the examination of the inside diameter surface, it is not likely that the leak could have occurred due to penetration of one of the grooves, since no grooves were found in straight tubing in tube No. 24 (last tube before the outlet, the coolest section of the heat exchanger). Penetration of a pit would not normally be elongated. Thus, there is a possibility that stress corrosion cracking developed in the heat-affected zone of the weld. 


\section{Zone 2 - Supercritical Zone $\left(>350^{\circ} \mathrm{C}\right.$ and acidic or basic $\left.\mathrm{pH}\right)$}

A coupling with a tube on each side, all made of Alloy 625, was removed by MODAR from an area upstream of the second stage reactor. Estimated operating temperature at the coupling had been in the range of 575 to $585 \circ \mathrm{C}$.

One of the tubes was sectioned for a metallographic examination at the weld joining the tube and coupling. The examination revealed incipient pitting (less than 0.001 -in. deep) and no evidence of cracking.

No Alloy 625 tubing was examined from Zone 2 tubing downstream of the second stage reactor. The visual examination of Alloy C-276 heat exchanger tubes indicated a drastic reduction in pitting attack in higher tube runs where temperatures are expected to be above the critical point. However, later in the project, stress corrosion cracking was observed in Alloy C-276 exposed to the zone 2 environment.

\section{Zone 3 - Liquid Effluent $\left(<250^{\circ} \mathrm{C}\right.$ and acidic $\left.\mathrm{pH}\right)$}

Based on the successful operating history at MODAR, and from similar commercial applications, no testing was conducted on this zone.

\section{Zone 4 - Liquid Brine $\left(<350^{\circ} \mathrm{C}\right.$ and basic $\left.\mathrm{pH}\right)$}

A welded coupling joining Alloy 625 and Alloy C-276 tubes was removed by MODAR from an area upstream of heat exchanger HX 481 in the brine cooldown path $\left(\mathrm{T}<250^{\circ} \mathrm{C}\right)$.

Both tubes were sectioned at the welds for a metallographic examination. The examination revealed pits in both Alloy 625 and Alloy C-276 tubes. Deep stress corrosion cracks were present in the Alloy 625 tube (Figure A.1-5), whereas the Alloy C-276 tube section showed shallow, less than 0.005 in deep cracks (Figure A.1-6). The Alloy C-276 tube under the weld was locally remelted by the heat of welding all the way to the inside diameter surface.

\section{System Evaluation - Non Destructive Examination}

An ultrasonic (UT) examination of full penetration girth and longitudinal seam welds, as well as of selected base metal areas in the pressure vessel and in a filter arm was performed by a Level III UT inspector on April 19, 1993. A procedure used for the examination was developed specifically for detection of stress corrosion cracks in austenitic materials.

The examination did not detect any evidence of cracking. A number of indications were recorded, however, in two girth and four longitudinal seam welds. While these indications were attributed to the root geometry, they should be monitored in the future by UT to verify this conclusion. 
The examination did not detect any wall thinning. The middle section of the vessel has thickness between 1.00 and 1.04 inches, while the thickness of the machined areas in the upper and lower portions of the vessel is 0.88 and 0.84 in., respectively.

\section{Corrective Action}

Based on the results of the examinations, the following corrective actions were taken:

Zone 1 - Fourteen tubes (seven rows) of the regenerative heat exchanger were replaced, and the entire zone was removed and subjected to solution annealing heat treatment.

Zone 2 - No corrective action warranted

Zone 3 - No corrective action warranted

Zone 4 - All Alloy 625 material was replaced with Alloy C-276 with the exception of the nozzles and thermowells on the reactor vessel.

\section{NOzZLE N-16A IN THE REACTOR BRINE ZONE}

During Run 924 (May 1993), a leak was detected in Nozzle N-16a, a thermowell in Zone 4 in the upper portion of the pressure vessel bottom cylindrical section, i.e., right below the tapered section. The leak was located at the partial penetration weld. The nozzle was fabricated from a 9/16-in. diameter Alloy 625 tube.

\section{Observations - Laboratory Analyses}

A metallographic examination of the removed section of nozzle $\mathrm{N}-16$ a revealed pits as well as both transgranular (TG) and intergranular (IG) stress corrosion cracking in the nozzle (Figures A.1-7 and A.1-8). Nozzle material under the weld was locally remelted during welding all the way to the inside diameter surface. TG stress corrosion cracks were found in the remelted section of the nozzle, while IG stress corrosion cracks developed in the heat-affected zone. Pits (Figure A.1-9) were present on the inside diameter surface of the nozzle, primarily in the vicinity of the weld. Metallographic examination of nozzle N-16a away from the weld did not detect stress corrosion cracking or any significant pitting. However, it revealed multiple laps (Figure A.1-10) at the I.D. surface which apparently formed during manufacture of the nozzle material. These laps form tight cracklike crevices which can serve as initiation sites for stress corrosion cracking. The microstructure at the laps is characterized by a much finer grain size than elsewhere in the nozzle base metal. No stress corrosion cracking was found under the thread. 
Judging by the predominance of transgranular cracks in the leak area, the leak most likely occurred when one of the transgranular stress corrosion cracks propagated through the wall.

The weld contained a lack of fusion between the beads (Figure A.1-11), however, the subsurface, i.e. not exposed to the process fluid crevices formed by the lack of fusion were oriented parallel to the inside diameter surface of the nozzle and were unlikely to have caused the leak.

Two Alloy 625 nozzles from this zone, were also examined metallographically at the welds to the vessel. $\mathrm{N}-13$ was another thermowell that was located higher in the vessel near the liquidsupercritical fluid transition, and $\mathrm{N}-40$ was a larger nozzle located in the lower brine section. Both nozzles exhibited pitting and stress corrosion cracking. A wide open crack in nozzle $\mathrm{N}-40$ at the weld had grown to a depth close to $3 / 4$ of the nozzle wall thickness (Figure A.1-12). An area near the mouth of the crack shows a network of intergranular cracks (Figure A.1-13). Stress corrosion cracks in noz?le N-13 which is in the transition zone between generally caustic brine and acidic supercritical zone are very shallow, less than 0.003 in. and also intergranular.

Nozzle N-30 (Alloy 625) located at the top of the pressure vessel was also removed for an examination subsequent to the leak in nozzle $\mathrm{N}-16 \mathrm{a}$. A metallographic examination revealed no evidence of cracking. Wall thinning, up to 20 percent of wall thickness, was observed in the examined cross-section in nozzle N-30 at the weld (Figure A.1-14).

\section{Observations - Non Destructive Examination}

Six nozzles, i.e. $\mathrm{N}-29$ and $\mathrm{N}-30$ (one inch penetrations) at the top of the vessel and N-38 through $\mathrm{N}-41$ (one inch penetrations) at the bottom of the vessel were examined visually with a borescope and by liquid penetrant. The liquid penetrant examination did not detect any cracking on the I.D. surface of the nozzles. However, as explained above, stress corrosion cracks were found in nozzle $\mathrm{N}-40$ by metallography. In fact, one crack was very deep and wide open. The failure of the liquid penetrant examination to detect this crack can be attributed to poor accessibility of the I.D. surface for the liquid penetrant examination. Liquid penetrant methods are normally sensitive enough to detect significantly more shallow and tighter cracks.

The borescopic examination detected pitting in all six nozzles. Pits on the I.D. surface were present along the entire length of each nozzle. The area of the I.D. surface under the partial penetration weld experienced a more severe pitting attack resulting in significantly deeper pits compared to the remainder of each nozzle. This was especially true for nozzles $\mathbf{N}-30$ (Zone 2) and nozzles $\mathrm{N}-40$ and $\mathrm{N}-41$ (Zone 4).

Nozzles N-13 through N-20 (thermowells) and N-38 through 41 (one inch penetrations) were replaced in June 1993. After removal of the old nozzles and associated partial penetration welds, the borehole surfaces, counterbore, and weld preparation surfaces were examined by liquid penetrant and visually. Cracks were detected in the pressure vessel at nozzles $\mathbf{N}-13, \mathbf{N}$ $16, \mathrm{~N}-16 \mathrm{a}, \mathrm{N}-17, \mathrm{~N}-18$ and $\mathrm{N}-20$, i.e., at 6 out of 13 nozzles. The cracks were oriented in the

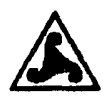


direction of the borehole axis. Sizable cracks were found at nozzles $\mathrm{N}-16, \mathrm{~N}-16 \mathrm{a}$ and $\mathrm{N}-17$. The worst case crack was at nozzle $\mathrm{N}-16 \mathrm{a}$, the very nozzle which leaked and prompted a wider evaluation of the vessel nozzles. This longitudinal crack was over 3/8 -in. long as measured along the axis of the borehole and was centered around the counterbore so that part of it ran along the borehole and part of it was on the tapered weld preparation surface. This crack was readily detectable visually as well.

Cracks at nozzle $\mathrm{N}-18$, and especially at nozzles $\mathrm{N}-13$ and $\mathrm{N}-20$, were significantly smaller than at nozzles $\mathrm{N}-16, \mathrm{~N}-16 \mathrm{a}$ and $\mathrm{N}-17$.

\section{Corrective Action}

Nozzles N-13 - 20 (thermowells) and nozzles N-38 - 41 (one inch penetrations) were replaced in June 1993 with Alloy C-276 components. Nozzles N-29 and 30 at the top of the vessel were replaced with Alloy 626 components.

\section{Discussion OF Findings}

Table A.1-3 summarizes major findings of the laboratory and on-site examinations performed over the period from April to June 1993.

As Table A.1-3 shows, pitting attack has occurred in all zones. The worst cases of pitting were typically associated with heat-affected zone. None of the above components had been heat treated after welding, with the exception of C-276 heat exchanger tubing which was given a "mill anneal" heat treatment.

No evidence of Alloy 625 experiencing stress corrosion cracking was detected in the supercritical region (Zone 2) at this time. However, Alloy 625 did experienced severe stress corrosion cracking in Zones 1 and 4. Cracks were found on both sides of MTC-2; in a tube at the tee downstream of valve AV-290; in nozzle N-16a; and in the pressure vessel adjacent to nozzles $\mathrm{N}-16, \mathrm{~N}-16 \mathrm{a}, \mathrm{N}-17$, and $\mathrm{N}-40$.

Observation of stress corrosion cracking of Alloy C-276 was limited at this time to one case of shallow cracking at a weld in Zone 4. This means, however, that in the brine zone Alloy C-276 is also susceptible to stress corrosion cracking, albeit it may have a higher resistance compared to Alloy 625.

Chloride level, $\mathrm{pH}$ and temperature are only some of the critical parameters for an onset of pitting and stress corrosion cracking. Pitting and stress corrosion cracking can be caused by other aggressive anions. However, in the case of SCWO with the environments tested recently, chlorides are the most likely cause. Of course, oxygen is present virtually everywhere in the system and tensile stresses required for SCC are also present, especially at welds, bends and at threads. 
Table A.1-3

Summary of Service Failure Material Analyses (April - June 1993)

\begin{tabular}{|c|c|c|c|c|c|}
\hline ZONE & MATERIAL & LOCATION & PITTING & SCC & COMMENTS \\
\hline 1 & $\begin{array}{l}625 \\
C-276\end{array}$ & $\begin{array}{l}\text { At weld } \\
\text { Away from weld } \\
\text { Under thread } \\
\text { At weld } \\
\text { Away from weld } \\
\text { Bend }\end{array}$ & $\begin{array}{l}\mathbf{Y} \\
\mathbf{Y} \\
\mathbf{Y} \\
\mathbf{Y} \\
\mathbf{Y} \\
\mathbf{Y}\end{array}$ & $\begin{array}{c}\mathbf{Y} \\
\mathbf{N} \\
\mathbf{Y} \\
\text { N.A. } \\
\text { N.A. } \\
\text { N.A. }\end{array}$ & $\begin{array}{l}\mathrm{HT} \text { at } 1875^{\circ} \mathrm{F} \\
\mathrm{HT} \text { at } 1875^{\circ} \mathrm{F} \\
\text { "grooves" in } \\
\text { bends }\end{array}$ \\
\hline 2 & $\begin{array}{l}625 \\
C-276 \\
\end{array}$ & $\begin{array}{l}\text { At weld } \\
\text { Away from weld } \\
\text { Under thread } \\
\text { Any }\end{array}$ & $\begin{array}{r}Y \\
Y \\
Y \\
\text { N.A. }\end{array}$ & $\begin{array}{l}\mathbf{N} \\
\mathbf{N} \\
\text { N.A. } \\
\text { N.A. }\end{array}$ & See Section A.2 \\
\hline 3 & Any & Any & N.A. & N.A. & No failures \\
\hline 4 & $\begin{array}{l}625 \\
C-276\end{array}$ & $\begin{array}{l}\text { At weld } \\
\text { Away from weld } \\
\text { Under thread } \\
\text { At weld } \\
\text { Away from weld } \\
\text { Under thread }\end{array}$ & $\begin{array}{l}\mathbf{Y} \\
\mathbf{Y} \\
\mathbf{Y} \\
\mathbf{Y} \\
\mathbf{Y} \\
\mathbf{Y}\end{array}$ & $\begin{array}{c}\text { Y } \\
\text { N.A. } \\
\text { N.A. } \\
\text { Y } \\
\text { N.A. } \\
\text { N.A. }\end{array}$ & cracks $<0.005^{\prime \prime}$ \\
\hline
\end{tabular}

$\mathrm{N}=$ no, $\mathrm{Y}=$ yes, $\mathrm{N} . \mathrm{A}$. = data not available or insufficient for definitive conclusions

\section{A.2 SERVICE FAILURES AUGUST 1993}

In August 1993, several leaks developed in the system including:

- Inner sleeves of Thermowells 4008 and 4014

- Filter A backwash exit line

- Heat exchanger HX-210

Analyses of these are contained in this section.

Stone \& Webster 

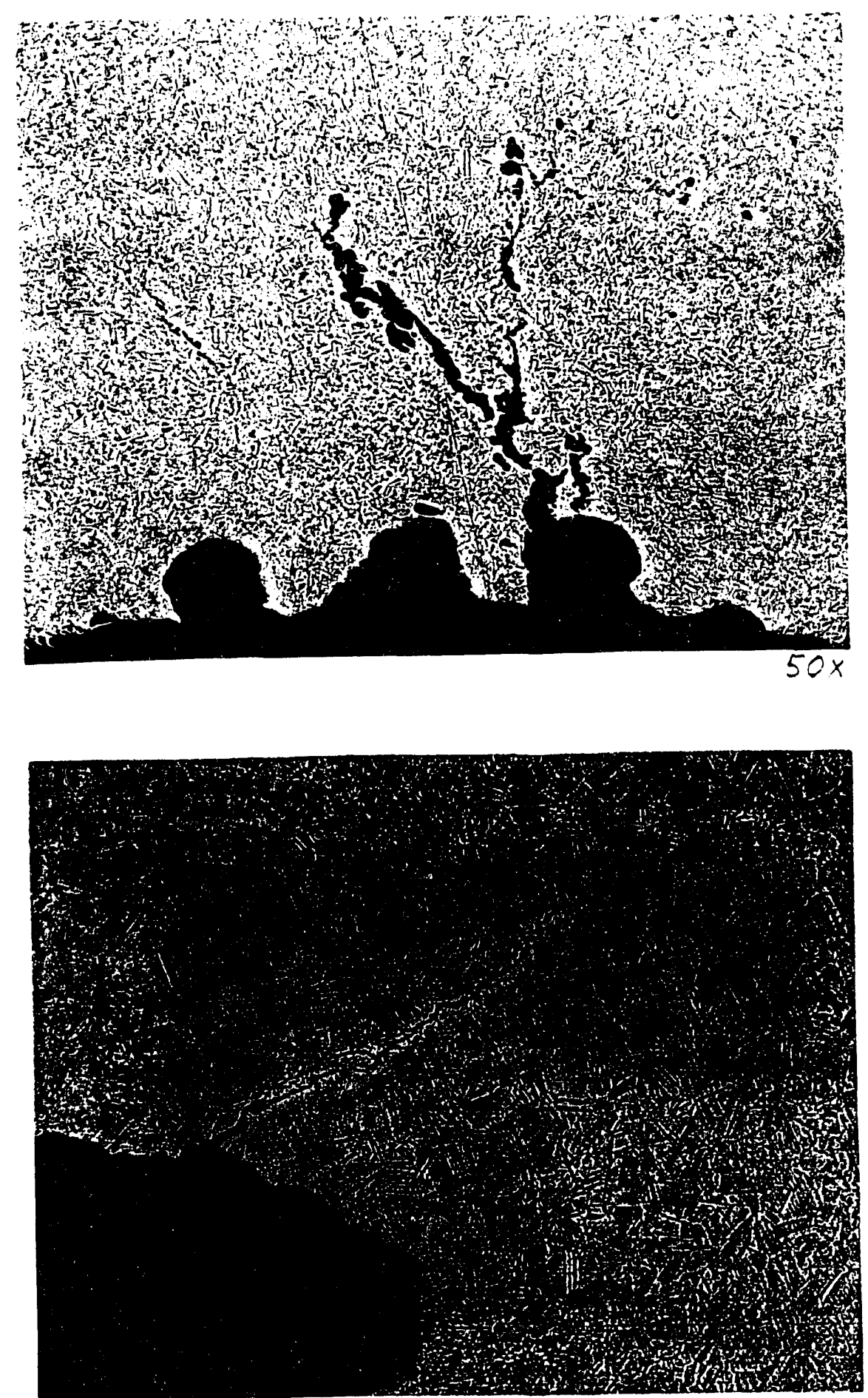

FIGURE A.1-1

STRESS CORROSION CRACKS AT THE I.D. SURFACE OPPOSITE TO THREAD

I.E. AWAY FROM WELD IN INLET

TUBE AT TEE D.S. OF AV-290

(Note that the cracks initiated

at corrosion pits)

Magnification: 150X 


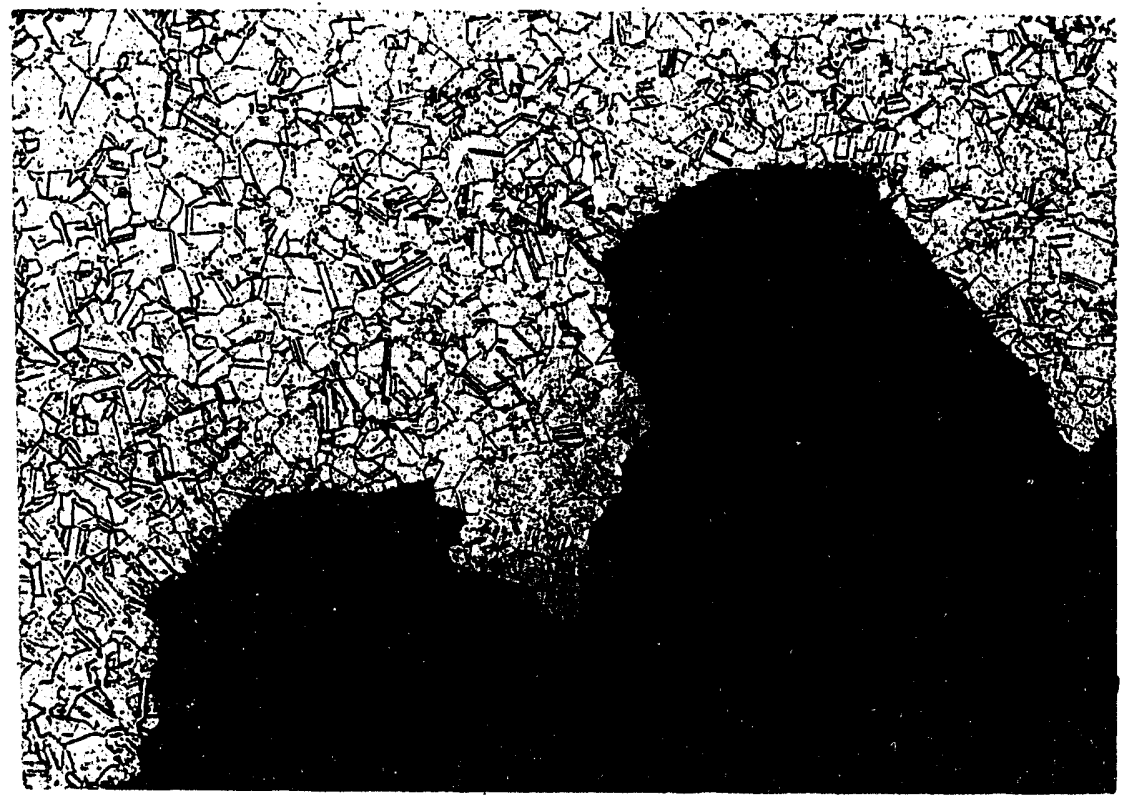

FIGURE A.1-2

PITS IN ALLOY 625 BASE METAL IN OUTLET TUBE AT THE TEE DOWNSTREAM OF AV-290

(The section was 1 in. downstream of the tee)

Magnification: 100X 


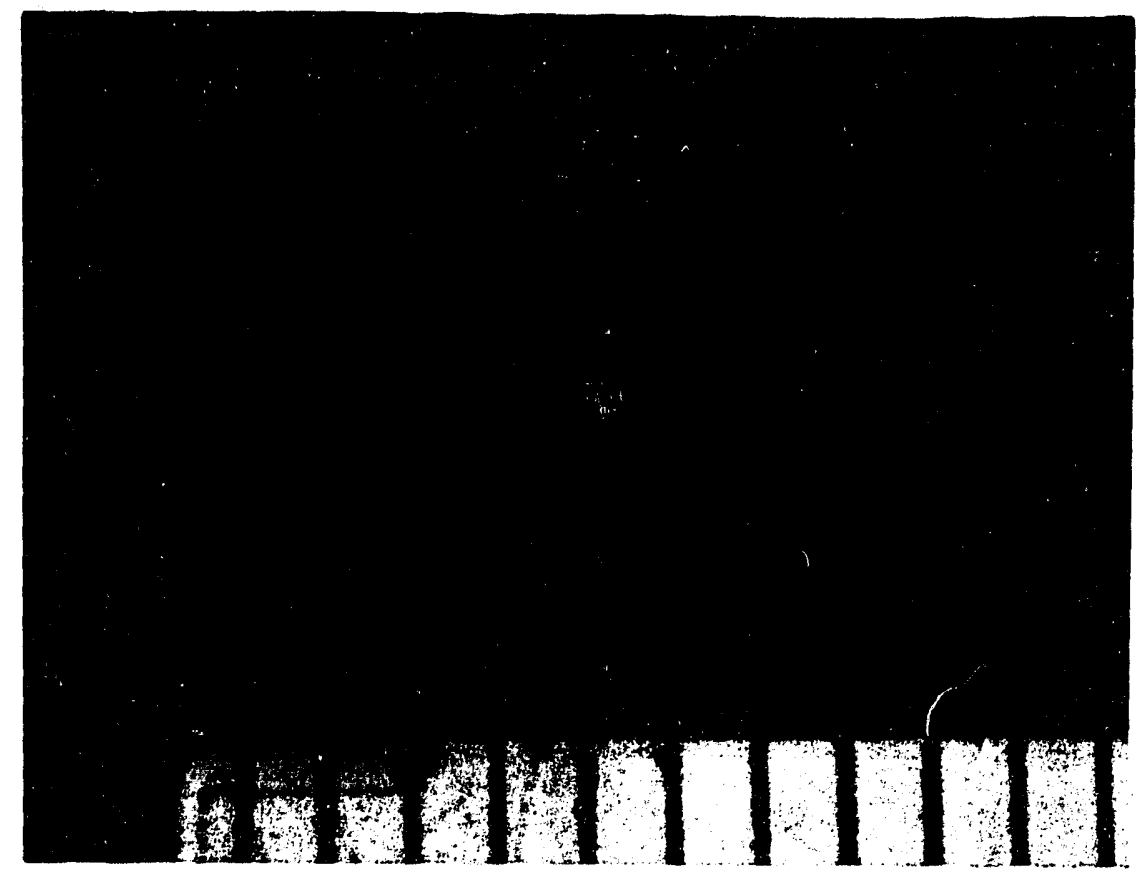

FIGURE A.1-3

PITS IN ALLOY C-276

HEAT EXCHANGER TUBE FROM

THE BOTTOM ROW

(Each division is 1 millimeter) 

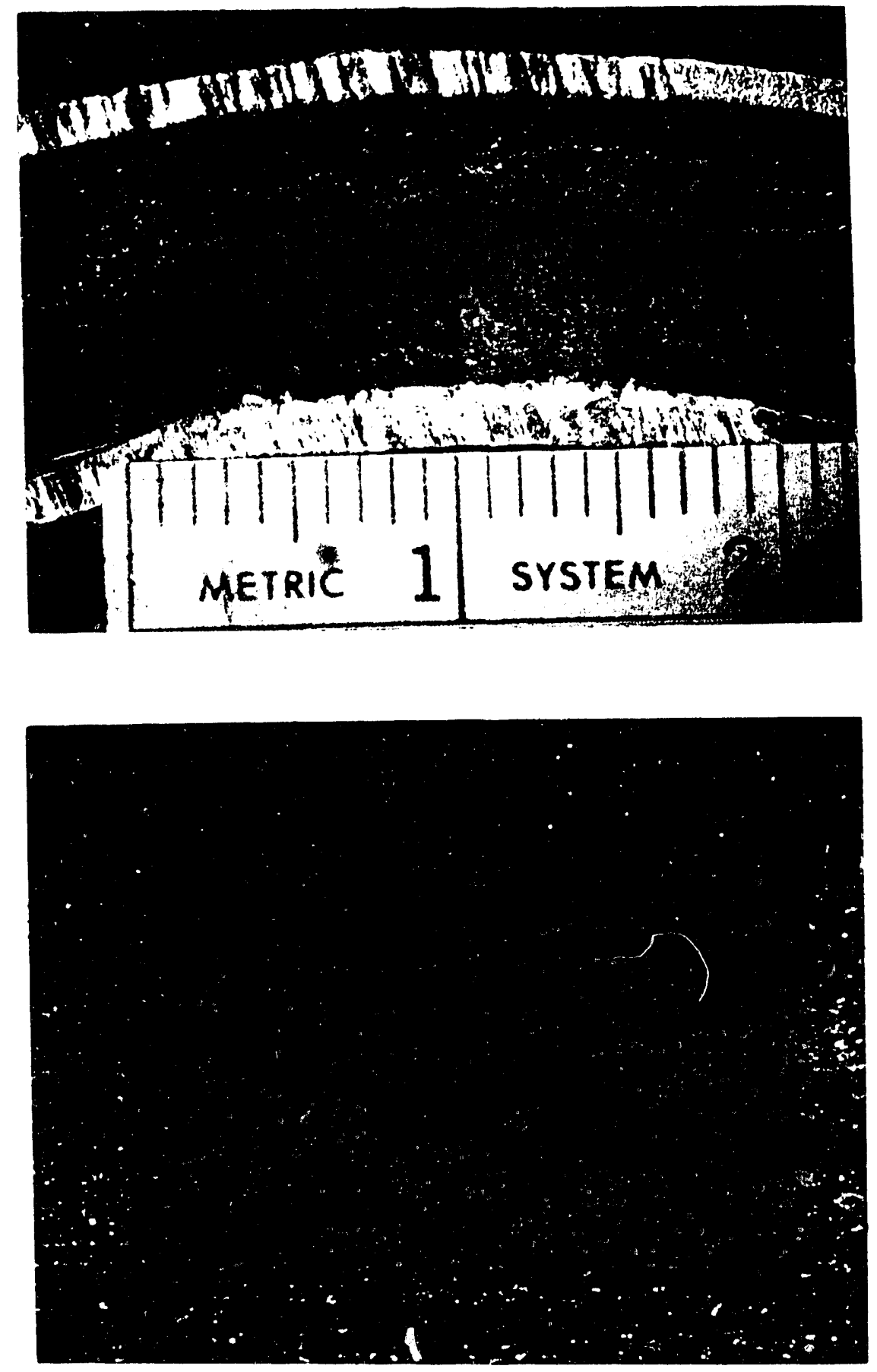

FIGURE A.1-4

GROOVES IN A BEND OF ALLOY C-276 TUBING

Magnification on the bottom photo: $5 \mathrm{X}$ 


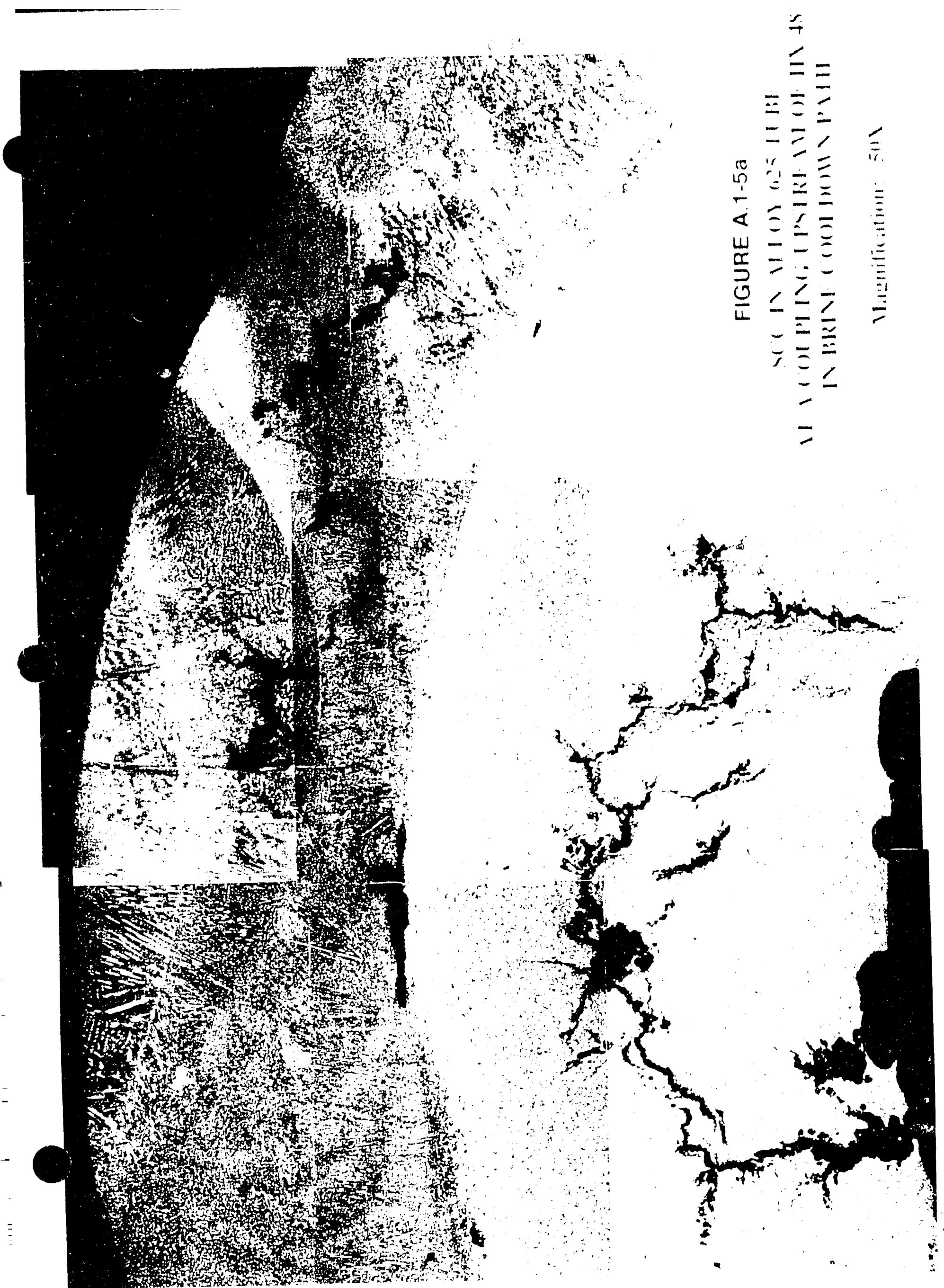




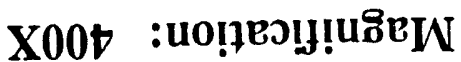 HJИOW YวVY LV

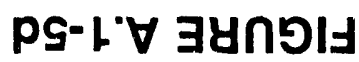

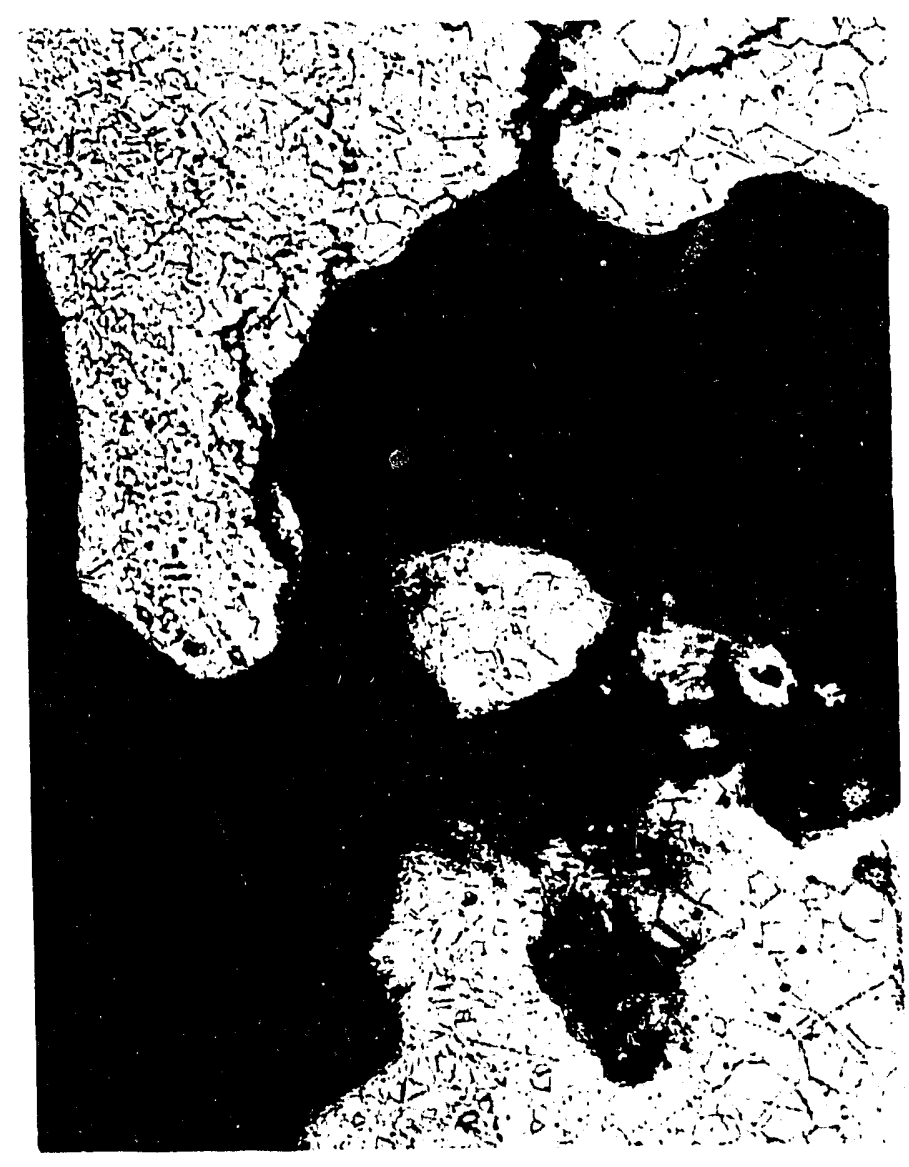

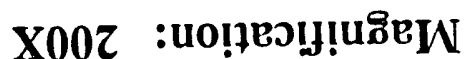 \\ dIL YวVมว $\mathbf{L V}$

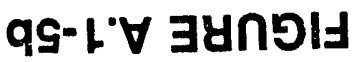
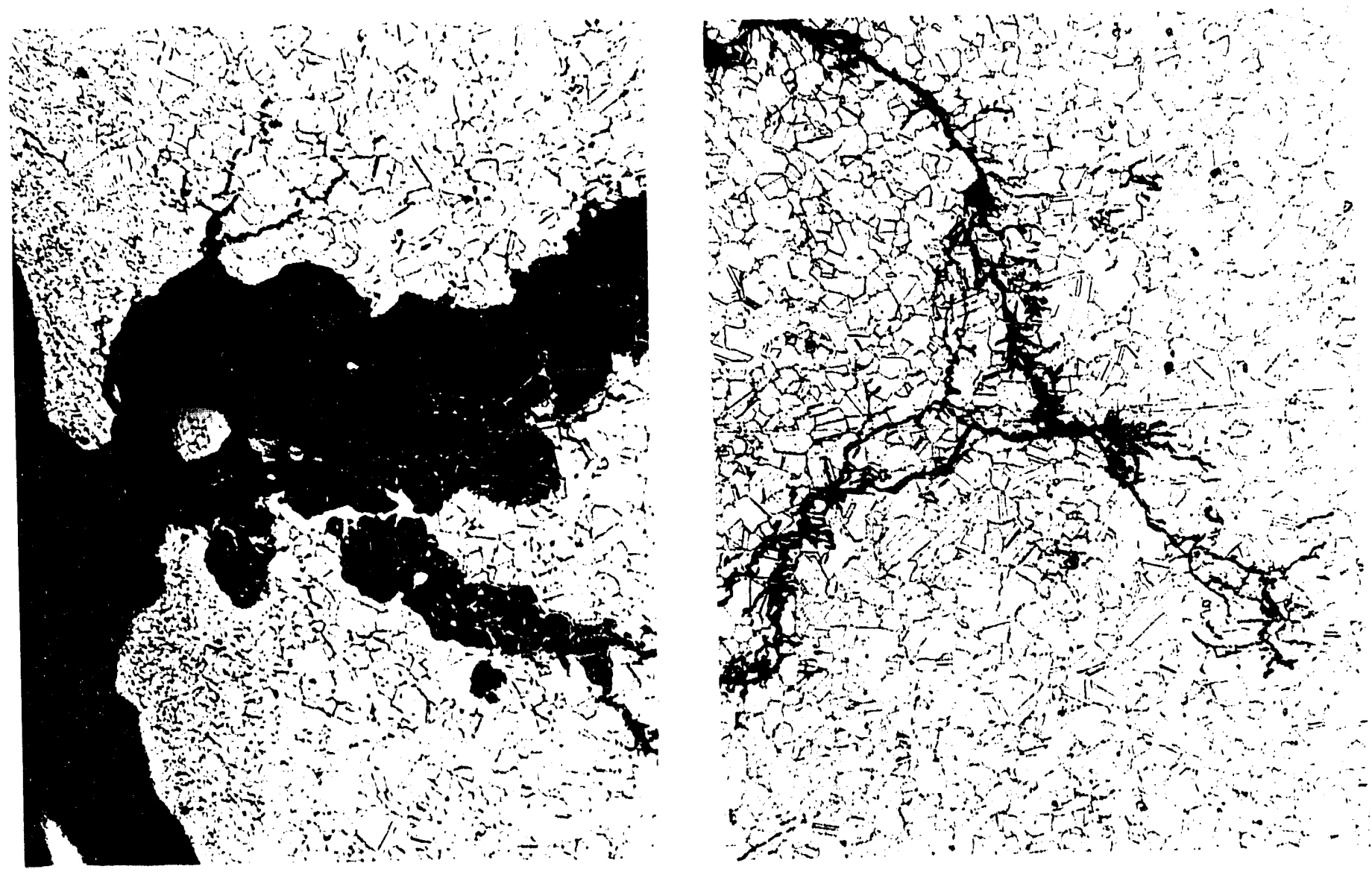


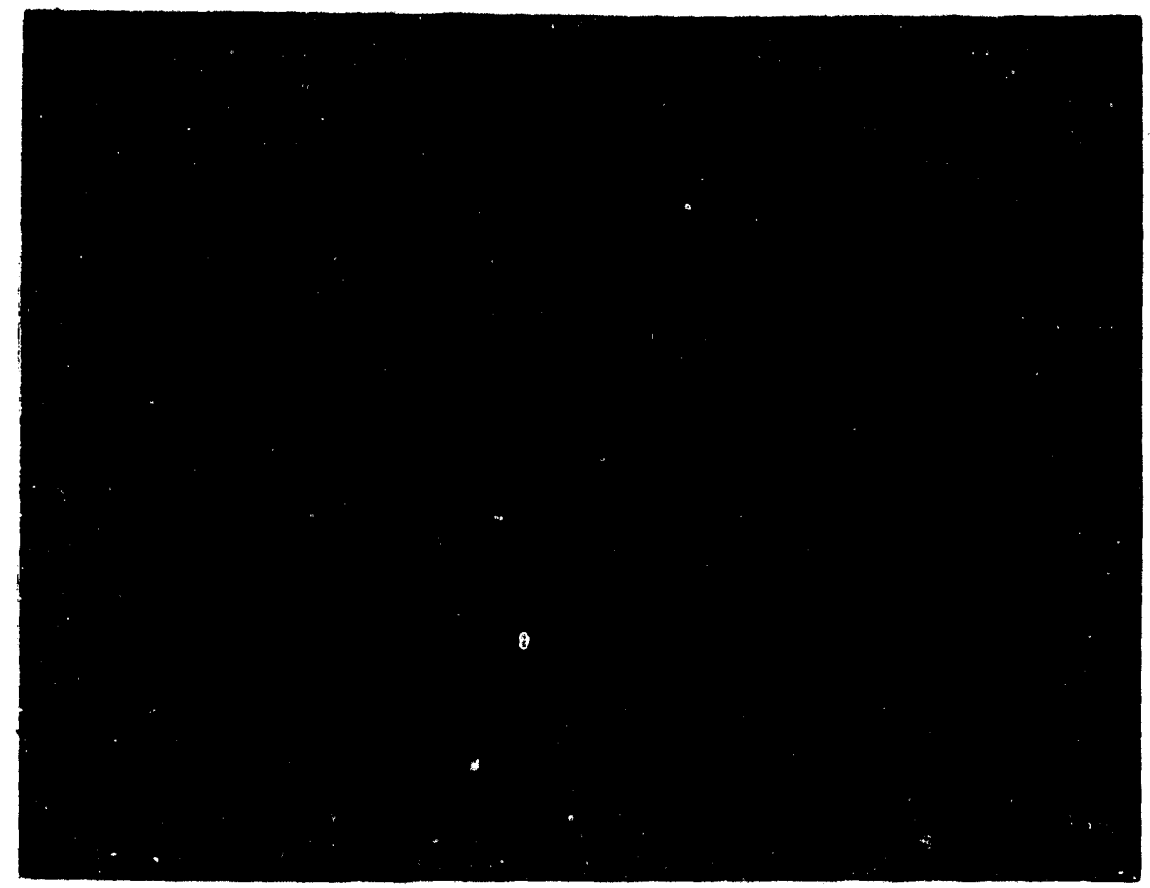

FIGURE A.1-6

SHALLOW CRACKS IN C-276 TUBE AT COUPLING UPSTREAM OF HX-481 IN BRINE COOLDDOWN PATH

Magnification: $400 X$ 


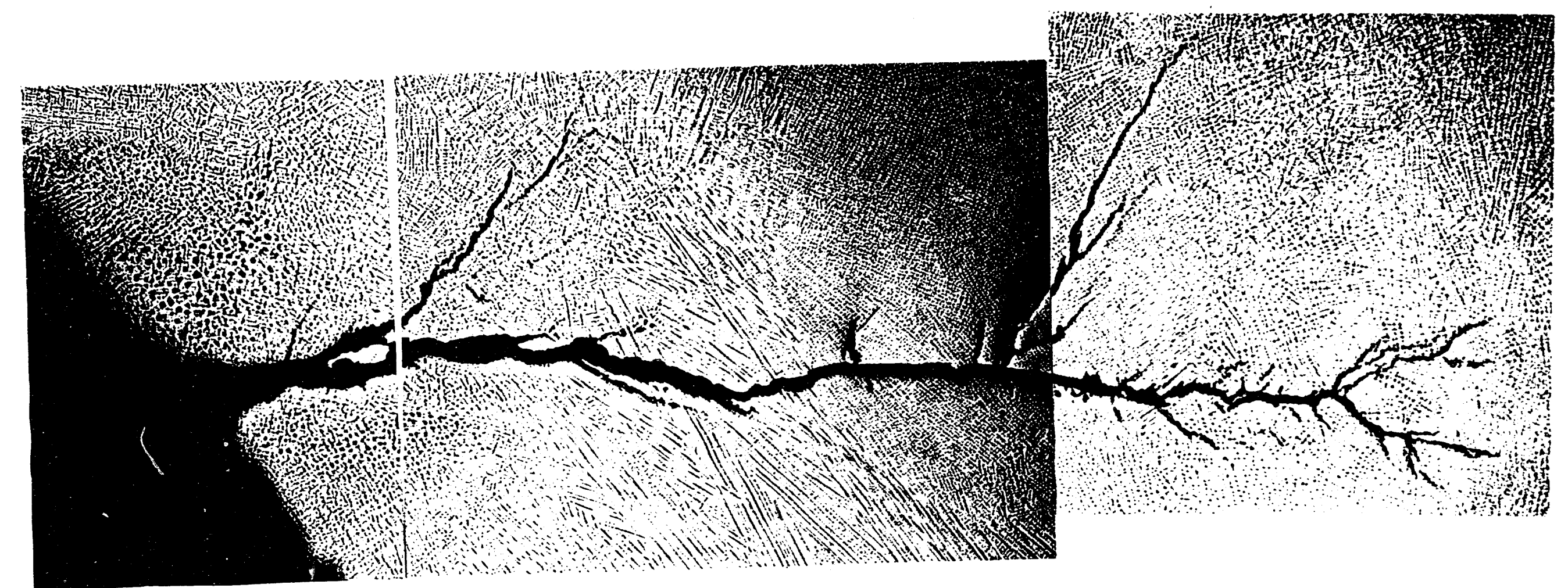

\section{FIGURE A.1-7 \\ STRESS CORROSION CRACKING IN NOZZLE N-16a}

Magnification: 50X

(The nozzle was locally remelted all the way to the I.D. during welding; material: (Alloy 625), 


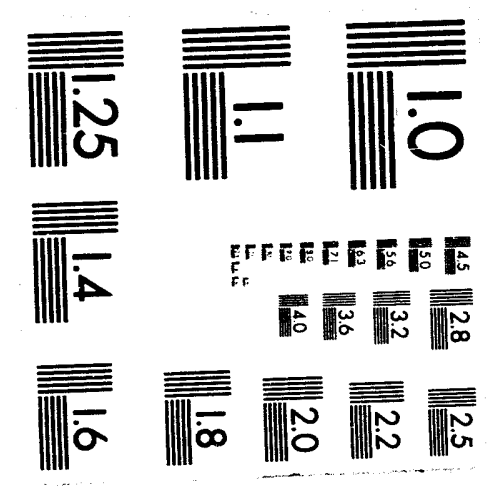



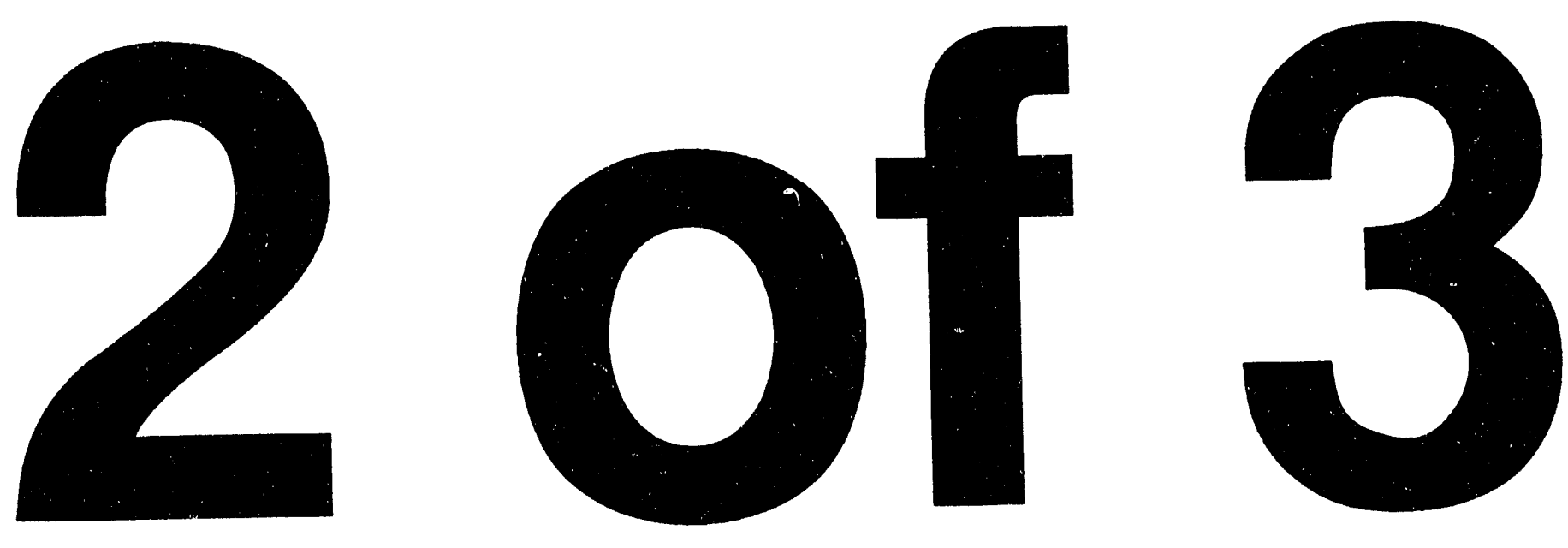


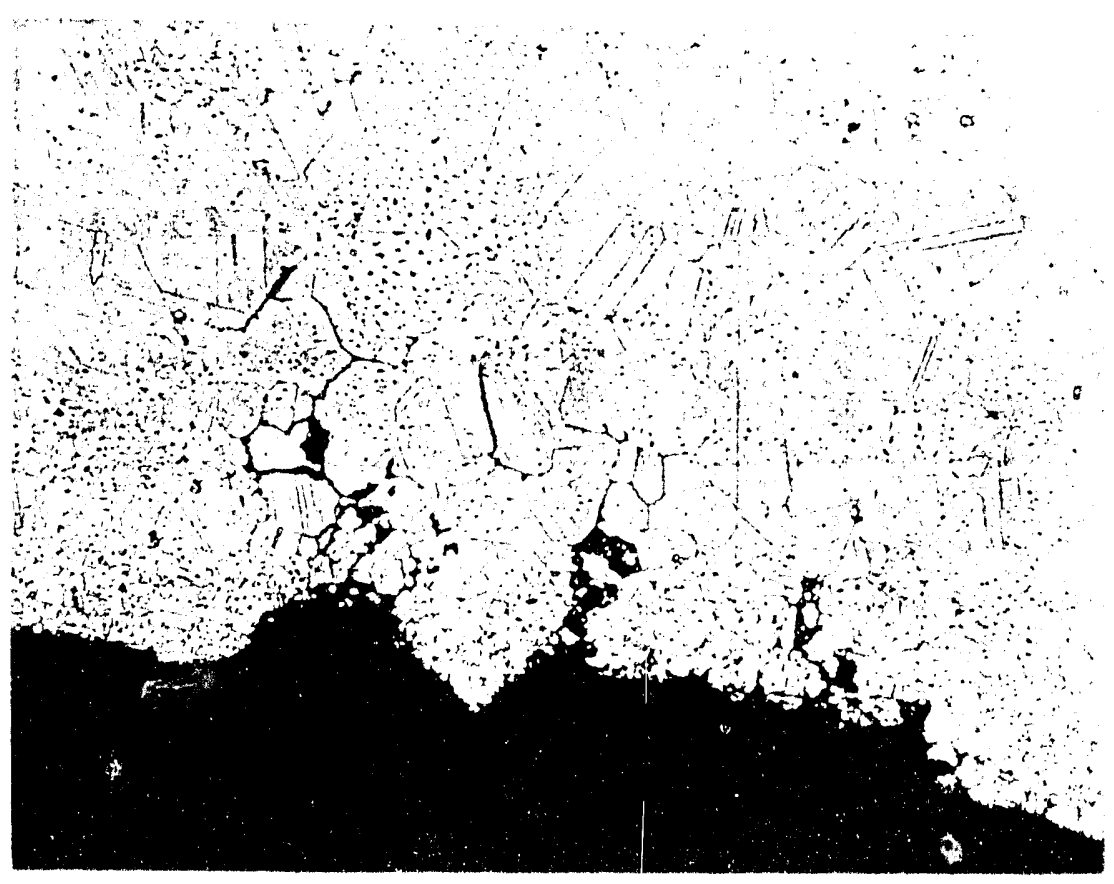

Fibli A :

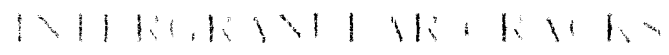

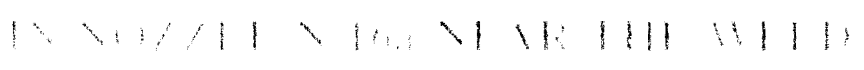

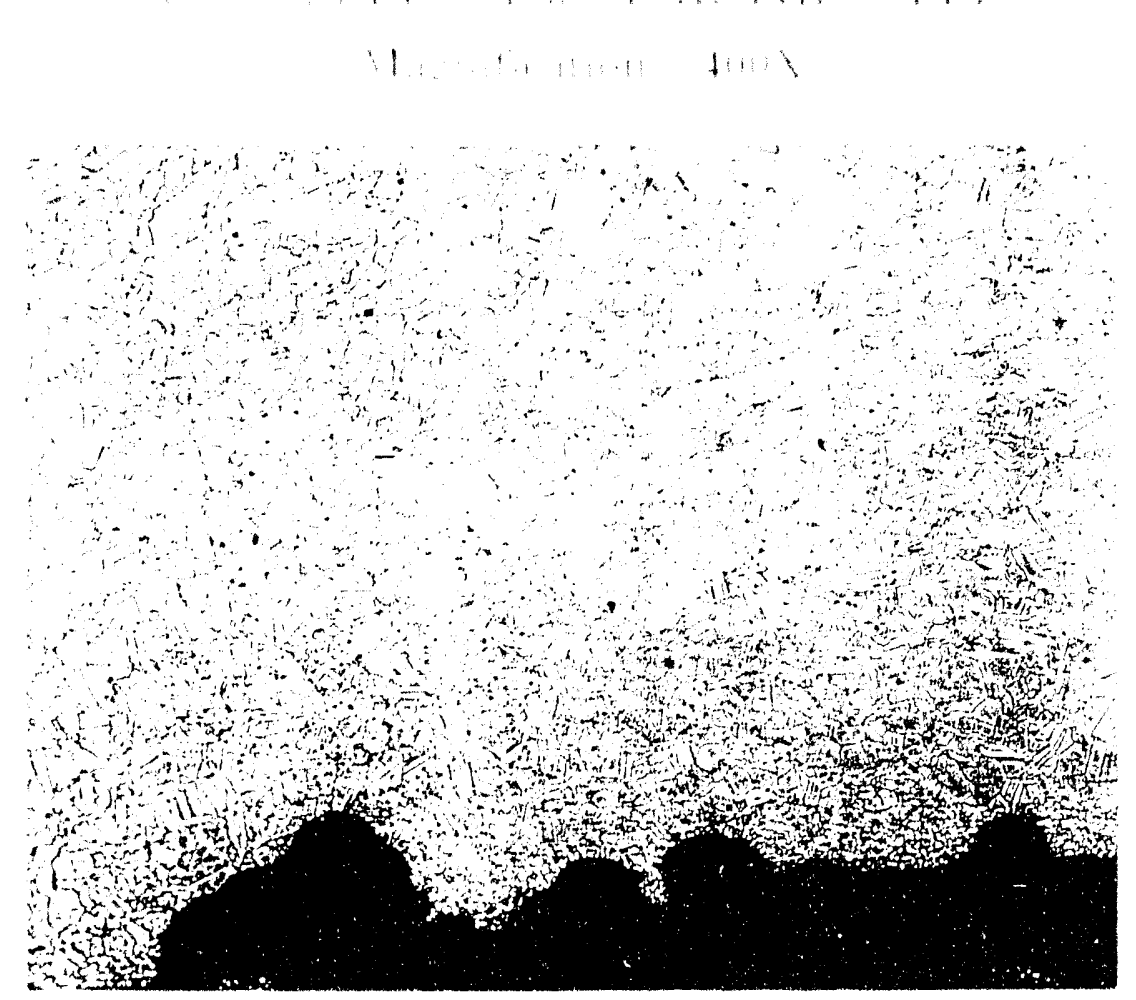

tholth A : B

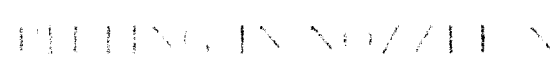




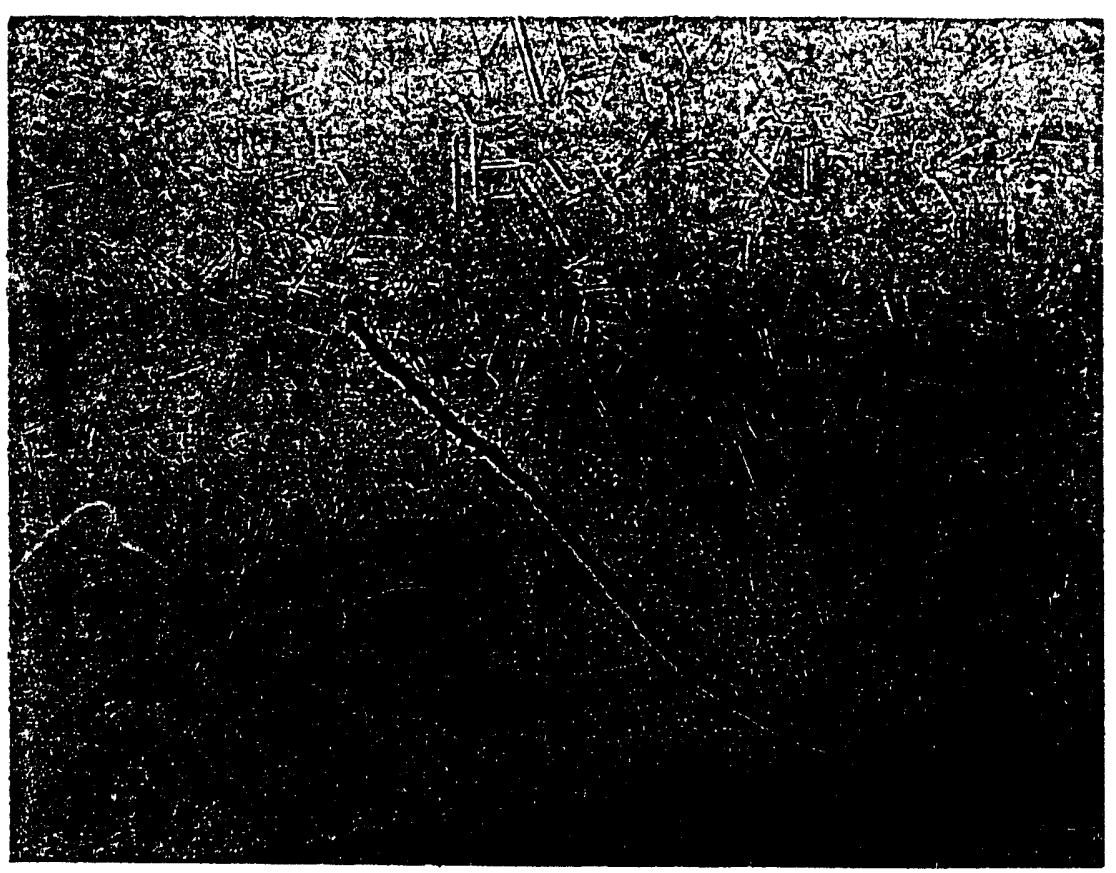

FIGURE A.1-10a

A LAP AT NOZZLE N-16A I.D. SURFACE (3/8 in. away from thread)

Magnification: 200X

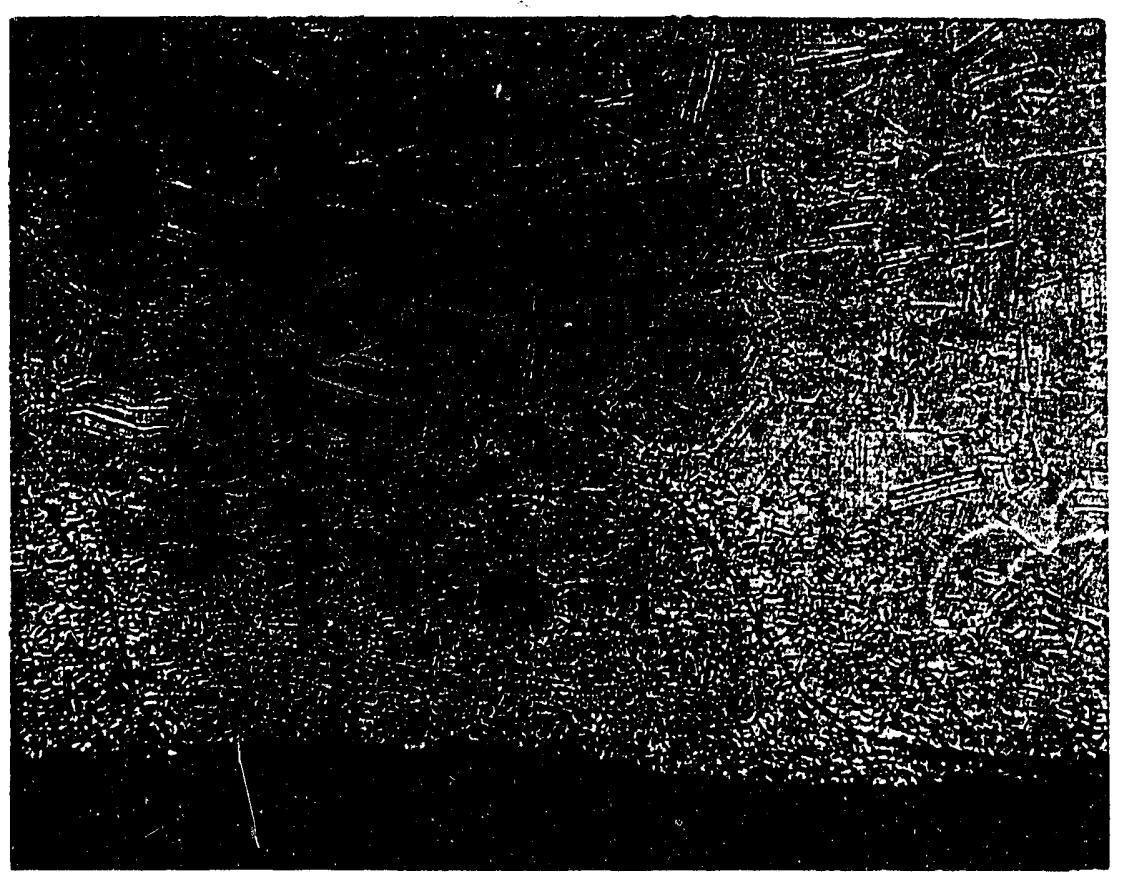

FIGURE A.1-10b

A LAP AT THE I.D. SURFACE OF NOZZLE N-16a

(Under the thread)

Magnification: 270X 


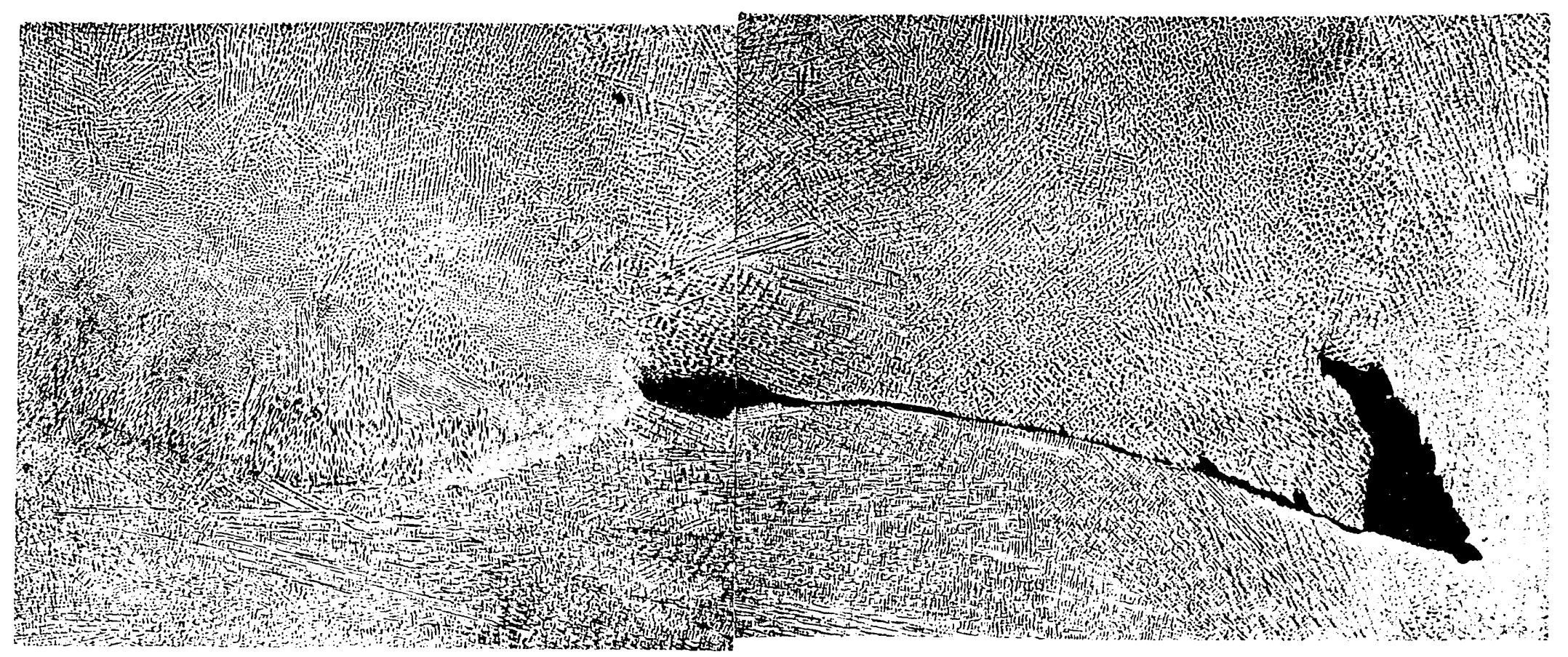

FIGURE A.1-11

A LACK OF FUSION IN THE WELD

AT NOZZLE N-16a

Magnification: $50 \mathrm{X}$ 
I.D.

O.D.

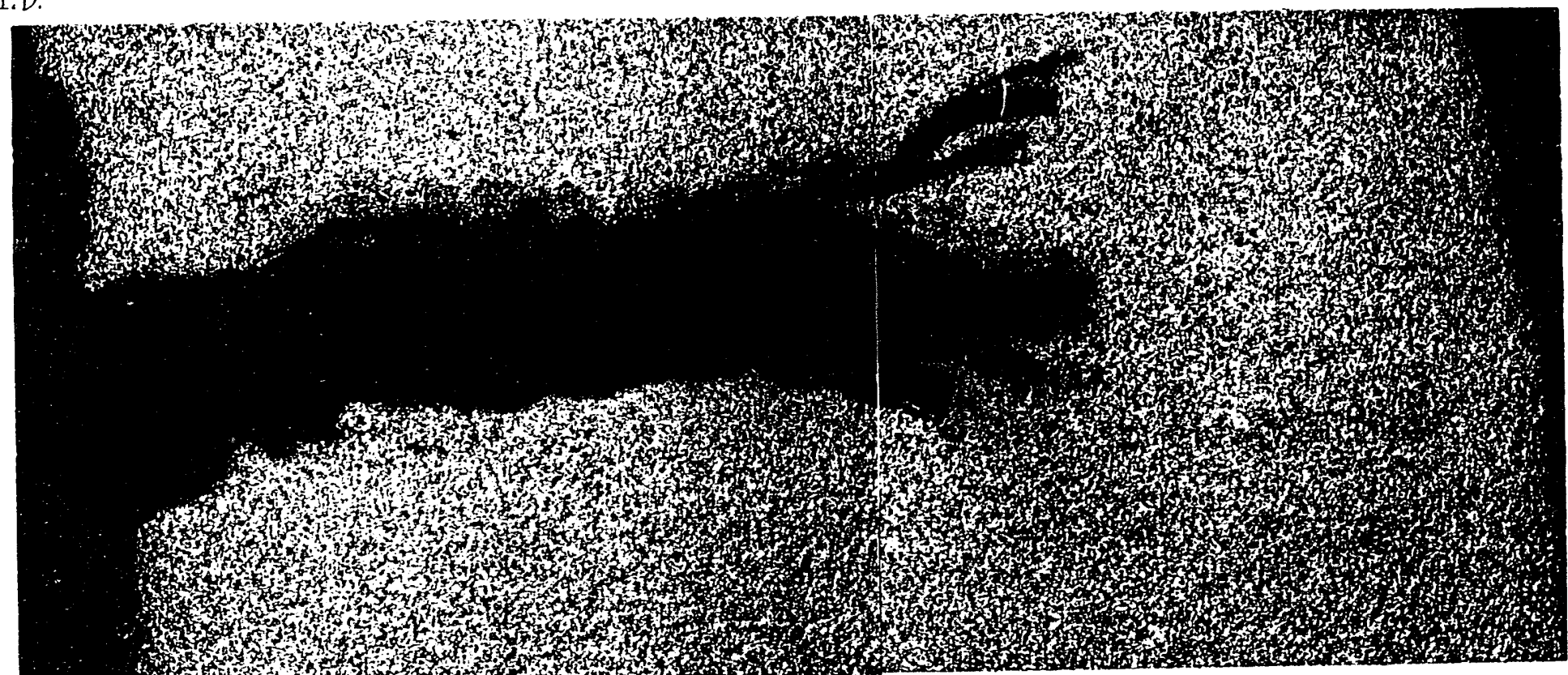

FIGURE A.1-12

A STRESS CORROSION CRACK AT THE

WELD IN NOZZLE N-40

(See Figure 5.7.2-14)

Magnification: 50X 


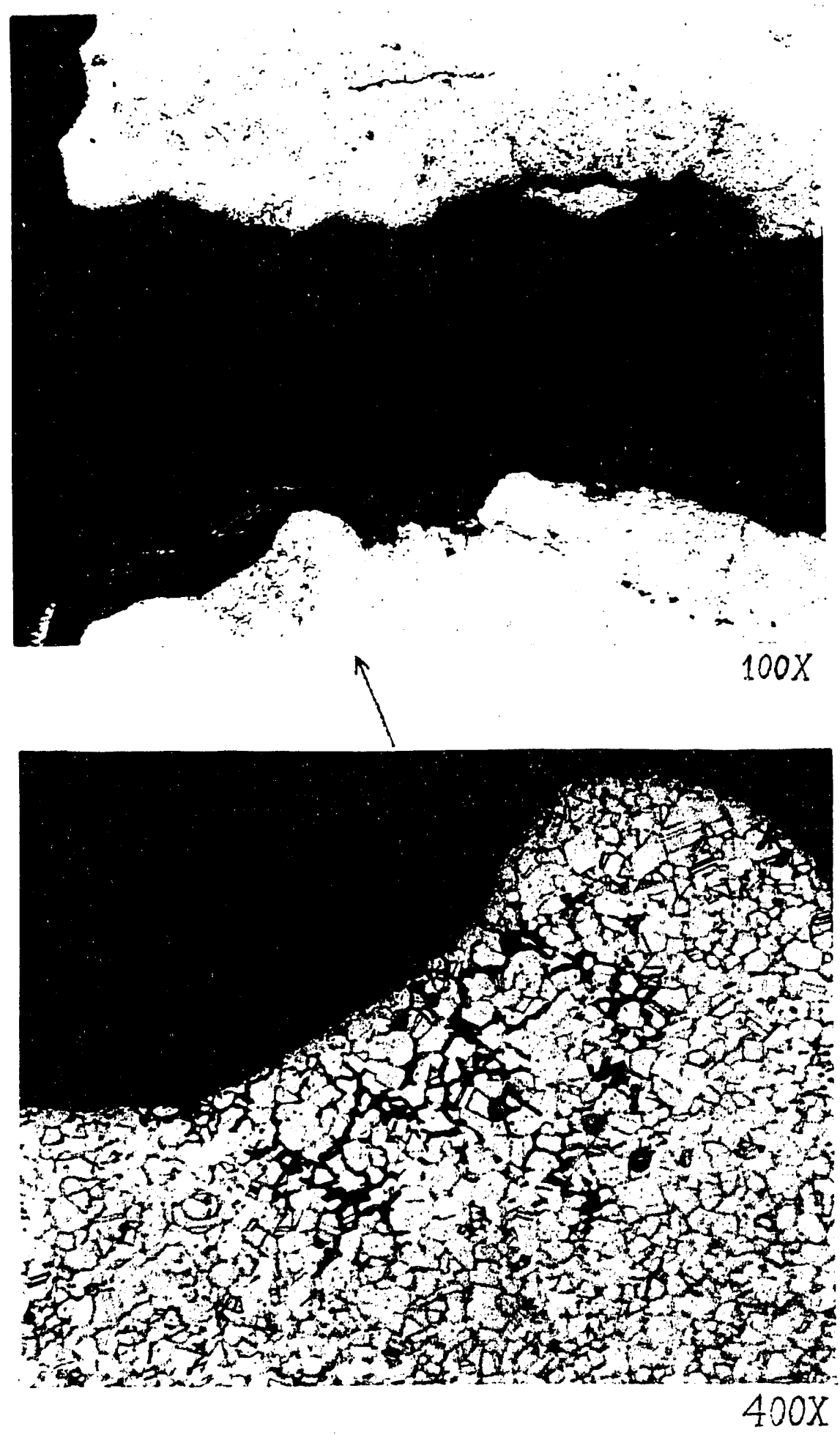

FIGURE A.1-13

INTERGRANULAR STRESS CORROSION

CRACKS AT THE MOUTH OF THE

CRACK SHOWN IN FIG - 5.7.2-13 


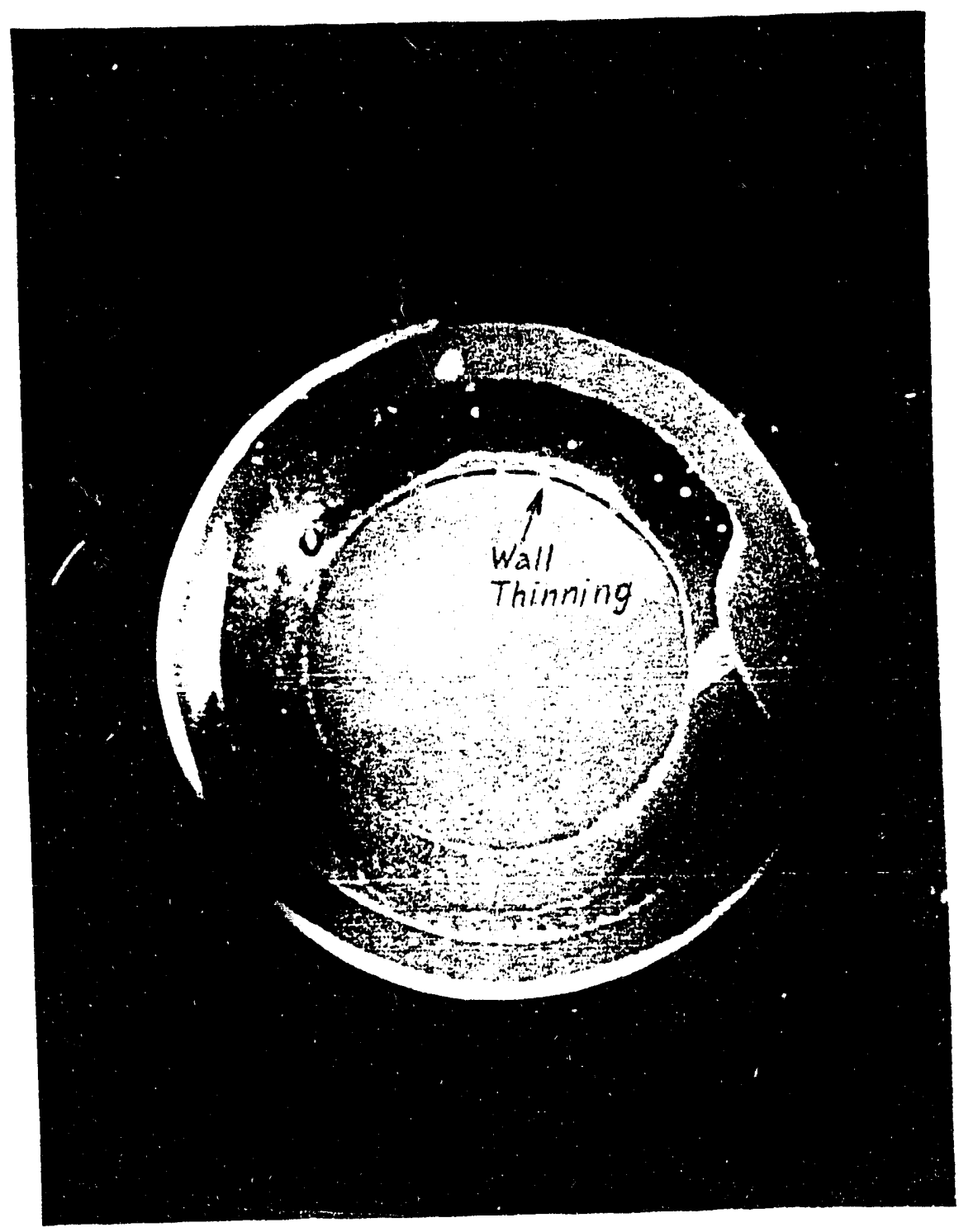

FIGURE A.1-14

CROSS-SECTION OF NOZZLE N-30

AT THE WELD

SHOWING WALL THINNING 


\section{THERMOWELLS 4014 AND 4008}

During the 168 hour performance test (Run 932), two thermowell leaks were detected. The first occurred during startup in Thermowell 4014. This was a minor leak caused by a failure of the inner sleeve that protects the actual thermocouple wires. The leaking inner sleeve was removed, the thermowell capped, and operations preceded. Approximately 77 hours into the 168 hour performance test, a second leak was detected in thermowell 4008. This leak was more severe and necessitated shutdown of the system.

\section{Observations}

Prior to Run 932, all nineteen Alloy C-276 thermowells located on the reactor were visually inspected for signs of degradation on the exposed surfaces. Based on the results of the inspection, thermowell 4018 was replaced. No significant degradation was detected on any other thermowells. Exposure time for the thermowells prior to Run 932 ranged from 39 to $198 \mathrm{hrs}$. Only thermowell 4019 was exposed directly to the process fluid. All other thermowells were shielded, at least initially (see the discussion of thermowell 4008 below), by the reactor liner and were exposed to the water purged through the annulus between the liner and reactor wall.

A leak in thermowell 4014 was detected about 4 hours into Run 932, after 113 hrs of total service exposure. No formal metallurgical examination has been performed. A visual examination of the thermowell by MODAR personnel did not detect any obvious signs of degradation. The failure was attributed by MODAR to a fabrication flaw.

Thermowell 4008 located in the reactor supercritical fluid/brine transition zone developed a leak. 77 hours into Run 932. An orderly shutdown was performed and all thermowells were removed and inspected. It was suspected and subsequently observed that the integrity of the liner had been compromised which could allow process fluid to cross-flow into the annulus resulting in a more corrosive environment at the thermowells. Previous experience with Alloy C-276 thermowells directly exposed to the process fluid, i.e. prior to the insertion of the liner, would have predicted a longer service life for the thermowells, even without the liner protection. In the presence of the liner, a dramatic increase in the service life of the thermowells was expected. It is suspected that the liner failure resulted in a corrosive environment which had a deleterious effect on the thermowells. Again, no metallurgical examination has been performed.

\section{Corrective Action}

When the leak was detected, an orderly shutdown was performed and all thermowells were removed and inspected. Thermowells which showed even the slightest signs of degradation (11 of 19) were replaced. For future applications, substitute materials with a higher corrosion resistance in the environment have been identified. 


\section{FILTER A backWASh EXIT LINE}

A leak in the Alloy C-276 backwash exit line occurred shortly into Run 933 (post performance test). The environment in this tube at the leak location is unique in that during normal operation it approximates Zone 1 conditions. At the onset of a filter backwash it resembles Zone 2-c environment and during the remainder of the backwash cycle, it is similar to Zone 4 but with a near neutral pH. During this project, the majority of the exit line exposure $(722 \mathrm{hrs})$ was under normal operation mode (Zone 1).

\section{Observations}

The leak apparently occurred through a crack oriented perpendicular to the tube longitudinal axis. The crack is $3 / 32$ " long as measured on the O.D. surface of the tube and located $1 / 16$ " away from the toe of the weld which joins the tube to an Alloy 625 socket weld fitting. The assembly was not annealed after welding. No metallurgical examination has been performed.

\section{Sorrective Action}

The leaking portion of the tubing was removed and replaced with Alloy 625 in order to continue the experiment.

\section{Regenerative Heat Exchanger HX-210}

The regenerative heat exchanger developed a leak near the end of Run 933, the final experiment of the project. Once detected, the system was shutdown and the experimental program ended.

\section{Observations}

The leak occurred in a bend of the 9th row of tubes counting from the outlet row. In April 1993, seven rows of tubes, from the outlet up, were replaced (see Section A.1). Thus, the August 1993 leak occurred in the original tubing. The heat exchanger was built about 10 years ago. The tube material was Alloy C-276 and annealed at $1750^{\circ} \mathrm{F}$ in 1983 and then subjected to a second annealing in May 1993 at $2050^{\circ} \mathrm{F}$. The ninth row of tubes is believed to be a part of Zone 2, and exposed to supercritical fluid at neutral or acidic $\mathrm{pH}$. It is estimated that this tubing has been exposed to operating conditions for approximately 2700 hours, with the exception of short duration post-test flushing when it may have been exposed to brine solution at $300^{\circ} \mathrm{C}$.

The leak occurred through a longitudinal crack along the bend "neutral axis" where the tube was supposedly least deformed during bending. The length of the crack at the outside diameter (O.D.) surface of the tube was $\sim 1 \frac{1}{2}$ in. (Figure A.2-1). The crack was considerably longer on the inside diameter (I.D.) surface judging by the fact that the cross-section at the cut in front of the O.D. surface crack tip contained a deep I.D. - connected part-through crack (Figure A.2- 
2). At the I.D. surface the crack is about $1 / 16$ in. away from the nearest toe of the longitudinal seam weld.

A metallographic examination has shown that axial transgranular stress corrosion cracks developed at a few locations in the bend. The composite photograph in Figure A.2-3 shows the crack which had grown through the wall and resulted in the leak. This particular crack formed at the margin of the longitudinal weld heat-affected zone.

The heat-affected zone can still be readily identified microstructurally in spite of prior triple annealing (see below). The heat-affected zone width is $\sim 1 / 16$ in. A shallow transgranular crack can also be seen in Figure A.2-3 near the major crack but farther into the base metal.

The cross-section at the opposite end of the removed bend $(\sim 3$ in. from the nearest crack tip of the major crack on the O.D. surface) contained shallow ( 0.01 to 0.02 in. deep) transgranular stress-corrosion cracks. One of these cracks developed near a fusion line of the longitudinal seam weld and three more were located in the base metal (Figure A.2-4) about 1/8 in. away from the fusion line toward the neutral axis, i.e., approximately in line with the through-wall crack.

Figures A.2-3 and A.2-4 also show pitting at the I.D. surface.

The observed stress corrosion cracking in a row of tubes which is normally exposed to supercritical fluid is significant for a number of reasons:

There had not been any published evidence of stress corrosion cracking in supercritical fluid and, until this incidence, Alloy C-276 was not expected to suffer stress corrosion cracking under Zone 2 conditions. It remains unclear whether the stress corrosion cracking was induced by the supercritical fluid or by rare and relatively short exposures of subcritical fluid, e.g., during flushing.

The upstream rows of the longitudinally seam welded tubing, including row No. 9, were probably annealed three times: 1) at the mill, 2) upon completion of original fabrication of the heat exchanger and 3) upon a partial replacement of tubes in 1993. After annealing, the tubing was not expected to have any significant welding residual stresses associated with the longitudinal seam weld or, for that matter, in the girth welds. Residual stresses, if present, could contribute to stress-corrosion cracking since they are typically tensile at the I.D. surface. Stresses due to tube bending have been shown by others to be maximum at the "neutral" axis but these stresses would also be expected to relax during annealing. In the absence of residual stresses, the pressure-induced stresses would remain the only other mechanical driving force for the observed stress corrosion cracking. At the relatively low pressure-induced stresses in the tubing, i.e., $6000 \mathrm{psi}$, autofrettage would become the only option for avoiding stress corrosion cracking in Alloy C-276 tubing. 
The cracks formed at the heat-affected zone of the longitudinal seam weld and in the base metal away from the heat-affected zone. Strictly speaking, thrice-annealed heat-affected zone was not expected to be microstructurally different from the base metal. While Figure A.2-3 shows some differences, the heat-affected zone did not appear to be the source of cracking, since cracks were also observed in base metal. Thus, Alloy C-276 base metal appears to be susceptible to stress corrosion cracking in the portion of the heat exchanger that is supercritical during operation.

\section{Corrective Action}

Since this was the end of the experimental program, no corrective action was taken. In future designs, this regenerative heat exchanger will probably be separated into at least two units that will allow the use of different materials.

\section{A.3 MATERIALS/COMPONENTS ANALYSES}

Between December 1992 and August 1993 (Runs 914 through 933), a number of alloys and ceramic materials were exposed for various periods of time in materials test chamber No. 1 (MTC-1), materials test chamber No. 2 (MTC-2), and filter arm A. In addition, several components were removed from the reactor (the nozzle centering plate, the filter housing, and the reactor liner) at the completion of testing. Results of physical observations are included herein.

Presented are the results of metallurgical laboratory evaluation and physical observation of the test samples. It summarizes observations characterizing types and severity of material deterioration, if any, and identifies the most promising materials for SCWO units based on the test program.

\section{ENVIRONMENT}

Based on classification of major zones in the SCWO unit given in Section A.1, the following zone designations and operating temperatures apply to the materials test locations (see Section A.1 for additional information): 


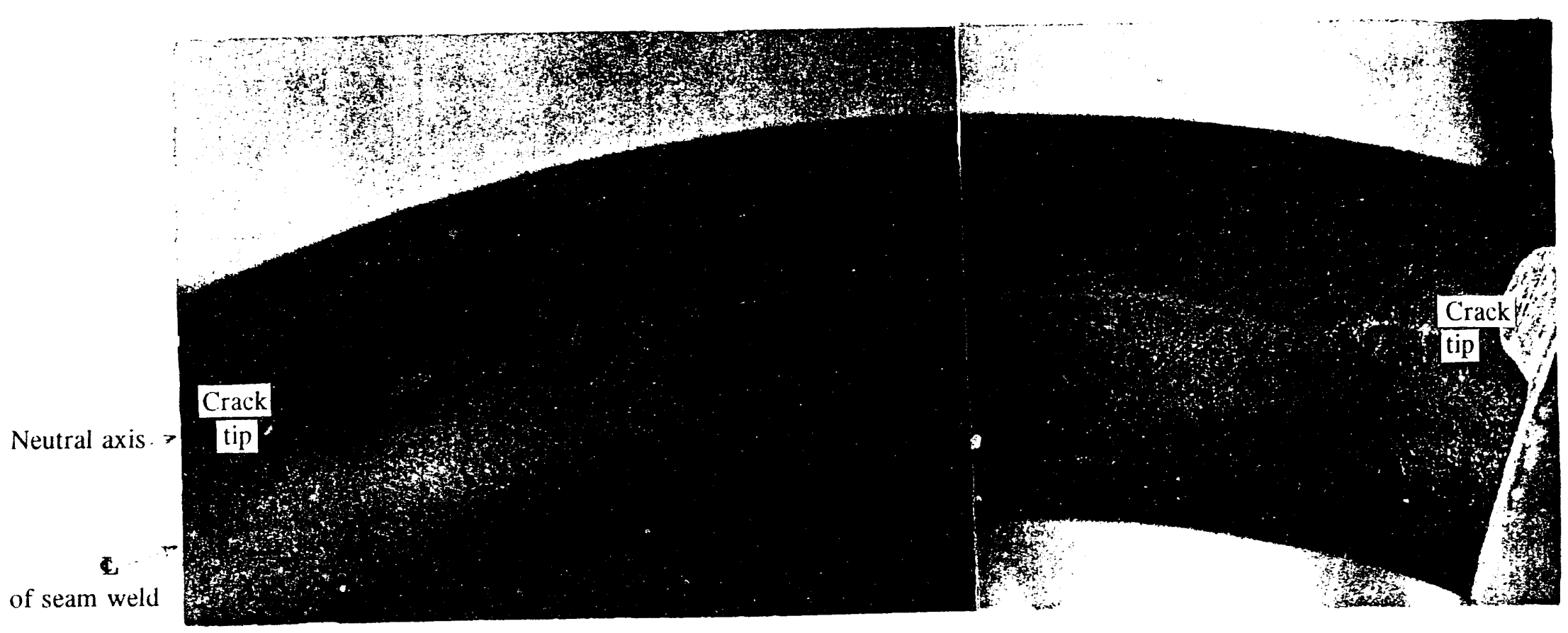

FIGURE A.2-1

LONGITUDINAL CRACK IN THE BEND

OF THE NINTH ROW OF C-276 TUBES

IN HEAT EXCHANGER HX-210

Magnification: $4 X$ 


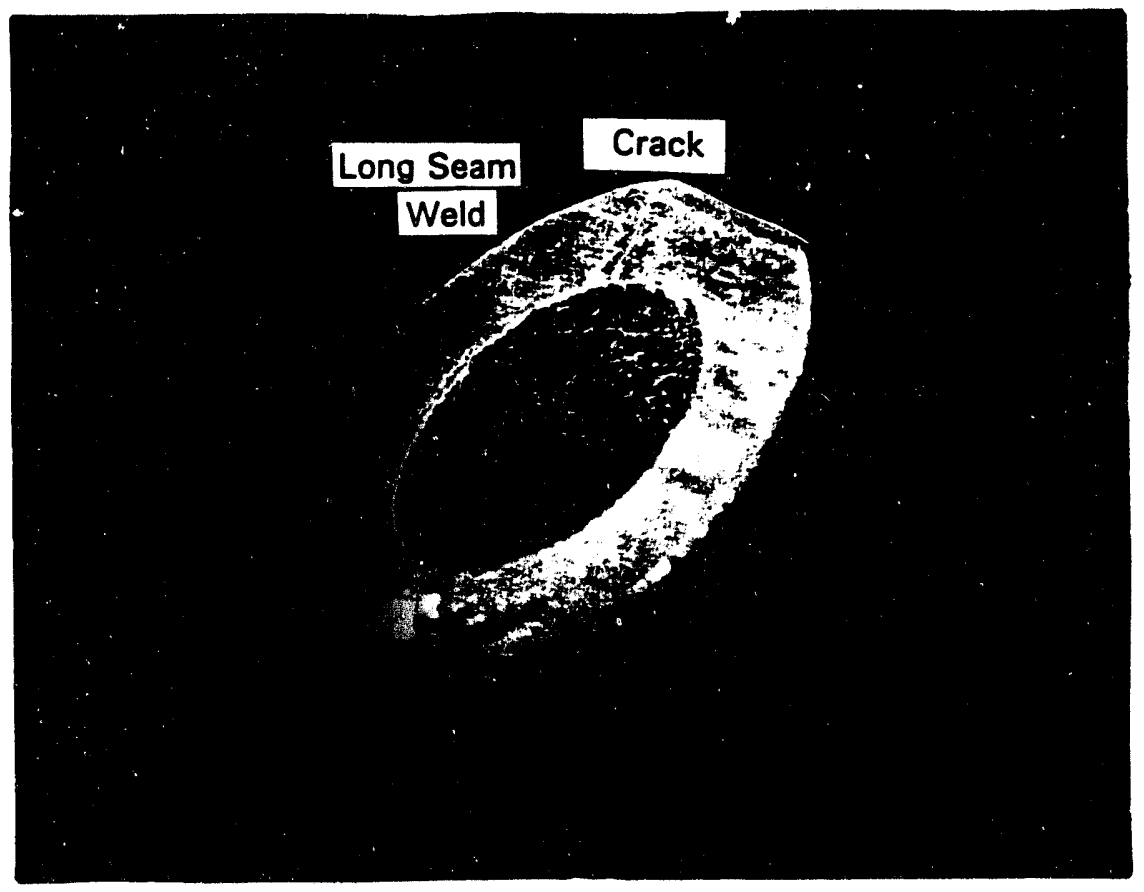

FIGURE A.2-2

END VIEW OF THE REMOVED BEND

The cross-section is $1 / 8$ in. from the crack tip at the O.D. (see Fig.A1) 
1858

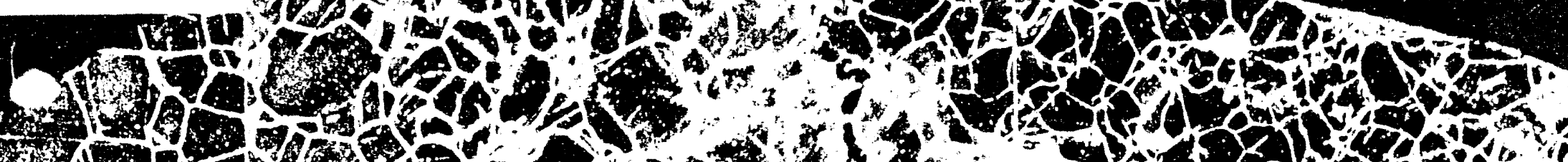

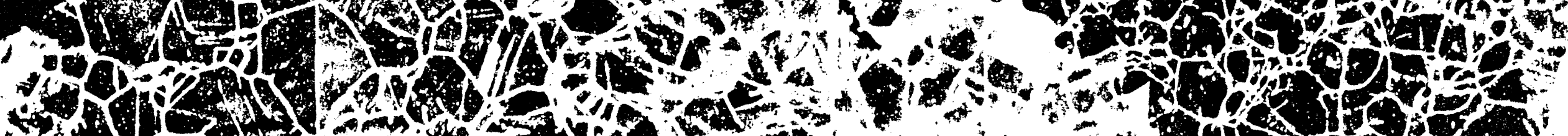
1.p

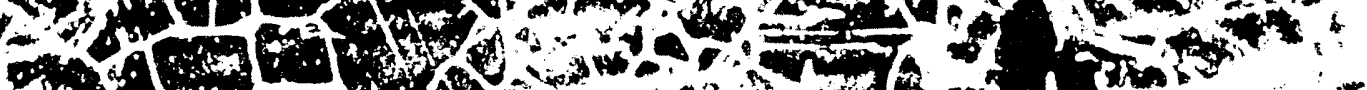

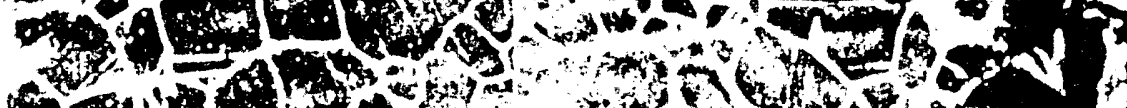
4.

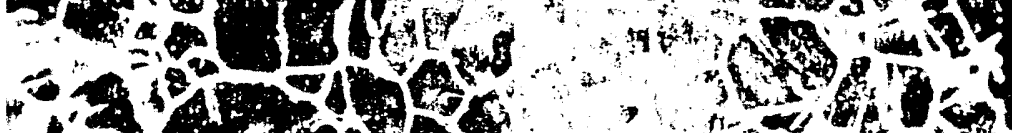

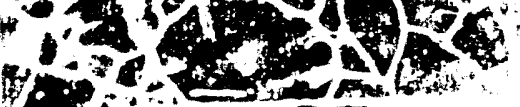

:

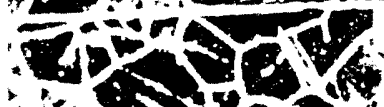

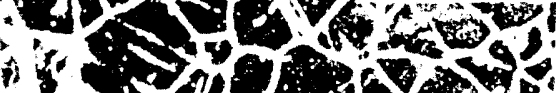

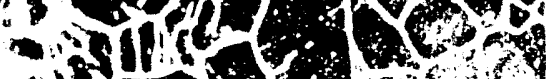
H.

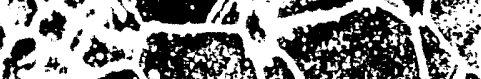

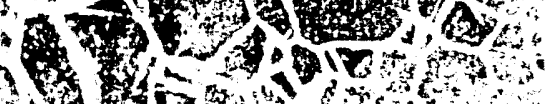

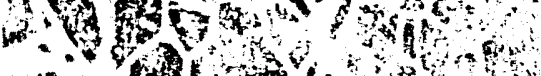
o. 30

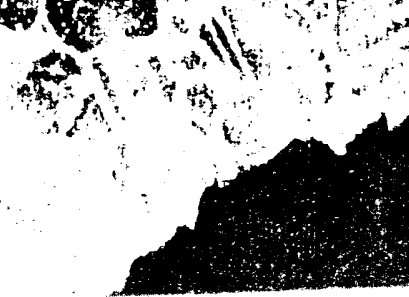
$=1+$

\section{(5)}

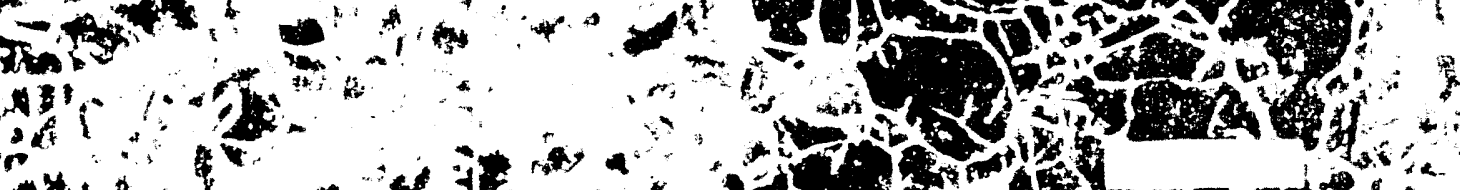

,, 4

Ifffolstis

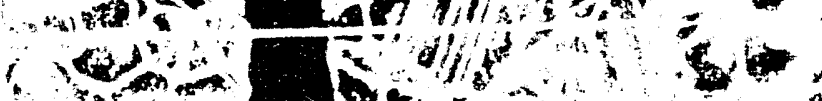

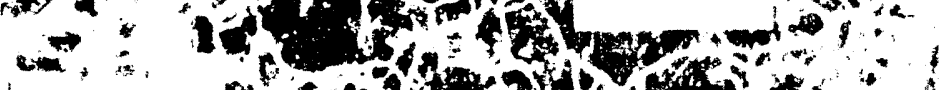

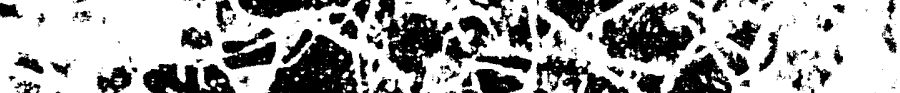
- w e n

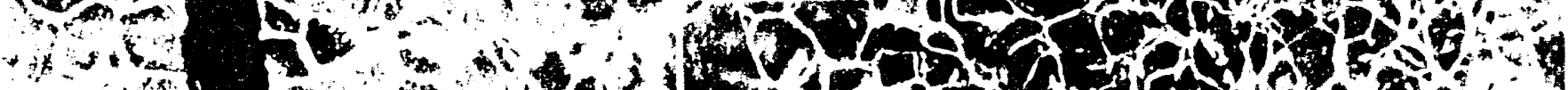

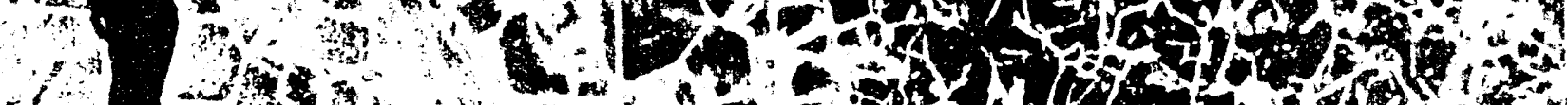

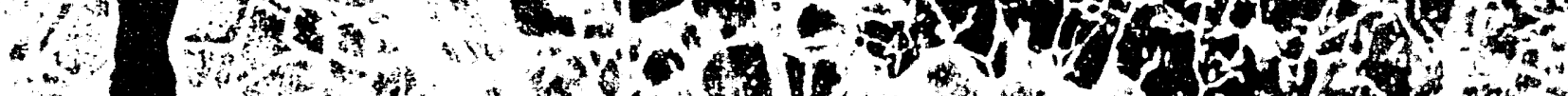

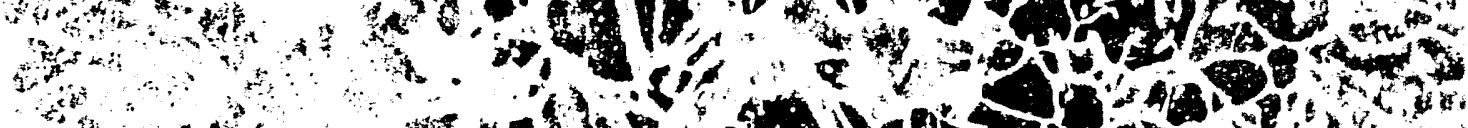

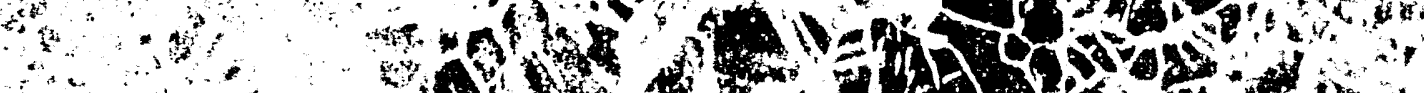

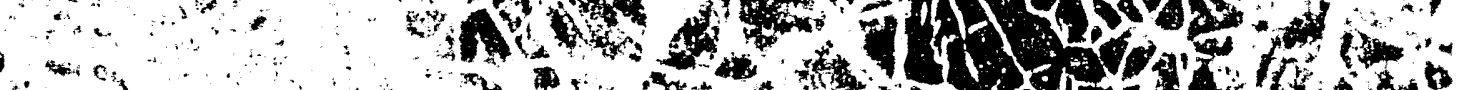

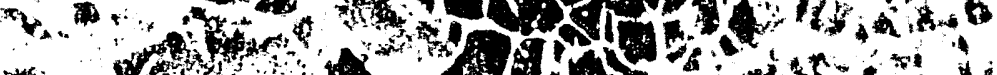

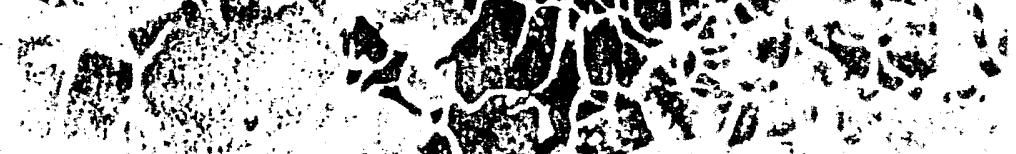

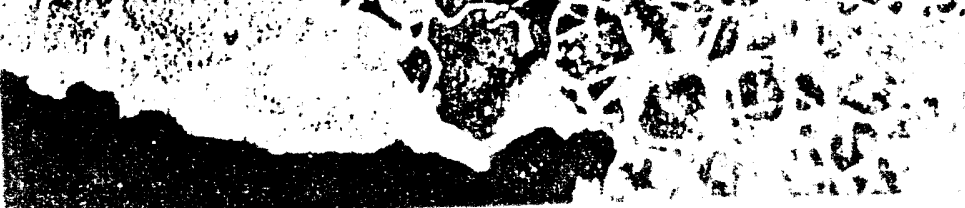




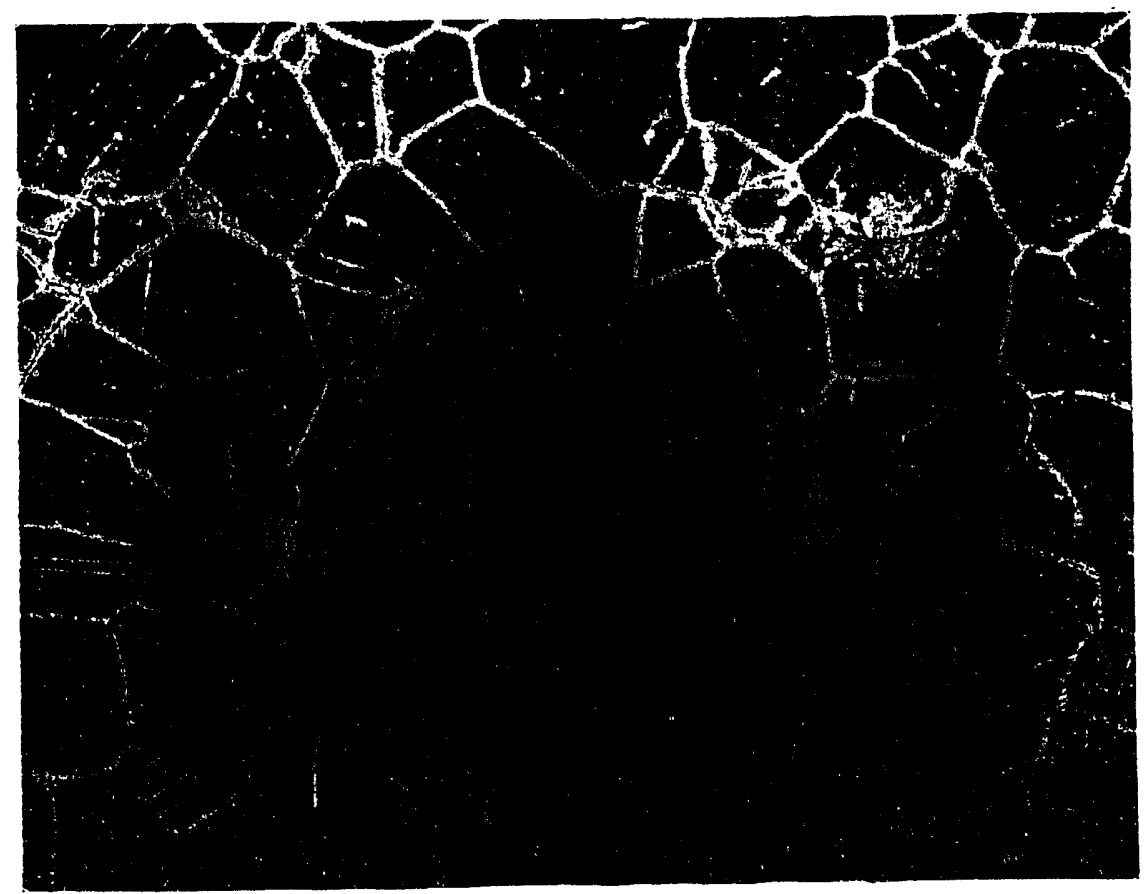

FIGURE A.2-4

\title{
TRANSGRANULAR STRESS-CORROSION CRACKS AT THE END OF THE BEND OPPOSITE TO THE LEAK LOCATION
}

\author{
All three cracks are in the base metal $\sim 3 / 16$ in. from the root \\ of the longitudinal seam weld
}

Magnification: $100 \mathrm{X}$ 


\begin{tabular}{|c|c|c|}
\hline LOCATION & ZONE & $\begin{array}{c}\text { TEMPERATURE } \\
\text { (' } \mathbf{C} \text { ) }\end{array}$ \\
\hline Filter Arm A & $\begin{array}{c}2 \mathrm{~b} \\
\text { (Supercritical) }\end{array}$ & $580-615$ \\
\hline MTC-1 & $\begin{array}{c}2 \mathrm{c} \\
\text { (Supercritical) }\end{array}$ & $550-560$ \\
\hline MTC-2 & $\begin{array}{c}1 \\
\text { (Subcritical) }\end{array}$ & $295-305$ \\
\hline
\end{tabular}

The above temperatures refer to steady-state operating conditions. During relatively brief excursions (minutes to an hour), maximum temperatures could exceed the above ranges by 10 $15^{\circ} \mathrm{C}$.

Each coupon location has gone through a number of startup and shutdown cycles and, in some cases, flushing at subcritical conditions was performed in nominally supercritical zones. Thus, each zone has actually been exposed to a wide range of environments.

Effluent composite analyses provide some insight into the severity of the environments at the test locations. The chloride levels/pH in the effluent varied between $1 \mathrm{ppm} / \mathrm{pH} 3.75$ (Run 914) and $7,800 \mathrm{ppm} / \mathrm{pH} 0.73$ (Run 922) in the first nine runs (914 through 922), and between $16 \mathrm{ppm} / \mathrm{pH}$ 3.5 (Run 925) and $900 \mathrm{ppm} / \mathrm{pH} 1.7$ (Run 926) in the eleven subsequent runs (923 through 933).

\section{TeST SAMPLES}

Materials were selected for testing based on previous experience, and the literature. Table A.3-1 provides a list of materials sources and heat numbers. In the case of the nickel-based alloys, the source material was, as a rule, in mill-annealed condition. Three out of seven samples tested in MTC-2 were annealed after welding at $2025 \pm 15^{\circ} \mathrm{F}$. Most test specimens were fabricated by Metal Samples. The following is a description of the test samples.

\section{Filter Arm A}

Fourteen samples were exposed in the filter arm for varying periods including:

Alloy 625 flat coupon (Runs 914-932)

Alloy 718 flat coupon (Runs 914-932)

Alloy 718 U-bend (Runs 924-932)

Alloy X-750 flat coupon (Runs 914-932)

Alloy AX flat coupon (Runs 925-932)

Alloy BX flat coupon (Runs 924-932)

Alloy CX flat coupon (Runs 931 and 932)

Ceramic A sheet (Runs 919-932) 
Ceramic B cast (Runs 924-932)

Ceramic C (Runs 914-932)

Ceramic D (Runs 914-932)

Pt wire (Runs 914-932)

Pt-10\% Ir wire (Runs 914-932)

Pt-30\% Rh wire (Runs 914-932)

Note that the composition of materials (alloys and ceramics) designated by letters (AX, BX, CX, A, B, C, and D) are considered proprietary by MODAR.

\section{Materials Test Chamber 1}

Six samples representing four high-nickel alloys were exposed to the MTC-1 supercritical environment (Runs 914-933). They include:

Alloy 625 flat coupon

Alloy 625 welded flat coupon

Alloy 625 U-bend

Alloy 718 flat coupon

Alloy X-750 flat coupon

Alloy H-9M flat coupon

There was no heat treatment of the welded Alloy 625 coupon after welding.

\section{Material Test Chamber 2}

Ten samples representing one high-alloy austenitic steel, three high-nickel alloys, and two grades of titanium were exposed to the MTC-2 environment. The first three materials listed below were exposed during Runs 914 through 922/923. The other seven materials were exposed during Runs 924 through 933 . These samples include:

20Cb-3 flat coupon

Alloy H-9M flat coupon

Ti, Grade 12 flat coupon

Alloy 625 welded U-bend, as-welded

Alloy 625 welded U-bend, annealed at $1850^{\circ} \mathrm{F}$

Alloy 625 socket weld, as-welded

Alloy 625 socket weld, annealed at $1850^{\circ} \mathrm{F}$

Alloy C-276 butt-welded tubes with Alloy 625 filler, as-welded

Alloy C-276 butt-welded tubes with Alloy 625 filler, annealed at $1850^{\circ} \mathrm{F}$

Titanium, Grade 2 welded U-bend 
Table A.3-1

Test Materials and Sources

\begin{tabular}{|c|c|c|c|}
\hline MATERIAL & SPECIMEN & HEAT * & MANUFACTURER/SUPPLIER \\
\hline $\begin{array}{l}\text { MTC-1 } \\
\text { Alloy } 625 \\
\text { Alloy } 625 \\
\text { Alloy } 718 \\
\text { Alloy X-750 } \\
\text { Alloy H-9M } \\
\text { Alloy } 625 \\
\end{array}$ & $\begin{array}{l}\text { Coupon } \\
\text { Welded Coupon } \\
\text { Coupon } \\
\text { Coupon } \\
\text { Coupon } \\
\text { U-Bend } \\
\end{array}$ & $\begin{array}{l}\text { H233 } \\
\text { H250 } \\
\text { H873 } \\
\text { D537 } \\
\text { G296 } \\
\text { H408 } \\
\end{array}$ & $\begin{array}{l}\text { VDM } \\
\text { INCO Alloys } \\
\text { Universal Cyclops Corp. } \\
\text { INCO Alloys } \\
\text { Haynes International } \\
\text { Allegheny Ludlum } \\
\end{array}$ \\
\hline $\begin{array}{l}\text { MTC-2 } \\
\text { Ti (grade 12) } \\
\text { Alloy H-9M } \\
20 \text { Cb-3 } \\
\text { Ti (grade 2) } \\
\text { Alloy C-276 } \\
\text { Alloy } 625\end{array}$ & $\begin{array}{l}\text { Coupon } \\
\text { Coupon } \\
\text { Coupon } \\
\text { U-Bend } \\
\text { Tube } \\
9 / 16^{\prime \prime} \text { tube } \\
3 / 4^{\prime \prime} \text { bar (machined) } \\
\end{array}$ & $\begin{array}{l}\text { B046 } \\
\text { G296 } \\
\text { H996 } \\
\text { J192 } \\
2760-0-3749 \\
\text { VX0968AK } \\
\text { VX1547AK-14 } \\
\end{array}$ & $\begin{array}{l}\text { Timet } \\
\text { Haynes International } \\
\text { Rolled Alloys } \\
\text { Titanium \& Alloys } \\
\text { Salem Tube Co. } \\
\text { Superior Tube Co. } \\
\text { INCO/Castle Metals } \\
\end{array}$ \\
\hline $\begin{array}{l}\text { Filter A Samples } \\
\text { Alloy } 625 \\
\text { Alloy } 718 \\
\text { Alloy X-750 } \\
\text { Alloy } 718 \\
\text { Pt }(99.99 \%) \\
\text { Pt-10\%Ir } \\
\text { Pt-30\%Rh }\end{array}$ & $\begin{array}{l}\text { Coupon } \\
\text { Coupon } \\
\text { Coupon } \\
\text { U-Bend } \\
\text { Wire } \\
\text { Wire } \\
\text { Wire }\end{array}$ & $\begin{array}{l}\text { H233 } \\
\text { H873 } \\
\text { D537 } \\
\text { HT \#H873 } \\
\text { Lot \# J21B04 } \\
\text { Lot \# K15A01 } \\
\text { Lot \# 18794 }\end{array}$ & $\begin{array}{l}\text { VDM } \\
\text { Universal Cyclops Corp. } \\
\text { INCO Alloys } \\
\text { Universal Cyclops Corp. } \\
\text { Johnson Matthey Co. } \\
\text { Johnson Matthey Co. } \\
\text { Johnson Matthey Co. }\end{array}$ \\
\hline
\end{tabular}

\section{Examination Procedures}

The samples were examined by:

- $\quad$ optical stereomicroscopy and

- metallography (selected samples)

An additional characterization of flat coupons was done on a light optical microscope at magnifications between 100 and $800 x$ which permitted determination of pit depth and examination of pit morphology. 
The optical stereomicroscopy was used at magnifications between 3 and 40x. Metallographic examinations were performed on welded tube and socket weld samples, as well as the titanium Grade 2 U-bend from MTC-2.

All samples were first examined at low magnifications. Then, the samples were cleaned, rinsed, and dried at MODAR per an ASTM G1 cleaning procedure (para. 7.9 and 7.10). Weighing was also done at MODAR. Reproducibility of weighing was within $0.0001 \mathrm{~g}$, as verified by two operators who performed five consecutive measurements of the same piece.

\section{OBSERVATIONS}

\section{Materials Test Coupons/Samples}

Table A.3-2 summarizes percentage mass changes and (for the flat coupons), "average" corrosion rates calculated in accordance with ASTM G1. These average corrosion rates were calculated based on the total area and total exposure time. The use of only boldly exposed, i.e. not shielded by the washers, area would increase the values stated in Table A.3-2 by a factor of about 1.1. Using the boldly exposed area and assuming, conservatively, that corrosion occurred only during periods when salt-generating feeds were introduced would increase the corrosion rate values by a factor of about 2.3 .

The average corrosion rates given in Table A.3-2 are used here only as one of the ranking parameters in evaluation of the test materials. The use of the alternate area or exposure time would not necessarily change the ranking.

Tables A.3-3 through A.3-7 summarize observations and measurements made during the laboratory examinations. The tables indicate occurrence of pitting corrosion, crevice corrosion, stress corrosion cracking, and scale spalling, where applicable, and reference relevant Figures (A.3-1 through A.3-30) illustrating the observations. For convenience, the mass changes and average corrosion rates from Table A.3-2 are also included in Tables A.3-3 through A.3-7.

\section{Components}

As mentioned previously, several components of the reactor were removed after the test program and visual observations were made.

\section{Nozzle Centering Plates and Filter Housing}

These components are made of Alloy C-276. The nozzle centering plates are exposed to Zone $2 \mathrm{a}$ environment, while the filter housing is exposed to Zone $2 \mathrm{~b}$ environment (see Section A.1 for definitions of the zones). All these components suffered a severe nonuniform wastage. No metallurgical examination of these components has been performed. 
Titanium Liner

Titanium Grade 2 liner suffered a massive nonuniform metal loss with drastic thinning and numerous perforations in Zone 2 . Titanium is known to be susceptible to accelerated oxidation and a slew of other problems (hydriding, nitriding) at Zone 2 temperatures. Oxidation becomes a serious problem at $\mathrm{T}>450^{\circ} \mathrm{C}$. No metallographic examination of the liner has been performed.

\section{DISCUSSION OF RESULTS}

The test conditions were far from steady-state, which makes an interpretation of the results rather difficult. Fortunately, differences in the results obtained in the three test zones are still significant and permit one to draw important conclusions. In fact, the variability in test conditions is probably more severe than commercial unit operation.

During evaluation of the test results, the goal was to identify suitable materials of construction for a commercial unit. Among the samples tested a ranking was developed that classified each material's suitability for commercial use. This ranking was based on corrosion resistance, and formed the basis for the table of preferred materials presented in Sections 1 and 5 of the report.

The ranking given below is based on limited data for the specific zones tested. Future testing or component materials performance may significantly modify the ranking.

The following criteria were used for the ranking:

- $\quad$ percent mass loss/mass gain (and average corrosion rate)

- $\quad$ presence and severity of pitting and/or crevice corrosion

- occurrence of stress corrosion cracking

- $\quad$ scale spalling

As discussed above, the use of severity of pitting as a ranking criterion might prove useful for thick compnnents with a relatively short design life. In thin components, e.g., in tubing, severity of pitting is generally useless since pits may grow through the wall unpredictably fast. 


\section{Zone 2b (Supercritical Fluid - Chloride Rich Salts Present)}

The materials tested in filter arm A, had the following relative ranking:

\begin{tabular}{||l|l|}
\hline RANKING & MATERIAL \\
\hline EXCELLENT & $\begin{array}{l}\text { Alloy BX } \\
\text { Ceramic C } \\
\text { Pt, Pt-Rh }\end{array}$ \\
\hline SATISFACTORY & $\begin{array}{l}\text { Alloys AX, CX, 625, 718 } \\
\text { Ceramics A, B, D } \\
\text { Pt-Ir }\end{array}$ \\
\hline POOR & Alloy 750 \\
\hline
\end{tabular}

A "satisfactory" ranking for materials which are susceptible to localized corrosion (pitting, crevice corrosion) does not imply that the materials are suitable for long-term service as pressure boundary materials; localized corrosion may propagate fast and result in a violation of the pressure boundary. They may still be acceptable for experimental units provided their condition is monitored regularly by appropriate nondestructive examinations. In general, materials that are susceptible to stress corrosion cracking would not be used for pressure boundaries.

No testing has been done to verify whether any embrittlement his occurred in the tested alloys and, therefore, suitability of the alloys such as $\mathrm{AX}, \mathrm{BX}$, and $\mathrm{CX}$ for pressure-retaining components has not been demonstrated. Alloys $\mathrm{AX}, \mathrm{BX}$, and $\mathrm{CX}$ require further testing to verify their long-term performance in supercritical environments.

Both Alloys 625 and 718 developed a fairly thick scale which spalled off. Pitting developed primarily in the areas where the scale came off in both alloys. The deepest pits in Alloy 718 were up to $0.01 \mathrm{in}$. and they would most likely grow faster than in Alloy 625 since the molybdenum content at comparable or lower chromium level in Alloy $718(\sim 3$ percent $\mathrm{Mo})$ is significantly lower than in Alloy 625 (9 percent Mo). Thus, although Alloy 718 had a lower overall mass loss compared to Alloy 625 , the former is not judged to be a better material for Zone $2 \mathrm{~b}$ than Alloy 625 . In fact, the average corrosion rate in Alloy 718 accelerated from 2.4 mpy (before Run 930) to 12.7 mpy (Runs 930 to 932), while the averar? corrosion rate in Alloy 625 dropped from 24.6 mpy (Runs 919 to 924 ) to $7.7 \mathrm{mpy}$ in subsequent runs.

Alloy 718 is an age-hardenable alloy; effects of aging and welding on corrosion resistance in Zone $2 \mathrm{~b}$ are not known at this time. 


\section{Zone 2c (Supercritical Fluid - No Salts Present)}

The materials tested in materials test chamber 2 had the following relative ranking:

\begin{tabular}{||l|l|}
\hline RANKING & MATERIAL \\
\hline EXCELLENT & None of the tested materials \\
\hline SATISFACTORY & Alloys 625,718, X-750, H-9M \\
\hline POOR & None of the tested materials \\
\hline
\end{tabular}

All four alloys tested in MTC-1 have shown a satisfactory performance in terms of "average" corrosion rate which has been below $3 \mathrm{mpy}$ in Alloy 625 samples and even lower in the other three alloys. However, they all suffered from pitting and crevice corrosion. The deepest pits in all four alloys were between 0.006 and 0.008 in. deep.

No stress corrosion cracking was detected in the Alloy $625 \mathrm{U}$-bend and butt-welded coupon. In addition, no significant difference was found in corrosion resistance of Alloy 625 base metal and weld/heat-affected zone area.

At nearly the same exposures, Alloy 625 tested in MTC-1 had a significantly lower mass loss ( 0.3 to 0.55 percent) compared to the mass loss in Filter A ( 2.3 percent); however, the MTC-1 samples of Alloy 625 developed deeper pits (up to 0.008 in.) compared to the Filter A sample. The differences in the mass loss may be attributed to the heavy deposition of salts and higher temperatures in Filter A.

The test results, in terms of mass loss, do not indicate a strong preference for any of the tested alloys. However, no stress-corrosion cracking data are available at this time for Alloys 718 , $\mathrm{X}-750$, and $\mathrm{H}-9 \mathrm{M}$ in the Zone $2 \mathrm{c}$ environment or in any supercritical environment, for that matter. The Alloy $625 \mathrm{U}$-bend tested in Zone $2 \mathrm{c}$ did not show any evidence of stress-corrosion cracking.

While Alloys X-750 and H-9M may prove, in future tests, to have corrosion resistance in Zone $2 c$ comparable to Alloy 625 , their poor performance in adjacent zones indicate potential problems with the use of these two alloys even in Zone 2c. As discussed above, Alloy X-750 suffered severe corrosion in the Filter A environment (Zone 2b) and parts of Alloy H-9M coupon have become paper thin and perforated in MTC-2 (Zone 1). The Alloy X-750 problems in the Filter A environment seem to be associated with the salt deposits. However, some salt deposition, albeit relatively minor, also occurs downstream of Filter A. The lower temperature in MTC-1 would tend to slow down the kinetics of the corrosion processes in Alloy X-750 compared to Filter A. Therefore, corrosion damage similar to that observed in the Alloy X-750 coupon exposed in the Filter A environment might be simply postponed at the MTC-1 temperatures. 
Alloy H-9M, in spite of high advertised pitting resistance ("higher than in Alloy 625," according to one of the published data sheets), is obviously intolerant to the subcritical environment. Therefore, even transient exposures of Alloy $\mathrm{H}-9 \mathrm{M}$ to subcritical fluid in a nominally supercritical region such as Zone $2 \mathrm{c}$ may prove very damaging. Thus, the use of Alloys X-750 and $\mathrm{H}-9 \mathrm{M}$ as materials of construction in the Zone $2 \mathrm{c}$ environment should not be considered unless additional long-term test data in this environment indicate that the above concerns are not as serious as they appear to be based on the limited available data.

Alloy 718 tested in MTC-1 has thus far shown materials performance closely matching Alloy 625. Unless longer exposures of Alloy 718 to the Zone $2 \mathrm{c}$ environment show a significant acceleration of corrosion (see the discussion of the Filter A results above), Alloy 718 may prove an acceptable substitute material for Alloy 625. Of course, both materials proved susceptible to localized corrosion known for its irregular behavior in terms of time to initiation and penetration rates. For the time being, Alloy 625 is more likely to have a longer life expectancy in the Zone $2 \mathrm{c}$ environment than the other tested alloys, albeit still limited by the progression of localized corrosion. While a limited service life may be acceptable for pilot units, a further search for a material resistant to localized corrosion is of paramount importance for future commercial units with similar operating/environmental conditions.

It should be noted that no ceramic materials were included in MTC-1. Previous work by MODAR has indicated excellent corrosion resistance in this environment for several proprietary materials.

\section{Zone 1 (Subcritical Liquid and Gas)}

The materials tested in materials test chamber 2 had the following relative ranking:

\begin{tabular}{||l|l|}
\hline RANKING & MATERIAL \\
\hline EXCELLENT & Titanium Grades 2 and 12 \\
\hline SATISFACTORY & Alloy C-276 \\
\hline POOR & Alloys $625, \mathrm{H}-9 \mathrm{M}, 20 \mathrm{Cb}-3$ \\
\hline
\end{tabular}

In striking contrast to the other zones, Alloy 625 is unacceptable in the hot subcritical fluid environment. Both U-bend samples fell apart due to stress corrosion cracking and both Alloy 625 base metal and weld metal suffered severe corrosion in all the samples tested in MTC- 2 .

Alloys H-9M and $20 \mathrm{Cb}-3$ performed even worse. The Alloy $\mathrm{H}-9 \mathrm{M}$ coupon became paper thin in some areas and contained a number of perforations.

The only nickel-based alloy showing any appreciable resistance to localized corrosion attack in MTC-2 was Alloy C-276. No stress corrosion cracking was detected in the C-276 welded tubes tested in MTC-2. However, this result cannot be considered as conclusive evidence of high 
resistance to stress-corrosion cracking since a welded tube is not the most reliable sample for determination of stress corrosion cracking resistance. In fact, Alloy C-276 heat exchanger tubes have apparently suffered stress corrosion cracking in the subcritical region and even in the nominally supercritical region (see Sections A.1 and A.2).

The only materials which performed remarkably well in the MTC-2 tests are Titanium Grade 2 and Titanium Grade 12. There was some discoloration in the washer-shielded area of the Titanium, Grade 12 sample, but otherwise both samples remained essentially intact.

The use of titanium as a Zone 1 material of construction would require a thorough review of compatibility with the other materials as well as a review of fabricating issues. 
MASS CHANGES AND AVERAGE CORROSION RATES

Material

Length Width Thickn.

\section{PERASTM G1
$(k=3.45 E+06)$}

\section{MTC-1}

625,coupon

625 weld coupon

718 ,coupon

X-760.coupon

HOM,coupon

in.

in.

in.

dia.
in.

in. $\mathrm{cm}^{\wedge 2} \mathrm{~cm}^{\wedge} 2$

Time

Exposure to salt-

generating feeds

hrs

Mass

Density Corr.

$\begin{array}{lll} & & \text { Pato } \\ & \mathrm{g} / \mathrm{cm} 3 & \mathrm{mpy}\end{array}$

$625 \mathrm{U}$-bend

$\begin{array}{rrrr}2 & 0.738 & 0.115 & 0.322 \\ 2.005 & 0.75 & 0.113 & 0.366 \\ 2.009 & 0.734 & 0.126 & 0.391 \\ 2.1 & 0.745 & 0.127 & 0.411 \\ 2.005 & 0.743 & 0.06 & 0.386 \\ 5 & 0.761 & 0.052 & 0.4\end{array}$

$\begin{array}{rrr}0.533 & 17.7065 & 19.0942 \\ 0.648 & 16.8532 & 18.8728 \\ 0.569 & 17.7204 & 18.5257 \\ 0.621 & 18.5559 & 19.6261 \\ 0.634 & 14.9245 & 16.9684 \\ 0.6 & 46.8816 & 48.4869\end{array}$

\section{4}

979.4

979.4

979.4

979.4

979.4

$0.6 \quad 46.8816 \quad 48.4869$

MTC-2

Ti-12,coupon

$\begin{array}{lll}2.007 & 0.739 & 0.124 \\ 2.008 & 0.744 & 0.062\end{array}$

$\begin{array}{rrrr}0.42 & 0.7 & 16.4374 & 18.2194 \\ 0.43 & 0.65 & 14.8912 & 16.5803 \\ 0.37 & 0.63 & 17.5354 & 19.2854\end{array}$

HaM,colpon

$20 \mathrm{Cb3}$, coupon

$\begin{array}{lll}2.008 & 0.744 & 0.062\end{array}$

0.37

$0.63 \quad 17.5354$

9.2854

Ti-2,U-bend, welded

C-276 tubes butt-welded with 625 filler, as-welded

C-276 tubes butt-welded with 625 filler, annealed

625 , sockel weld, as - welded

625 , socket weld annealed

625, U-bend, as-welded

625, $U$-bend, annealed

Filter $\mathbf{A}$

$\begin{array}{lrrr}\text { CX,coupon } & 2 & 0.735 & 0.1 \\ \text { 625,coupon } & 2.003 & 0.742 & 0.126 \\ 718, \text { coupon } & 2.008 & 0.745 & 0.127 \\ \text { X-750,coupon } & & & \\ \text { BX,coupon } & & & \\ \text { AX,coupon } & & & \\ 718, U \text {-bend } & & & \\ \text { PI wire } & 1 & 0.02 \text { dia. } \\ \text { PU/r wire } & 1 & 0.02 \text { dia. } \\ \text { PURh wire } & 1 & 0.02 \text { dia. }\end{array}$

PUPh wire

0.02 dia.

Ceramic D

Ceramic C

Ceramic B

Ceramic A

$\begin{array}{ll}377.9 & 101 \\ 373.9 & 101 \\ 373.9 & 101.7 \\ 601.5 & 344 \\ 601.5 & 344.3 \\ 601.5 & 344 \\ 601.5 & 344 \\ 601.5 & 344 \\ 601.5 & 344.3 \\ 601.5 & 344 .\end{array}$

$\begin{array}{lrrl}446 & -0.44 & 8.44 & 2.1 \\ 446 & -0.55 & 8.44 & 2.6 \\ 446 & -0.18 & 8.19 & 1.0 \\ 446 & -0.40 & 8.25 & 2.0 \\ 446 & 0.00 & 8.3 & 0.0 \\ 446 & -0.30 & 8.44 & 0.6 \text { (approxarea) }\end{array}$

$\begin{array}{rrrl}101.7 & 0.05 & 4.51 \text { Mass Gain } \\ 101.7 & -40.53 & 8.3 & 300.7 \\ 101.7 & -26.37 & 8.05 & 391.0\end{array}$

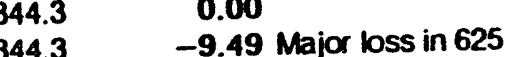

-8.01 Major loss in 625

$-14.09$

$-7.39$

$-37.34$

$344.3-\mathbf{3 0 . 3 9}$

nrate is based on the tolal area and total exposure time the effect of other assumplions is discussed in Soction A.3

File:crA12A wk3 
TABLE A.3-3

PERFORMANCE OF ALLOY SAMPLES EXPOSED IN FILTER A

(Zone II-b, SC fluid, high $\mathrm{Cl}^{\prime}, \mathrm{T}=580$ to $615^{\circ} \mathrm{C}$ )

\begin{tabular}{|c|c|c|c|c|c|c|c|c|c|c|}
\hline $\begin{array}{l}\text { Item } \\
\text { No }\end{array}$ & Material & $\begin{array}{l}\text { Sample } \\
\text { Type }\end{array}$ & $\begin{array}{l}\text { Run } \\
\text { * } \$ \text { s }\end{array}$ & $\begin{array}{l}\text { Time } \\
\text { hours } \\
\text { (total) }\end{array}$ & $\begin{array}{l}\text { Mass } \\
\text { Change, } \\
\text { percent }\end{array}$ & $\begin{array}{l}\text { Ave.Corr. } \\
\text { Rate } \\
\text { mpy }\end{array}$ & Pitting & $\begin{array}{l}\text { Crevice } \\
\text { Corrosion }\end{array}$ & General Comments & $\begin{array}{l}\text { Fig. } \\
\text { No }\end{array}$ \\
\hline 1 & $\begin{array}{l}\text { Alloy } \\
625\end{array}$ & Coupon & $\begin{array}{c}914 \\
- \\
932\end{array}$ & 951.4 & -2.3 & 11.5 & Yes & $\begin{array}{l}\text { See next } \\
\text { column }\end{array}$ & $\begin{array}{l}\text { Surface (brushed and rinsed) is covered with a dark thick } \\
\text { scale; in spots, where the scale came off, small pits (0.075 } \\
\text { mm dia, } 0.06 \mathrm{~mm} \text { deep) filled with yellow substance are } \\
\text { evident; the scale is not strongly adherent - it crumbles } \\
\text { when probed with a needle; corrosion in the crevice areas } \\
\text { is similar but less extensive than in boldly exposed areas }\end{array}$ & A.3-1 \\
\hline 2 & $\begin{array}{l}\text { Alloy } \\
718\end{array}$ & Coupon & $\begin{array}{c}914 \\
- \\
932\end{array}$ & 951.4 & -1.02 & 5.3 & Yes & Yes & $\begin{array}{l}\text { Spots of corrosion attack apparently preceded by } \\
\text { exfoliation of layered scale, with pits (up to } 0.25 \mathrm{~mm} \text { deep } \\
\text { and up to } 1.5 \mathrm{~mm} \text { dia) in the exfoliated areas; numerous }\end{array}$ & A.3-2 \\
\hline 3 & $\begin{array}{c}\text { Alloy } \\
718\end{array}$ & U-bend & $\begin{array}{c}924 \\
- \\
932\end{array}$ & 573.5 & N/A & - & Yes & Yes & $\begin{array}{l}\text { No stress corrosion cracking; fairty significant corrosion in } \\
\text { some areas apparently preceded by exfoliation; typical } \\
\text { pits - } 0.025 \text { to } 0.05 \mathrm{~mm} \text { deep; the depth of attack in the }\end{array}$ & A.3-3 \\
\hline 4 & $\begin{array}{l}\text { Alloy } \\
X-750\end{array}$ & Coupon & $\begin{array}{c}914 \\
- \\
932\end{array}$ & 951.4 & -10.35 & 56.4 & Yes & Yes & $\begin{array}{l}\text { Severe corrosion virtually over the entire surface, although } \\
\text { two of the initially stamped figures, e.g." } 5 \text { " from } X-750 \text {, are } \\
\text { still discemible; the sample is covered with a thick }\end{array}$ & A.3-4 \\
\hline 5 & $\begin{array}{l}\text { Alloy } \\
\text { AX }\end{array}$ & Coupon & $\begin{array}{c}925 \\
- \\
932\end{array}$ & 529.5 & +1.05 & $\begin{array}{l}\text { Mass } \\
\text { gain }\end{array}$ & Yes & N.A. & $\begin{array}{l}\text { Oxide film spalling; at the spallations the film is dark } \\
\text { yellow to brown; pits }(0.4 \text { to } 2 \mathrm{~mm} \text { dia) where oxide film } \\
\text { had spalled; the pits are filled with yellow corrosion } \\
\text { product }\end{array}$ & A.3-5 \\
\hline 6 & $\begin{array}{l}\text { Alloy } \\
\text { BX }\end{array}$ & Coupon & $\begin{array}{c}924 \\
- \\
932\end{array}$ & 573.5 & +0.95 & $\begin{array}{l}\text { Mass } \\
\text { gain }\end{array}$ & No & No & $\begin{array}{l}\text { A few small(<2 mm dia) area of spalled oxide; no pitting } \\
\text { and no crevice corrosion }\end{array}$ & A.3-6 \\
\hline 7 & $\begin{array}{l}\text { Alloy } \\
\text { CX }\end{array}$ & Coupon & $\begin{array}{c}931 \\
\& \\
932\end{array}$ & 268.4 & +0.41 & $\begin{array}{l}\text { Mass } \\
\text { gain }\end{array}$ & No & No & $\begin{array}{l}\text { Extensive exfoliation; scale thickness }-0.01 \mathrm{~mm} \text {; no pitting } \\
\text { and no crevice corrosion }\end{array}$ & A.3-7 \\
\hline
\end{tabular}

Notes: Of the above samples, only Alloy 718 U-bend had a potential for stress corrosion cracking; no evidence of cracking in the U-bend or any flat coupons was detected in stereomicroscopeat magnifications up to $40 \mathrm{X}$.

The corrosion products have not been analyzed by either EDS or X-ray diffraction. 
TABLE A.3-4

PERFORMANCE OF CERAMIC AND NOBLE WIRE SAMPLES EXPOSED IN FILTER A

(Zone II-b, SC fluid, high $\mathrm{Cr}, \mathrm{T}=580$ to $615^{\circ} \mathrm{C}$ )

\begin{tabular}{|c|c|c|c|c|c|c|c|c|c|}
\hline $\begin{array}{l}\text { Item } \\
\text { No }\end{array}$ & Material & $\begin{array}{c}\text { Sample } \\
\text { Type }\end{array}$ & $\begin{array}{l}\text { Run } \\
\text { *is }\end{array}$ & $\begin{array}{l}\text { Time } \\
\text { hours } \\
\text { (total) }\end{array}$ & $\begin{array}{c}\text { Mass } \\
\text { Change, } \\
\text { percent }\end{array}$ & $\begin{array}{c}\text { Ave.Corr. } \\
\text { Rate } \\
\text { mpy }\end{array}$ & Pitting & General Comments & $\begin{array}{l}\text { Fig. } \\
\text { No }\end{array}$ \\
\hline 1 & Ceramic A & Sheet & $\begin{array}{r}919- \\
932\end{array}$ & 786 & $\mathbf{0}$ & 0 & Yes & $\begin{array}{l}\text { The entre surface is pitted; most pits are very } \\
\text { shallow }(-0.01 \mathrm{~mm}) \text {; of a few deeper pits, the } \\
\text { deepest is } 0.2 \mathrm{~mm}\end{array}$ & A.3-8 \\
\hline 2 & Ceramic B & Cast & $\begin{array}{l}824 \\
932\end{array}$ & 573.5 & -0.71 & 4.7 & Yes & $\begin{array}{l}\text { The surface is pltted; the largest plts observed } \\
\text { were } 0.2 \mathrm{~mm} \text { dia and } 0.15 \mathrm{~mm} \text { deep }\end{array}$ & A.3-8 \\
\hline 3 & Ceramic C & Tube & $\begin{array}{l}914 . \\
932\end{array}$ & 951.4 & +0.08 & $\begin{array}{l}\text { Mass } \\
\text { gain }\end{array}$ & No & No signs of degradation & A.3-10 \\
\hline 4 & Ceramic D & Tube & $\begin{array}{r}914 \\
932\end{array}$ & 951.4 & -0.07 & 0.3 & Yes & $\begin{array}{l}\text { The largest observed pits had } 0.8 \mathrm{~mm} \text { dia and } \\
0.2 \mathrm{~mm} \text { depth }\end{array}$ & A.3-11 \\
\hline 5 & Pt & Wire & $\begin{array}{l}914 \\
932\end{array}$ & 951.4 & +0.17 & $\begin{array}{l}\text { Mass } \\
\text { gain }\end{array}$ & No & No signs of deterioration & A.3-12 \\
\hline 6 & PU/r & Wire & $\begin{array}{l}914 \\
932\end{array}$ & 951.4 & -0.51 & 0.2 & No & $\begin{array}{l}\text { No apparent signs of deteriormusu in spite of } \\
\text { the mass loss }\end{array}$ & A.3-13 \\
\hline 7 & PIRh & Wire & $\begin{array}{l}914 \\
932\end{array}$ & 951.4 & +1.28 & $\begin{array}{l}\text { Mass } \\
\text { gain }\end{array}$ & No & No signs of deterioration & A.3-14 \\
\hline
\end{tabular}

Flle:modartbifitcw.doc 
TABLE A.3-5

MATERIALS PERFORMANCE OF SAMPLES EXPOSED IN MTC-1 RUNS 914-933: TOTAL EXPOSURE - 979.4 HRS; SALT-GEN.FEEDS - 446 HRS

(Zone il-c, SC fluid, high $\mathrm{Cr}$, $\mathrm{T}=550$ to $560^{\circ} \mathrm{C}$ )

\begin{tabular}{|c|c|c|c|c|c|c|c|c|c|}
\hline $\begin{array}{l}\text { Item } \\
\text { No }\end{array}$ & Material & $\begin{array}{l}\text { Sample } \\
\text { Type }\end{array}$ & $\begin{array}{l}\text { Mass } \\
\text { change. } \\
\text { percent }\end{array}$ & $\begin{array}{l}\text { Âve.Corr. } \\
\text { Rate. } \\
\text { mpy }\end{array}$ & Pltting & $\begin{array}{l}\text { Crevice } \\
\text { Corrosion }\end{array}$ & $\begin{array}{l}\text { Stress } \\
\text { Corrosion } \\
\text { Cracking }\end{array}$ & Beneral Comments & $\begin{array}{l}\text { Flg. } \\
\text { No }\end{array}$ \\
\hline 1 & $\begin{array}{l}\text { Alloy } \\
625\end{array}$ & Coupon & -0.44 & 2.1 & Yes & Yes & N.A. & $\begin{array}{l}\text { Surtace is covered with scale } s 0.05 \mathrm{~mm} \text { thick which came of } \\
\text { at a number of spots; occastonal ptts up to } 0.18 \mathrm{~mm} \text { deep. up } \\
\text { to } 0.3 \mathrm{~mm} \text { dia; shallow crevice corrosion }(-0.04 \mathrm{~mm} \text { deep) on } \\
\text { one side }\end{array}$ & A.3-15 \\
\hline 2 & $\begin{array}{l}\text { Alloy } \\
625\end{array}$ & $\begin{array}{c}\text { Coupon, } \\
\text { bust-welded }\end{array}$ & -0.55 & 2.6 & Yes & Yes & No & $\begin{array}{l}\text { No scc: more extensive extollation than on the coupon above; } \\
\text { scale thickness so.5 mm: the deepest pht is } 0.2 \mathrm{~mm} \text {; some } \\
\text { corroslon in the crevice area; no difference between condition } \\
\text { of base metal and weld metal surfaces }\end{array}$ & A.3-16 \\
\hline 3 & $\begin{array}{l}\text { Alloy } \\
625\end{array}$ & U-bend & -0.3 & 0.6 & Yes & Yes & No & $\begin{array}{l}\text { No scC: most plts are shallow ( } 0.02 \text { to } 0.05 \mathrm{~mm} \text { in depth) } \\
\text { varying in diameter from } 0.1 \text { to } 1 \mathrm{~mm} \text {, they are nat-bottom phs } \\
\text { wth an appearance of spotty extollation; sorne smaller diameter } \\
\text { pits are up to } 0.15 \mathrm{~mm} \text { deep; crevice corrosion up to } 0.06 \mathrm{~mm} \\
\text { deep }\end{array}$ & A.3-17 \\
\hline 4 & $\begin{array}{l}\text { Alloy } \\
718\end{array}$ & Coupon & -0.18 & 1 & Yes & Yes & N.A. & $\begin{array}{l}\text { Some areas are extensively pltted, most phts are up to } 0.1 \mathrm{~mm} \\
\text { deep, a few up to } 0.2 \mathrm{~mm} \text { deep; crevice corrosion (up to } 0.1 \\
\mathrm{~mm} \text { deep) occurred primartly at the borehole edge }\end{array}$ & A.3-18 \\
\hline 5 & $\begin{array}{l}\text { Alloy } \\
x-750\end{array}$ & Coupon & -0.4 & 2 & Yes & Yes & N.A. & $\begin{array}{l}\text { Areas of shallow corrosion where the scale ( } 50.03 \mathrm{~mm} \text { thick) } \\
\text { came off; typlcal plts outside of exfollated areas are } 0.05 \mathrm{~mm} \\
\text { deep; shallow crevice corrosion }\end{array}$ & A.3-19 \\
\hline 6 & H9M & Coupon & 0 & 0 & Yes & Yes & N.A. & $\begin{array}{l}\text { Isolated plts and a few clusters of pits up to } 0.15 \mathrm{~mm} \text { deep: } \\
\text { shallow crevice corroslon: the metal loss due to locallzed } \\
\text { corrosion was apparently offset by mass gain due to oxidation }\end{array}$ & A.3-20 \\
\hline
\end{tabular}

Flle:modarttbimtc1.doc 
TABLE A.3-6

MATERIALS PERFORMANCE OF SAMPLES EXPOSED IN MTC-2

RUNS 924 TO 933: TOTAL EXPOSURE - 601.5 HAS; SALT-GEN.FEEDS - 344.3 HRS

(Zone I, subcritical, low $\mathrm{pH}$, high $\mathrm{Cr}$, $\mathrm{T}=295$ to $305^{\circ} \mathrm{C}$ )

\begin{tabular}{|c|c|c|c|c|c|c|c|c|}
\hline $\begin{array}{l}\text { Item } \\
\text { No }\end{array}$ & Materlal & $\begin{array}{l}\text { Sample } \\
\text { Descript. n }\end{array}$ & $\begin{array}{l}\text { Mass } \\
\text { Change. } \\
\text { percent }\end{array}$ & Pitting & $\begin{array}{l}\text { Crevice } \\
\text { Corrosion }\end{array}$ & $\begin{array}{l}\text { Stress } \\
\text { Corrosion } \\
\text { Cracking }\end{array}$ & General Comments & $\begin{array}{l}\text { Flg. } \\
\text { No }\end{array}$ \\
\hline 1 & $\begin{array}{l}\text { Alloy } \\
625\end{array}$ & $\begin{array}{l}\text { Welded } \\
\text { U-bend., } \\
\text { no PWHT", }\end{array}$ & -37.3 & Yes & Yes & Yes & $\begin{array}{l}\text { Completely separated due to SCC in the bend area and at one of the lugs: } \\
\text { severe corrosion on all surfaces }\end{array}$ & A.3-21 \\
\hline 2 & $\begin{array}{l}\text { Alloy } \\
625\end{array}$ & $\begin{array}{l}\text { Welded } \\
\text { U-bend, } \\
\text { postweld } \\
\text { annealed } \\
\text { at } 2025^{\circ} \mathrm{F}\end{array}$ & -30.4 & Yes & Yes & Yes & Completely separated in the bend area; severe corroston on all surtaces & A.3-22 \\
\hline 3 & $\begin{array}{l}C 276 / \\
625 / \\
C 276\end{array}$ & $\begin{array}{l}\text { C-276 tubes } \\
\text { butt-weided } \\
\text { wth } 625, \\
\text { as-welded }\end{array}$ & -9.5 & Yes & Yes & Yes & $\begin{array}{l}\text { No SCC in C-276 tubes and weld O.D. surface, however, SCC has apparently } \\
\text { started at the root of Alloy } 625 \text { weld: moderate pltting on C-276 tubes, the } \\
\text { deepest pt }-0.25 \mathrm{~mm} \text { deep; slgns of inclplent crevice corrosion }\end{array}$ & A.3-23 \\
\hline 4 & $\begin{array}{l}\text { C276/ } \\
625 / \\
\text { C276 }\end{array}$ & $\begin{array}{l}\text { C-276 tubes } \\
\text { butt-welded } \\
\text { with } 625 \text {, } \\
\text { postweld } \\
\text { annealed } \\
\text { at } 2025^{\circ} \mathrm{F} \\
\end{array}$ & -8 & Yes & Yes & No & $\begin{array}{l}\text { No SCC; severe corrosion of Alloy } 625 \text { weld; small shallow plts on C-276 tubes } \\
\text { (typical phts - } 0.01 \mathrm{~mm} \text { deep. the deepest pit - } 0.06 \mathrm{~mm} \text { deep); minor crevice } \\
\text { corrosion }\end{array}$ & A.3-24 \\
\hline 5 & $625 / 625$ & $\begin{array}{l}\text { Socket weld. } \\
\text { as-welded }\end{array}$ & -14.1 & Yes & Yes & No & $\begin{array}{l}\text { No SCC; severe corrosion of both base and weld metal, primarlly on the O.D. } \\
\text { surface: corrosion on the } 1.0 \text {. surface is less pronounced, probably because } \\
\text { of orlentation of the sample to the flow direction; some crevice corrosion }\end{array}$ & A.3-25 \\
\hline 6 & $625 / 625$ & $\begin{array}{l}\text { Socket weld. } \\
\text { postweld } \\
\text { annealed } \\
\text { at } 2025^{\circ} \mathrm{F}\end{array}$ & -7.4 & Yes & Yes & No & $\begin{array}{l}\text { No SCC: severe corrosion of both base and weld metal, primarly on the O.D. } \\
\text { surface: corrosion on the I.D. surface is less pronounced, probably because } \\
\text { of orlentation of the sample to the flow direction;crevice corrosion near the } \\
\text { I.D. surface }\end{array}$ & A.3-25 \\
\hline 7 & $\begin{array}{c}\text { Titanlum } \\
\text { Gr.2 }\end{array}$ & $\begin{array}{l}\text { Welded } \\
\text { U-bend. } \\
\text { as-welded }\end{array}$ & 0 & No & No & No & $\begin{array}{l}\text { No SCC: no apparent corrosion: readlly removable brown deposit on one of } \\
\text { the legs came from elther an adjacent sample or the holder (no chemical } \\
\text { analysls of the deposit has been pertormed); thanium surface under the } \\
\text { deposit is completely unaffected }\end{array}$ & A.3-27 \\
\hline
\end{tabular}

-) PWHT - postweld heat treatment. 
TABLE A.3-7

\section{MATERIALS PERFORMANCE OF SAMPLES EXPOSED IN MTC-2}

(Zone I, suberitical, low pH, high Cl, T=295 to $305^{\circ} \mathrm{C}$ )

\begin{tabular}{|c|c|c|c|c|c|c|c|c|c|c|}
\hline $\begin{array}{l}\text { Item } \\
\text { No }\end{array}$ & Material & $\begin{array}{l}\text { Sample } \\
\text { Type }\end{array}$ & Runs & $\begin{array}{l}\text { Exposure. } \\
\text { hours }\end{array}$ & $\begin{array}{c}\text { Mass } \\
\text { Change. } \\
\text { percent }\end{array}$ & $\begin{array}{c}\text { Ave.Corr. } \\
\text { Rate. } \\
\text { mpy } \\
\end{array}$ & Pritting & $\begin{array}{l}\text { Crevice } \\
\text { Corrosion }\end{array}$ & General Comments & $\begin{array}{l}\text { Fig. } \\
\text { No }\end{array}$ \\
\hline 1 & $\begin{array}{c}\text { Alloy } \\
20 \mathrm{Cb}-3\end{array}$ & Coupon & $\begin{array}{l}914- \\
922\end{array}$ & 373.9 & -26.4 & 391 & Yes & Yes & $\begin{array}{l}\text { Extensive corrosion on all surfaces; the crevtce area has been } \\
\text { less affected than boldty exposed surtaces }\end{array}$ & A.3-28 \\
\hline 2 & H9M & Coupon & $\begin{array}{l}914 \\
922\end{array}$ & 373.9 & -40.5 & 301 & Yes & Yes & $\begin{array}{l}\text { Very severe loss of metal; a part of the coupon became paper- } \\
\text { thin and was pertorated; the crevice area has been signilicanty } \\
\text { less affected }\end{array}$ & A.3-29 \\
\hline 3 & $\underset{\text { Gr.12 }}{\text { Thtanlum }}$ & Coupon & $914-$ & 377.9 & +0.05 & $\begin{array}{l}\text { Mass } \\
\text { galn }\end{array}$ & No & No & $\begin{array}{l}\text { No discernible corrosion attack; the oxide film appears to be } \\
\text { thintly adherent }\end{array}$ & A.3-30 \\
\hline
\end{tabular}

Flle:modar|tmimtc2.doc 


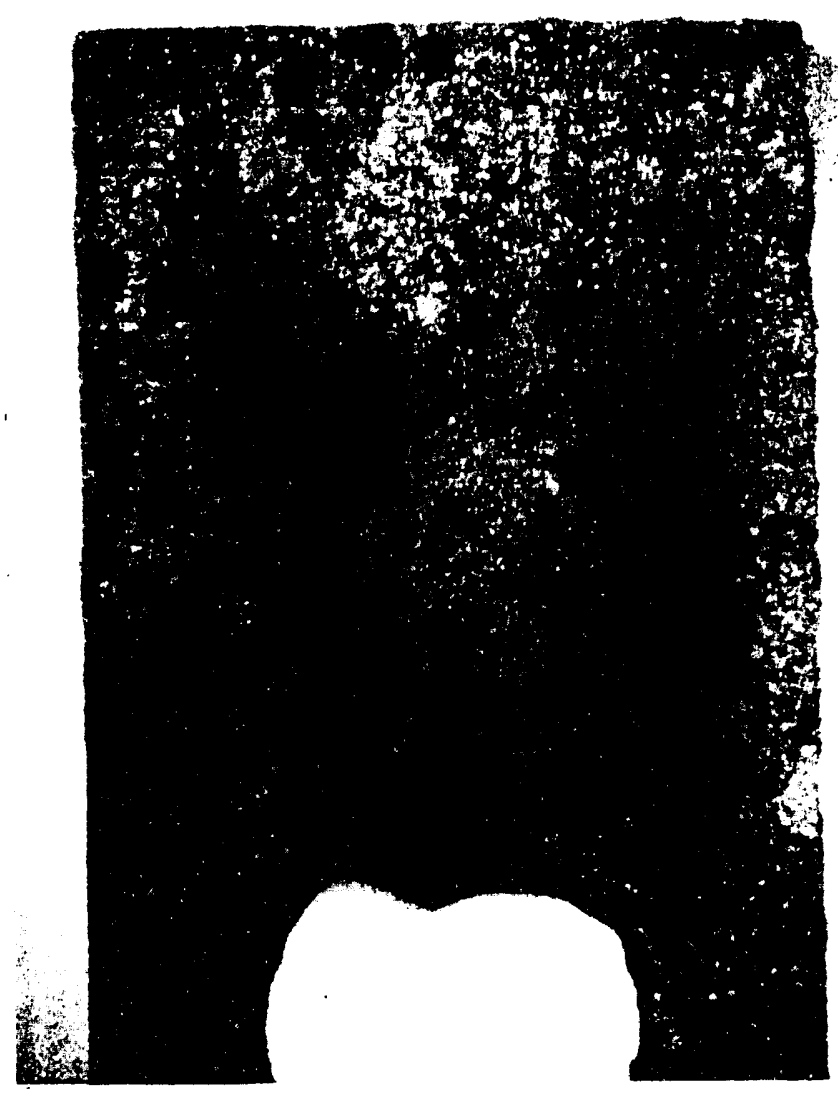

a

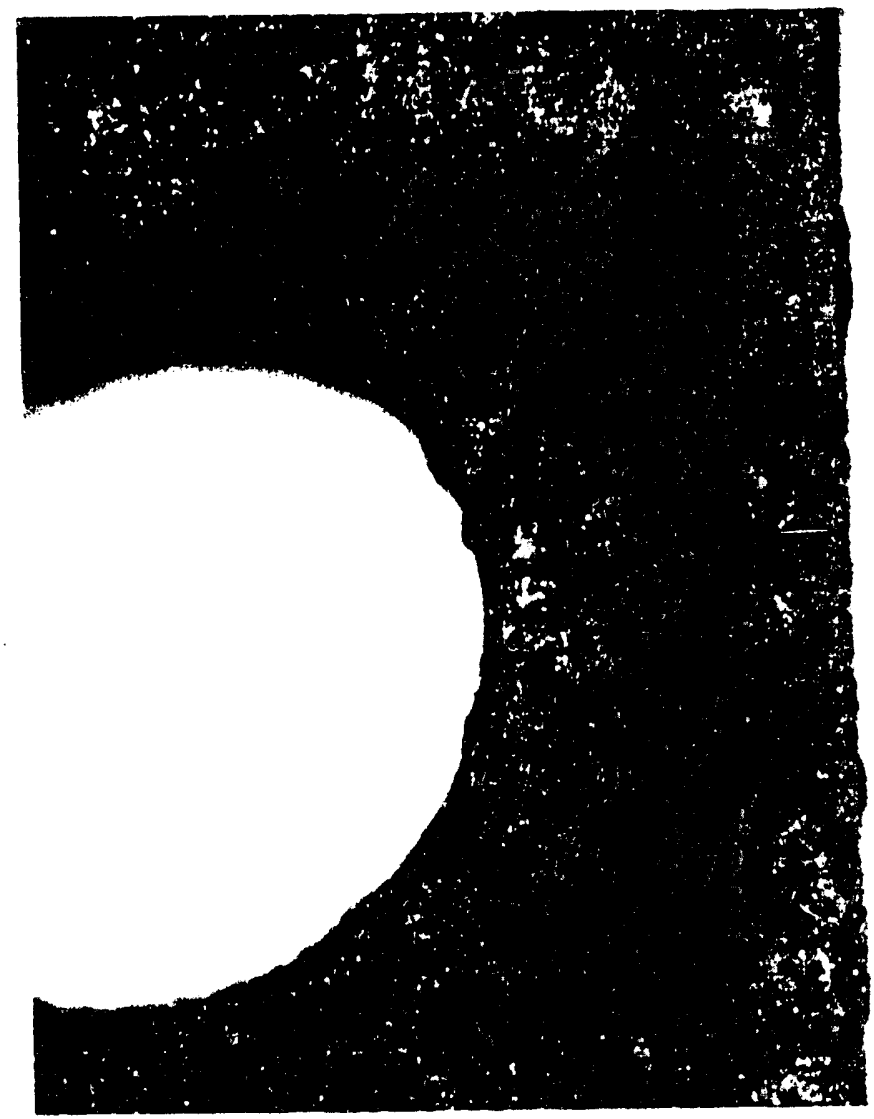

b

FIGURE A.3-1

ALLOY 625 COUPON FROM FILTER A

Magnification: a-4X; b-8X

File:modarlfig5741.doc 


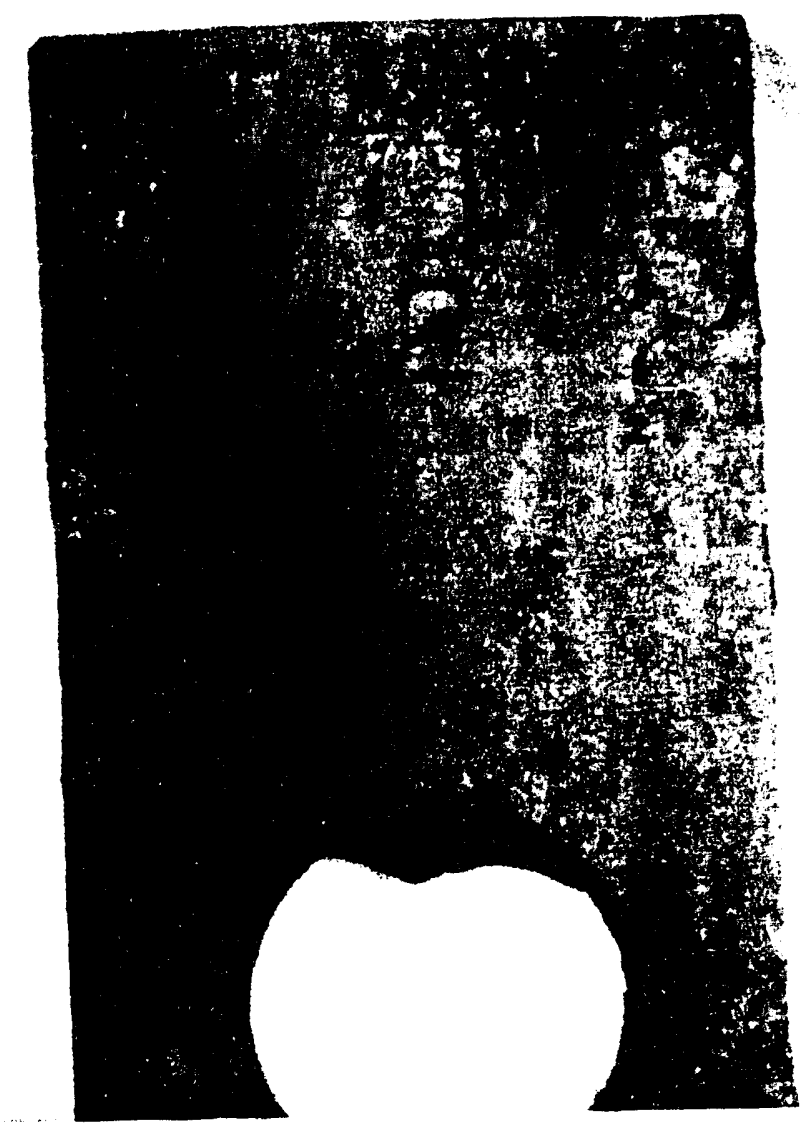

a

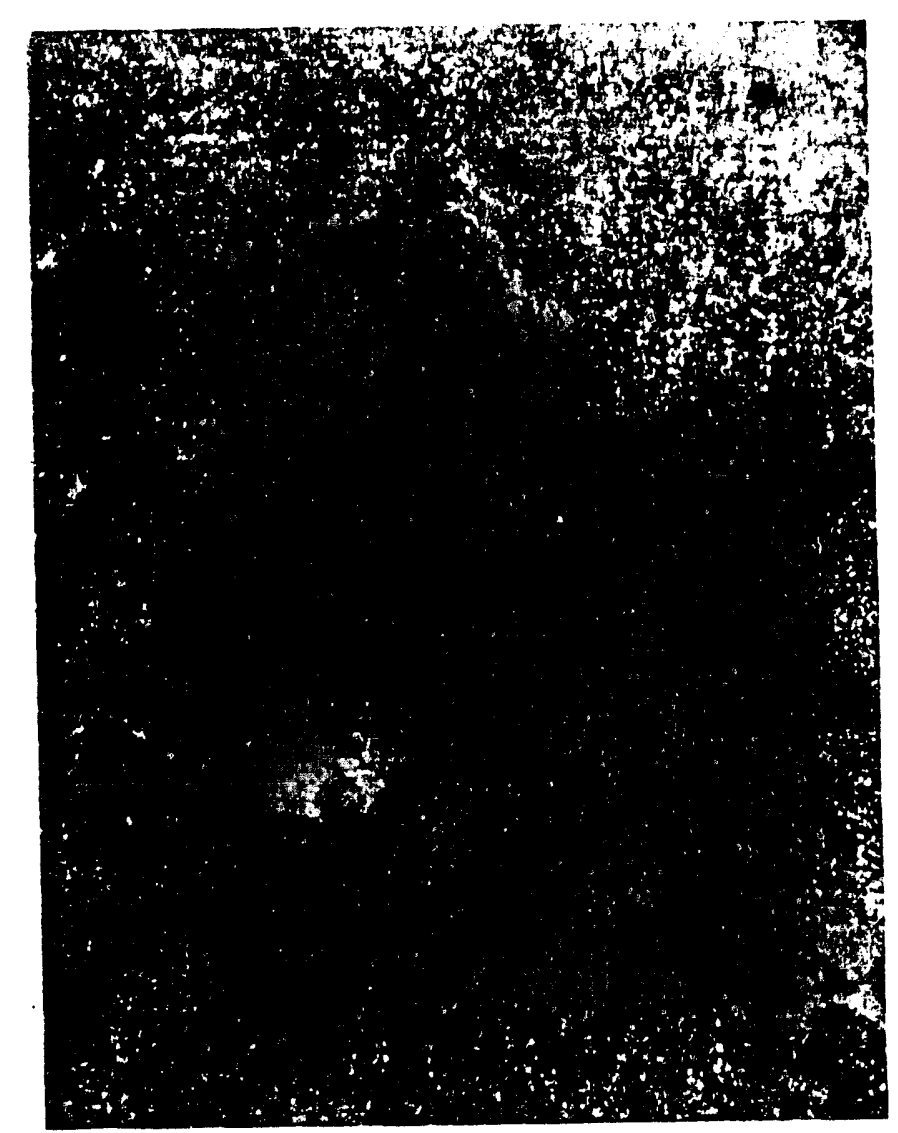

b

FIGURE A.3-2

ALLOY 718 COUPON FROM FILTER A

Magnification: a-4X; b-8X 


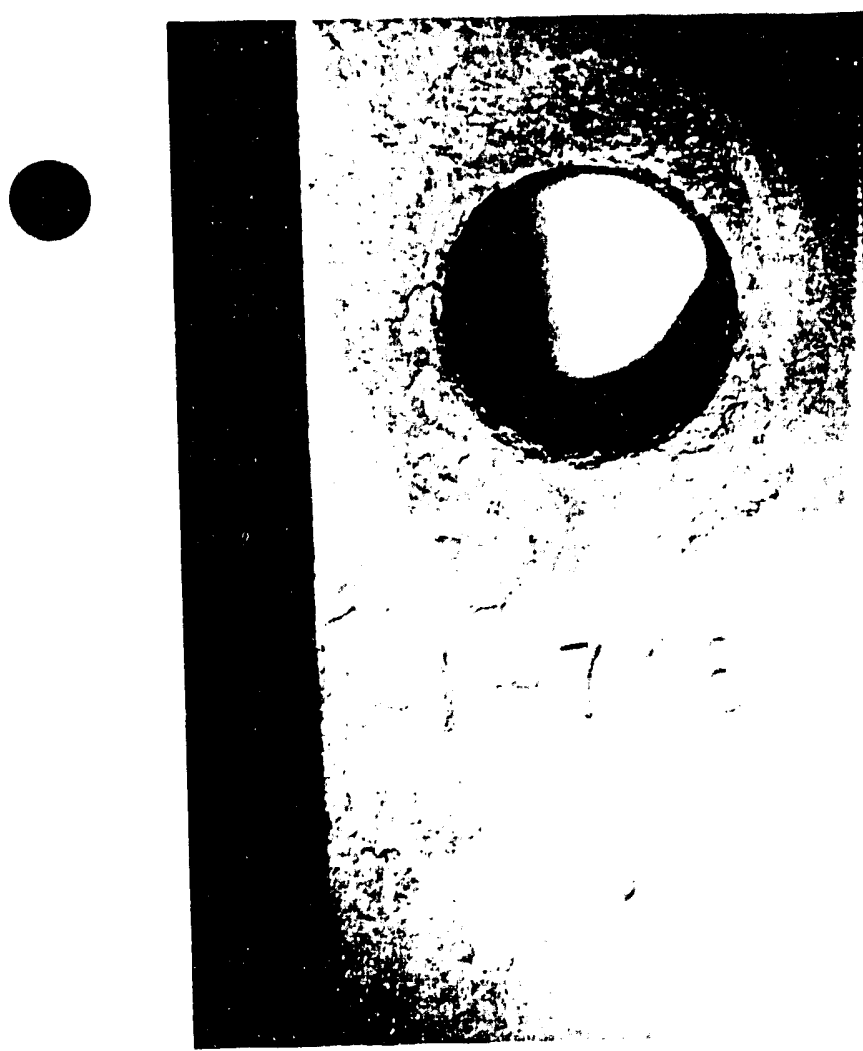

a

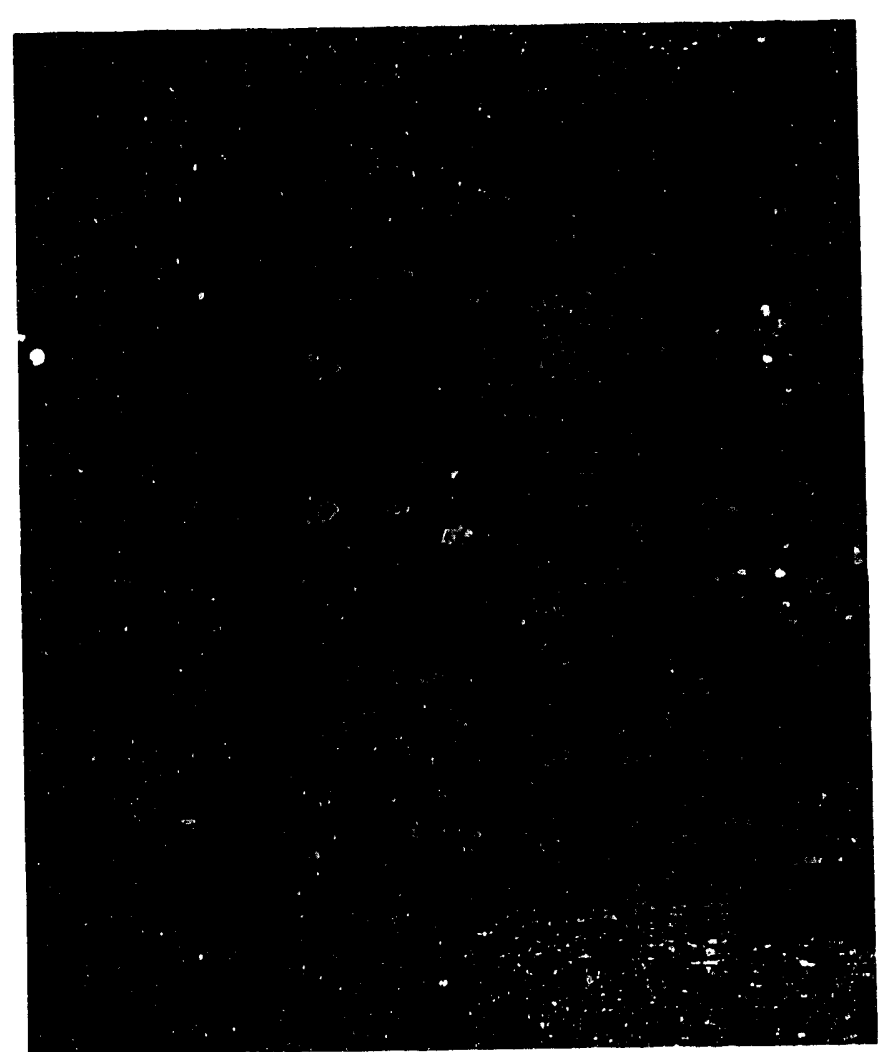

C

FIGURE A.3-3

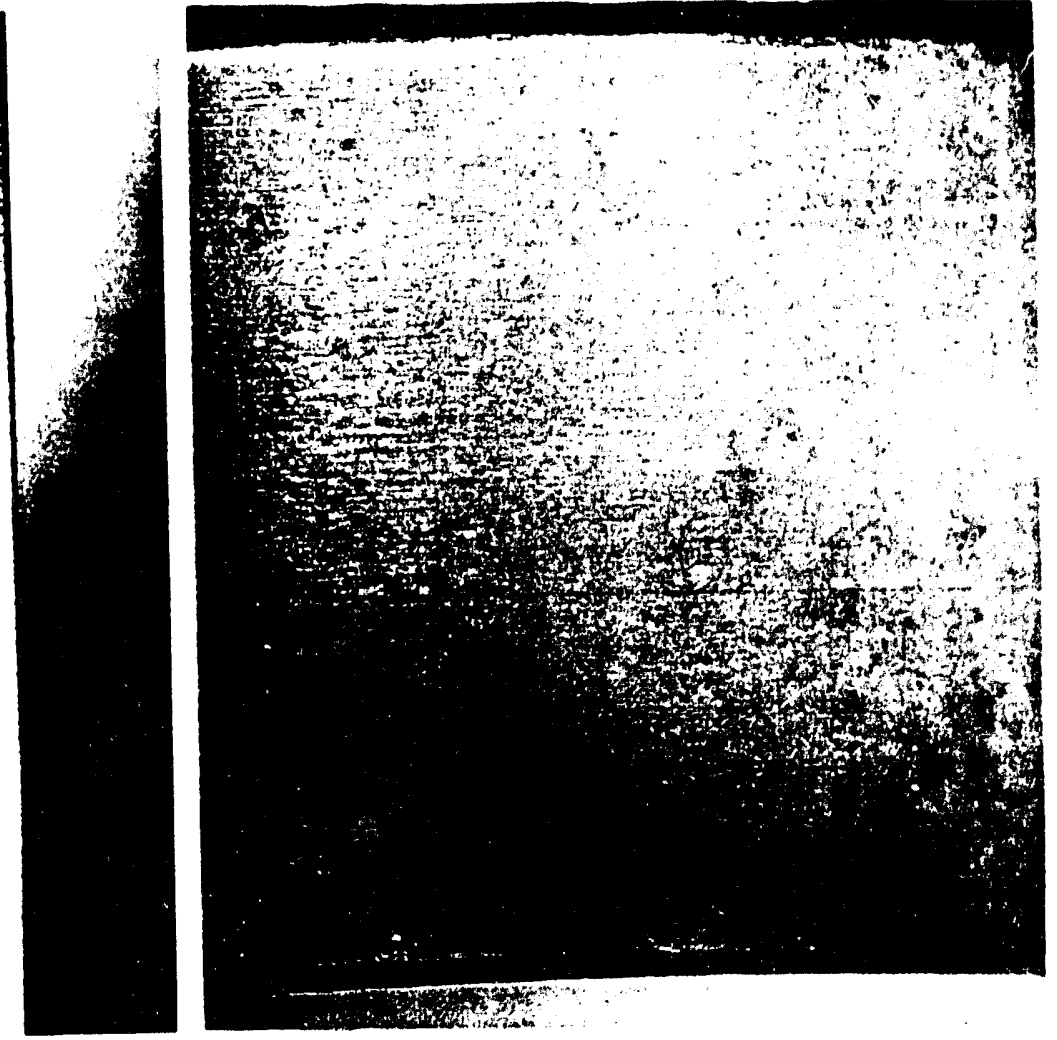

b

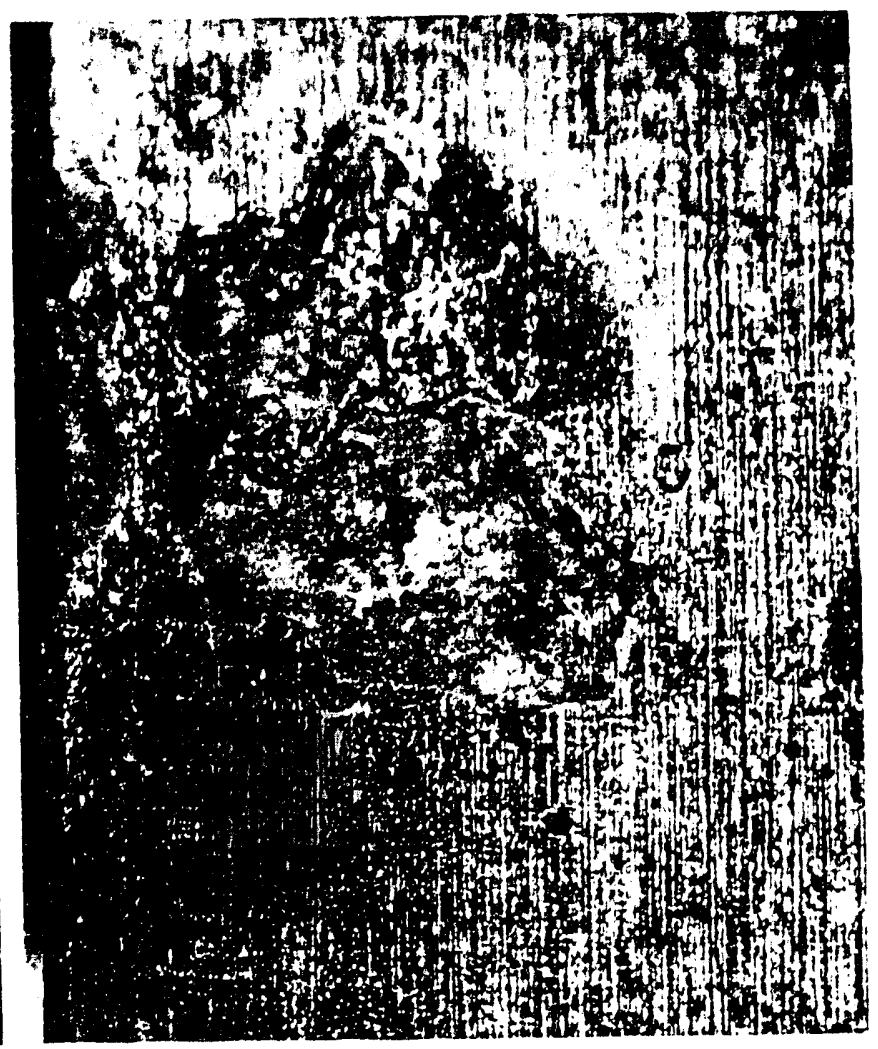

d

\section{ALLOY 718 U-BEND FROM FILTER A}

a - in and near a washer-shielded area, 3X; $b$ - top of the bend, $5 X$

$c$ - pitting on the inside surface of the bend, $10 X$

d - corrosion in boldly exposed area, 10X 


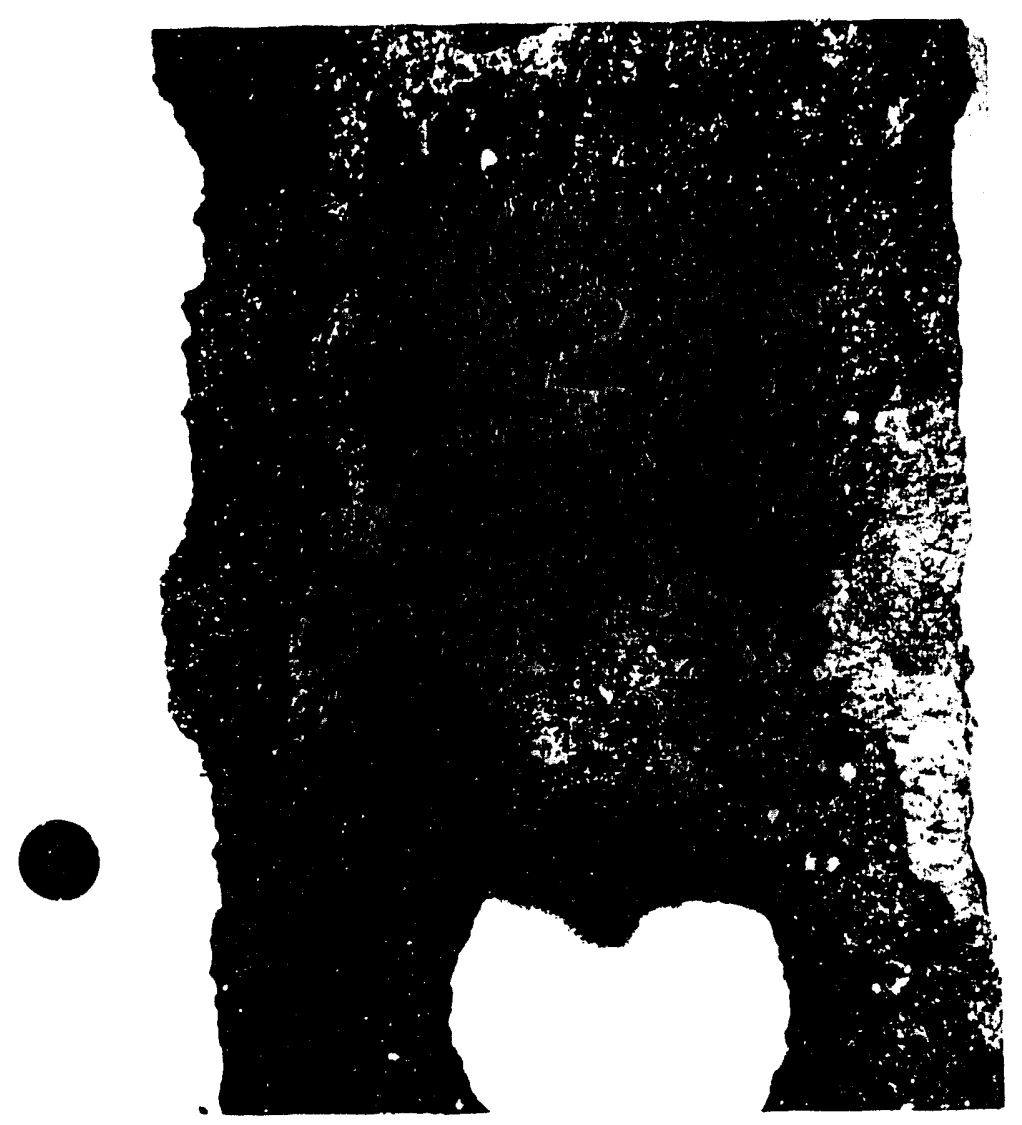

a

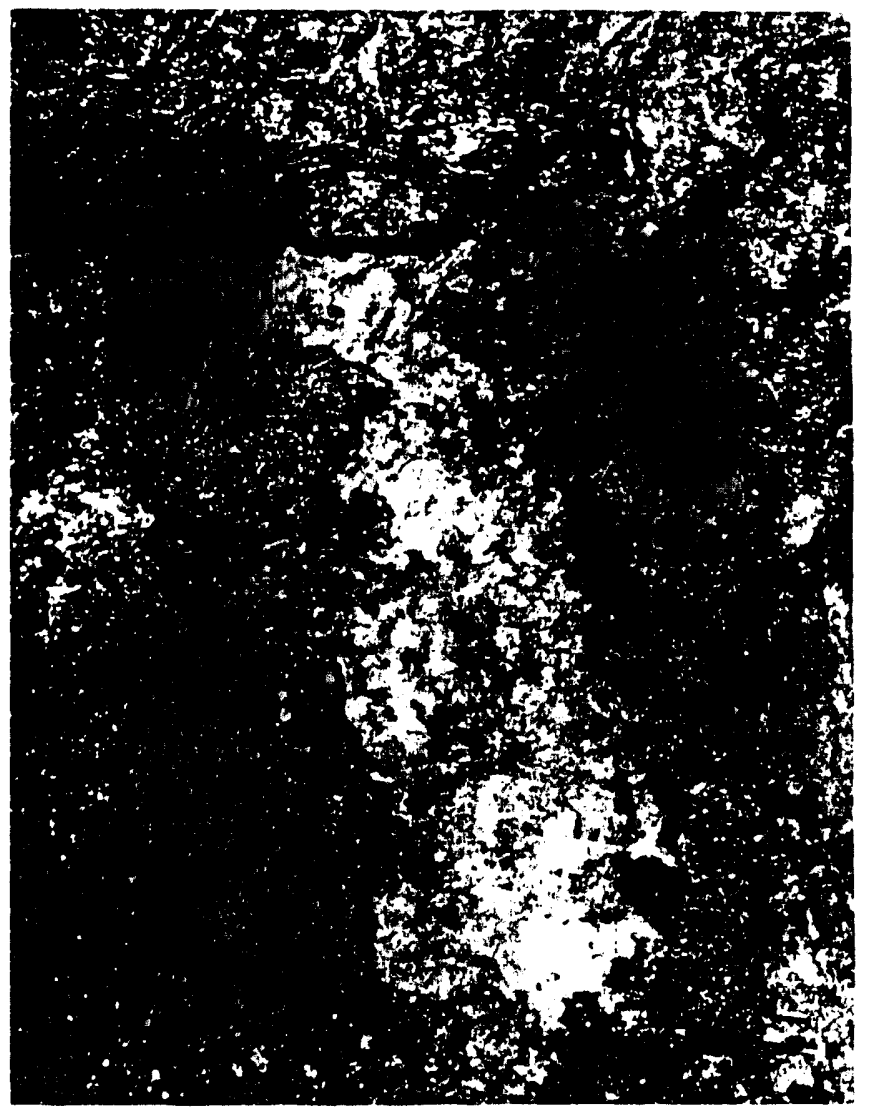

b

FIGURE A.3-4

ALLOY 750 COUPON FROM FILTER A

Magnification: a-4X; b-8X

File:modarifig5744.doc 


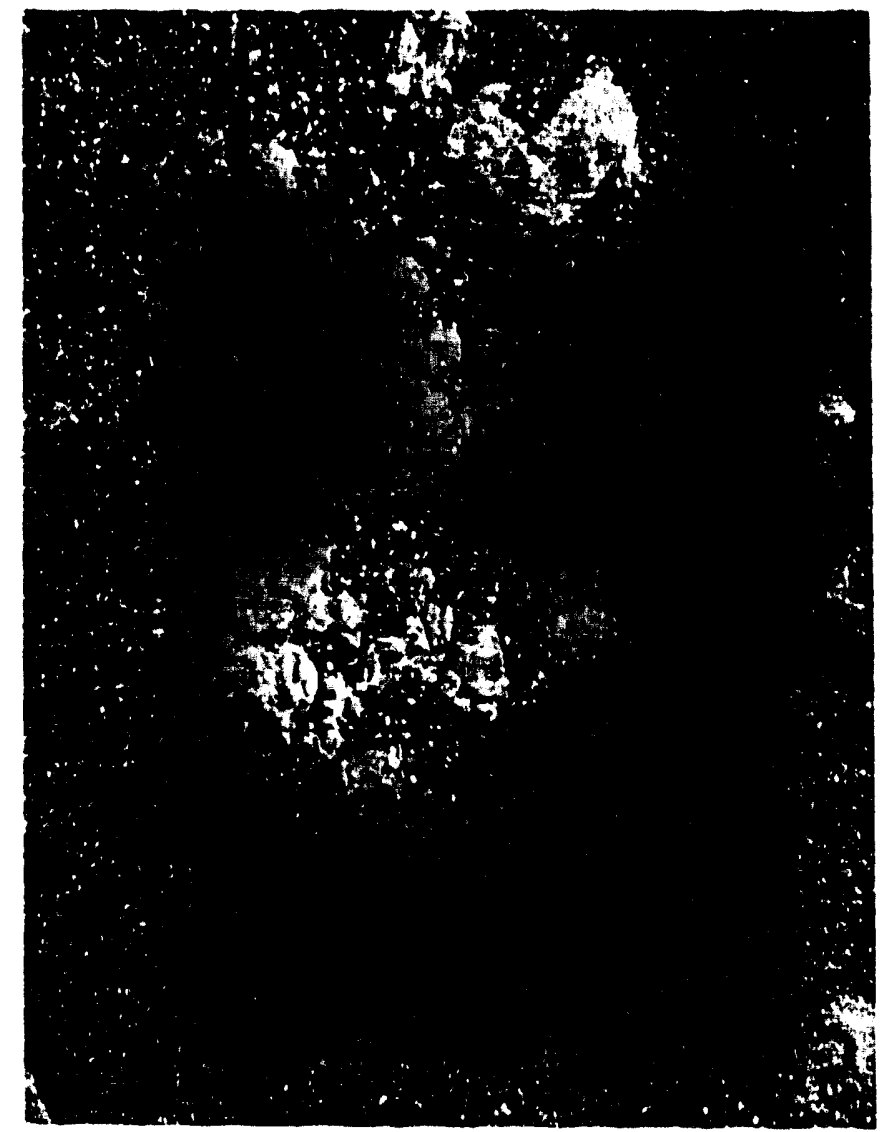

FIGURE A.3-5

ALLOY AX COUPON FROM FILTER A

\author{
Magniflcation: 19X
}




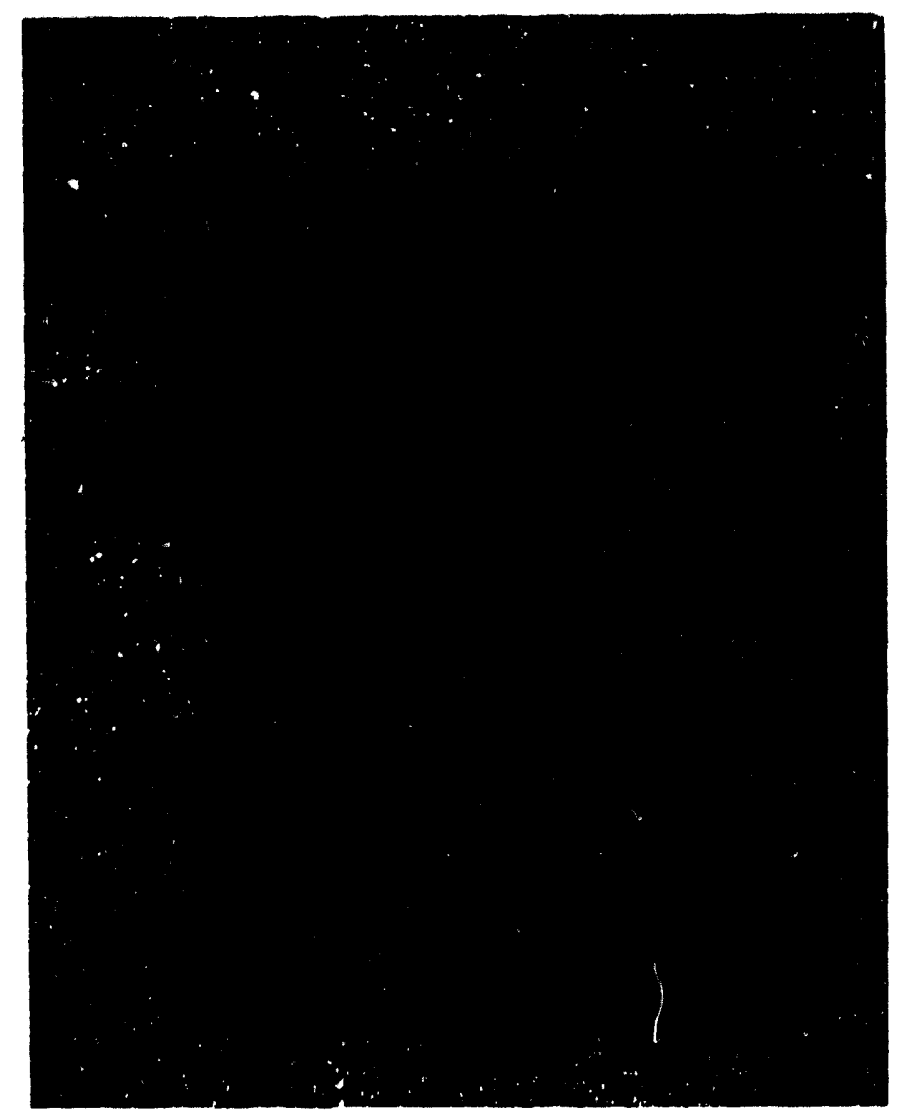

FIGURE A.3-6

ALLOY BX COUPON FROM FILTER A

Magnification: 19X 


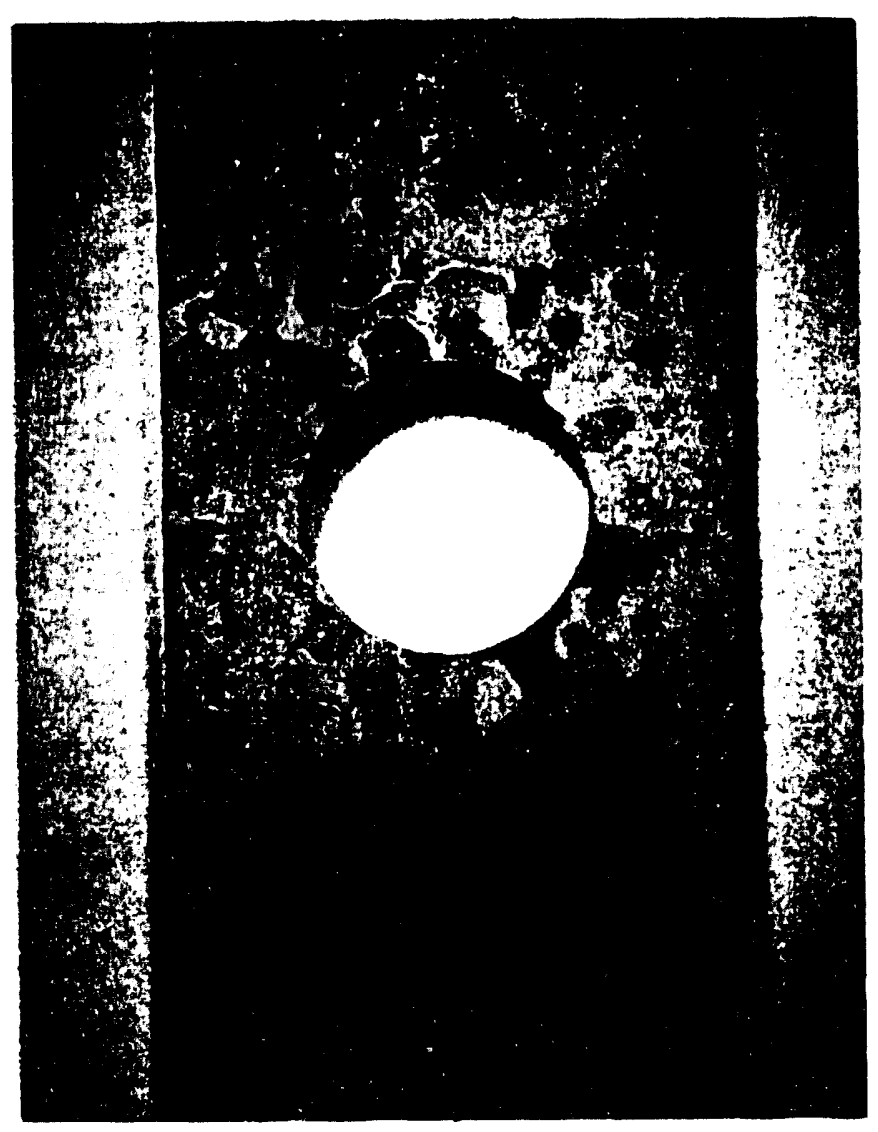

a

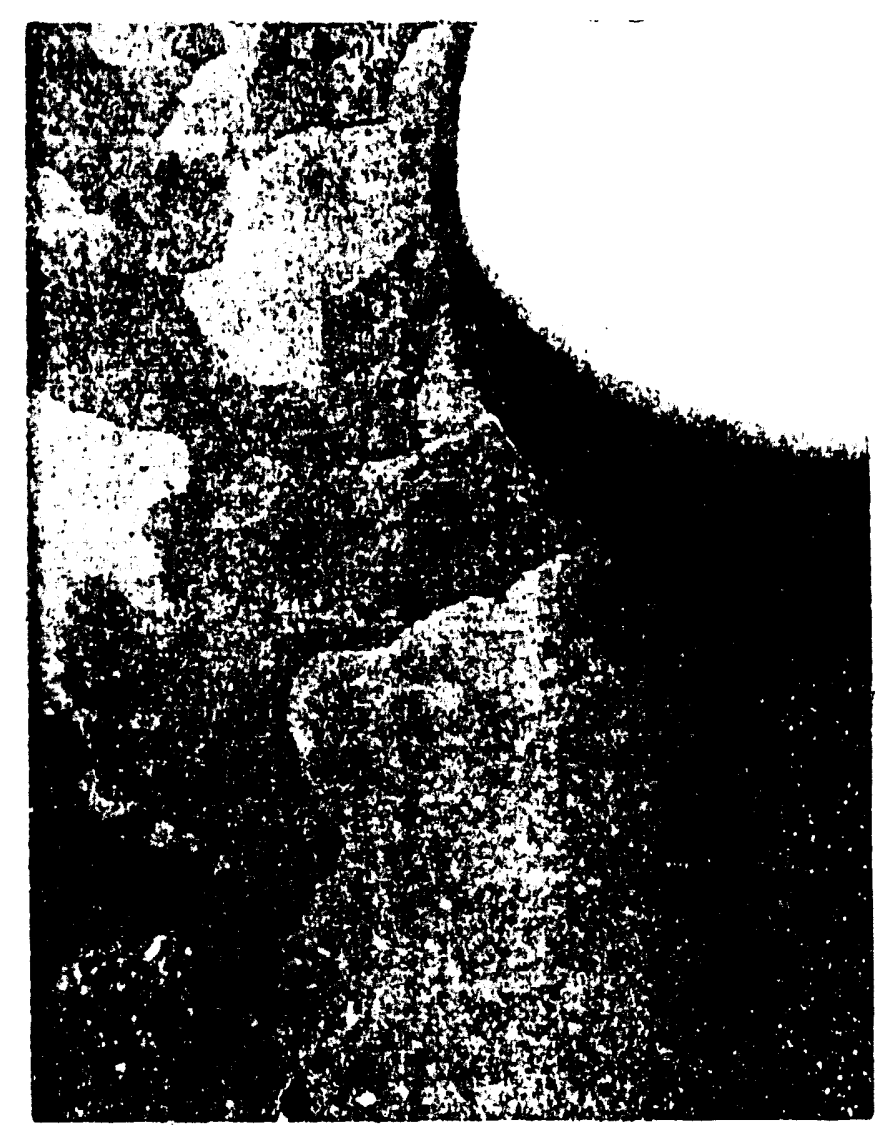

b

FIGURE A.3-7

ALLOY CX COUPON FROM FILTER A

Magnification: $a-3 X ; b-10 X$ 


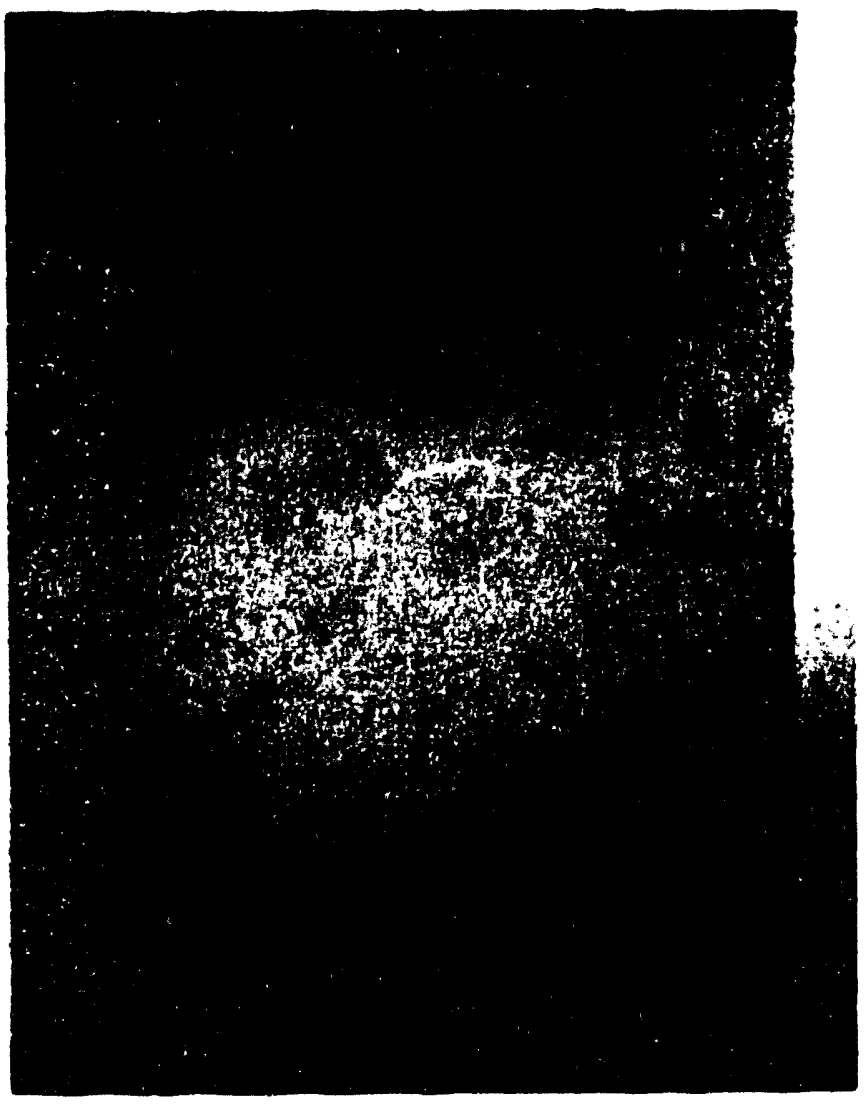

a

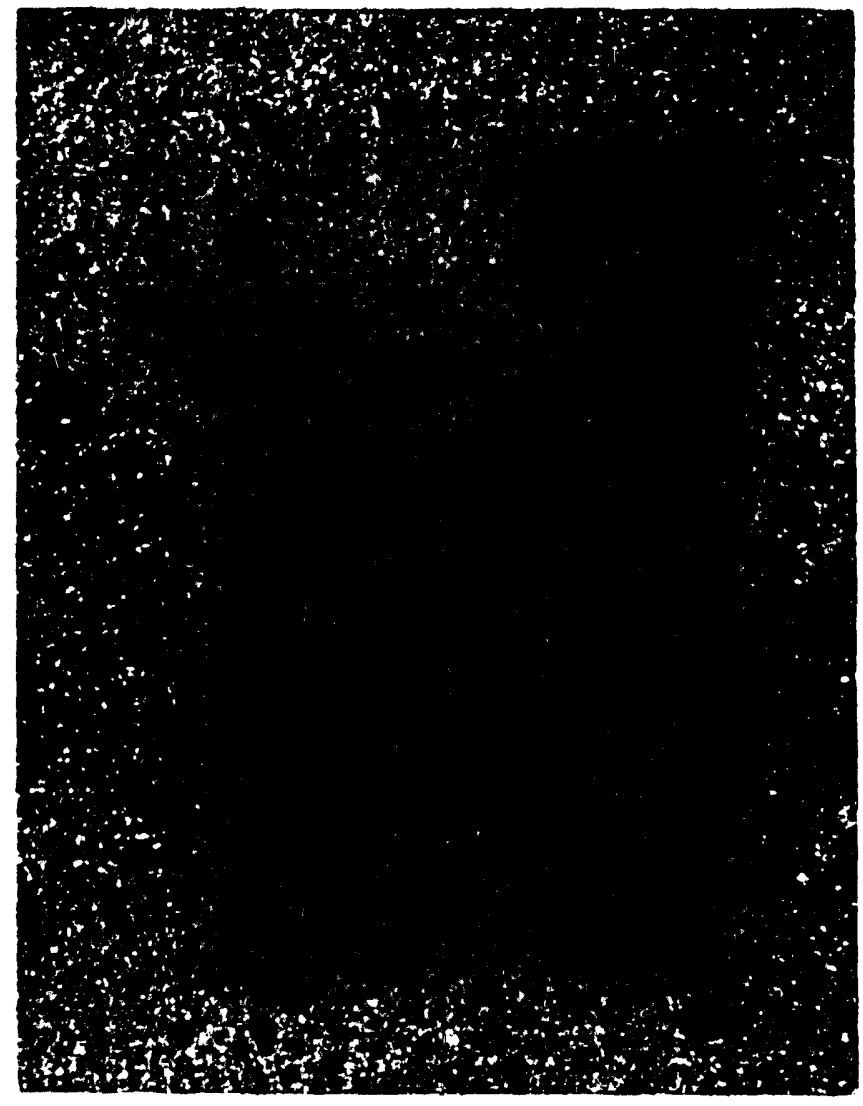

b

FIGURE A.3-8

CERAMIC A IN SHEET FORM FROM FILTER A

Magnification: $a-7 X ; b-38 X$ 


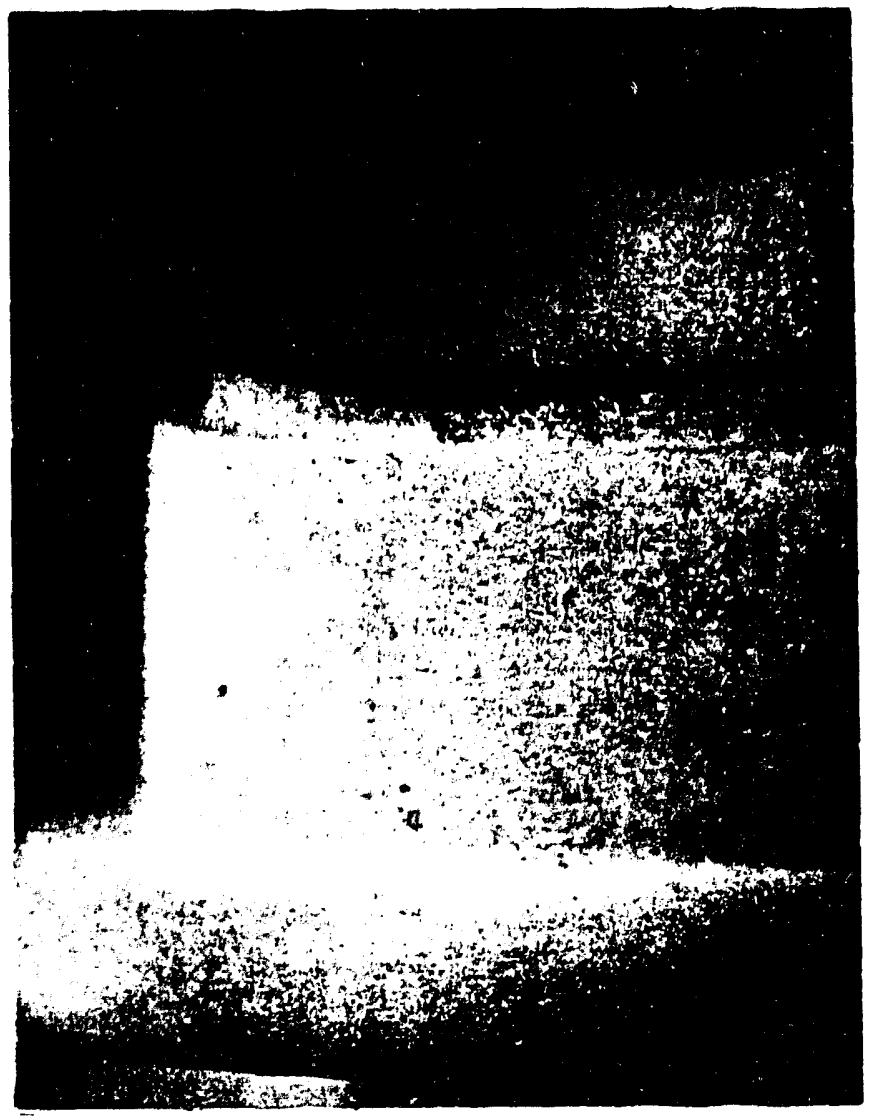

a

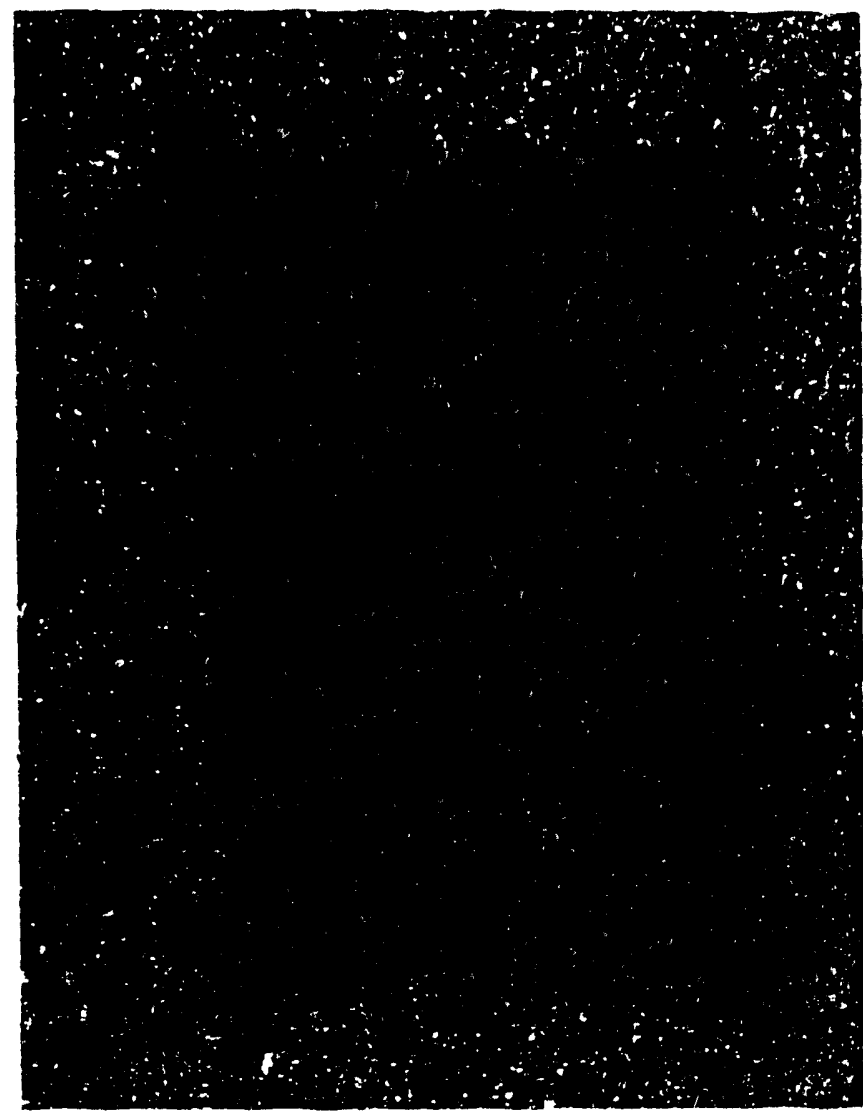

b

FIGURE A.3-9

CERAMIC B FROM FILTER A

Magnification: $a-7 X ; b-38 X$

File:modarlfig5 749.doc 


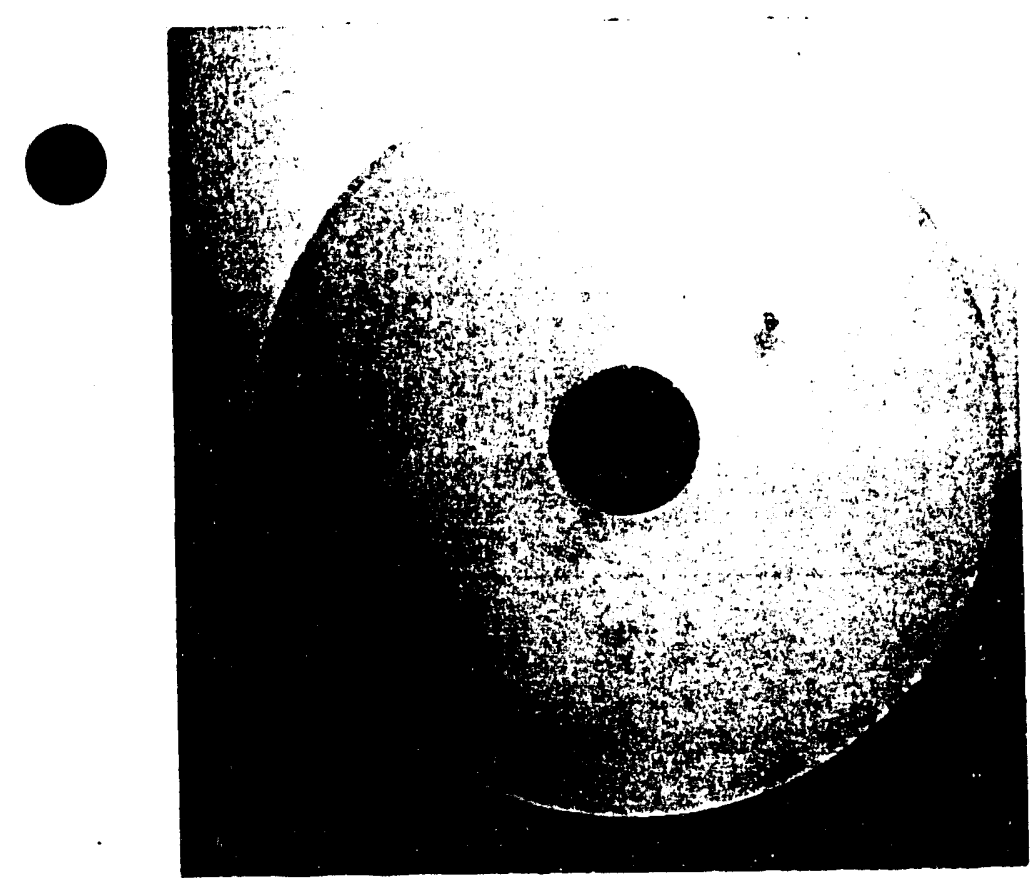

a

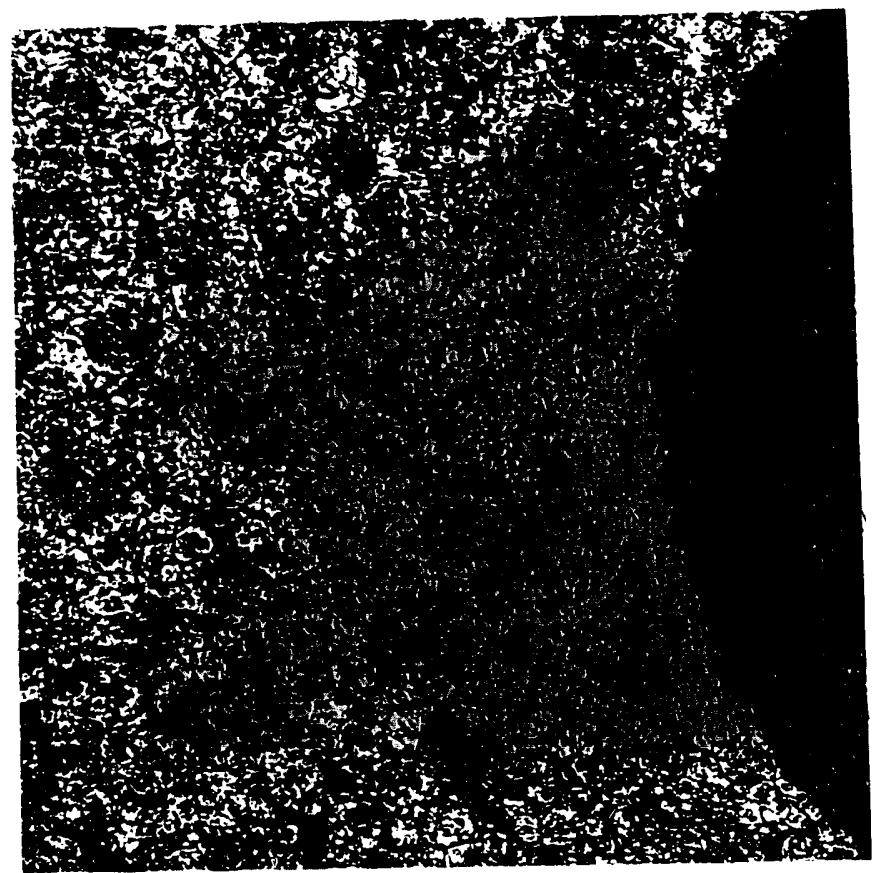

C

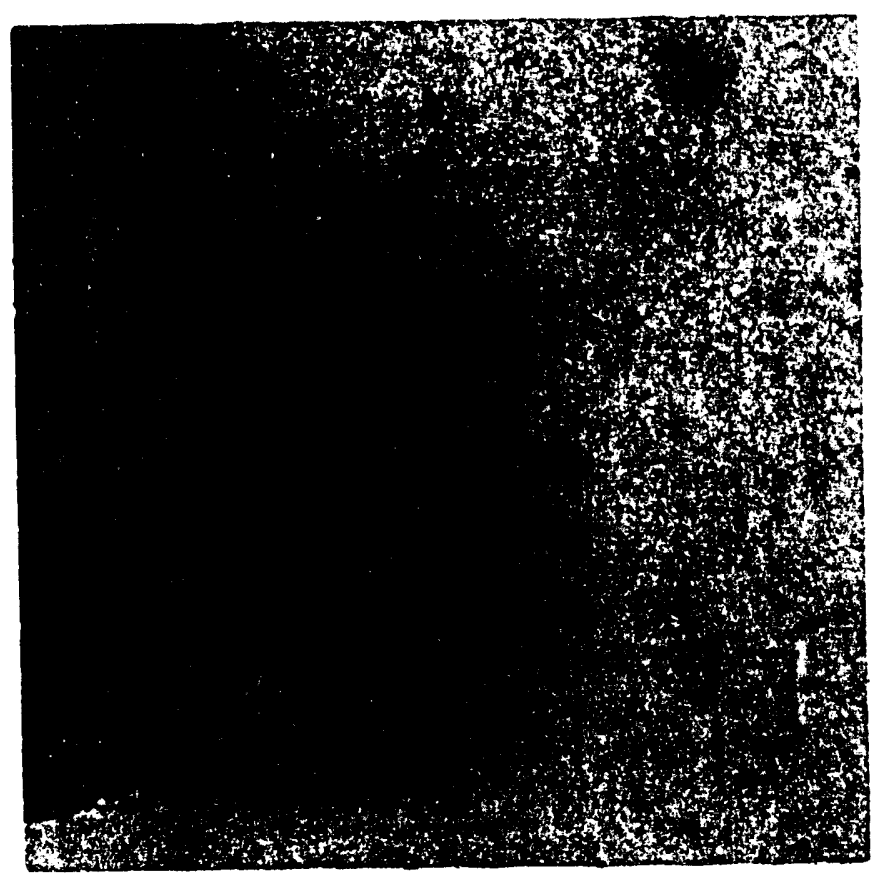

b

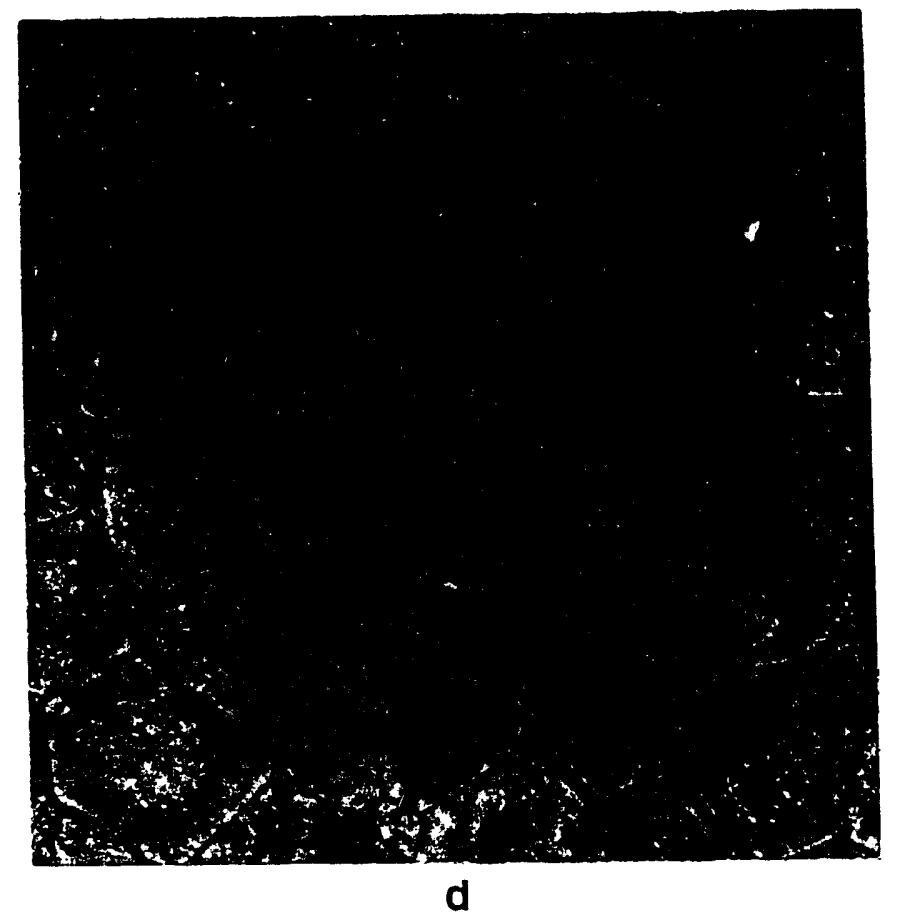

FIGURE A.3-10

CERAMIC C FROM FILTER A

Magnification: $a-7 X ; b-38 X$ (Stereomicroscope)

Magnification: c-50X; d-200X (As-is surface in a metallograph)

File:modarlfig5749.doc 


\begin{tabular}{|c|c|c|c|c|c|c|c|}
\hline 焉 & 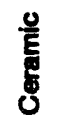 & 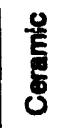 & 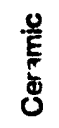 & 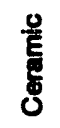 & $\Sigma$ & 흘 & $\frac{\sqrt{5}}{\frac{5}{2}}$ \\
\hline$\underline{\underline{\underline{\varepsilon}}}$ 울 & - & N & $\infty$ & + & n & 0 & r \\
\hline
\end{tabular}

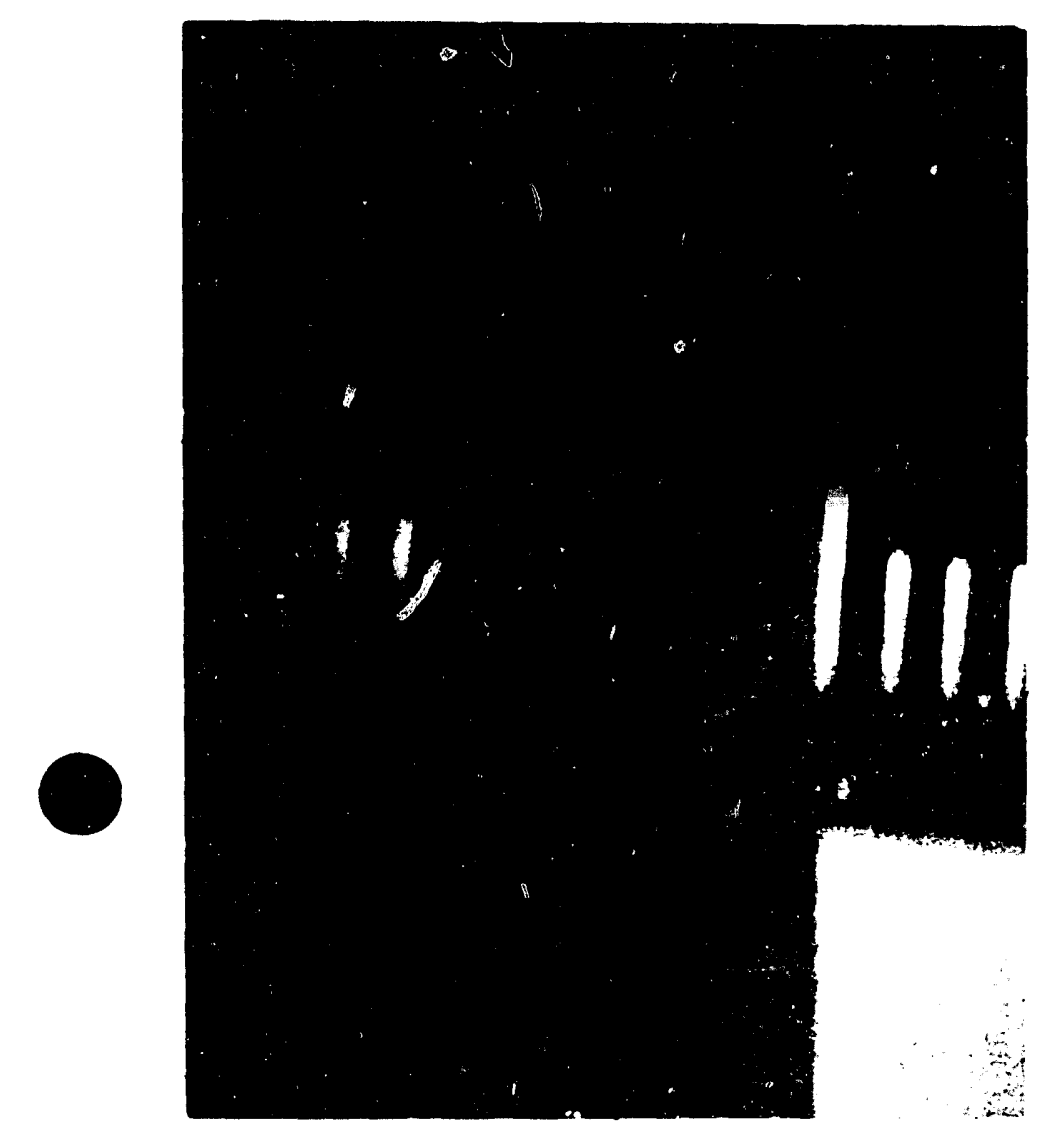

a

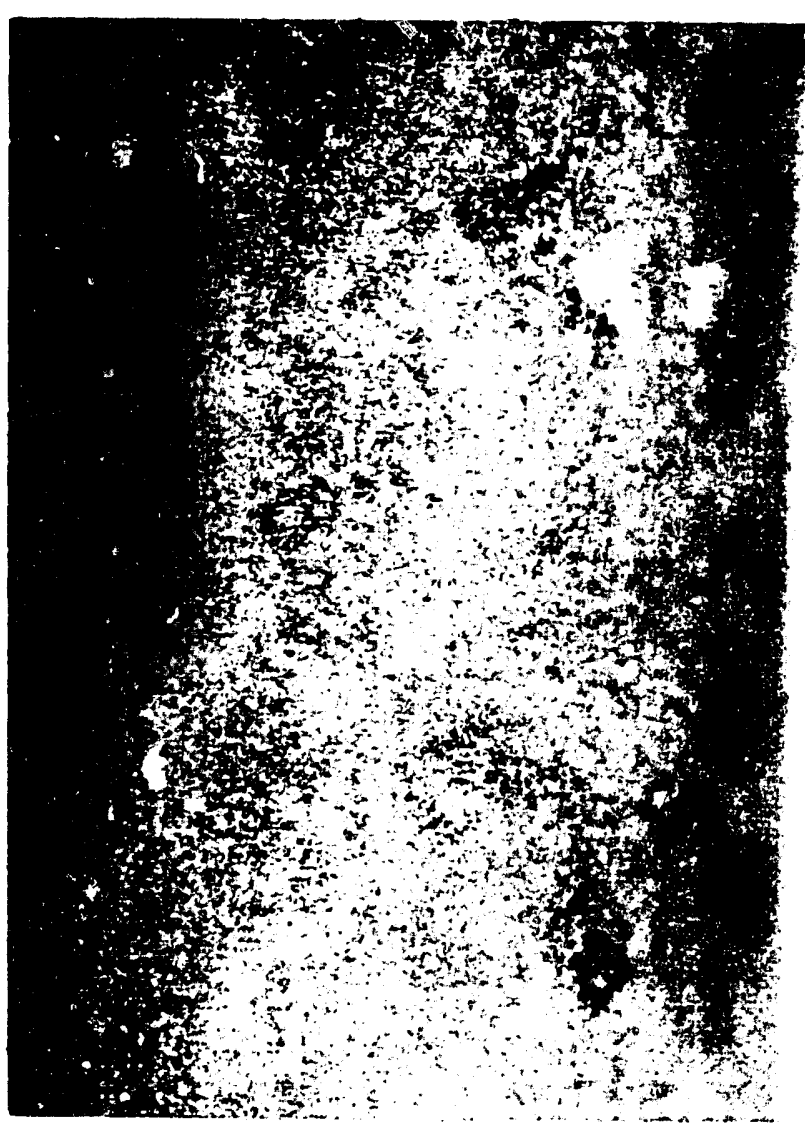

b

FIGURE A.3-11

CERAMIC D FROM FILTER A

Magnification: a-7X; b-15X 


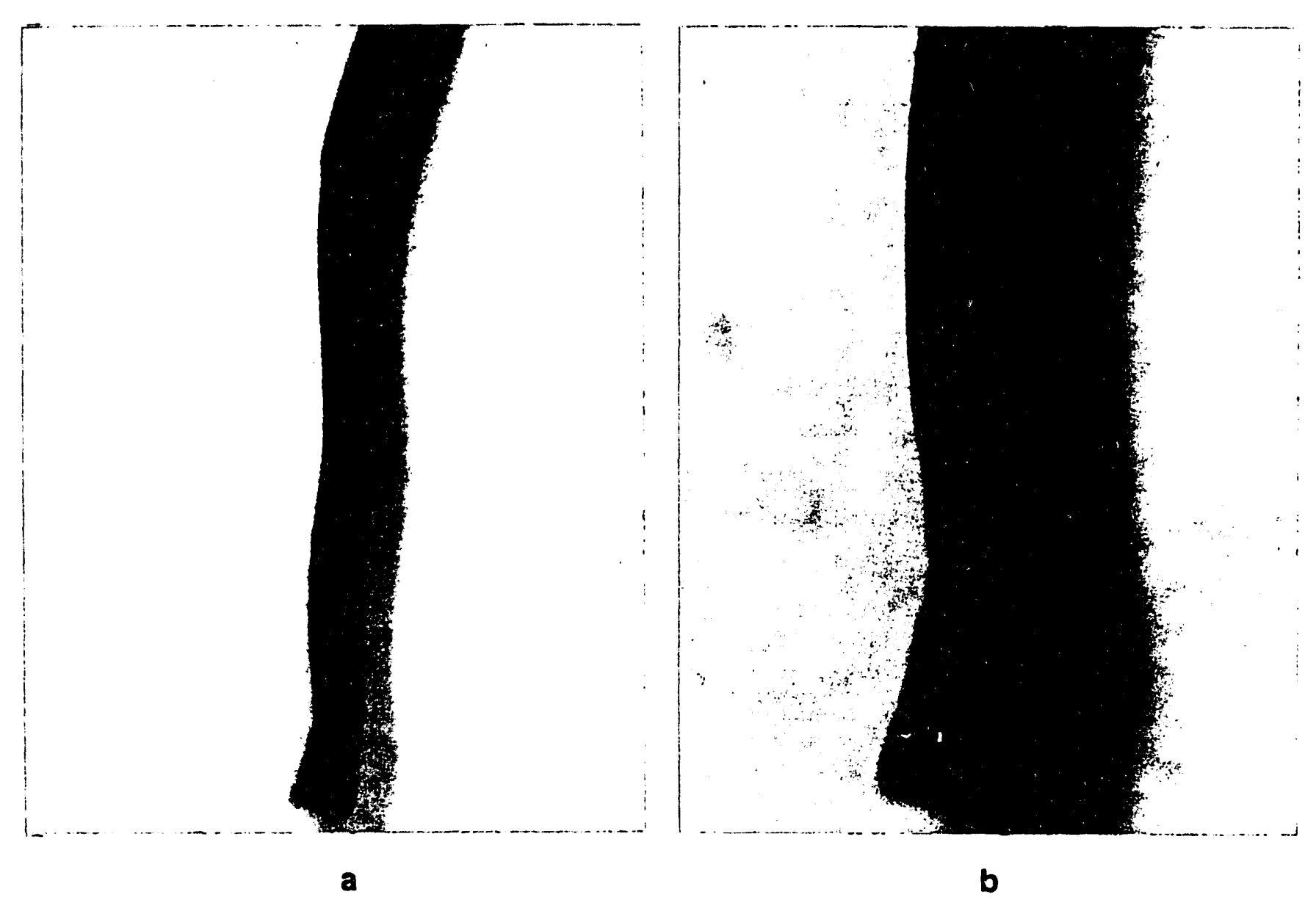

FIGURE A.3-12

PLATINUM WIRE FROM FILTER A

Magnification: a-15X; b-38X

File:modar|fig574112.doc 


$$
1]
$$




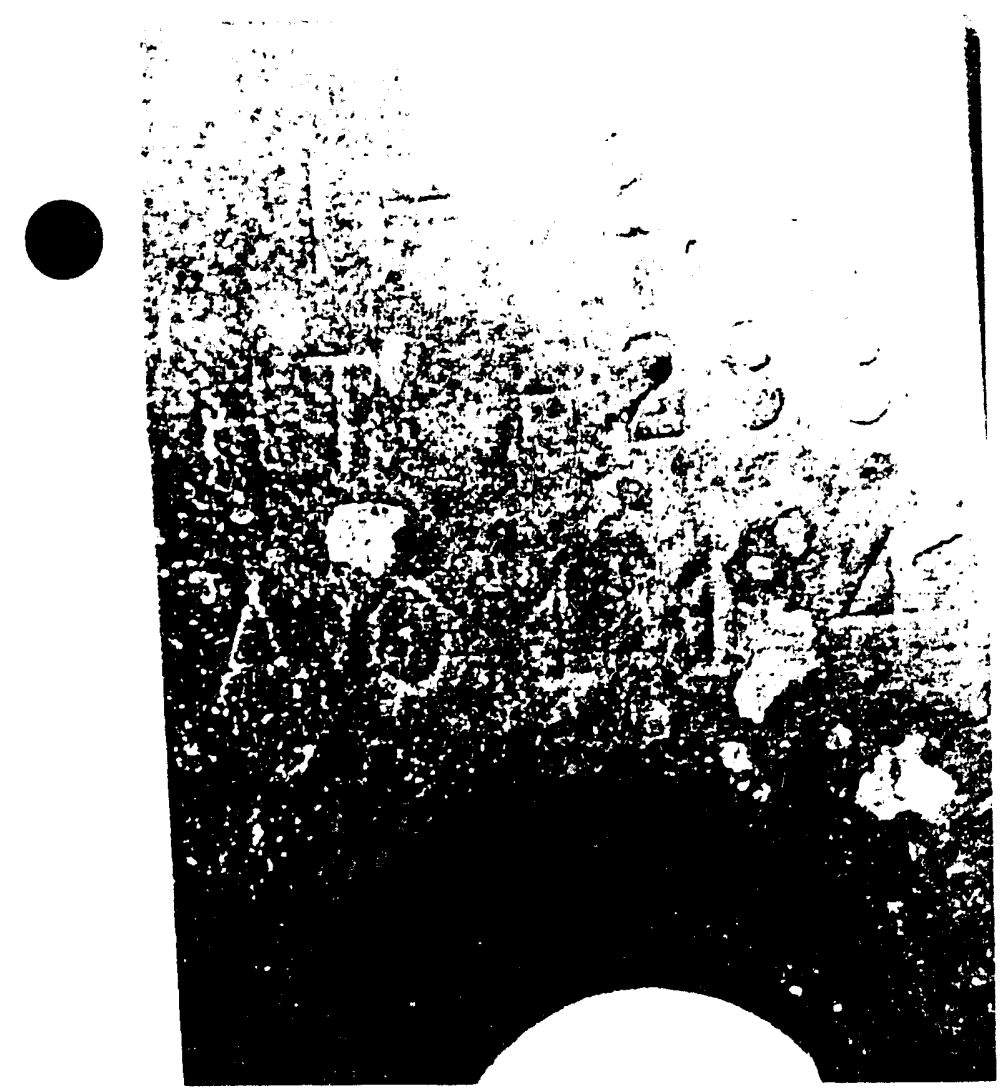

a
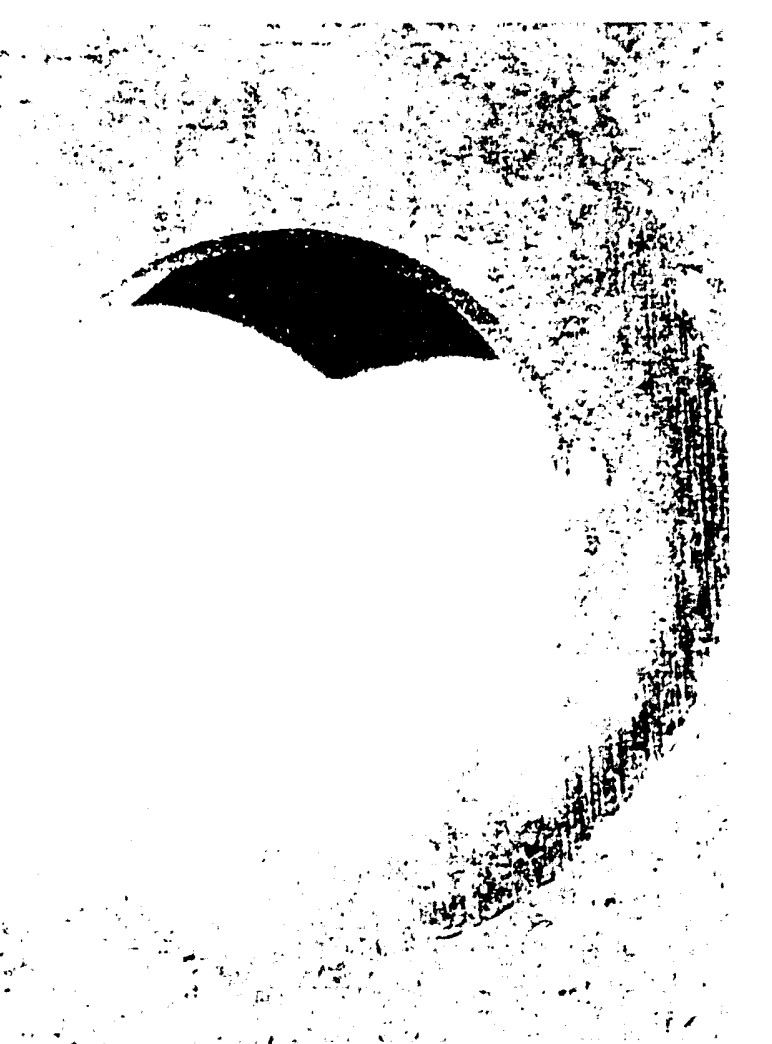

C

FIGURE A.3-15

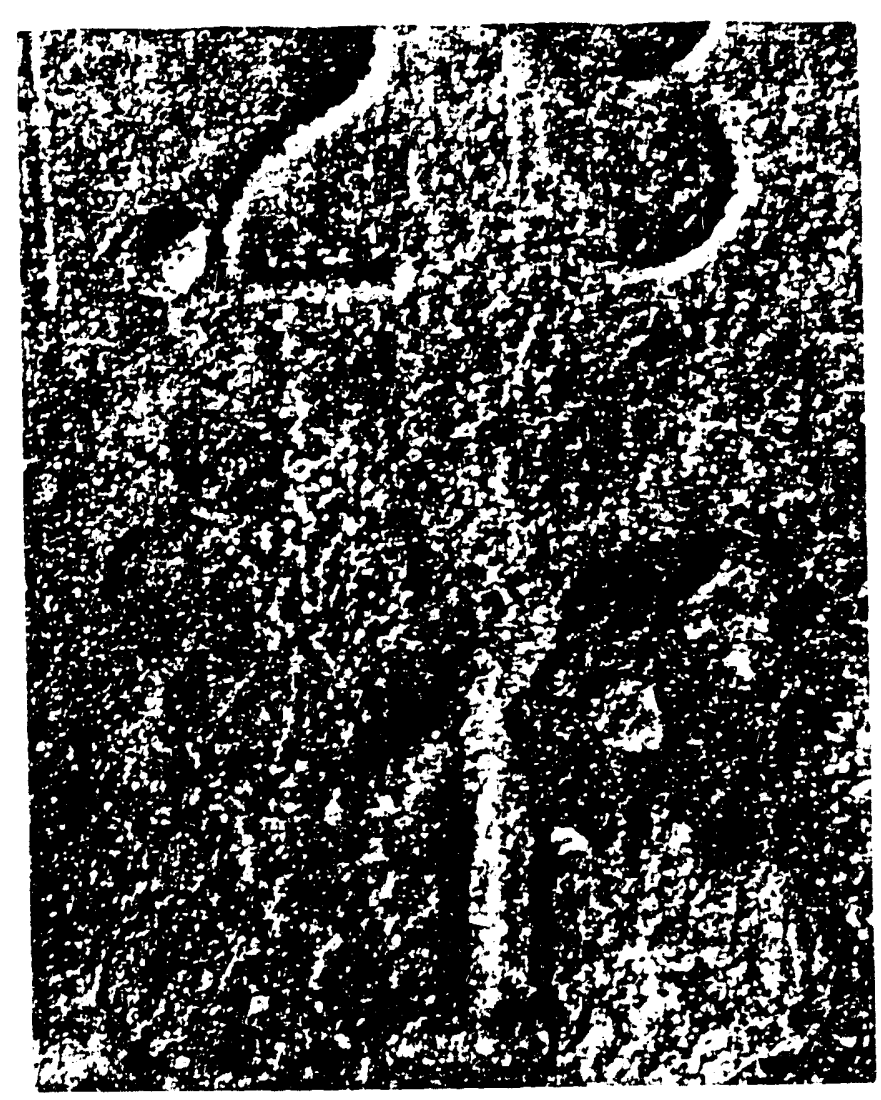

b

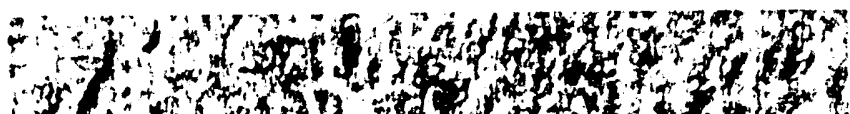
30 ond

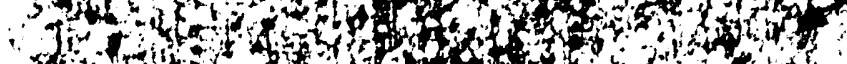

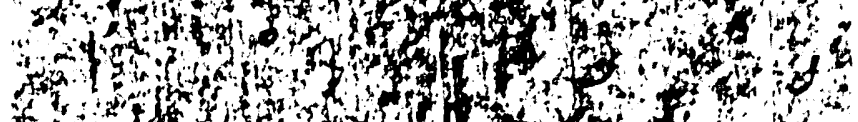

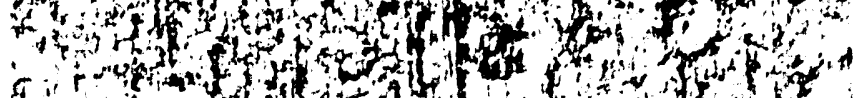

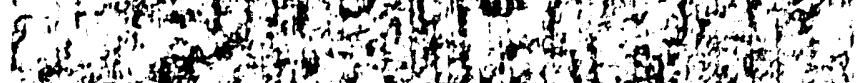

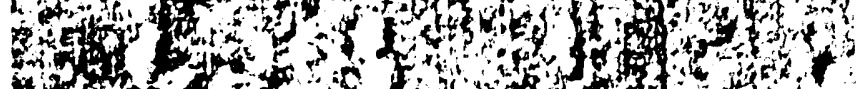
2.

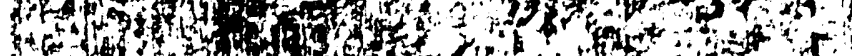

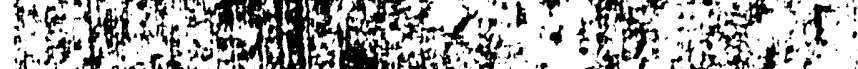

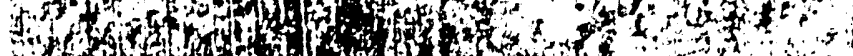

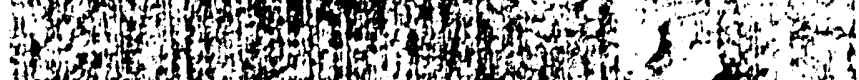

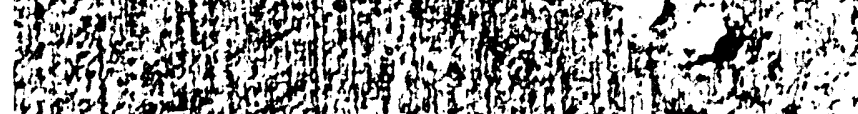
, 7. 7. .

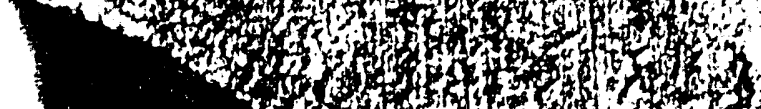

d

ALLOY 625 COUPON FROM MTC-1

Magnification: $a-6 X ; b-15 X$ (stamped area)

$c-6 X ; d-15 X$ (in and near washer-shielded area) 


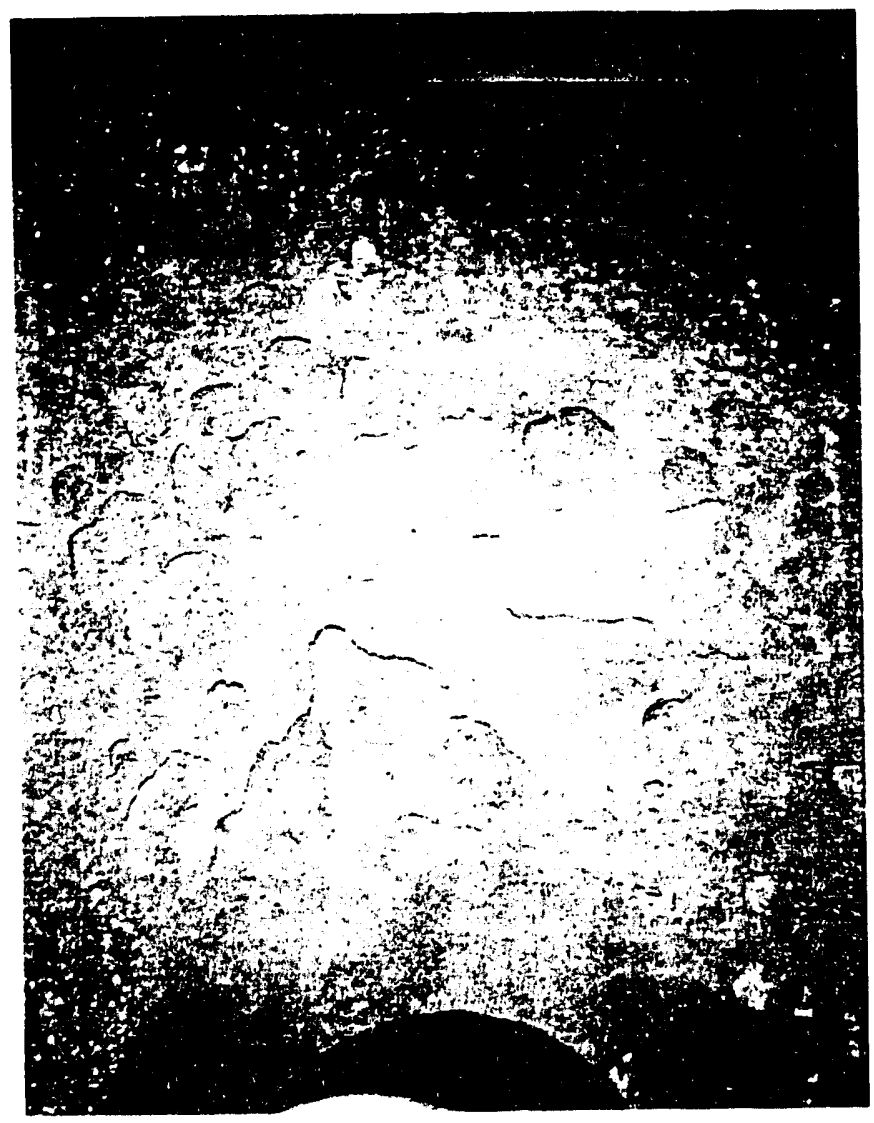

a

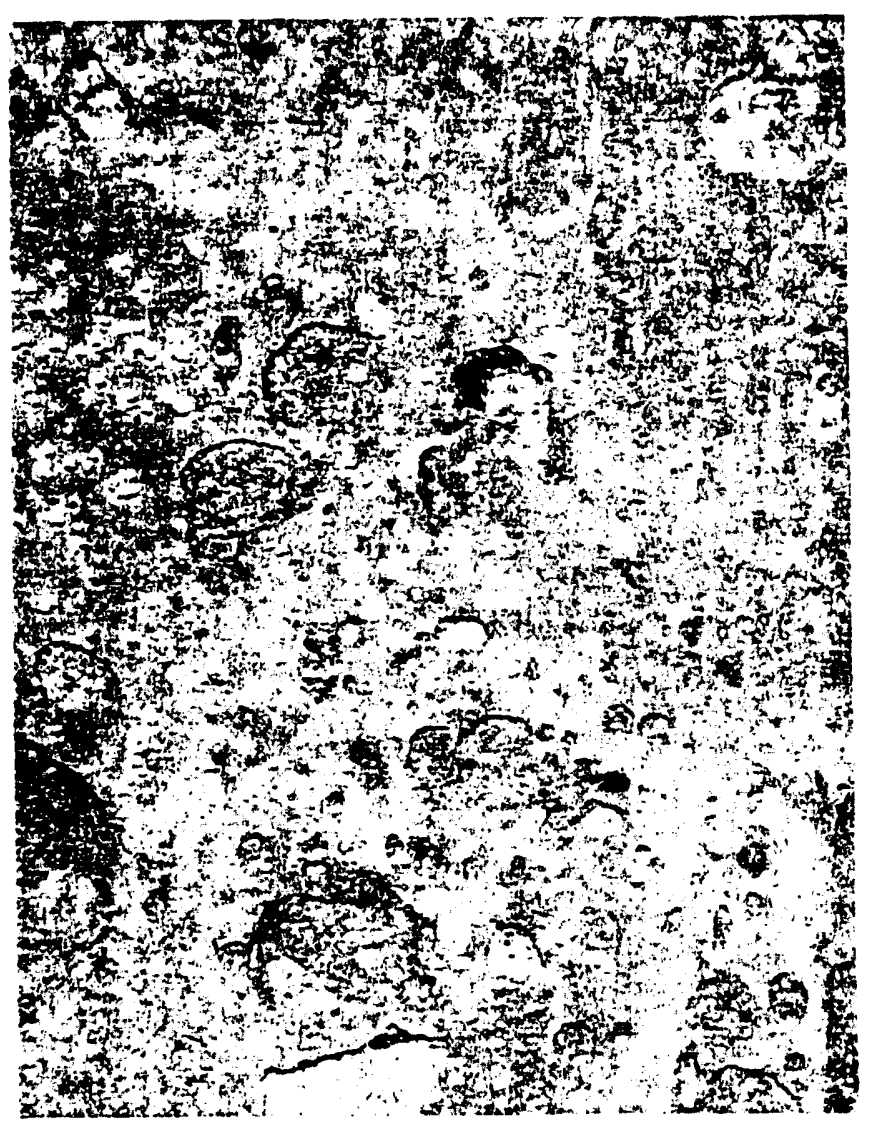

b

FIGURE A.3-16

BUTT-WELDED ALLOY 625 COUPON FROM MTC-1

Magnification: a-4X; b-15X 

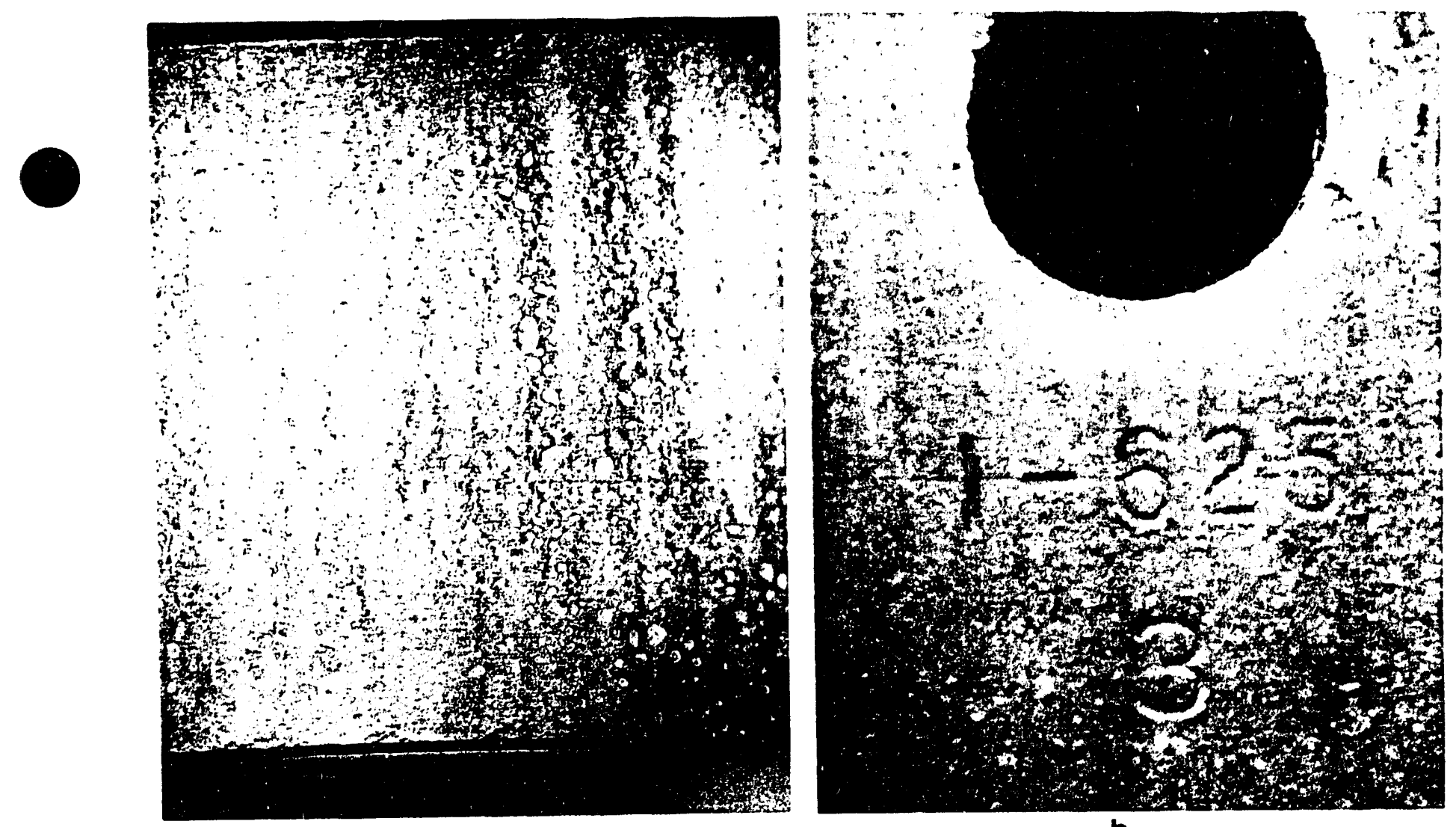

a

b

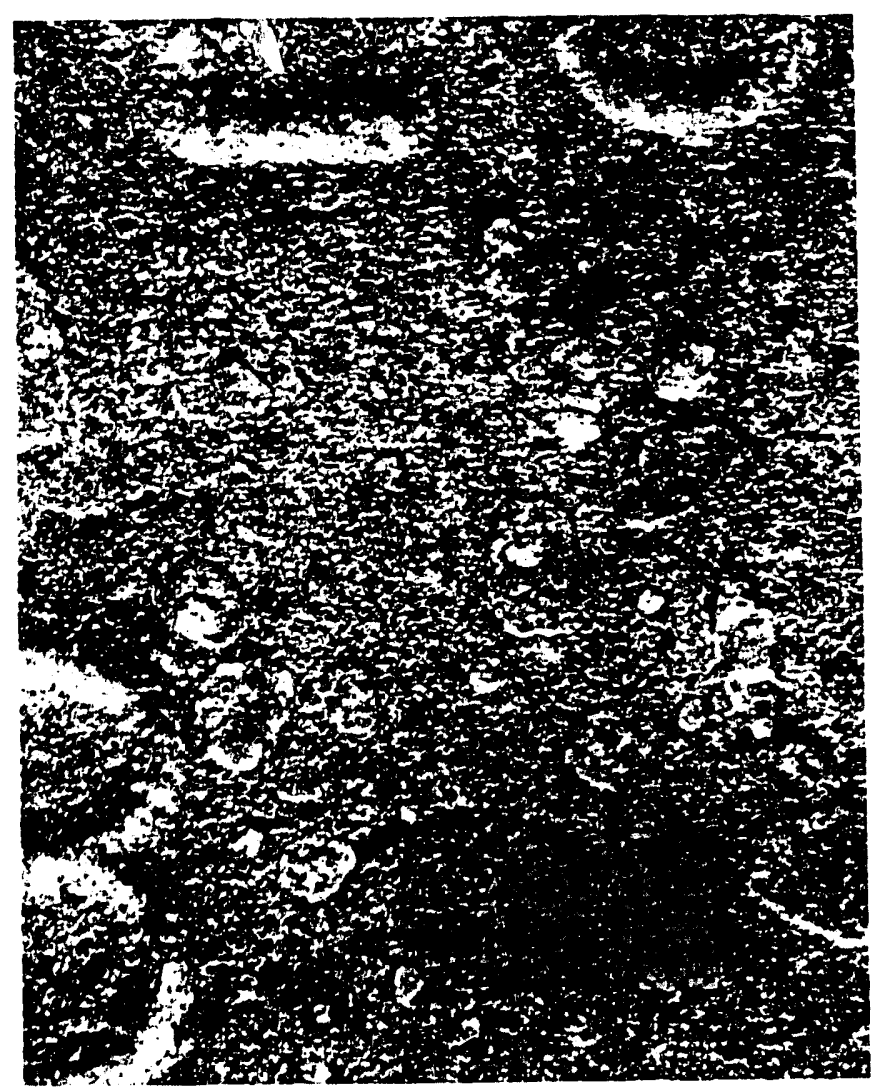

C

FIGURE A.3-17

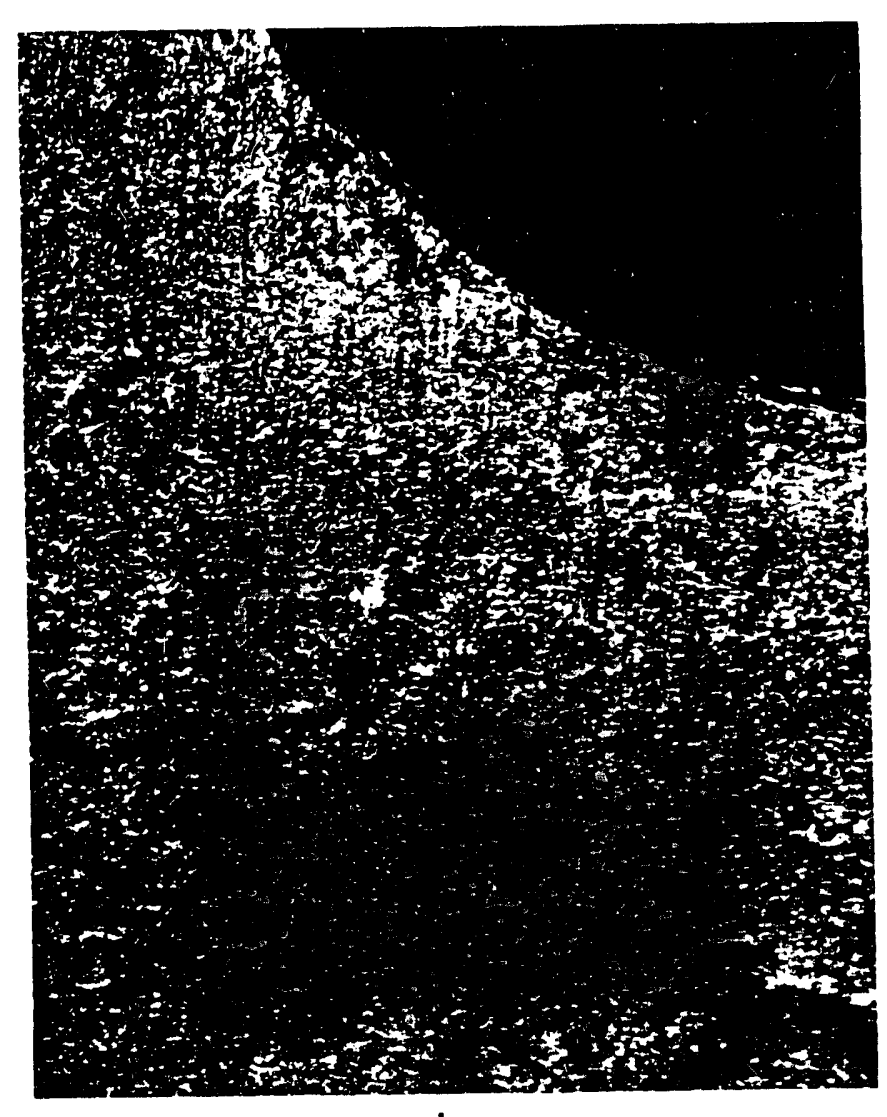

d

ALLOY 625 U-BEND FROM MTC-1

Magnification: a - top of the bend, 5X; b - stamped area, $5 X$

c - stamped area, 18X; $d$ - in and near washer-shielded area, 18X 


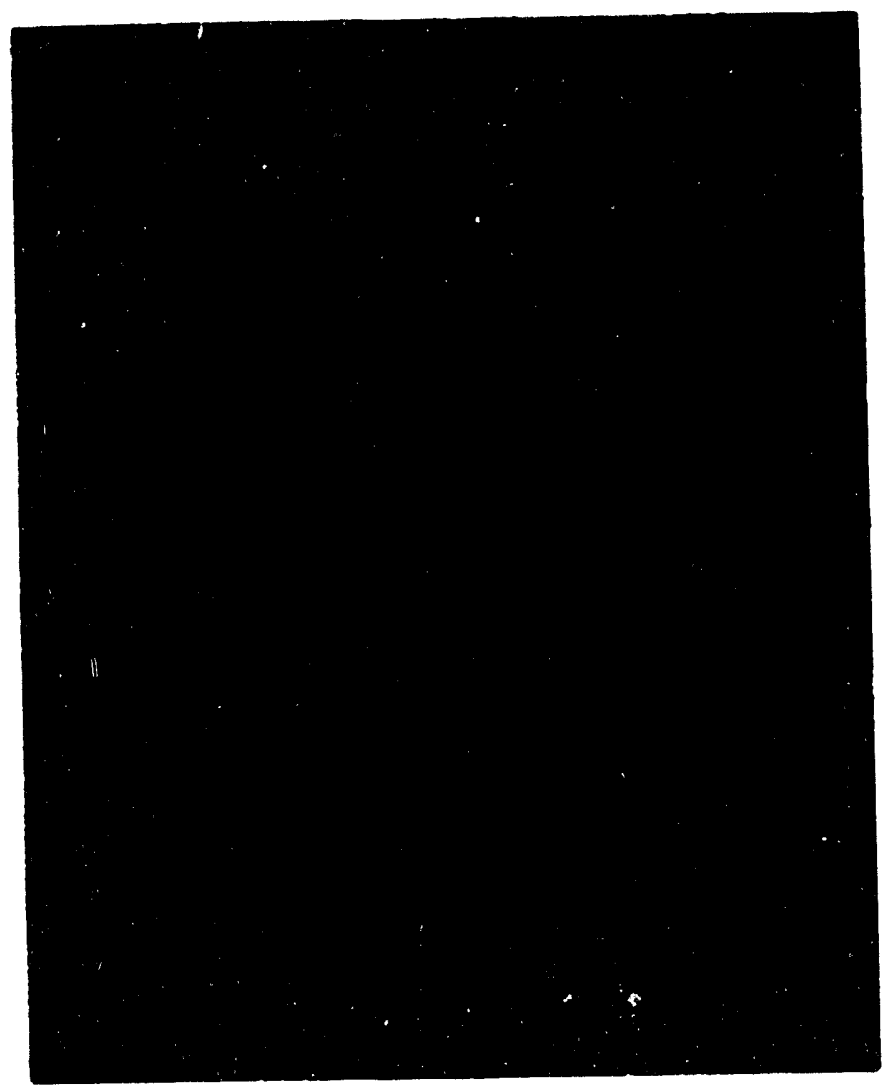

a

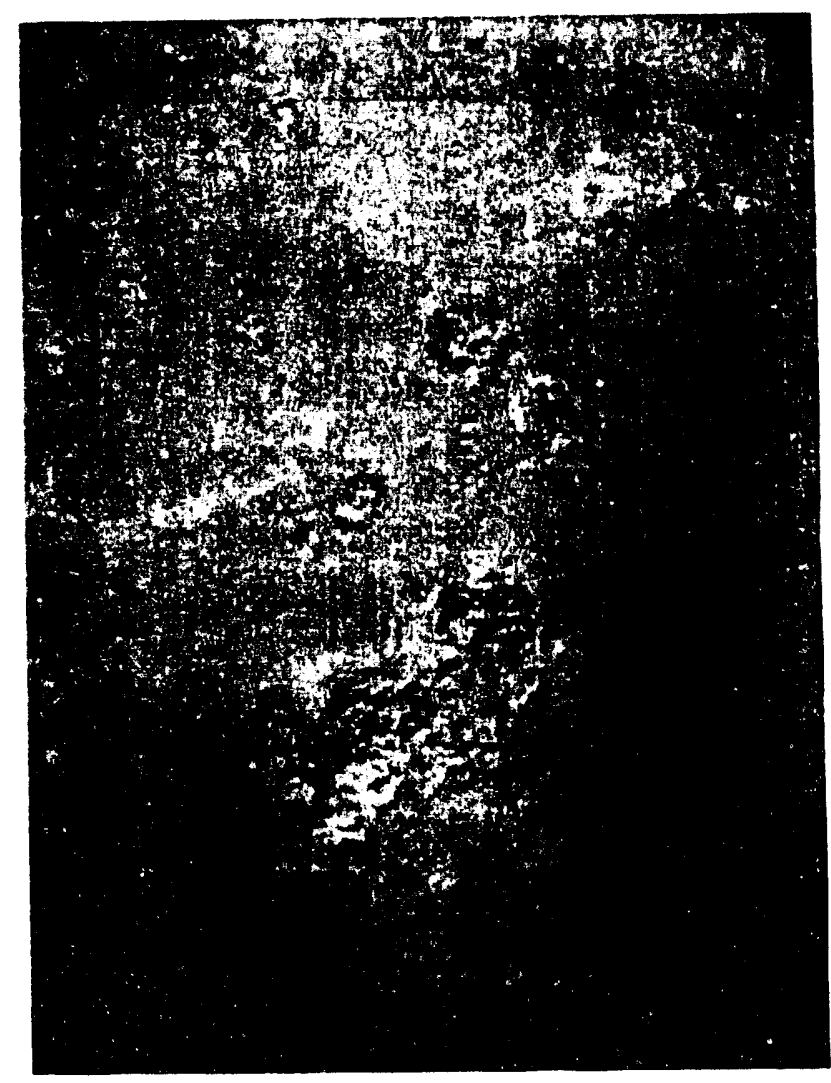

b

FIGURE A.3-18

ALLOY 718 COUPON FROM MTC-1

Magnification: a-6X 


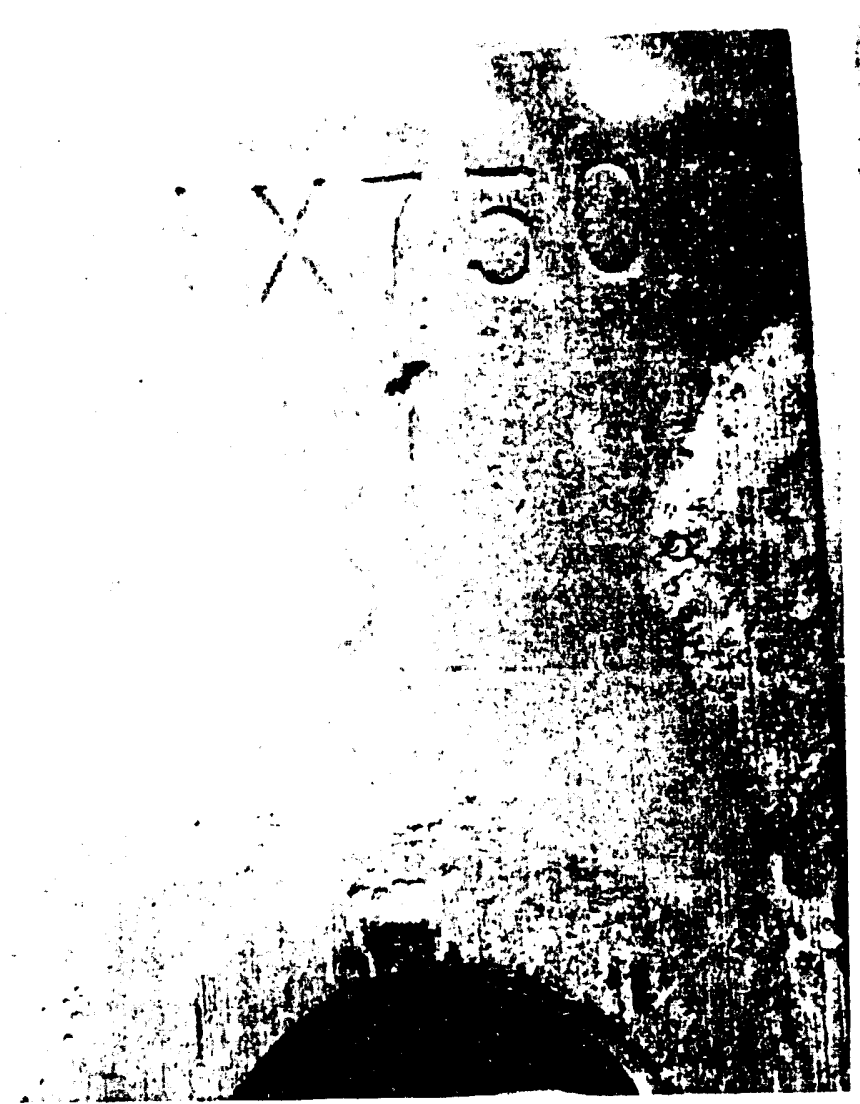

a

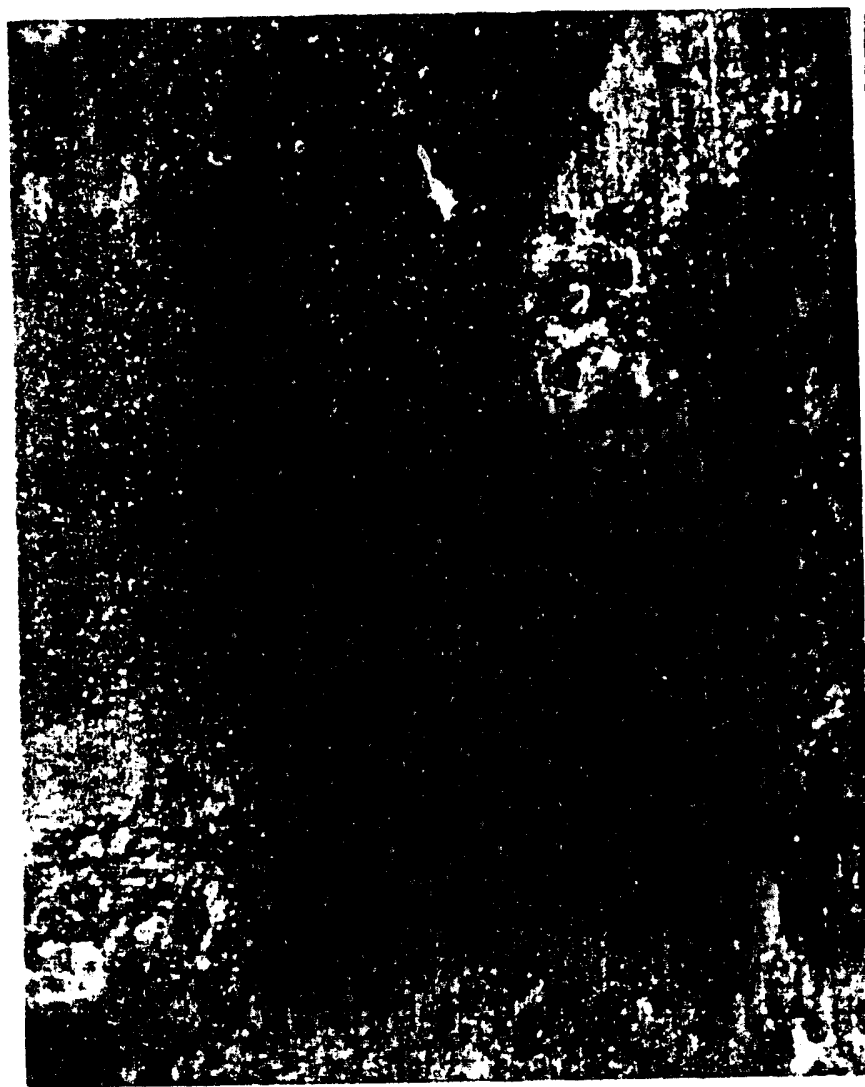

C

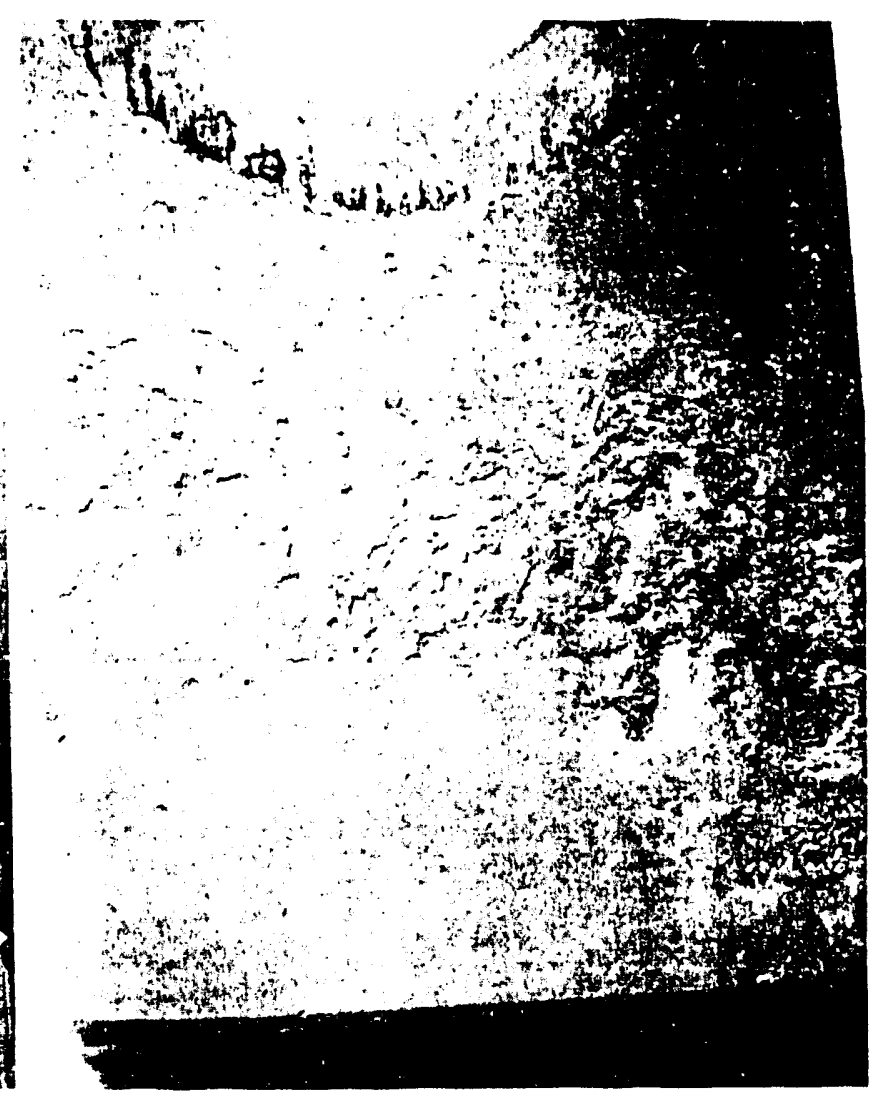

b

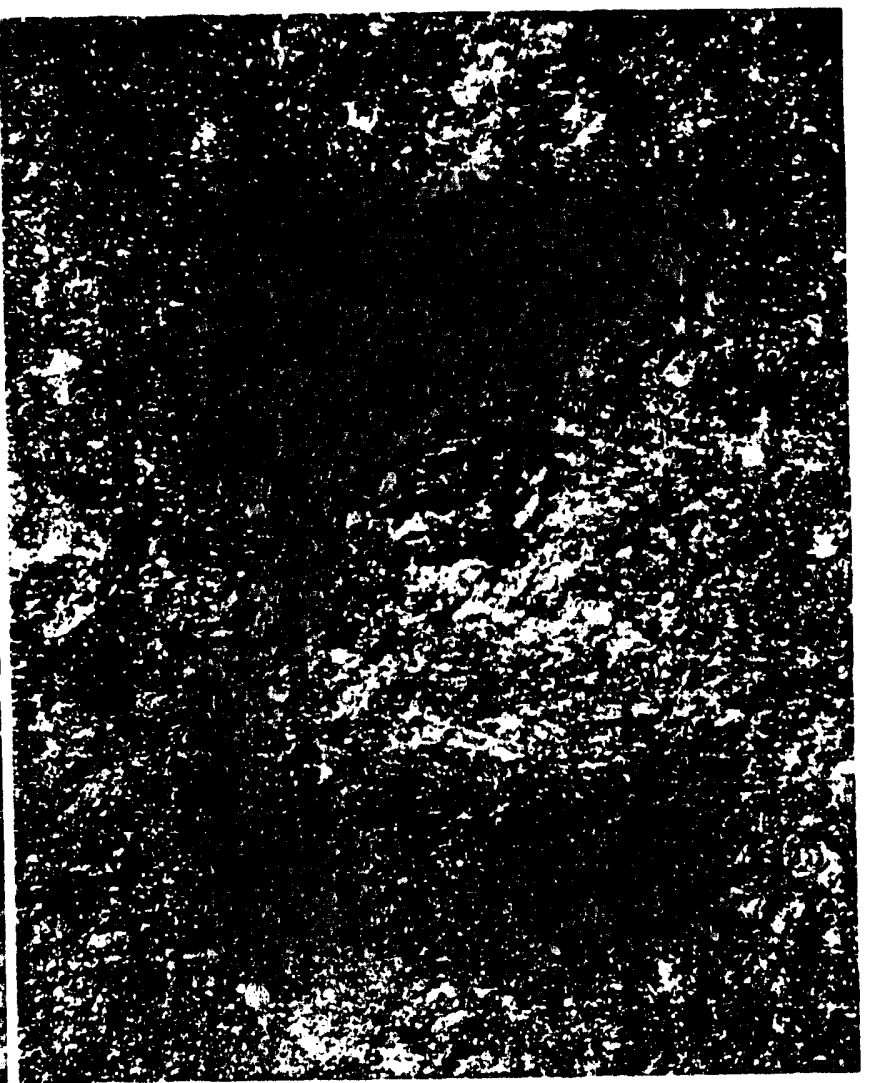

d

FIGURE A.3-19

ALLOYX750 COUPON FROM MTC-1

Magnification: $a$ and $b-4 X ; c-8 X ; d-30 X$ 

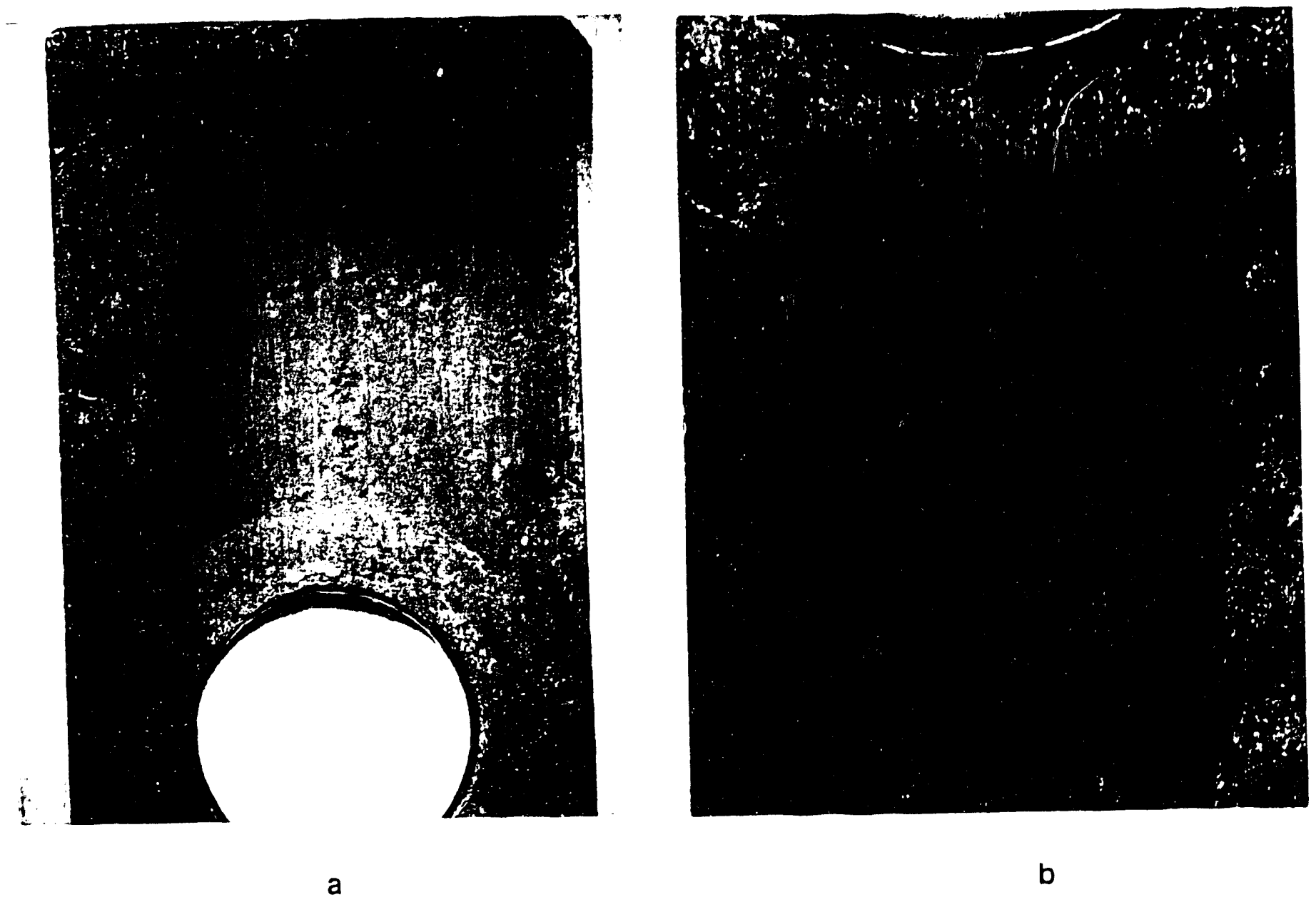

FIGURE A.3-20

ALLOY H-9M COUPON FROM MTC-1

Magnificatiori: $a-4 X ; b-10 X$ 


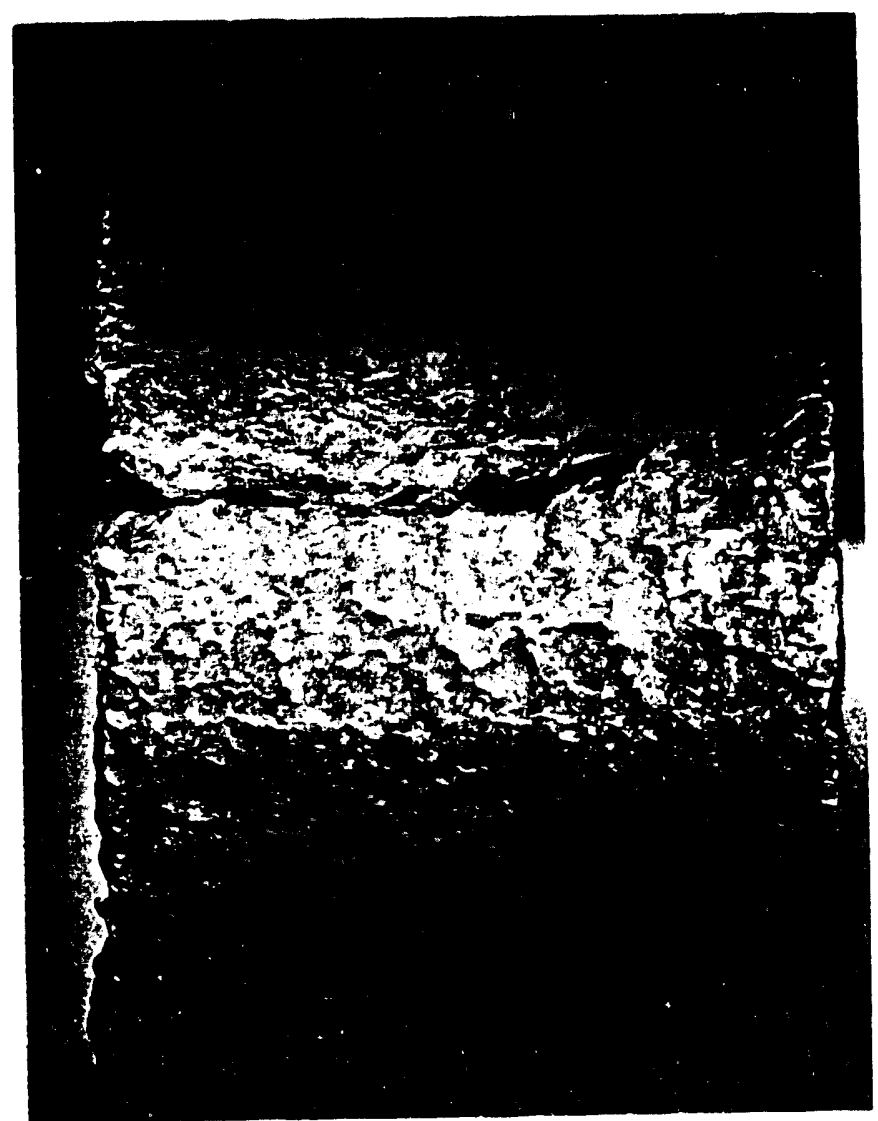

a

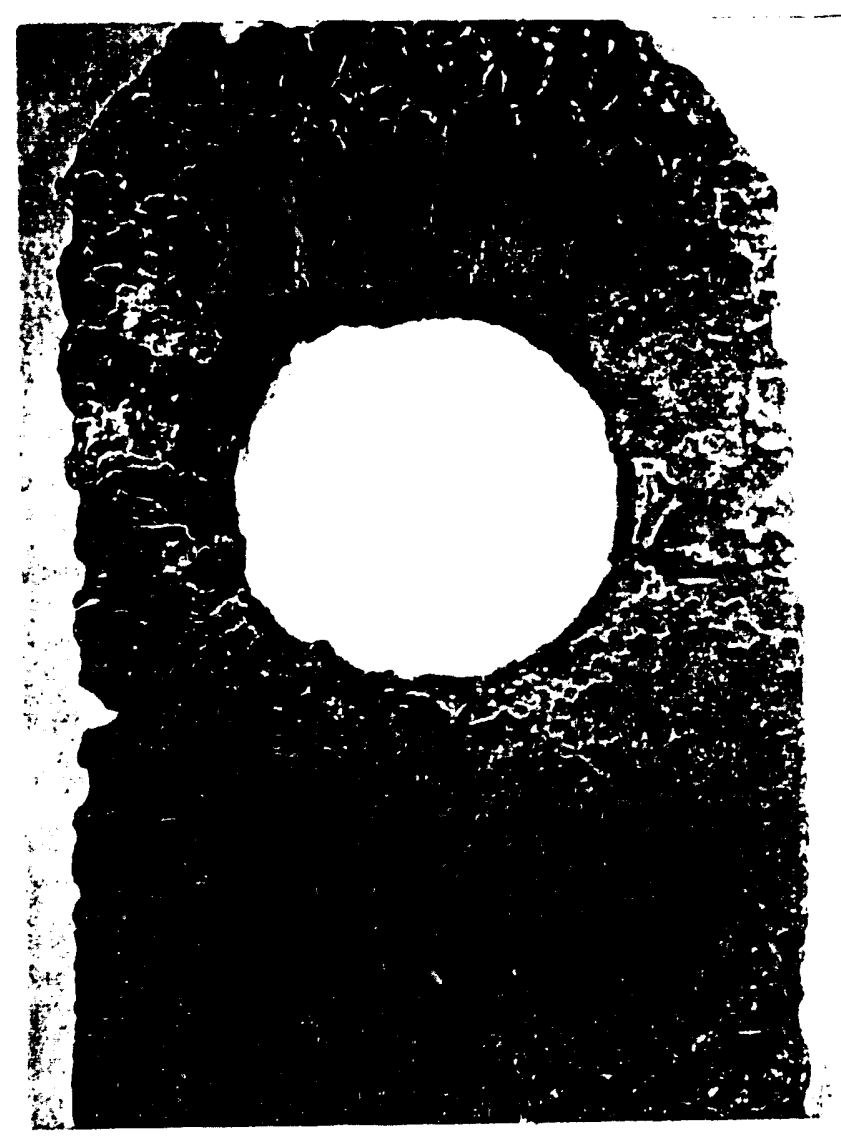

b

FIGURE A.3-21

ALLOY 625 U-BEND WITH A WELD IN THE BEND AREA FROM MTC-2 (NO STRESS RELIEF AFTER WELDING)

Magnification: a-4X 


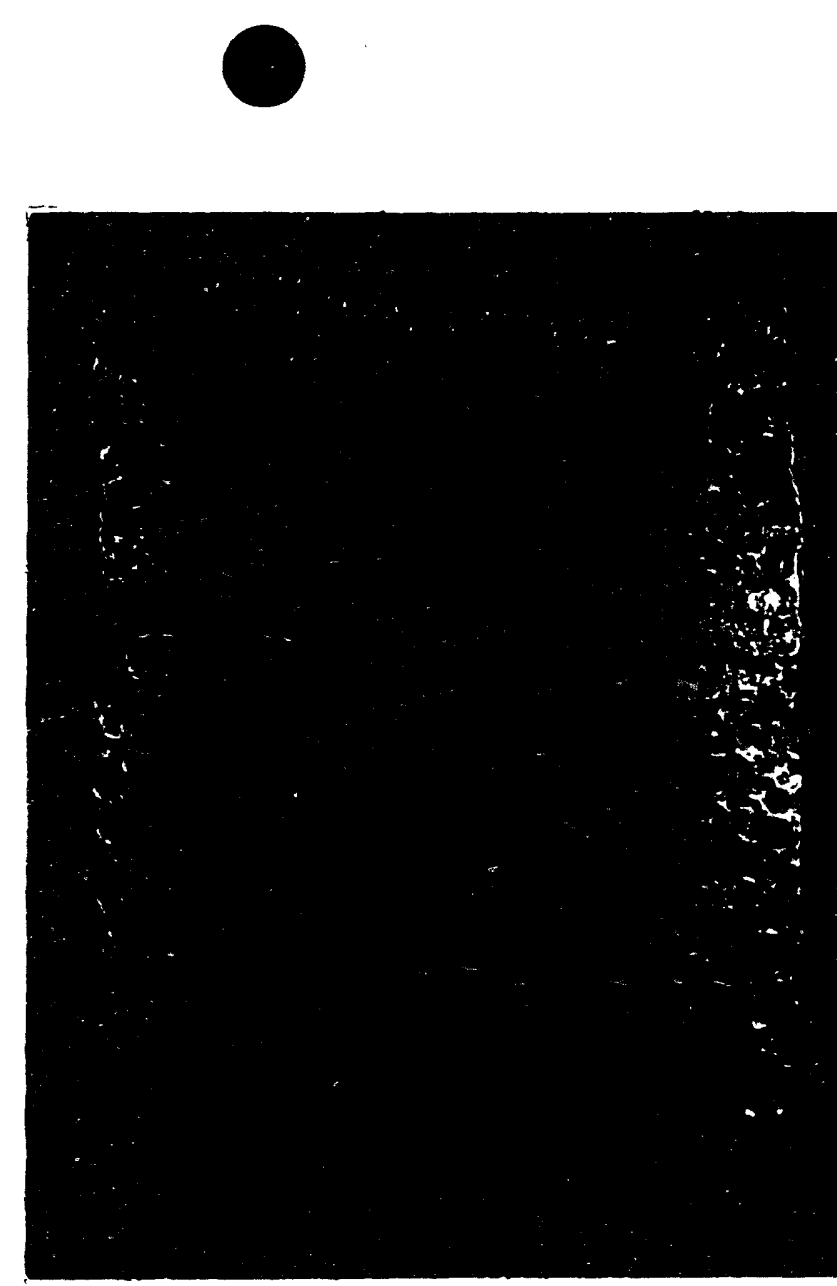

a

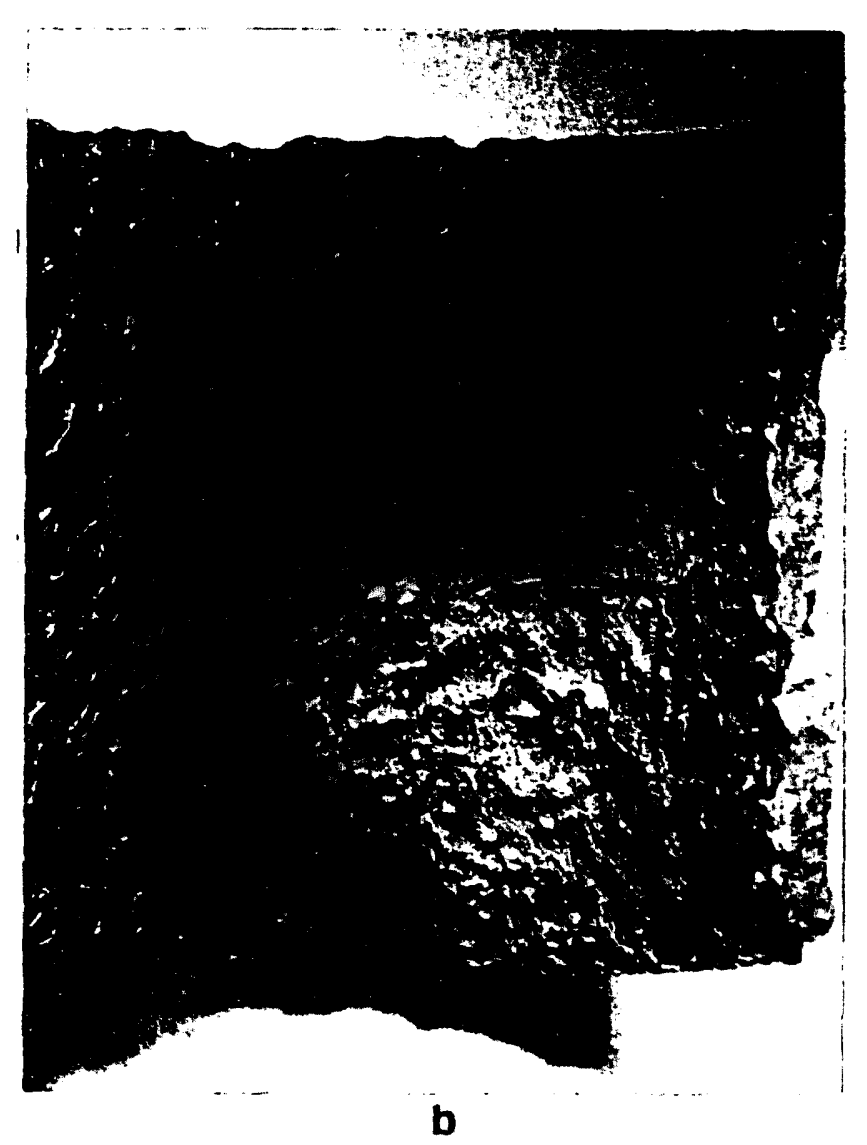

FIGURE A.3-22

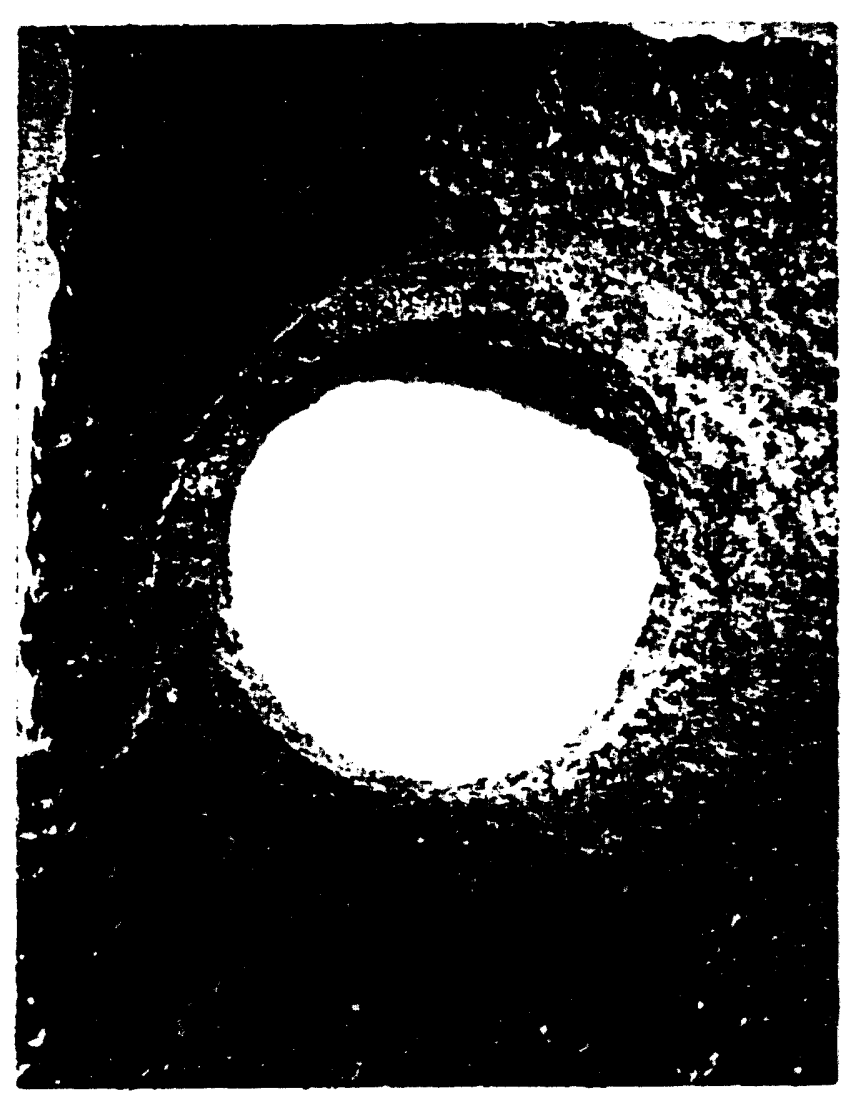

c

ALLOY 625 U-BEND WITH A WELD IN THE BEND AREA FROM MTC-2

(STRESS RELIEVED AFTER WELDING)

a - crack in the bend

$b$ - inside surface of the bend (fracture surface on the right)

$C$ - in and near washer-shielded area

Magnification: a through c - 4X 


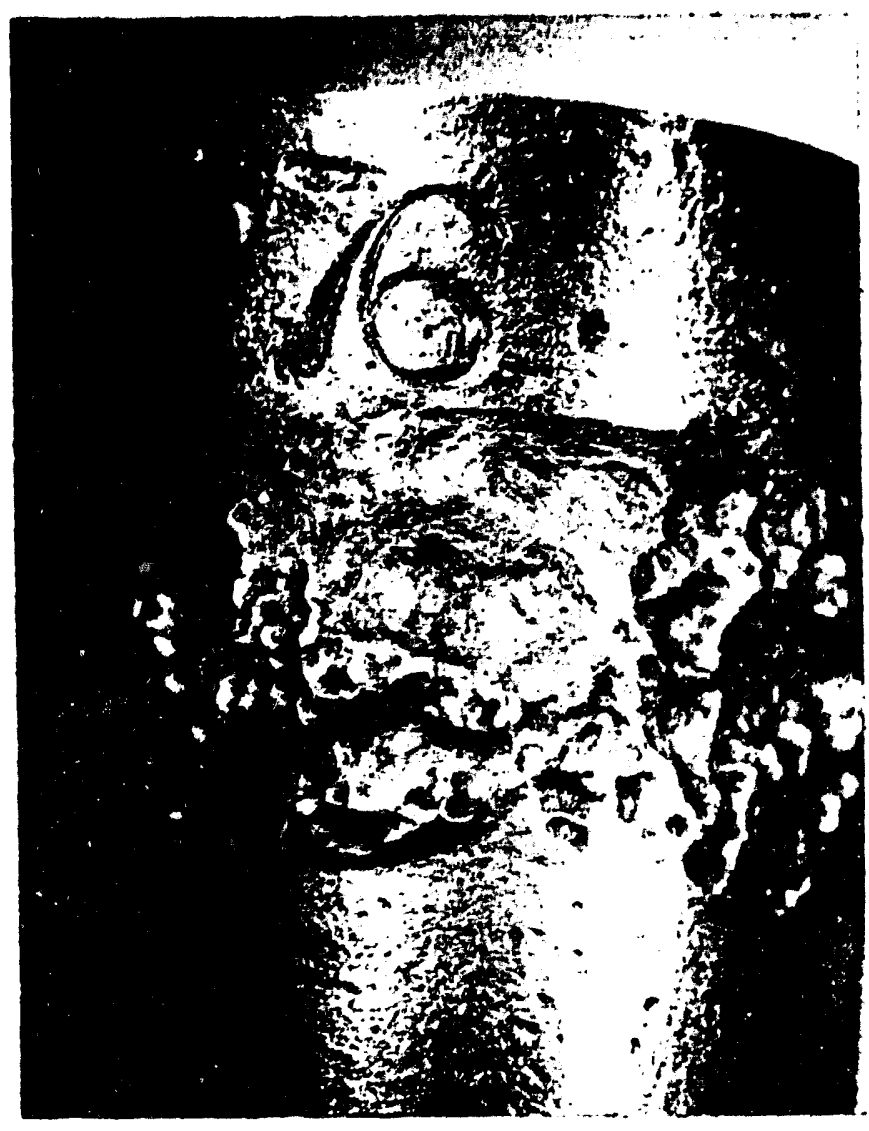

a

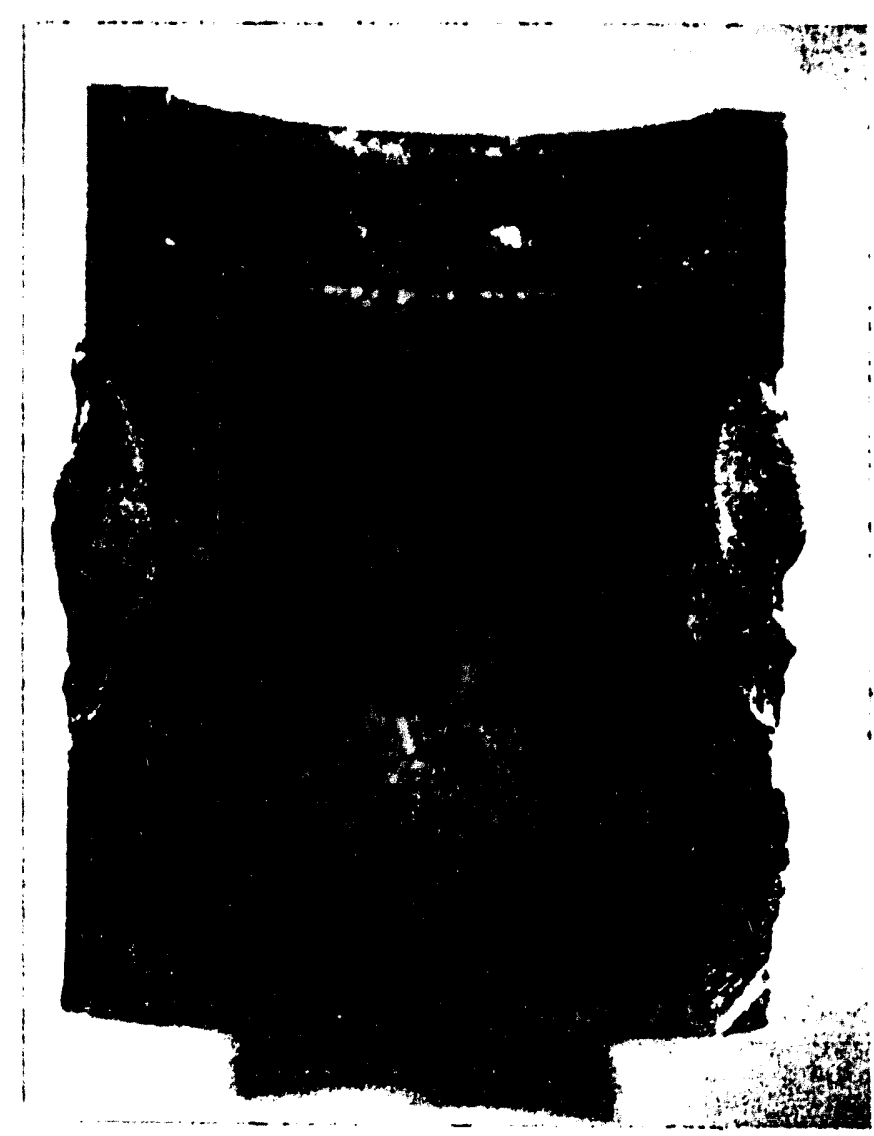

b

FIGURE A.3-23, $a$ and $b$

\begin{abstract}
ALLOY C-276 TUBES WITH ALLOY 625 BUTT WELD FROM MTC-2 (NO HEAT TREATMENT AFTER WELDING)
\end{abstract}

a - O.D. surface: severe corrosion of 625 we'-4, pits on C-276 tubes, $6 X$ b - cross-section of the sample, $5 X$ 


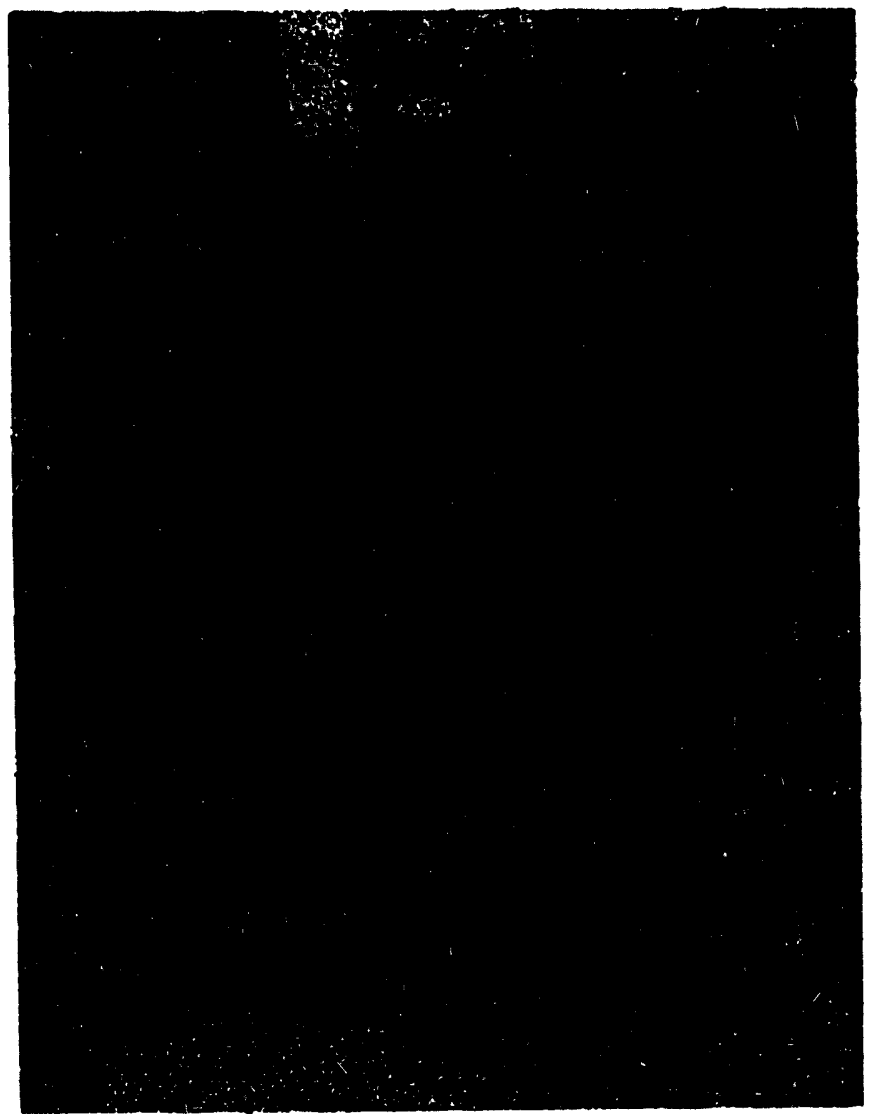

c

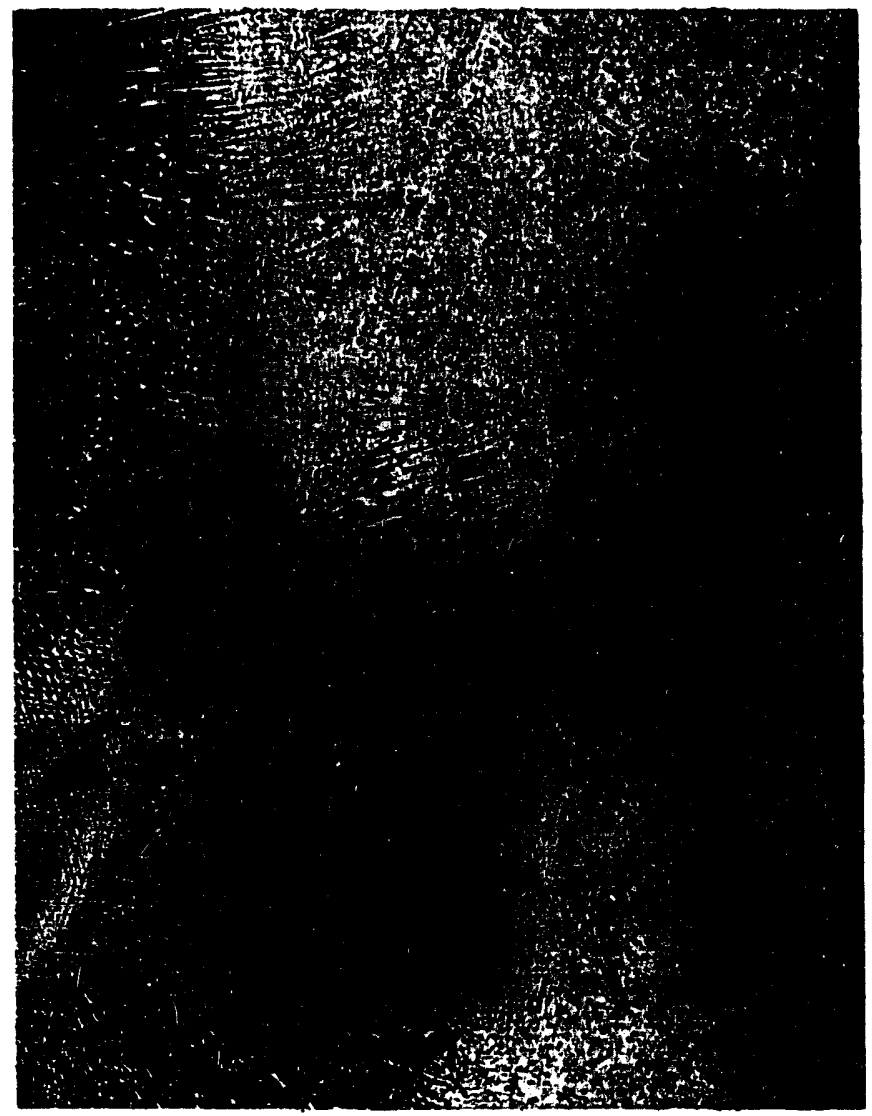

d

| FIGURE A.3-23, $c$ and $d$ CROSS-SECTION OF

ALLOY C-276 TUBES WITH ALLOY 625 BUTT WELD FROM MTC-2 (NO HEAT TREATMENT AFTER WELDING)

C - at a weld toe: 625 weld is severely corroded, $50 x$ d - at the root of the weld, $50 x$ 


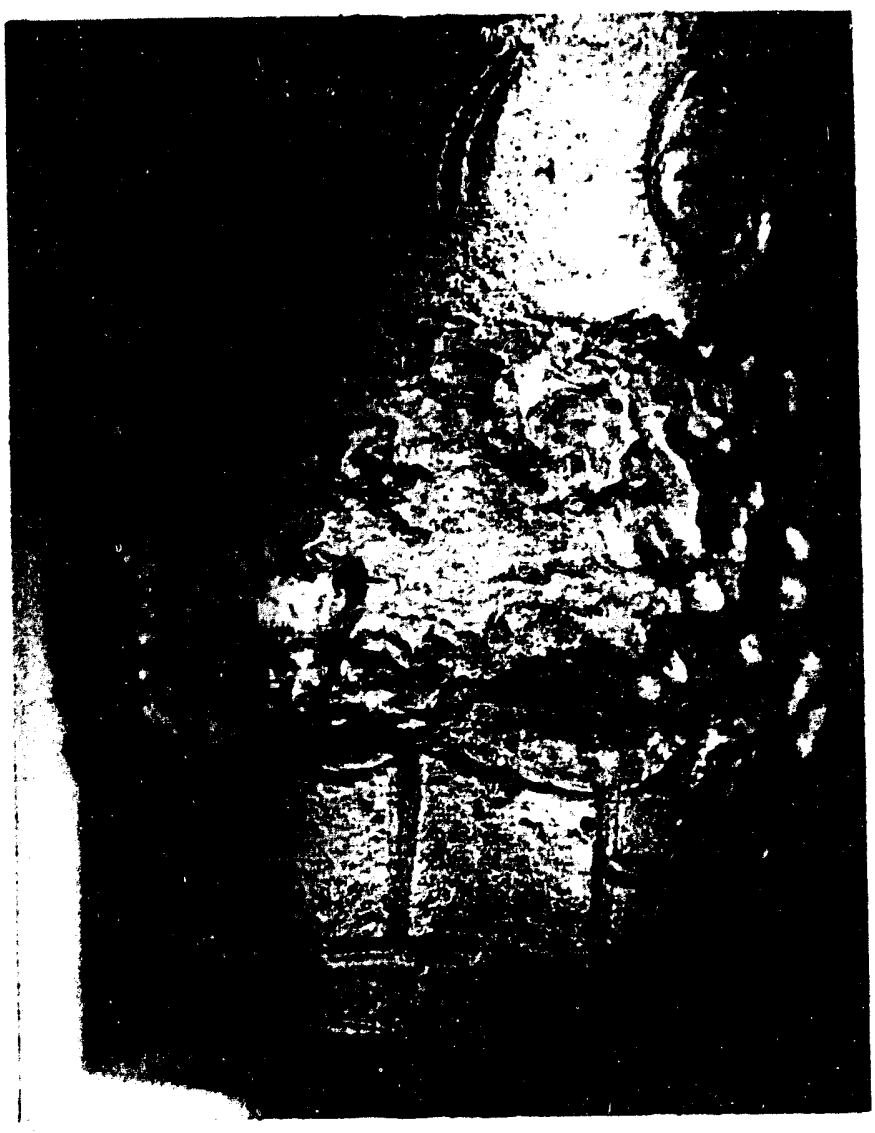

a

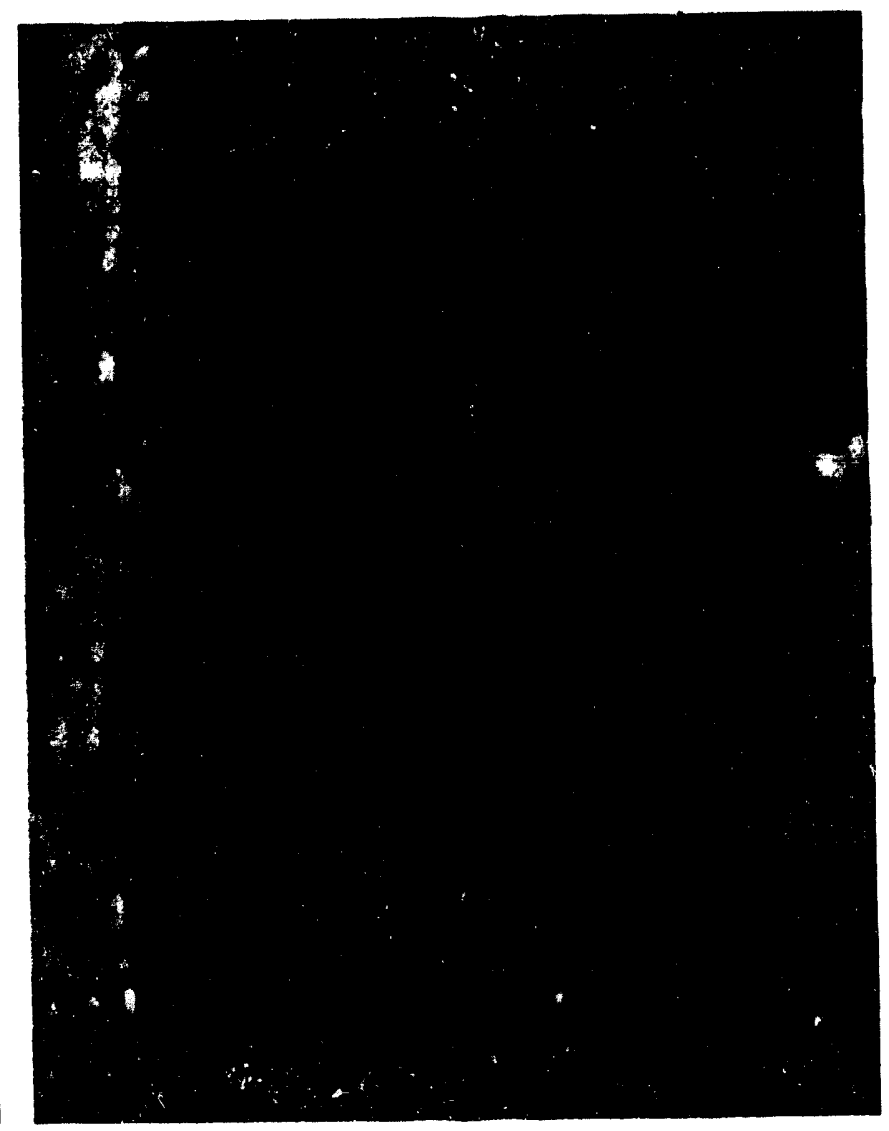

b

FIGURE A.3-24, $a$ and $b$

ALLOY C-276 TUBES WITH ALLOY 625 BUTT WELD FROM MTC-2 (ANNEALED AFTER WELDING)

a - outside diameter surface, $6 X$

$b$ - plts on the I.D. surface, $9 X$ 


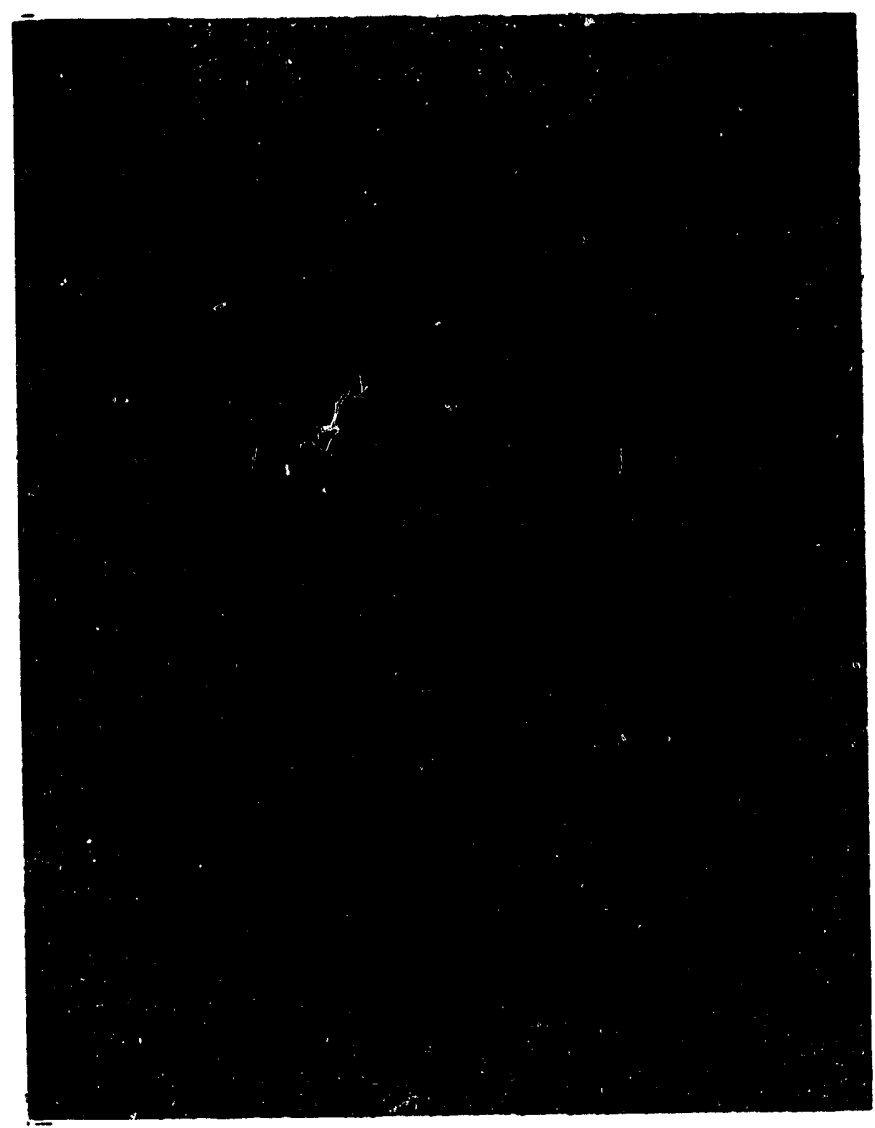

C

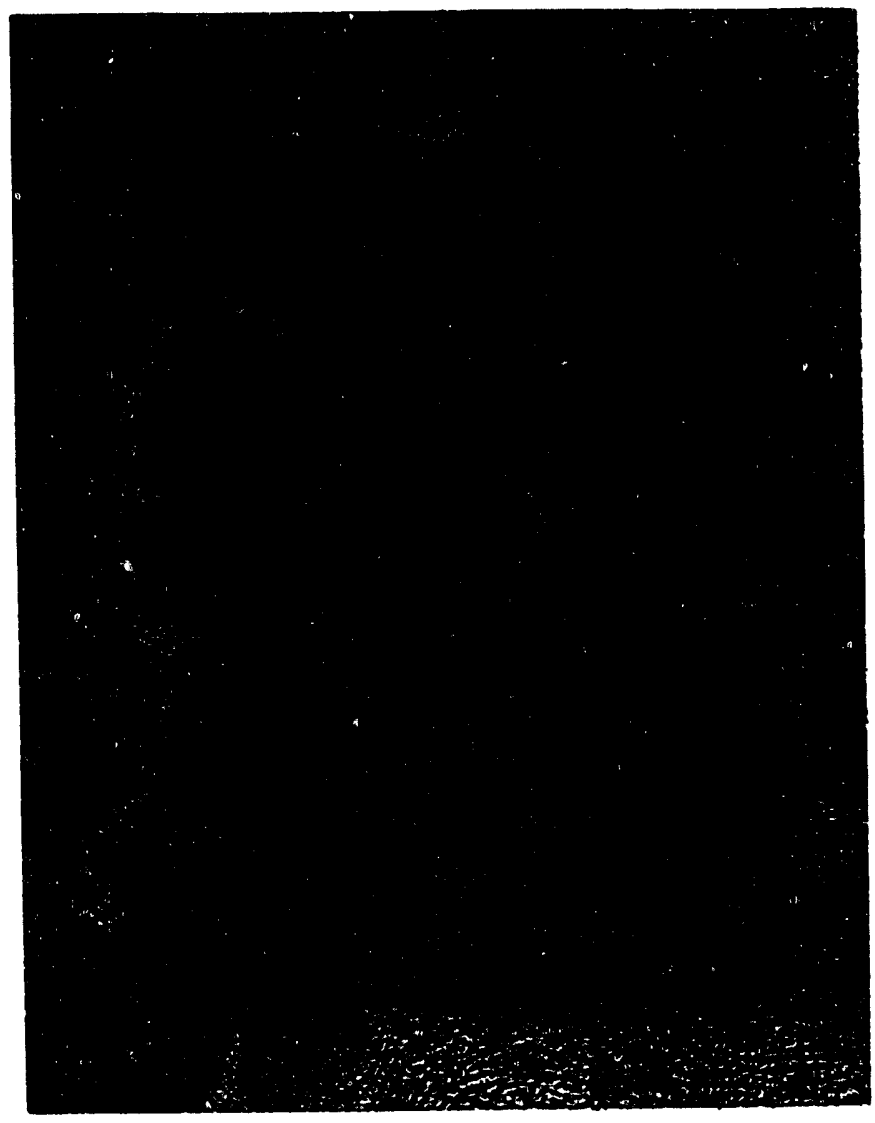

d

FIGURE A.3-24, $c$ and $d$

ALLOY C-276 TUBES WITH ALLOY 625 BUTT WELD FROM MTC-2 (ANNEALED AFTER WELDING)

C - typical pits on the C-276 tube O.D. surface, 50X d - severely corroded Alloy 625 weld, $50 X$ 

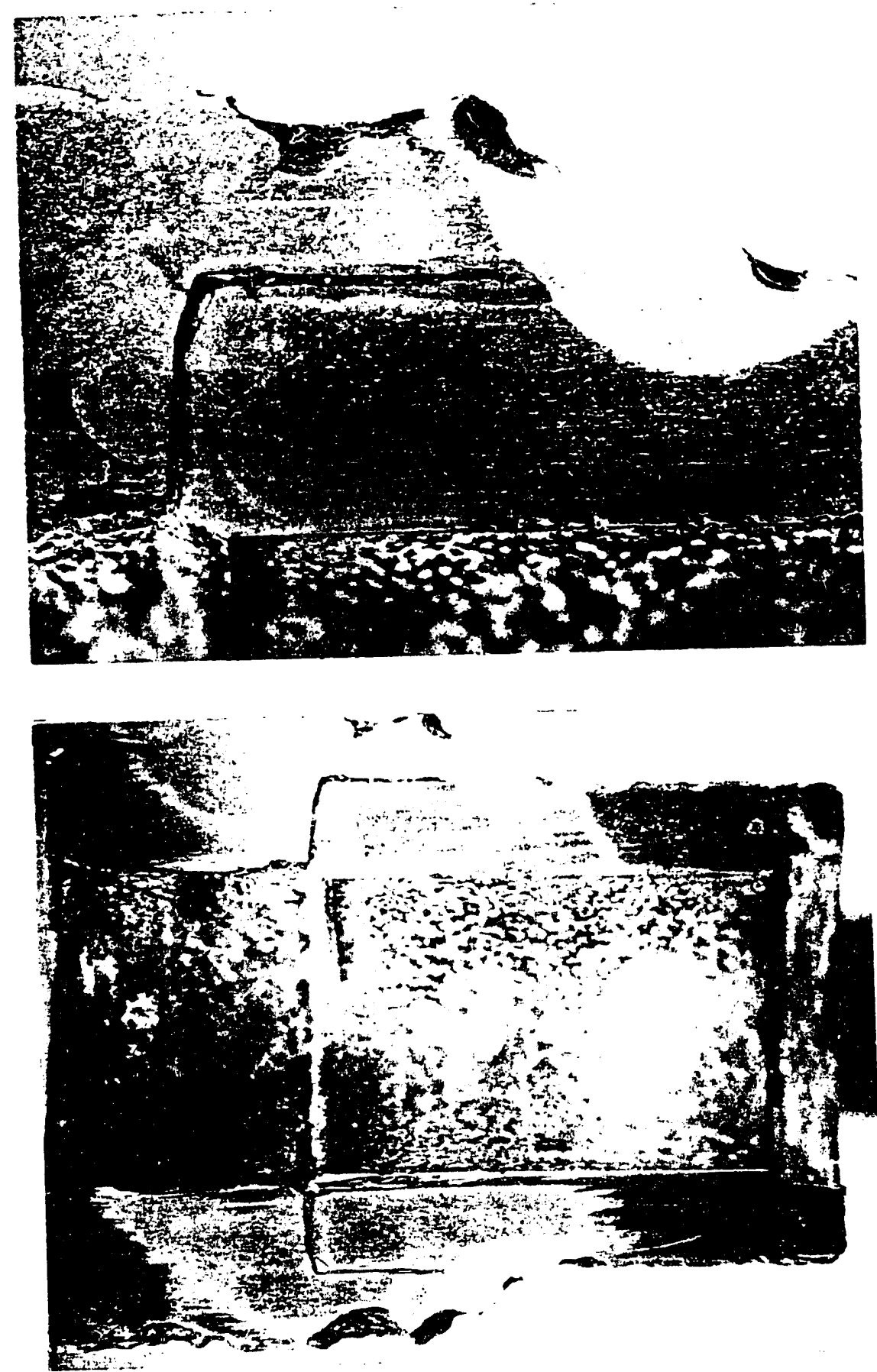

FIGURE A.3-25

CROSS-SECTION OF

ALLOY 625 SOCKET WELD FROM MTC-2

(NO HEAT TREATMENT AFTER WELDING)

Boldly exposed Alloy 625 weld and base metal are severely corroded while corrosion in the crevice has been minor Magnification: top - 12X; bottom - 4X 


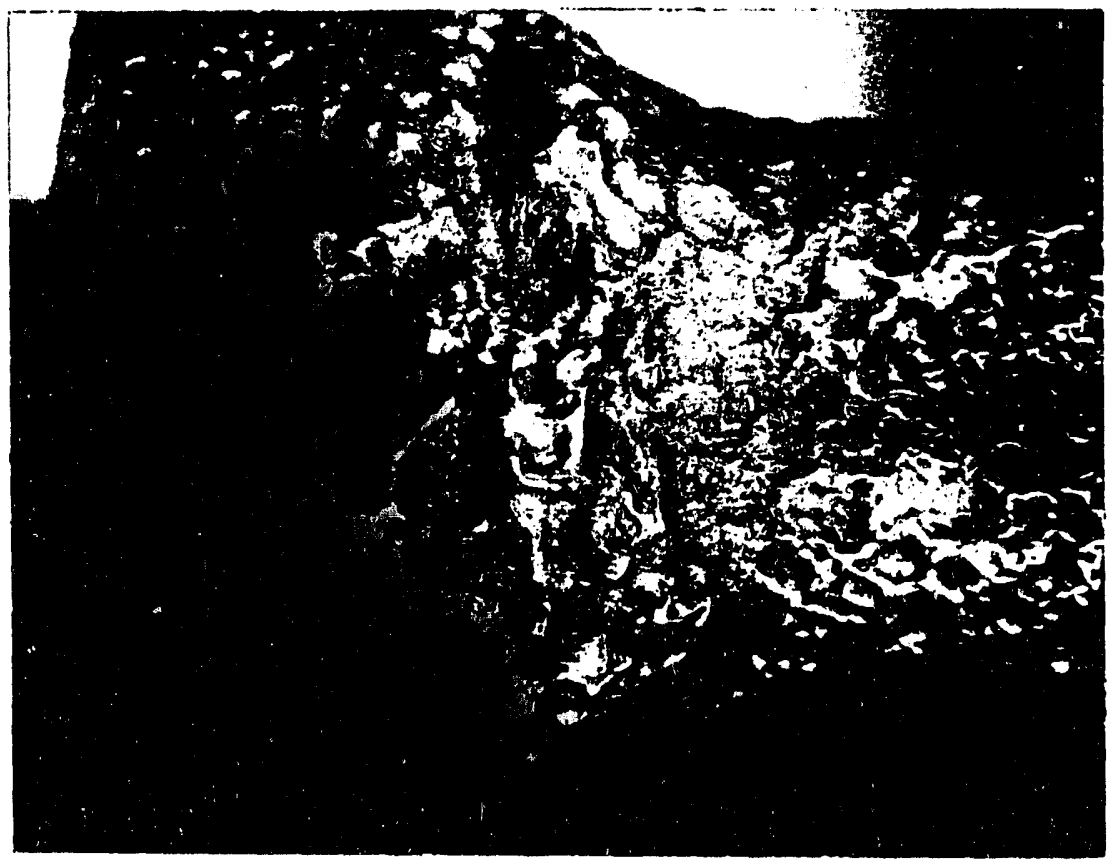

FIGURE A.3-26,a

ALLOY 625 SOCKET WELD SAMPLE FROM MTC-2 (ANNEALED AFTER WELDING)

Both Alloy 625 weld and base metal are severely corroded

Magnification: $\mathbf{4 X}$ 

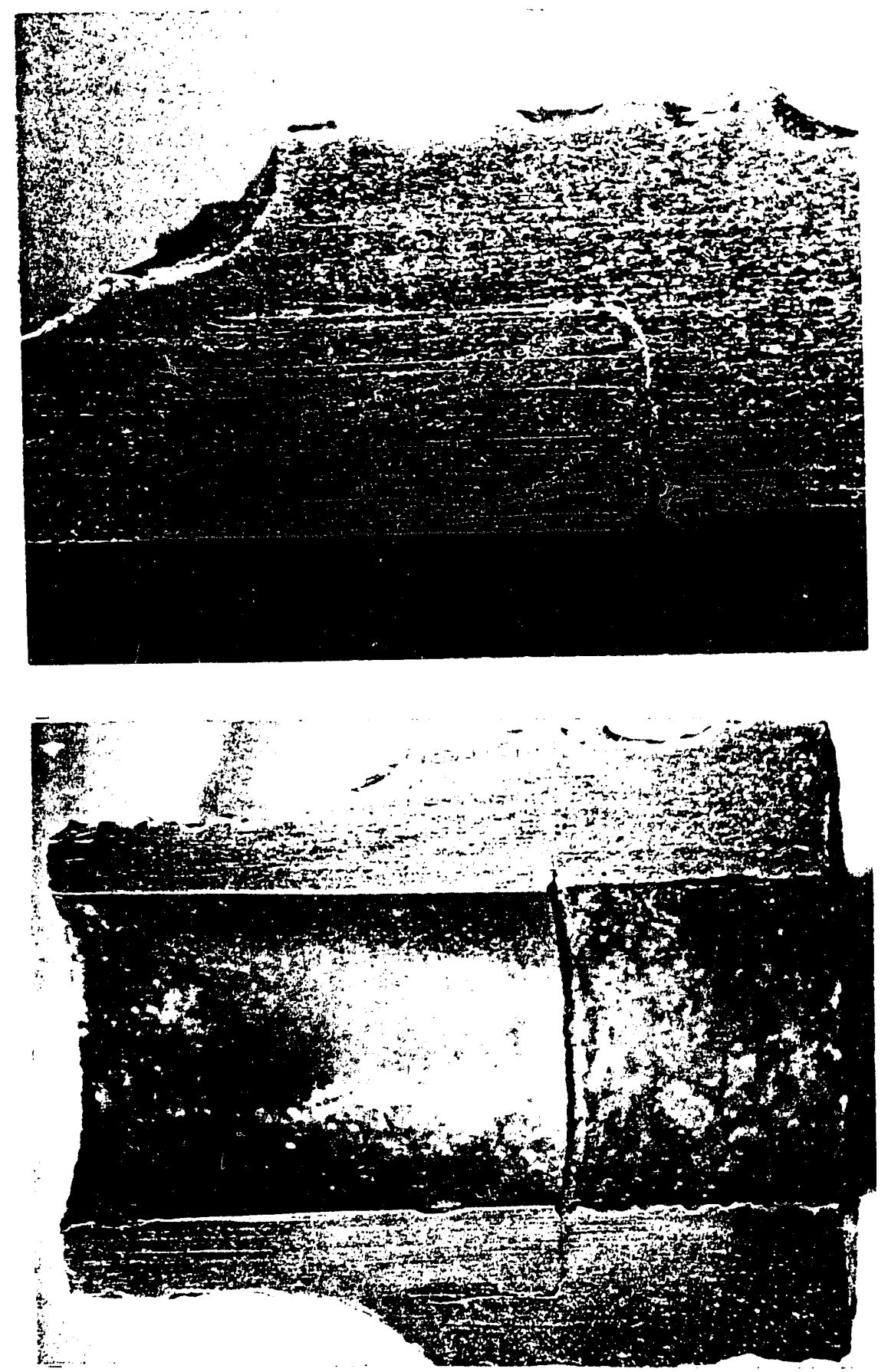

FIGURE A.3-26, $b$ and $c$ CROSS-SECTION OF

ALLOY 625 SOCKET WELD SAMPLE FROM MTC-2 (ANNEALED AFTER WELDING)

Boldly exposed Alloy 625 weld and base metal are severely corroded while corrosion in the crevice has been relatively minor Magnification: $b$ (top) - 12X; $c$ (bottom) - 4X 


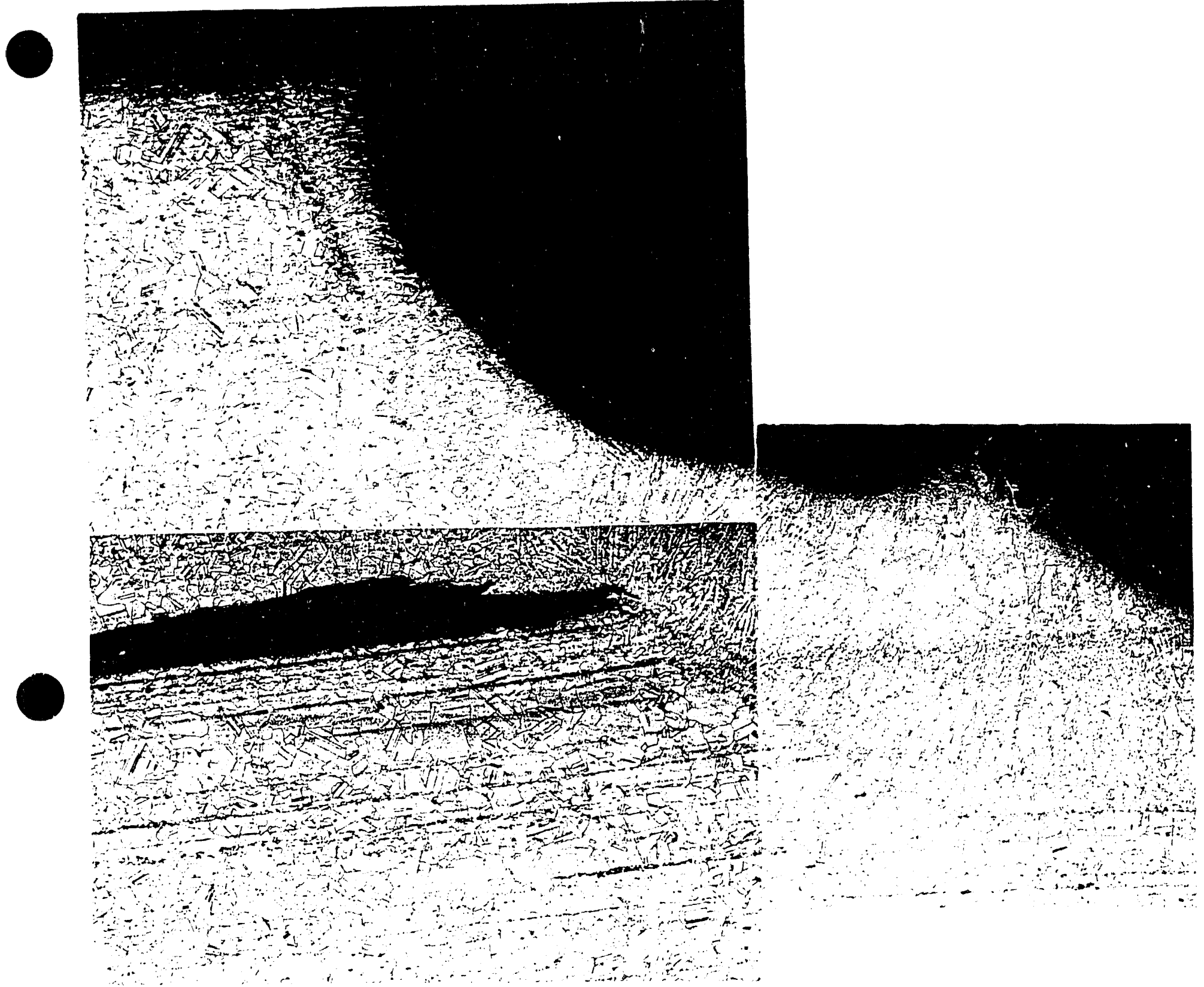

FIGURE A.3-26.d

CROSS-SECTION OF

ALLOY 625 SOCKET WELD SAMPLE FROM MTC-2

(ANNEALED AFTER WELDING)

Severe degradation of the weld:

note very thin remaining wall at and above the tip of the crevice

Magnification: - 50X 


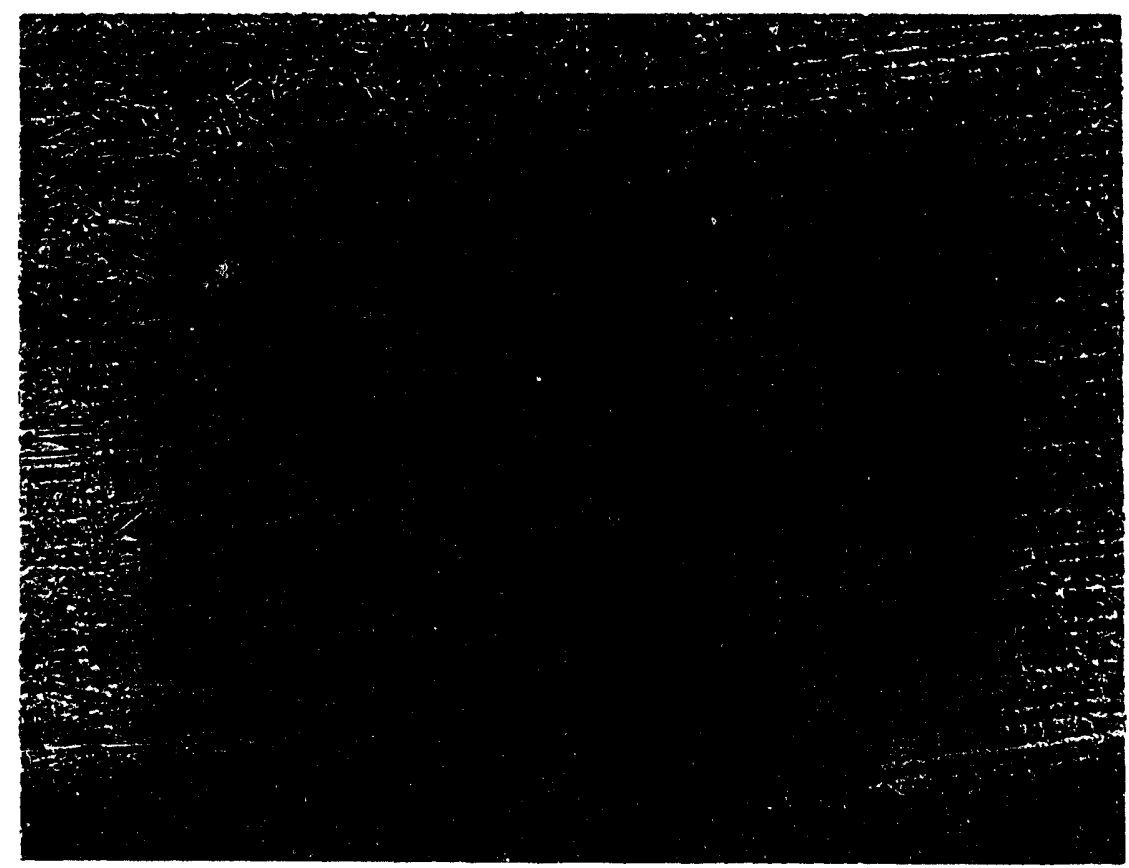

FIGURE A.3-26, e

CREVICE AT THE I.D. SURFACE OF

ALLOY 625 SOCKET WELD SAMPLE FROM MTC-2 (ANNEALED AFTER WELDING)

Some crevice corrosion is evident

Magnification: - $50 \mathrm{X}$ 

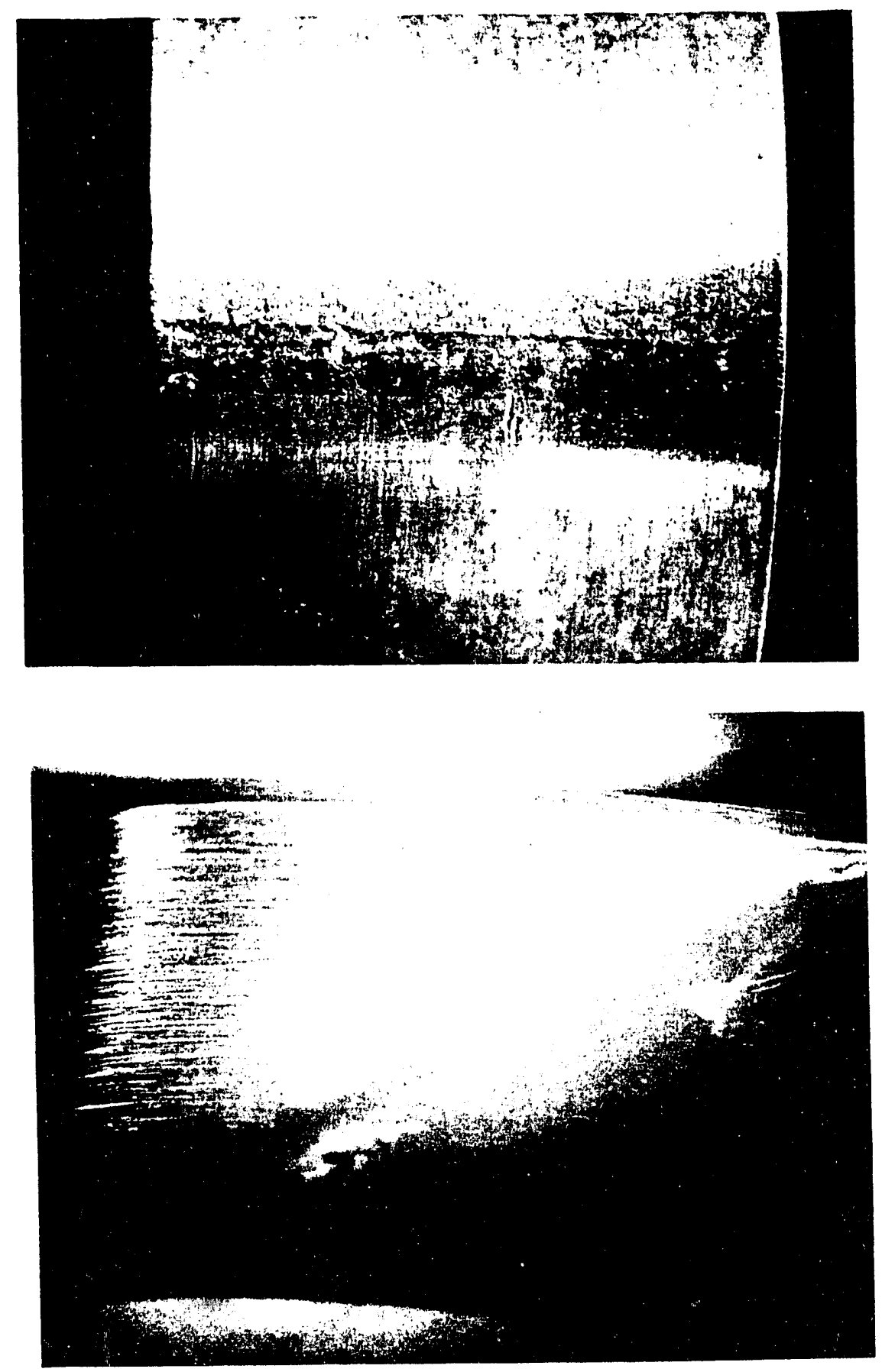

FIGURE A.3-27, $a$ and $b$

TITANIUM GRADE 2 U-BEND FROM MTC-2

WITH A WELD AT THE APEX OF THE BEND

$a$ (top) - at the weld, $b$ (bottom) - inside surface of a leg

Magnification - 4X 


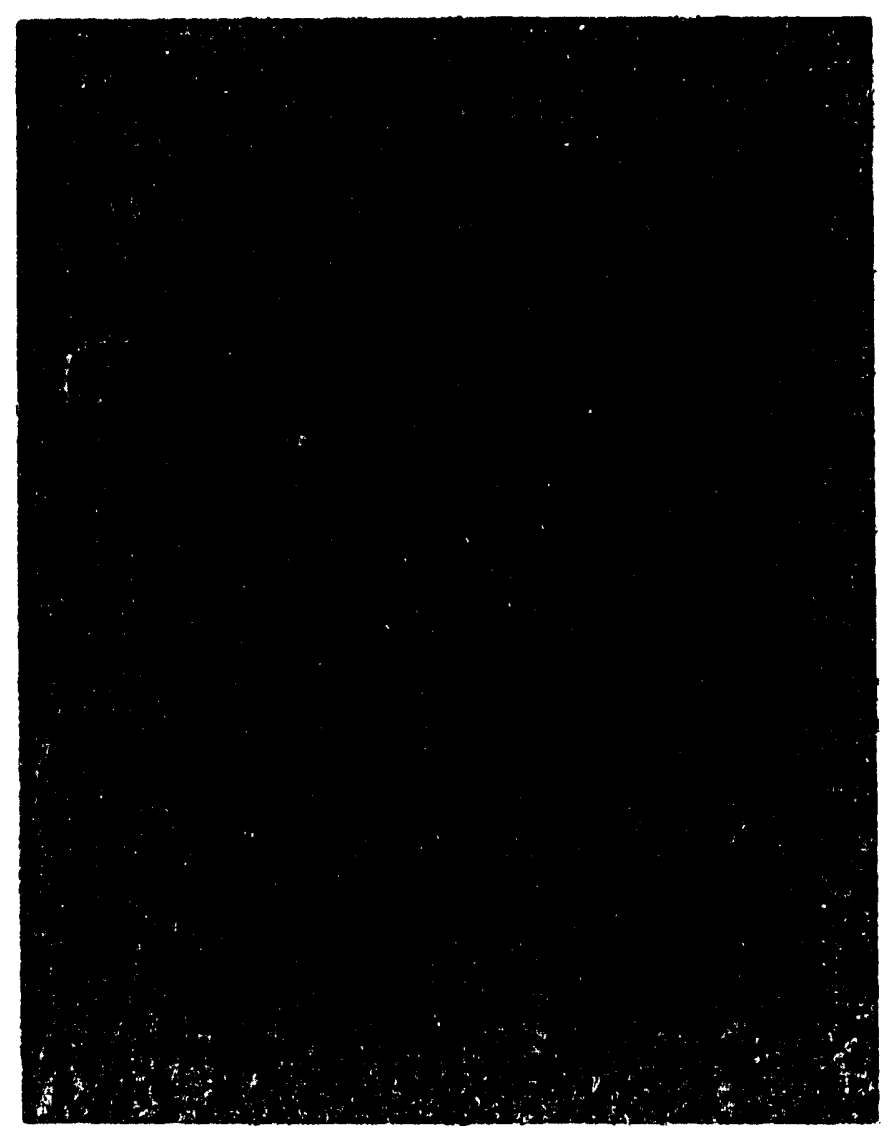

FIGURE A.3-27, C

BASE METAL MICROSTRUCTURE

IN THE TITANIUM GRADE 2 U-BEND FROM MTC-2

(The sample was taken from a leg of the U-bend)

Magnification - $800 \mathrm{X}$

Flle:modarlfg57427c.doc 


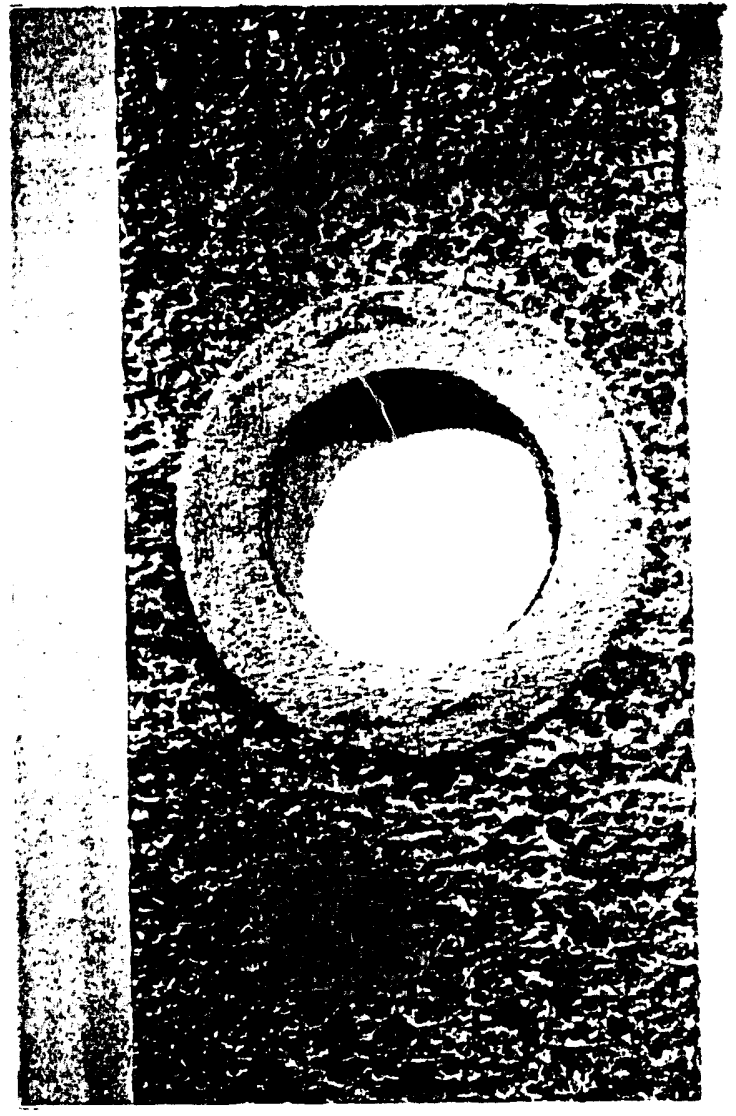

a

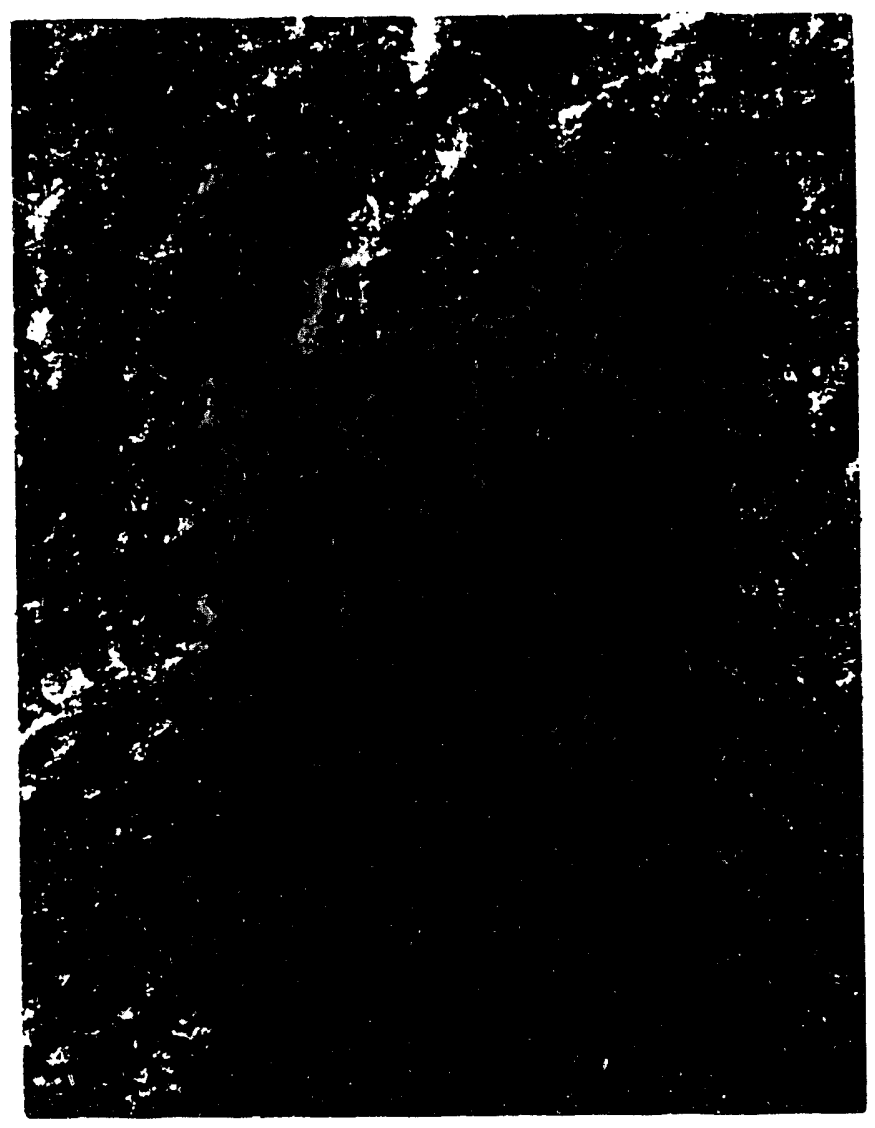

b

FIGURE A.3-28

ALLOY 20Cb-3 COUPON FROM MTC-2

Magnification: $a-3 X ; b-12 X$ 


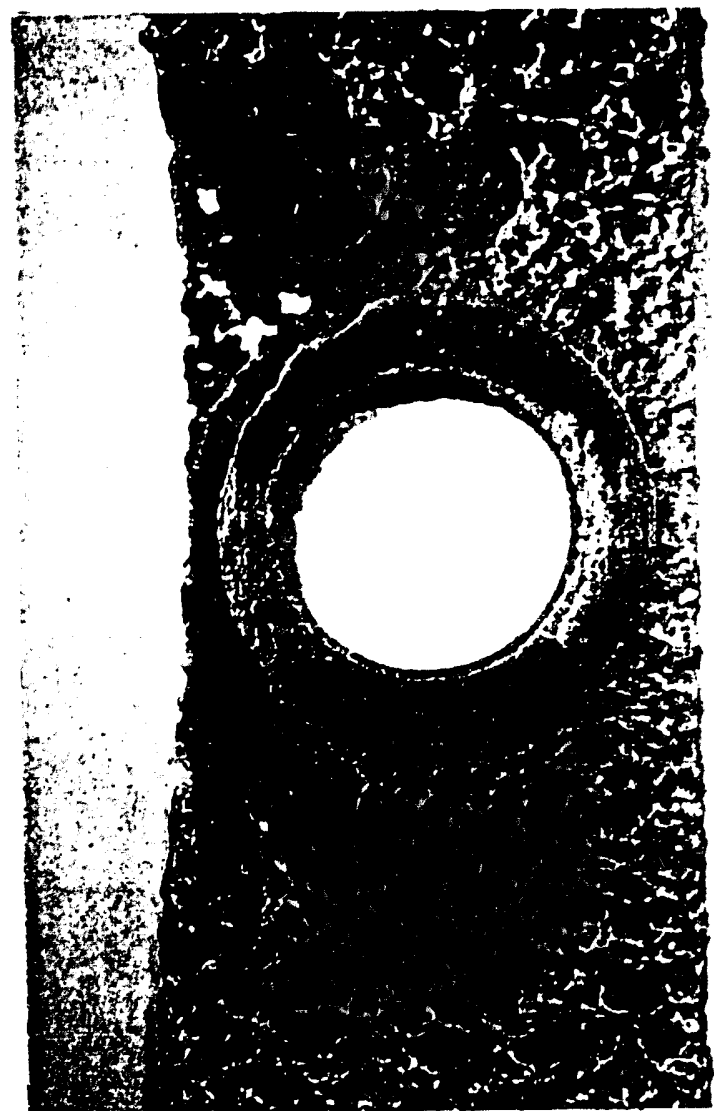

a

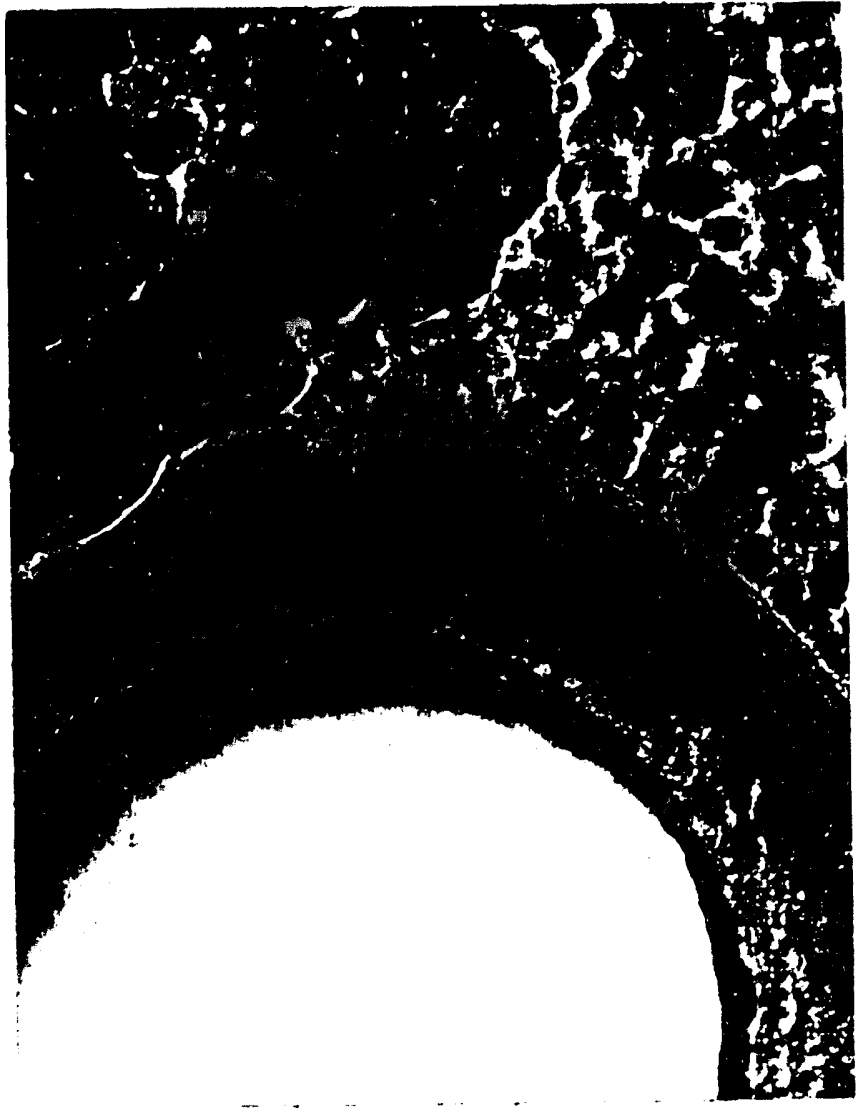

b

FIGURE A.3-29

ALLOY H-9M COUPON FROM MTC-2

Magnification: $a-3 X ; b-8 X$ 


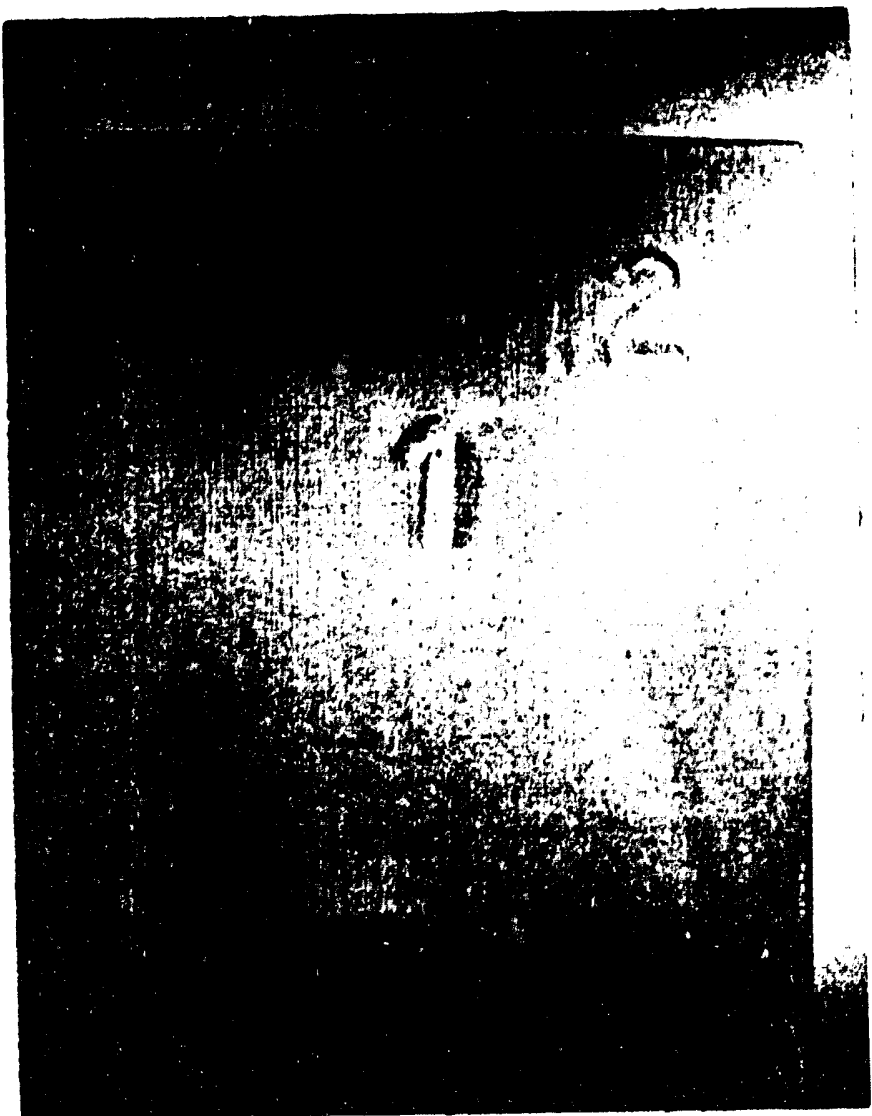

FIGURE A.3-30, a

TITANIUM GRADE 12 COUPON FROM MTC-2

Magnification: $\mathbf{4 X}$ 


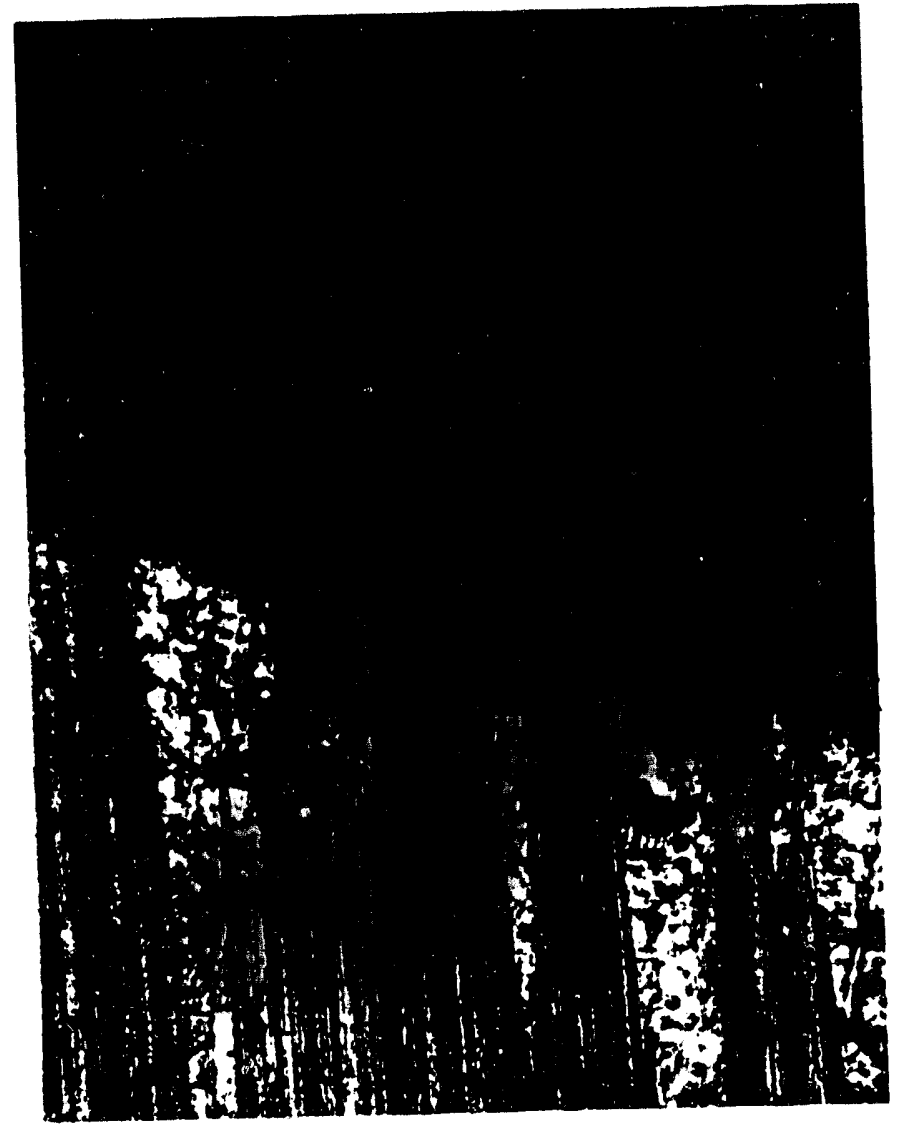

FIGURE A.3-30, $b$ and $c$

TITANIUM GRADE 12 COUPON FROM MTC-2

$b$ (top) - in the stamped area; $c$ (bottom) - at and under washer-shlelded area

Magnification: a-9X; b-200X

File:modarlfg57430b.doc 
APPENDIX B

168-HOUR PERFORMANCE TEST RUN SUMMARY 


\title{
APPENDIX B
}

\section{RUN 932 168-HOUR PERFORMANCE TEST}

\author{
RUN SUMMARY
}

\begin{abstract}
DATE OF RUN: HOURS HOT: NOZZLE TYPE: FEED FLOW:
\end{abstract}

\author{
August 17 - August 28 \\ 231.7 \\ Design A-15, Low Velocity \\ 313 gallons-per-day
}

\subsection{OBJECTIVE}

The objectives of the longest run of the program were to run continuously for 168 hours while demonstrating effective salt removal and neutralization, and to benchmark the progress of the MODAR process.

\subsection{RUN OVERVIEW}

The official 168 hour performance test commenced on August 20 at 2:26 and ended on August 28 at 10:00. Attempts at initiating the run were made from August 17 to August 20, however several nonprocess mechanical failures forced the plant down. This run report includes the entire time period in which the run was attempted. Although August 17, 18, and 19 are not officially part of the 168 hour test, they may have worn the nozzle and the system, and will therefore be included in the analysis. The 168 hours of the run are broken into two segments:

\section{Segment I - August 20 2:26 - August 23 7:31 \\ Segment II- August 24 14:25- August 28 10:00}

SIM and salt forming feeds were processed for 77.1 hours during segment I. A leak in a thermowell nozzle required shutdown of the plant. Based on the amount of salt in the reactor, as well as the filter, nozzle, and annular $\Delta \mathrm{ps}$, the system would likely have been forced down for a vessel rinse within twentyfour hours of the failure.

The vessel was rinsed between the first and second segments of the run to remove accumulated salt from the reactor. The vessel rinse and the resulting start-up are considered down time of the plant. Since repairs were conducted during the down time of Run 932, the plant turnaround for a vessel rinse has been extrapolated from Run 928, which is more indicative of the time a vessel rinse would take. 
SIM and salt-forming feeds were processed for 91.6 hours during segment II. The plant was shut down voluntarily when the required 168 hours had elapsed. The length of time the plant could have continued running is unknown. The most probable cause of shutdown would have been salt accumulating within the reactor.

\subsection{RUN SUMMARY}

Run 932 was initiated on August 17. The system was started up at 12:49. At 16:30 a minor leak at thermowell nozzle 4014 required shutdown of the system. The thermowell was capped and the system was started approximately twenty minutes later. At 19:22 IPA and Aqueous streams were sent to the system. A CO spike of $100 \mathrm{ppm}$ occurred at this time.

Salt precursors and SIM were sent to the system on August 18 at 1:43. At 6:39 the fifth stage rupture disk in the air compressor blew and resulted in an controlled shutdown. The disk was replaced and the system was restarted. At 13:46 salt precursors and SIM were again sent to the system.

After approximately 24 hours of running SIM and salt precursors, with filter $\Delta$ ps of 8.8 psi and 9.8 psi, the hot valve AV410A was closed to isolate filter arm A from the reactor so the filter could be backwashed. The packing of AV410B started to leak. An controlled shutdown was performed so the hot valves could be removed from the system. With the hot valves removed, the filters would still perform their function as a finishing stage of salt removal from the effluent, but they could no longer be backwashed. Both filters were used in parallel for the remainder of the run.

After removing the hot valves, the system was restarted. SIM and salt precursors were sent to the system at 2:26 on August 20. The salt feeds were processed for 77.1 hours, until August 23, 7:31, when a leak at thermowell 4008 required a shutdown. During segment $I$, seven run time rinse procedures (RTRPs) were completed (refer to section on RTRPs).

The core and nozzle $\Delta \mathrm{ps}$ increased steadily. After $\mathbf{5 9 . 2}$ hours of processing salt the core $\Delta \mathrm{p}$ was as high as $125 \mathrm{psi}$. In previous runs, the nozzle $\Delta \mathrm{ps}$ were reduced by turning off SIM, Perc, and Caustic. In an attempt to reproduce this effect, the Perc and Caustic feeds were put in recycle in the first step of turning off all salt feeds. Within a few minutes (with the SIM feed still on) the core, annular, and filter $\Delta \mathrm{ps}$ were drastically reduced (see section on core, annular and filter $\Delta \mathrm{ps)}$.

With $13 \mathrm{~kg}$. of salt in the reactor, filter $\Delta \mathrm{ps}$ of $42.2 \mathrm{psi}$ and $44.5 \mathrm{psi}$, and core and annular $\Delta \mathrm{ps}$ of 10.5 psi and 29.5 psi respectively, the decision was made to rinse the vessel before restarting the system.

On August 24, with repairs completed and the reactor and filters rinsed, the system was restarted. SIM and salt precursors were sent to the system at 14:25.

During segment II salt was processed through the system for 91.6 continuous hours with no process or mechanical failures. The system was shut down on August 28 at 10:00, after having met the 168 hour objective. Seven RTRPs were completed during this portion of the run. The Perc and Caustic feeds were put into recycle two times to reduce the core, annular, and filter $\Delta \mathrm{ps.} \mathrm{Each} \mathrm{of} \mathrm{the} \Delta$ ps were far lower in this second segment of the run than they had been in the first segment (see section on core, 
annular, and filter $\Delta \mathrm{ps})$.

Table 1: Reactor Conditions':

\begin{tabular}{|c|c|c|}
\hline & $\begin{array}{l}\text { SCW,IPA,Perc,Caustic } \\
\text { 8/20/93 11:00-8/23/93 3:00 } \\
\text { Segment I }\end{array}$ & $\begin{array}{l}\text { SCW,IPA,SIM,Perc,Caustic } \\
\text { 8/24/93 23:00-8/28/93 10:00 } \\
\text { Segment II }\end{array}$ \\
\hline $\mathrm{SCW}(\mathrm{ml} / \mathrm{min})$ & 1050 & 1010 \\
\hline Air (NLPM) & 930 & 930 \\
\hline IPA (ml/min) & 112 & 109 \\
\hline Brine Addition ${ }^{2}(\mathrm{ml} / \mathrm{min})$ & 228 & 122 \\
\hline BWA High & 102 & 83 \\
\hline BWA LO & 126 & 39 \\
\hline Aqueous Waste Flow (ml/min) & 722 & 708 \\
\hline Caustic & 26 & 25.6 \\
\hline Perc & 1.4 & 1.33 \\
\hline BTO (ml/min) & 365 & 491 \\
\hline Liner and Filter Purge & 144 & 129 \\
\hline
\end{tabular}

\subsection{ANALYSIS/CONCLUSIONS}

4.1 Data

TABLE 2: BRINE AND EFFLUENT COMPOSITE ANALYSIS

\begin{tabular}{|l|l|l|l|l|l|l|l|l|l||}
\hline COMPOSITE & $\mathrm{pH}$ & $\begin{array}{c}\mathrm{Cl}^{-} \\
(\mathrm{ppm})\end{array}$ & $\begin{array}{c}\mathrm{Na}^{+} \\
(\mathrm{ppm})\end{array}$ & $\begin{array}{c}\mathrm{SO}_{4} \\
(\mathrm{ppm})\end{array}$ & $\begin{array}{l}\text { TOC } \\
(\mathrm{ppm})\end{array}$ & $\begin{array}{l}\mathrm{Cr} \\
(\mathrm{ppm})\end{array}$ & $\begin{array}{l}\mathrm{Ni} \\
(\mathrm{ppm})\end{array}$ & $\begin{array}{l}\mathrm{Fe} \\
(\mathrm{ppm})\end{array}$ \\
\hline $\begin{array}{l}\text { Effluent Composite: } \\
\text { SCW, IPA, Salt } \\
8 / 20 / 93 \text { 11:00 - 8/23/93 7:00 Segment I } \\
8 / 25 / 93 \text { 23:00 -8/28/93 9:50 Segment II }\end{array}$ & 2.3 & 270 & 6 & $<1$ & $<1$ & 3.3 & 11 & $<0.1$ \\
\hline $\begin{array}{l}\text { Brine Composite: } \\
\text { SCW,IPA, Salt } \\
\text { 8/20/93 11:00 -8/23/93 7:00 Segment I } \\
\text { 8/25/93 23:00-8/28/93 9:50 Segment II }\end{array}$ & 6.7 & 12500 & 10000 & 3680 & 2 & 1.5 & 0.8 & 0.7 \\
\hline
\end{tabular}

\footnotetext{
'The flows are determined by averaging the flows recorded in ten minute intervals.
}

${ }^{2}$ See Run 931 Report for a diagram of the BTO/BWA configuration 
Conductivity: Brine Composite (of Segment I and II)- 17,400 umhos/cm

Acidity Results: $\quad$ Effluent Composite (of Segment I and II)- equivalent to $340 \mathrm{mg} \mathrm{CaCO}_{3} / \mathrm{L}$ of effluent

\section{Alpha Analytical}

The following samples were sent to Alpha Analytical:

- Brine \& Effluent Composites from 8/20/93 11:00 - 8/23/93 7:00, 8/25/93 23:00 - 8/28/93 9:50

- Tenax Trap of 8/22/93 3:15 - 21:05, $150 \mathrm{ng} / 215.8$ liters of effluent gas

- Tenax Trap of 8/25/93 13:50 - 8/26/93 06:30 $120 \mathrm{ng} / 200$ liters of effluent gas

- Brine Sludge resulting from in-house treatment of the Brine for TCLP

The results of the analyses are provided in the attached Tables 3, 4, and 5 . 
TABLE 3: ALPHA ANALYTICAL RESULTS- Brine and Effluent Composites

\begin{tabular}{|c|c|c|c|}
\hline Volntile Orennics by GC/MS & Emvent & Brine & RDL $(100 /])$ \\
\hline Methylene Chloride & ND & ND & 5.0 \\
\hline 1,1-Dichloroethane & ND & ND & 1.5 \\
\hline Chloroform & ND & ND & 1.5 \\
\hline Carbon Tetrachloride & ND & ND & 1.0 \\
\hline 1,2-Dichloropropane & ND & ND & 3.5 \\
\hline Dibromochlonomethane & ND & ND & 1.0 \\
\hline 1,1,2-Trichloroethane & ND & ND & 1.5 \\
\hline 2-Chloroethylvinyl ther & ND & ND & 10 \\
\hline Tetrachloroethene & ND & ND & 1.5 \\
\hline Chlorobenzene & ND & ND & 3.5 \\
\hline Trichlorofluoromethane & ND & ND & 5.0 \\
\hline 1,2-Dichloroethane & ND & ND & 1.5 \\
\hline 1,1,1-Trichloromethane & ND & ND & 1.0 \\
\hline Bromodichloromethane & ND & ND & 1.0 \\
\hline trans-1,3-Dichloropropene & ND & ND & 1.5 \\
\hline cir-1,3-Dichloropropene & ND & ND & 1.0 \\
\hline Bromoform & ND & ND & 1.0 \\
\hline 1,1,2,2-Tetrachloroethane & ND & ND & 1.0 \\
\hline Benzene & ND & ND & 1.0 \\
\hline Toluene & ND & ND & 1.5 \\
\hline Ethylbenzene & ND & ND & 1.0 \\
\hline Chloromethane & ND & ND & 10 \\
\hline Bromomethane & ND & ND & 2.0 \\
\hline Vinyl Chloride & ND & ND & 3.5 \\
\hline Chloroethane & ND & ND & 2.0 \\
\hline 1,1-Dichloroethene & ND & ND & 1.5 \\
\hline trans-1,2-Dichloroethene & ND & ND & 1.5 \\
\hline Trichloroethene & ND & ND & 1.0 \\
\hline 1,2-Dichlorobenzene & ND & ND & 10 \\
\hline 1,3-Dichlorobenzene & ND & ND & 10 \\
\hline 1,4-Dichlorobenzene & ND & ND & 10 \\
\hline
\end{tabular}




\begin{tabular}{|l|l|l|l|}
\hline Volatile Onganics by GC/MS & Emuent & Brine & RDL (ug//) \\
\hline Methyl tert butyl cher & ND & ND & 10 \\
\hline Xylenes & ND & ND & 1.0 \\
\hline cir-1,2-Dichlorocthene & ND & ND & 1.0 \\
\hline Dibromomethane & ND & ND & 10 \\
\hline 1,4-Dichlorobutane & ND & ND & 10 \\
\hline Iodemethane & ND & ND & 10 \\
\hline 1,2,3-Trichloropropane & ND & ND & 10 \\
\hline Styrene & ND & ND & 1.0 \\
\hline Dichlorodifluoromethane & ND & ND & 10 \\
\hline Acetone & ND & ND & 10 \\
\hline Carbon dimulfide & ND & ND & 10 \\
\hline 2-Butanone & ND & ND & 4.5 \\
\hline Vinyl Acetate & ND & ND & 10 \\
\hline 4-Methyl-2-pentanone & ND & ND & 10 \\
\hline 2-Hexanone & ND & ND & 10 \\
\hline Ethyl methacrylate & ND & ND & 10 \\
\hline Acrolein & ND & ND & 25 \\
\hline Acrolonitrile & ND & ND & 10 \\
\hline & & & \\
\hline
\end{tabular}

RDL = Reportable Detection Limit 
TABLE 4: ALPHA ANALYTICAL RESULTS- Brine Sludge

\begin{tabular}{|c|c|c|}
\hline Compound & Resulis $(\mathrm{mo} / \mathrm{M})$ & BDL $(m a / n)$ \\
\hline \multicolumn{3}{|l|}{ TCLP Extraction } \\
\hline Anenic & ND & 1.0 \\
\hline Barium & ND & 0.50 \\
\hline Cadmium & ND & 0.10 \\
\hline Chromium & ND & 0.20 \\
\hline Lead & ND & 0.50 \\
\hline Mercury & ND & 0.005 \\
\hline Selenium & ND & 0.50 \\
\hline Silver & ND & 0.10 \\
\hline \multicolumn{3}{|l|}{ TCLP Volatic Ompanics } \\
\hline Benzene & ND & 0.005 \\
\hline Carton Tetrachloride & ND & 0.005 \\
\hline Chlorobenzene & ND & 0.018 \\
\hline Chloroform & ND & 0.0075 \\
\hline 14-Dichlorobenzene & ND & 0.05 \\
\hline L.2-Dichlomethane & ND & 0.0075 \\
\hline 1.1-Dichlonoethane & ND & 0.0075 \\
\hline Tetrachloroethane & ND & 0.0075 \\
\hline Trichloroethene & ND & 0.005 \\
\hline Vinul Chloiide & ND & 0.018 \\
\hline Methvl ethvl ketone & ND & 0.05 \\
\hline \multicolumn{3}{|c|}{ TCLP Semi-Volatile Oranics } \\
\hline Cresol, total & ND & 0.058 \\
\hline 2.4-Dinitrotoluene & ND & 0.030 \\
\hline Hexachlorobenzene & ND & 0.022 \\
\hline Hexachloro-1.3-butadiene & ND & 0.064 \\
\hline Hexachlomethane & ND & 0.040 \\
\hline Nitrobenzene & ND & 0.0152 \\
\hline Pentachlorophenol & ND & 0.0736 \\
\hline 2,4,5-Trichlorophenol & ND & 0.038 \\
\hline 2.4.6-Trichlorophenol & ND & 0.022 \\
\hline Eyridine & ND & 0.20 \\
\hline
\end{tabular}


TABLE 5: NICKEL AND CHROMIUM CONCENTRATIONS IN THE BRINE AND EFLUENT COMPOSITES

SFFLUENT

BRINE

\begin{tabular}{|c|c|c|c|c|}
\hline Tine & $\mathrm{Cr}(\mathrm{ppm})$ & Ni (ppm) & Cr (ppm) & NI (ppm) \\
\hline \multicolumn{5}{|l|}{ SEGMENT I } \\
\hline $8 / 20 / 93 \quad 3: 00-8 / 20 / 93 \quad 10: 00$ & 2.2 & 12 & 2.0 & 1.0 \\
\hline $8 / 20 / 9311: 00-8 / 20 / 9319: 00$ & 2.0 & 11 & 1.0 & 0.5 \\
\hline $8 / 20 / 93 \quad 20: 00-8 / 21 / 93 \quad 3: 00$ & 2.0 & 10 & 0.5 & 0.5 \\
\hline $8 / 21 / 93 \quad 4: 00-8 / 21 / 93 \quad 11: 00$ & 2.0 & 9.0 & 0.5 & 0.3 \\
\hline $8 / 21 / 9312: 00-8 / 21 / 9319: 00$ & 2.0 & 9.0 & 1.0 & 1.0 \\
\hline $8 / 21 / 93 \quad 20: 00-8 / 22 / 93 \quad 3: 00$ & 2.0 & 9.0 & 0.5 & 1.0 \\
\hline $8 / 22 / 93 \quad 4: 00-8 / 22 / 93 \quad 11: 00$ & 2.0 & 9.0 & 1.0 & 1.0 \\
\hline $8 / 22 / 9312: 00-8 / 22 / 9319: 00$ & 2.0 & 9.0 & 1.0 & 1.0 \\
\hline $8 / 22 / 93 \quad 20: 00-8 / 23 / 93 \quad 3: 00$ & 2.0 & 8.0 & 1.0 & 3.0 \\
\hline $8 / 23 / 93 \quad 4: 00-8 / 23 / 93 \quad 7: 00$ & 2.0 & 8.0 & 1.0 & 1.0 \\
\hline \multicolumn{5}{|l|}{ SEGMENT II } \\
\hline $8 / 24 / 9315: 00-8 / 24 / 9322: 00$ & 7.0 & 9.0 & 5.0 & 1.0 \\
\hline $8 / 24 / 9323: 00-8 / 25 / 93 \quad 6: 00$ & 5.0 & 8.0 & 3.0 & 1.0 \\
\hline $8 / 25 / 93 \quad 7: 00-8 / 25 / 93 \quad 14: 00$ & 6.0 & 8.0 & 2.0 & 1.0 \\
\hline $8 / 25 / 9315: 00-8 / 25 / 9322: 00$ & 4.0 & 8.0 & 2.0 & 1.0 \\
\hline $8 / 25 / 9323: 00-8 / 26 / 93 \quad 6: 00$ & 4.0 & 7.0 & 2.0 & 1.0 \\
\hline $8 / 26 / 93 \quad 7: 00-8 / 26 / 9314: 00$ & 4.0 & 7.0 & 2.0 & 0.5 \\
\hline $8 / 26 / 9315: 00-8 / 26 / 9322: 00$ & 4.0 & 6.0 & 2.0 & 0.3 \\
\hline $8 / 26 / 9323: 00-8 / 27 / 93 \quad 6: 00$ & 5.0 & 6.0 & 2.0 & 1.0 \\
\hline $8 / 27 / 93 \quad 7: 00-8 / 27 / 93 \quad 14: 00$ & 4.0 & 6.0 & 1.0 & 0.5 \\
\hline $8 / 27 / 9315: 00-8 / 27 / 9322: 00$ & 4.0 & 6.0 & 1.0 & 0.5 \\
\hline $8 / 27 / 93 \quad 23: 00-8 / 28 / 93 \quad 6: 00$ & 3.0 & 6.0 & 1.0 & 1.0 \\
\hline $8 / 28 / 93 \quad 7: 0.0-8128 / 93 \quad 9: 50$ & 3.0 & 6.0 & 10 & 10 \\
\hline
\end{tabular}

The nickel and chromium levels in both the brine and the effluent were consistent during Segment I of the run. In the beginning of Segment II, the chromium levels had increased over those of Segment I. The chromium concentration slowly decreased with time. The nickel concentrations from Segment II appeared consistent with those from Segment I. Based on post run observations, the nickel and chromium were most likely from the observed corrosion of the filter end plates and nozzle. 
TABLE 6: EFFLUENT GAS SAMPLING BOTTLE RESULTS

\begin{tabular}{|l|l|l||}
\hline Gas & Result $\left(\mathrm{mg} / \mathrm{m}^{3}\right)$ & $\begin{array}{l}\text { Detection Limit } \\
\left(\mathrm{mg} / \mathrm{m}^{3}\right)\end{array}$ \\
\hline Hydrochloric Acid & ND & 10 \\
\hline Sulfur Dioxide & ND & 2.5 \\
\hline Chlorine & ND & 1.5 \\
\hline
\end{tabular}




\subsection{Mass Balances/Destruction Calculations}

\begin{tabular}{|l|l|l|l|}
\hline Mass Balance & Date & Closure(\%) & Dest. Efriciency \\
\hline Water & $8 / 20 / 9311: 00-8 / 23 / 933: 00$ & 99.2 & - \\
\hline Water & $8 / 24 / 9323: 00-8 / 28 / 9310: 00$ & 97.6 & -- \\
\hline $\begin{array}{l}\text { Salt (based on } \mathrm{Cl}^{\prime}, \mathrm{SO}_{4}^{-2} \\
\text { readings) }\end{array}$ & $8 / 24 / 9323: 00-8 / 28 / 9310: 00$ & 95.7 & $\ldots$ \\
\hline Carbon & $\begin{array}{l}8 / 20 / 9311: 00-8 / 23 / 937: 00 \\
8 / 25 / 9323: 00-8 / 28 / 939: 50\end{array}$ & 98.8 & $>99.99$ \\
\hline Perc & $8 / 22 / 933: 15-21: 05$ & -- & $>99.9998$ \\
\hline
\end{tabular}

\subsection{Salt}

\section{On-line recovery}

\section{Segment I:}

The feed was 2.0 weight percent salt. Assuming 80 percent neutralization of Perc, $76.3 \mathrm{~kg}$. of salt were processed over 77.1 hours. The average salt processed on a per minute basis was 16.5 grams: 13.7 grams of sodium chloride and 2.8 grams of sodium sulfate. Assuming 80 percent neutralization, 2.6 grams of sodium chloride per minute resulted from the neutralization of Perc. Based on the specific gravity of the brine, 75.3 percent of the salt was removed.

\section{Segment II:}

The feed was 1.9 weight percent salt. Assuming 80 percent neutralization of Perc, $87.4 \mathrm{~kg}$. of salt were processed over 91.6 hours. The average salt processed on a per minute basis was 15.9 grams: 13.2 grams of sodium chloride and 2.7 grams of sodium sulfate. Assuming 80 percent neutralization, 2.4 grams of sodium chloride per minute resulted from the neutralization of Perc.

\section{Deposit Location}

This data is based on Segment II of the run. The percent of salt removed is based on the salt recovered, not the total salt processed. The salt balance had $95.7 \%$ closure. The salt balance was calculated by assuming all $\mathrm{Cl}^{-}$formed $\mathrm{NaCl}$, and all $\mathrm{SO} 4$ formed $\mathrm{NaSO}$. Filter $\mathrm{A}$ was removed and analyzed. Filter B was assumed to have an equal amount of salt on it. The following summarizes the amount of salt contained in each section of the reactor system. 


\begin{tabular}{lcl} 
& Kilograms & \multicolumn{1}{c}{$\%$} \\
Reactor & 13.22 & 15.8 \\
Filters & 0.50 & 0.6 \\
Nozzle & 0.16 & 0.2 \\
Brine & 69.95 & 83.4
\end{tabular}

The physical description of the deposits follows:

Reactor

Based on visual observations, it appeared that the majority of the salt was deposited between TE 4019 to TE 4015 (Region I). This salt layer was estimated to be 1.5 inches thick. A second deposit, from TE 4015 to just above TE 4009 (Region II), was approximately .5 inches thick. Assuming these two regions account for all of the salt in the reactor, and assuming uniform salt density, $69 \%$ of the observed salt was found in Region I, and $31 \%$ was found in Region II.

A sample of the salt deposit from Region I of the reactor was analyzed. The $\mathrm{pH}$ was slightly higher than deposits taken from the nozzle tip and deposits from near the entrance of filter arm A, which had pHs near 7.0. The $\mathrm{NaCl}: \mathrm{Na} 2 \mathrm{SO} 4$ ratio was 7.5 , while the feed ratio was 4.9.

Filters

247 grams of salt were found on filter $\mathrm{A}$. The $\mathrm{pH}$ was 7.7 , which is higher than the vessel rinses which had $\mathrm{pHs}$ of 4.0 and 3.5. The $\mathrm{pH}$ does not indicate that carbonate was present. At this point, the cause for the difference in $\mathrm{pH}$ between various rinses is unknown. Assuming an identical amount of salt on filter B, this would account for $0.6 \%$ of the total salt processed. This value compares well with Run 931 where $1 \%$ of the total salt processed was found on the filters. The filter $\Delta \mathrm{p}$ increased throughout the run. (See the section on Filter, Core, and Annular $\Delta \mathrm{ps}$ ).

A: Filter A was pulled for analysis. The first nine inches of the arm (measuring from the reactor to the outboard end of the arm) had solid salt deposits on the top of the beads. This layer was approximately 0.6 inches thick closest to the reactor but tapered off to a thin layer 9 inches from the reactor. From 9 inches to 21 inches, there was little surface accumulation of salt. From 21 inches to 29 inches there was virtually no salt accumulation. The beads were stuck together the full depth of the filter closest to the reactor but this decreased along the length of the filter, with no filter bed penetration at the outboard end of the filter.

B: Filter B was observed by looking through the filter A hole. The entrance to the filter appeared to be entirely blocked by salt with no visible holes. The salt appeared to be approximately 0.5 inches thick above the filter endplate. At the top of the filter entrance a 1 inch outward lip had formed. The salt covering the filter endplate was uniform with the wall salt deposit which was estimated to be 1.5 inches thick. 


\subsection{Run Time Rinse Procedures (RTRPg)}

RTRPs improved the salt removal from the reactor. The RTRPs appeared to rinse additional salt from the lower section of the reactor wall. It is not clear whether RTRPs increased the on-line time of the system. At this time it is not clear if the limiting factor for this configuration was the integrity of the nozzle, the filter inlet plugging, blocking the upper part of the reactor with salt, or in the absence of RTRPs, a salt block in the lower part of the reactor.

As salt accumulated in the reactor, the brine level could be taken higher without reducing the destruction efficiency. In Run 931, which had the same nozzle configuration, high CO levels resulted from an RTRP where the L/D was 3.4. In this run, this occurred with approximately $9.8 \mathrm{~kg}$. of salt in the reactor, and after 22.2 hours of running salt precursors. The salt in the reactor decreased the effective diameter within the reactor (this increases the L/D), forcing the flow around more quickly. The flow is no longer forced into the brine. It turns around allowing more residence time. The evolving configuration resulting from changes in the nozzle configuration and the salt deposited within the reactor changed the RTRP capabilities.

Table 7 and the RTRP graphs summarize each of the run time rinses completed for the 168 hour run. Two of the thirteen rinses removed more than one kilogram of salt. The rinse on 8/26 from 21:37 to $22: 37$ removed approximately $1.76 \mathrm{~kg}$. of salt, and the rinse on $8 / 28$ from 2:30 to $3: 47$ removed approximately $1.15 \mathrm{~kg}$. of salt. 
TABLE 7: RTRPS PERFORMED DURING THE 168 HOUR RUN

\begin{tabular}{|l|l|l|l|}
\hline Time of Rinse & $\begin{array}{l}\text { Minimum L/D } \\
\text { Reached }\end{array}$ & $\begin{array}{l}\text { Hours of Cont. } \\
\text { SIM }\end{array}$ & $\begin{array}{l}\text { Hours Since } \\
\text { Beginning of Last } \\
\text { Rinse }\end{array}$ \\
\hline $8 / 20 \quad 11: 41-12: 11$ & 4.2 & - \\
\hline $8 / 21 \quad 17: 32-18: 18$ & 3.4 & 9.25 & 29.85 \\
\hline $8 / 22 \quad 03: 42-04: 59$ & 3.4 & 49.10 & 10.17 \\
\hline $8 / 22 \quad 08: 15-09: 26$ & 3.3 & 53.82 & 4.55 \\
\hline $8 / 22 \quad 17: 14-19: 18$ & 3.0 & 61.62 & 7.80 \\
\hline $8 / 22 \quad 22: 29-8 / 2300: 29$ & 2.9 & 64.80 & 3.18 \\
\hline $8 / 23 \quad 6: 30-H D S D$ & - & - & - \\
\hline $8 / 25 \quad 21: 32-22: 02$ & 3.7 & 31.12 & - \\
\hline $8 / 26 \quad 00: 15-00: 54$ & 3.5 & 33.34 & 2.22 \\
\hline $8 / 26 \quad 21: 37-22: 37$ & 3.6 & 54.71 & 21.37 \\
\hline $8 / 27 \quad 00: 29-01: 05$ & 3.4 & 56.58 & 1.87 \\
\hline $8 / 27 \quad 07: 18-08: 23$ & 3.3 & 62.80 & 6.22 \\
\hline $8 / 27 \quad 15: 20-16: 36$ & 3.2 & 70.83 & 8.03 \\
\hline $8 / 28 \quad 02: 30-03: 47$ & 3.2 & 80.73 & 9.90 \\
\hline & & & \\
\hline
\end{tabular}

${ }^{3}$ The Diameter does not take into account the salt accumulated in the reactor 


\subsection{Neutralization}

The neutralization efficiency was calculated every thirty minutes while Perchloroethylene and Caustic were being processed. The neutralization efficiency was approximately $70 \%$ at the first introduction of Perc and Caustic. The degradation of the nozzle and accumulation of salt appeared to improve the neutralization. In segment I the neutralization efficiency was between 68 to 87 percent. In segment II the neutralization efficiency was between 72 to 85 percent. The Perc flow varied between 1.1 and 1.5 $\mathrm{ml} / \mathrm{min}$. The average value for segments I and II was approximately $1.4 \mathrm{ml} / \mathrm{min}$.

\subsection{Nozzle Core, Annular, and Filter $\Delta p s$}

Based on Figures One and Two, the following trends were evident during the course of the run:

- The core $\Delta p$ increased with the time the salt was run. The rate of increase of the core $\Delta p$ varied. In segment $\mathrm{I}$, the maximum $\Delta \mathrm{p}$ was $125 \mathrm{psi}$. In segment II, the maximum $\Delta \mathrm{p}$ was approximately 30 psi.

- Turning the Perc and Caustic feeds off reduced the core $\Delta p$ in less than thirty minutes. It then took twenty four hours for the $\Delta \mathrm{p}$ to reach its original value.

- The annular $\Delta \mathrm{p}$ also decreased when the Perc and Caustic feeds were shut off, the trend was not as notable as that of the core $\Delta \mathrm{p}$. Based on the trend of Figure 1, annular $\Delta \mathrm{p}$ did not usually exceed the core $\Delta p$. 
FIGURE 1: CORE AND ANNULAR DPS

Pressure, psi

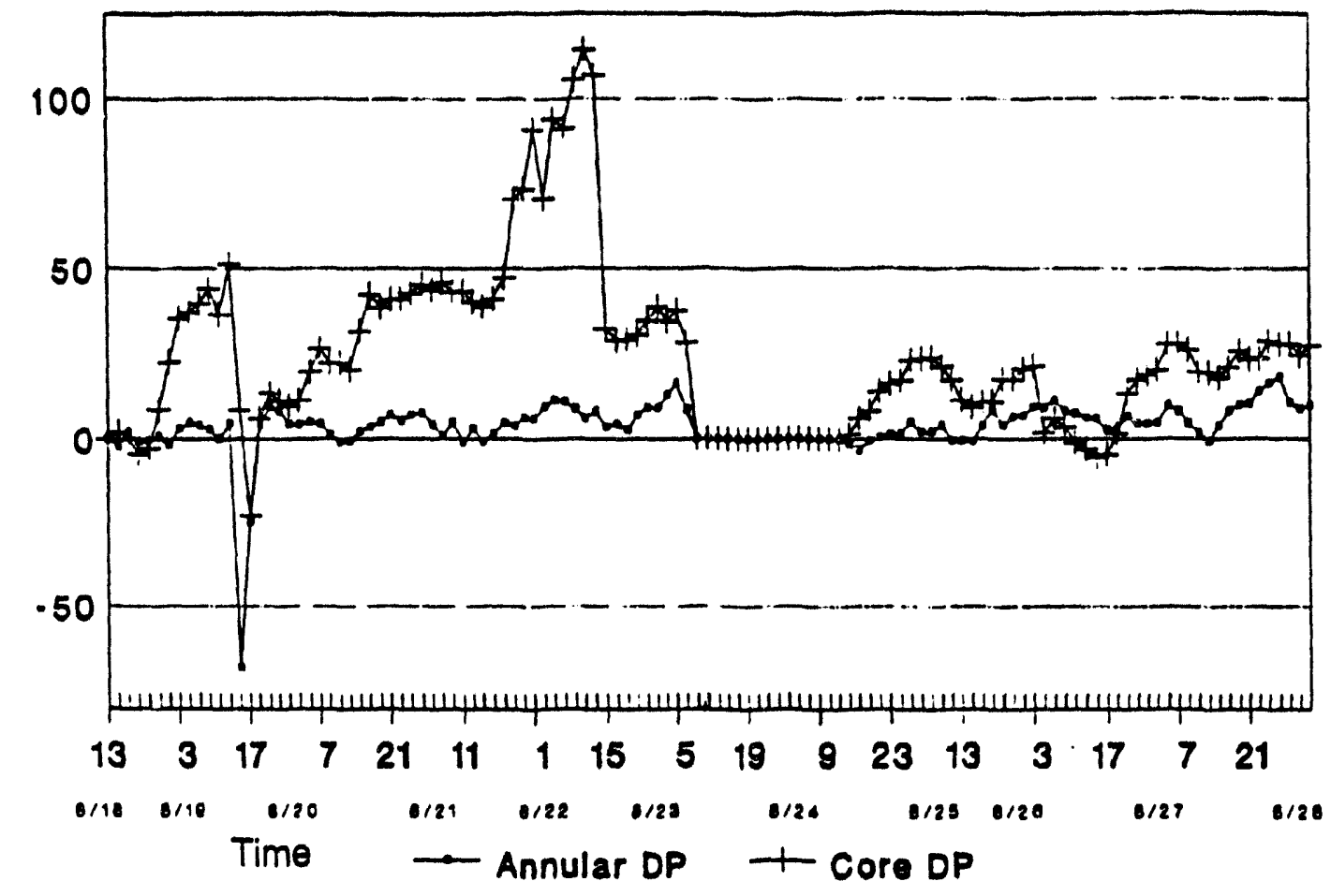

FIGURE 2: FILTER A AND B DPTS

Pressure, psi

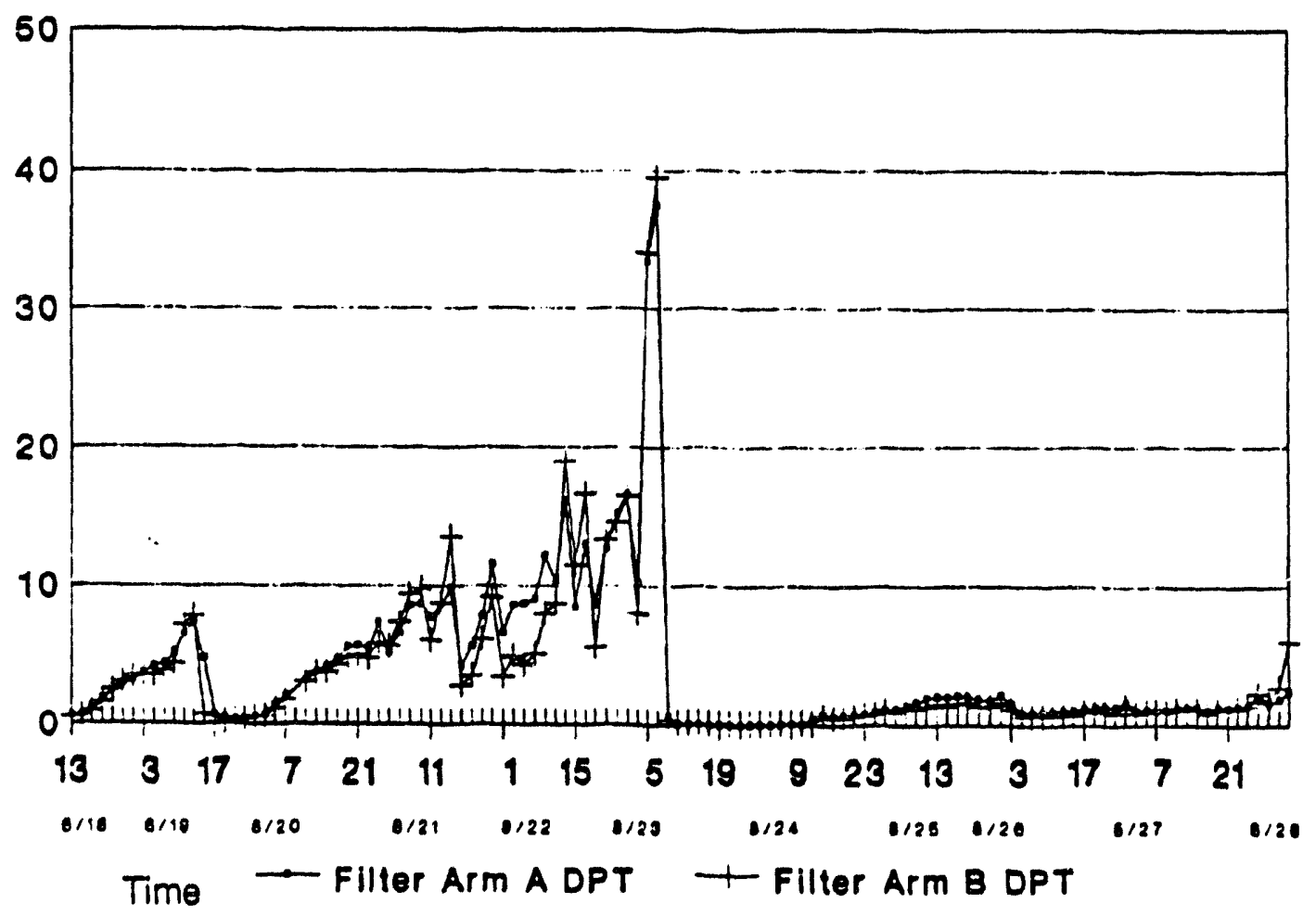




\subsection{Energy Balance}

Table 8: Energy Balance Summary Table

(All units are in $\mathbf{b J / S}$ )

\begin{tabular}{|l|l|l|}
\hline Date & $8 / 21 / 93$ 15:55 & $8 / 25 / 9316: 15$ \\
\hline Electrical Power & & \\
\hline Air Compressor & 32.085 & 32.085 \\
\hline All other motors & 21.610 & 21.807 \\
\hline Electric heaters & 51.843 & 52.008 \\
\hline Computer control & 1.70 & 1.70 \\
\hline Chemical Energy & 46.814 & 46.170 \\
\hline $\begin{array}{l}\text { Heat Rejected to Cooling } \\
\text { water }\end{array}$ & 79.504 & 69.870 \\
\hline Estimated Heat Loss & 73.836 & 83.212 \\
\hline
\end{tabular}

- On $8 / 21$ the SCWO unit was 55 per

ent. On $8 / 25$ the unit was 51 percent efficient.

- On 8/21, 29 percent of the energy ada . le process was from the chemical energy released from the oxidation of IPA. On 8/25, 28 percent of the energy was from the oxidation of IPA.

- On both $8 / 21$ and $8 / 25,32$ percent of the energy added to the process was required by the air compressor.

\footnotetext{
'See the appendix for the calculation

${ }^{5}$ (Electrical Power + Chemical Energy + Heat of Feeds in)- (Heat Rejected to cooling water + Heat of Feeds out)
} 


\subsection{SUMMARY OF CONCLUSIONS}

- Salt Removal: $83.4 \%$ of the recovered salt was removed via the brine. The change in the nozzle flows appeared to improve the percent of salt removed. This number also includes all salt which was removed by the RTRPs. The combination of the steady state removal and the RTRP removal of salt would not likely have allowed for 168 hours of continuous running.

- Neutralization: The objective of $90 \%$ or greater neutralization was not achieved. The overall neutralization efficiency for this run was approximately $80 \%$ for an average flow of $1.4 \mathrm{ml} / \mathrm{min}$. The neutralization appeared to improve and reach a maximum of 80 to 85 percent as more salt accumulated in the reactor, and as the nozzle flow characteristics changed.

- Filter Design: The filters met all of the design objectives. The usefulness of the filters was limited by the relative success of the hot valves, and salt removal within the reactor. The filters acted as a finishing step in removing salt from the effluent as it left the reactor. Filter backwashing was not tested in this run because of the hot valve failure. The post run analysis indicated that the entrances to both filters were almost entirely blocked by salt; there were no visible openings. This could have been the limiting factor which would have shut the plant down.

Hot Valves: The packing of the hot valves leaked immediately after switching from both trains to just one. The leak was significant enough to cause an operator controlled shutdown and subsequent removal of the valves. The valves, as configured, are not suitable for this application.

- Energy Balance: The heat loss of the pilot plant is estimated to be between thirty and thirty four percent. The air compressor accounts for 13.1 percent, while all other motors account for $\mathbf{2 1 . 9}$ percent of the energy into the plant. The heat of reaction provides $18.8 \%$ of the energy used.

Estimated Downtime of the Plant: Based on Run 925 and Run 928, a vessel rinse and a resultant start-up would take eight hours. Assuming the system can run for one hundred hours before a vessel rinse is required, the downtime of the plant would be seven percent. This is a preliminary indication of the achievable availability of the system with the current process. This data has not been reproduced and does not represent a long period of running. This number assumes that the plant would be limited by the process and not by corrosion or mechanical failures. These two items were more frequently the cause of shutdown than the process itself. 


\section{CALCULATIONS/APPENDIX}

- Run Chronology

- Salt Removal Spreadsheet and Process Graphs

- Energy Balance Data

- Selected Process Data (Reactor temperatures and system flows) 
$8 / 17 / 93$

$12: 49$

$12: 52$

13:25

$14: 25$

$16: 00$

16:30

16:55

19:07

$19: 22$

19:33

23:27

$8 / 18 / 93$

$00: 10$

$00: 21$

$01: 43$

$04: 40$

06:39

$08: 00$

$08: 19$

$08: 23$

$08: 24$

$08: 58$

09:18

10:26

13:46

23:00
SCR 320,220 on

Begin System pressurization

P51 to system

P651 to system

Noted in log book that only high range $\mathrm{CO}$ is available

TE 4014 caused a high temp. shudown due to leak @ thermowell, capped it- it is now a surface thermocouple

P51 into recycle

P51 to system

P651 to system

P151, P251 to system

CO spike occurred, $100 \mathrm{ppm}$

Zero DPT filters

P651 to recycle to boost lower reactor temps

P651 to boot

SIM,Perc,Caustic to system

Reference point for good salt removal

5th stage relief in air compressor blew

P251 suction to V51

P351 and P551 to recycle

P51 to recycle

Heaters off

FC21 to 0

P651 in recycle

Shear disc replaced, pressure test successful

Begin system pressurization

Brine switched to empty 30 gallon tank

SCR220,320 on

P51 to system

P651 to system

$P 151, P 251$ to system

SIM,Perc, Caustic to system

Brine Tank A dumped to sewer 
$8 / 19 / 93$

$\begin{array}{ll}\text { 13:44 } & \text { Close AV410A } \\ \text { 13:48 } & \text { AV410B leaking } \\ & \text { HDSD } \\ \text { 14:05 } & \text { AV410 A and B removed from system } \\ \text { 15:29 } & \text { New L\&N keyboard installed } \\ \text { 16:30 } & \text { Begin system pressurization } \\ \text { 17:00 } & \text { SCR220,320 on } \\ \text { 17:58 } & \text { P651 B to system } \\ \text { 18:04 } & \text { P151,251 to system } \\ \text { 18:37 } & \text { AV405A closed to soak filter A } \\ \text { 18:57 } & \text { P651 B to recycle } \\ \text { 19:09 } & \text { AV405B open } \\ \text { 19:11 } & \text { P51 in recycle } \\ \text { 19:24 } & \text { Open and Close AV405 A and B to soak filter trays } \\ \text { 19:56 } & \text { P251 in recycle } \\ \text { 19:58 } & \text { P651 B to boot } \\ \text { 19:59 } & \text { End of vessel/filter tray rinse } \\ \text { 20:41 } & \text { P51 to system } \\ \text { 21:45 } & \text { Effluent switched from off-skid to V-392 } \\ 22: 11 & \text { Transferred vessel rinse to filter backwash tank } \\ 22: 22 & \text { Brine switched to Brine tank } A \\ 23: 15 & \text { Effluent off-skid tank pumped to Brine tank A } \\ 23: 25 & \text { P151,251 to system }\end{array}$

$8 / 20 / 93$

02:26 SIM,Perc,Caustic to system

02:34 Switch from Brine tank $A$ to nalgene tank

11:41 Start RTRP

12:11 End RTRP

20:27 . . B Brine tank $B$ dumped to drain

22:13 Brine tank A pumped to black tank for later treatment

$8 / 21 / 93$

14:27 HV405A closed. Fluid flowing down HX400A up through HX400B and out the $B$ side into 2 nd stage reactor

16:30 Perc and Caustic pumps off for energy balance

16:33 Perc and Caustic to system

17:32 Start RTRP

18:18 End RTRP

22:05 Nalgene tank contents transferred to Brine tank C 
03:42

04:59

08:15

09:26

13:40

14:10

17:14

19:19

22:29

22:43

$8 / 23 / 93$

$00: 29$

01:55

02:24

02:34

$02: 38$

06:00

06:29

06:30

07:30

07:31

13:00

$15: 10$

15:39

16:32

16:35

17:31

18:13

18:24

18:36

18:57

19:19

20:06

$8 / 24 / 93$

$02: 43$

02:47

02:54
Start RTRP

End RTRP

Start RTRP

End RTRP

Perc, Caustic to recycle, Core dp > 125 psi

Perc, Caustic to system (reduced core dp)

Start RTRP

End RTRP

Start RTRP

Transfer contents of black brine tank to Brine tank $C$ for treatment

\section{End RTRP}

Perc, Caustic to recycle (filter dp dropped as a result)

Perc, Caustic to system

Evidence of downstream plugging

Pressures returning to normal

Perc, Caustic to recycle

Perc, Caustic to system

Start RTRP

Leak at TE 4008 thermowell

HDSD, Inspected all vessel thermowells repaired/replaced as required

Transfer brine from nalgene tank to Brine tank $A$

Begin system pressurization

Leak at TE 4009 thermowell

Depressurize

Begin system pressurization

Leak at TE 4006

Depressurize

Begin system pressurization

Control transferred to FC 780

P651 to system

Start filter soaks, Open/Close AV405 A,B every 3-5 minutes

Increase soak time to 5 minutes

Increase soak time to 8 minutes

Leak noticed in regenerative heat exchanger

Shutdown plant

Start vessel/filter rinse, $\mathrm{P} 751$ to filter arm A

P751 to recycle

P751 to filter arm A 
$02: 58$

03:03

03:08

03:10

03:11

03:16

03:23

03:24

$03: 29$

03:34

03:35

03:40

03:55

$04: 03$

04:07

$04: 12$

$04: 31$

$04: 32$

$04: 35$

05:00

05:20

06:02

$06: 10$

$07: 04$

$11: 24$

$11: 25$

11:31

13:11

$14: 25$

$8 / 25 / 93$

16:15

21:32

22:02

$8 / 26 / 93$

$00: 15$

$00: 54$

03:10

03:14

03:22

03:40

03:55
P751 to recycle

P751 to filter arm A

P751 to recycle

Open HV758B, Close AV758A

P751 to filter arm B

P751 to recycle

Close HV758B, Open AV758A

P751 to filter arm B

P751 to recycle

Drain filter arm $A$ rinse

P751 to filter arm A

P751 to recycle

Drain filter arm $A$ rinse

P751 to filter arm A

P251 to system

P51 to system

P51 to recycle

P251 to recycle

Drain and collect rinsate

P51,P251,P651,P751 to system

All pumps off, drain and collect

SCR220,320 on

Begin system pressurization

P51 to system

P151 to system

P251 to system

CO spike

Supernatant from Brine tanks $B$ and $C$ tested and can be dumped

SIM,Perc,Caustic to system

Plant energy balance data taken

Start RTRP

End RTRP

\section{Start RTRP \\ End RTRP}

Decrease in P351 flow, P 551 to $O$

P351,P551 to recycle

P351 making a metallic clacking sound, discovered it was cavitation.

P351,P551 to sysiem

P351,P551 to recycle, P351 still not coming up to full flow 
$04: 10$

$04: 55$

05:06

21:37

22:37

$8 / 27 / 93$

Clean filter elements to P351

P351 suction line at outlet from V-351 was filled with debris, it was cleaned and flushed

P351,P551 to system

Start RTRP

End RTRP

$\begin{array}{ll}\text { 00:29 } & \text { Start RTRP } \\ 01: 05 & \text { End RTRP } \\ 07: 18 & \text { Start RTRP } \\ 08: 23 & \text { End RTRP } \\ 15: 20 & \text { Start RTRP } \\ \text { 16:36 } & \text { End RTRP } \\ \text { 19:48 } & \text { Transfer large nalgene tank to Brine tank C }\end{array}$

$8 / 28 / 93$

$02: 30$

03:47

$07: 45$

10:00

Start RTRP

End RTRP

Badger data taken

HDSD

Vessel Rinse
23:40
P51 to system
23:53
P651 to system

$8 / 29 / 93$

00:22 Vessel Pressurized with water

00:32. Drain vessel

00:40 P51,P651 to system

00:53 Purge air on

00:54 P51,P651 off

$01: 30$

$03: 13$

P51,P651 to system

$03: 43$

2nd vessel rinse- $P 51, P 651, P 51$ Bench $A, B, C$ to system

$01: 41$

P51,P651, P51 Bench A,B,C to recycle

PT405HH, P51,P651 and purge air to recycle 


\section{Run 932: Salt Removal Data}

\begin{tabular}{|c|c|c|c|c|c|c|c|c|c|c|}
\hline ample & $\mathrm{pH}$ & $\mathrm{Cl}(\mathrm{ppm})$ & $\mathrm{Na}(\mathrm{ppm})$ & SO4(ppin) & Vol(L) & $\mathrm{NaCl}(9)$ & NaSO4(g) & TOTAL $(9)$ & NaCliNa2SO4 & Na Balance \\
\hline Srino Drain & 9.4 & 107500 & 82500 & 22600 & 2.9 & 514.0 & 96.9 & 611.0 & 5.3 & 0.98 \\
\hline st ves rinse & 4.0 & 17000 & 11500 & 2520 & 321.7 & 9017.8 & 1199.2 & 10217.1 & 7.5 & 1.06 \\
\hline nd ves rinse & 3.5 & 900 & 600 & 250 & 124.9 & 185.3 & 46.2 & 231.5 & 4.0 & 1.17 \\
\hline iw ves rinse (sludge) & 9.2 & 50000 & 36000 & 6450 & 8.1 & 667.8 & $77 . \overline{3}$ & 745.0 & 8.6 & 0.99 \\
\hline 102 rinse & 7.5 & 7400 & 5400 & 1900 & 10.3 & 125.9 & 29.0 & 154.9 & 4.3 & 1.06 \\
\hline ilt a rinse & 7.7 & 2400 & 1850 & 900 & 46.7 & 184.8 & 62.2 & 247.0 & 3.0 & 1.07 \\
\hline vereffluent from rinse & 5.1 & 6000 & 4400 & 1260 & 79.6 & 787.5 & 148.4 & 935.8 & 5.3 & 1.02 \\
\hline$x$ rinse(R933 start) & 3.6 & 6400 & 3200 & 645 & 75.7 & 798.8 & 72.2 & 871.0 & 11.1 & 1.39 \\
\hline ialt sampled from reactor & 8.5 & 1350 & 950 & 200 & 0.2 & 0.4 & 0.1 & 97.5 & 7.5 & 1.02 \\
\hline aall from vessel(nr fit a) & 6.7 & 2000 & 1300 & 140 & 0.2 & 0.7 & 0.04 & 95.0 & 15.9 & 1.05 \\
\hline Jozzle tip deposit & 6.8 & 1550 & 1075 & 100 & 0.2 & 0.5 & 0.03 & 285.0 & 17.3 & 0.98 \\
\hline SOTAL(nol incl. brine drain) & & & & 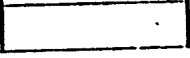 & & & & 13879.9 & & \\
\hline Vozzle plug solids & 6.7 & 130 & 80 & 365 & 0.115 & 0.0246 & 0.06 & & 0.4 & 3.24 \\
\hline
\end{tabular}

\begin{tabular}{|c|c|c|c|c|c|c|c|c|c|c|c|}
\hline Brino Comp. & $\mathrm{pH}$ & $\mathrm{Cl}(\mathrm{ppm})$ & Na(ppm) & SO4(ppm) & Vol(L) * & $\mathrm{NaCl}(\mathrm{g})$ & NaSO4(g) & TOTAL (9) & NaCl/Na2SO4 & $\mathrm{Na}+\mathrm{Cl}+\mathrm{SO}$ & Na Balance \\
\hline $3 / 2415: 00-22: 00$ & 6.0 & 9600 & 7400 & 2675 & 225.0 & 3561.4 & 890.3 & 4451.7 & 4.0 & 19675 & 1.01 \\
\hline 312423:00-6:00 & 5.8 & 12000 & 9000 & 3150 & 225.0 & 4451.8 & 1048.4 & 5500.1 & 4.2 & 24150 & 1.03 \\
\hline $8 / 257: 00-14: 00$ & 5.9 & 10500 & 8400 & 2640 & 225.0 & 3895.3 & 878.6 & 4773.9 & 4.4 & 21540 & 0.96 \\
\hline $812515: 00-22: 00$ & 6.0 & 11500 & 9000 & 2760 & 225.0 & 4266.3 & 918.6 & 5184.8 & 4.6 & 23260 & 0.98 \\
\hline $8 / 2623: 00-6: 00$ & 5.8 & 13500 & 10000 & 2980 & 225.0 & 5008.2 & 991.8 & 6000.0 & 5.0 & 26480 & 1.02 \\
\hline $81267: 00-14: 00$ & 6.1 & 13000 & 10000 & 3200 & 225.0 & 1822.7 & 1065.0 & 5887.7 & 4.5 & 26200 & 1.00 \\
\hline $812615: 00-22: 00$ & 6.1 & 12000 & 8400 & 2580 & 225.0 & 4451.8 & 858.7 & 5310.4 & 5.2 & 22980 & 1.07 \\
\hline $812623: 00-6: 00$ & 6.2 & 22000 & 17500 & 7200 & 225.0 & 8161.6 & 2396.3 & 10557.8 & 3.4 & 46700 & 1.01 \\
\hline $81277: 00-14: 00$ & 6.0 & 13000 & 9600 & 3760 & 225.0 & 1822.7 & 1251.4 & 6074.1 & 3.9 & 26360 & 1.07 \\
\hline $812715: 00-22: 00$ & 5.9 & 11500 & 8100 & 2580 & 225.0 & 4266.3 & 858.7 & 5124.9 & 5.0 & 22180 & 1.07 \\
\hline $8 / 2723: 00-6: 00$ & 6.2 & 9600 & 7600 & 2800 & 225.0 & 3561.4 & 931.9 & 4493.3 & 3.8 & 20000 & 1.00 \\
\hline $81287: 00-9: 50$ & 6.6 & 14500 & 11500 & 3280 & 84.0 & 2008.2 & 407.5 & 2415.8 & 4.9 & 29280 & 0.95 \\
\hline & & & & & & & & 65774.7 & & & \\
\hline
\end{tabular}

- The volume was estimated will an average BTO flow. 


\begin{tabular}{|c|c|c|c|c|c|c|c|c|c|c|}
\hline Integrated Brine Composite & $\mathrm{pH}$ & $\mathrm{Cl}$ & $\mathrm{Na}$ & $\mathrm{SO4}$ & Volume(l) & $\mathrm{NaCl}$ & NaSO4 & TOTAL (g) & $\mathrm{NaCl} / \mathrm{Na2SO4}$ & Na Balance \\
\hline $8 / 2500: 00^{\circ}$ & & 11000 & 8700 & 2920 & 212.0 & 3845.0 & 915.7 & 4760.7 & 4.2 & 0.98 \\
\hline $8 / 258: 00$ & 6 & 11000 & $870 \mathrm{C}$ & 2920 & 306.6 & 5560.7 & 1324.3 & 6885.0 & 4.2 & 0.98 \\
\hline $8 / 2521: 55$ & 6.1 & 11000 & 9000 & 2760 & 374.7 & 6795.9 & 1529.7 & 8325.6 & 4.4 & 0.94 \\
\hline $8 / 267: 00$ & 6.3 & 13500 & 11500 & 3460 & 253.6 & 5644.8 & 1297.9 & 6942.7 & 4.3 & 0.91 \\
\hline $8 / 26 \quad 19: 45$ & 6.4 & 12500 & 9600 & 2800 & 378.5 & 7800.9 & 1567.6 & 9368.5 & 5.0 & 0.98 \\
\hline $81277: 00$ & 6.3 & 13500 & 11500 & 3460 & 283.9 & 6319.3 & 1453.0 & 7772.3 & 4.3 & 0.91 \\
\hline $8 / 27 \quad 19: 45$ & 6.3 & 15500 & 12000 & 4120 & 333.1 & 8512.8 & 2030.0 & 10542.8 & 4.2 & 1.00 \\
\hline $8 / 283: 00$ & 6.1 & 11000 & 8400 & 2380 & 302.8 & 5491.8 & 1066.0 & 6557.8 & 5.2 & 0.99 \\
\hline $8 / 28 \quad 10: 55$ & 6.4 & 16000 & 13000 & 4840 & 244.1 & 6439.6 & 1747.6 & 8187.1 & 3.7 & 0.98 \\
\hline TOTAL & & & & & & & & 69342.5 & & \\
\hline
\end{tabular}

* No sample was taken. The volume was taken from the rounds sheet. The Na,Cl,SO4 were assumed to be identical to those of 8/25 @ 8:00.

The $\mathrm{Na}$ balance $=\mathrm{Na}$ Calculated based on $\mathrm{Cl}$ and $\mathrm{SO} 4$ divided by actual $\mathrm{Na}$ 
$2^{\text {nd }}$ seament of $-n=010$

Run 932 Salt Removal

8/24/93 15:00-00:00

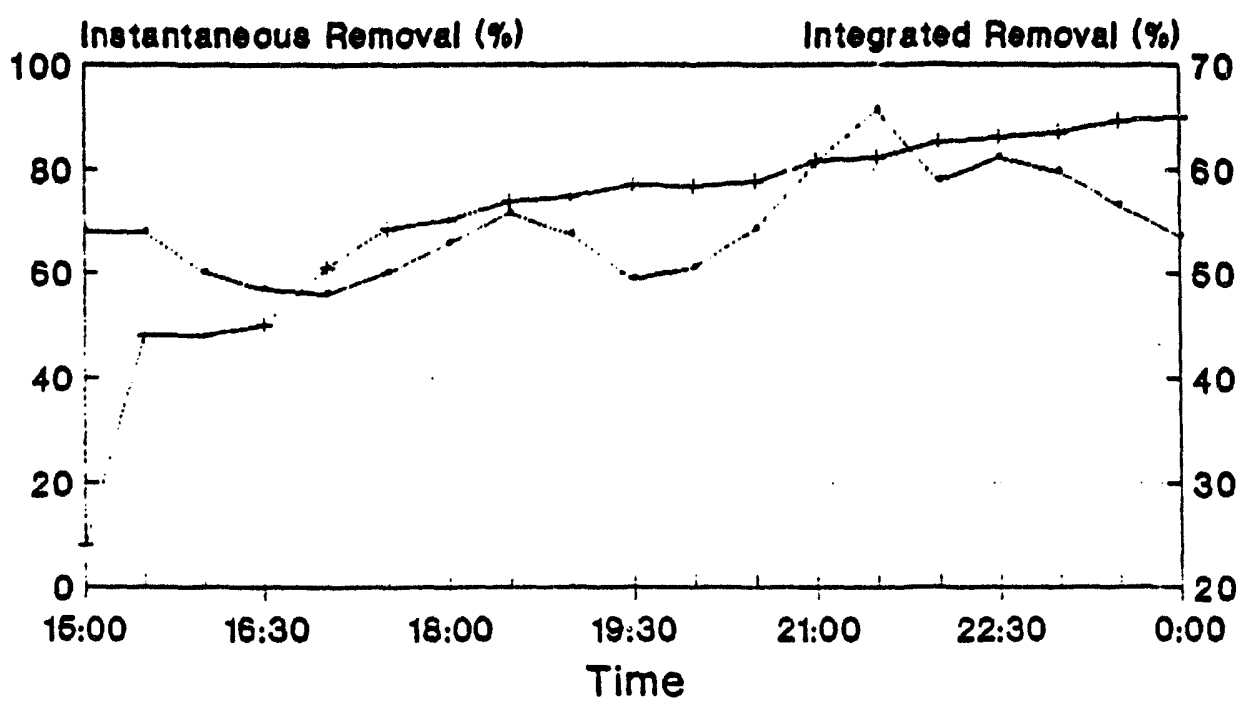

- Instantaneous rem. - Integrated rem.

Run 932 Salt Removal

$8 / 25 / 93$ 00:30-8/26 00:00

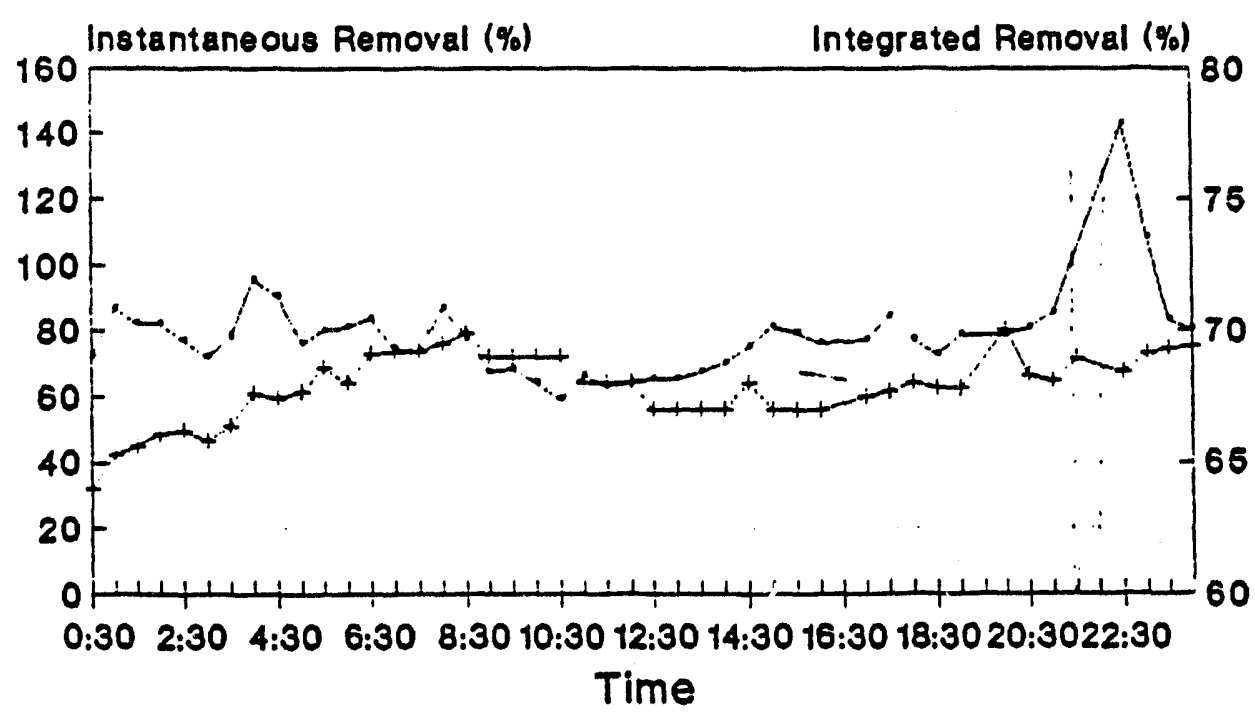

- Instantaneous rem. Integrated rem. 


\section{Run 932 Salt Removal 8/26/93 00:30-8/27 00:00}

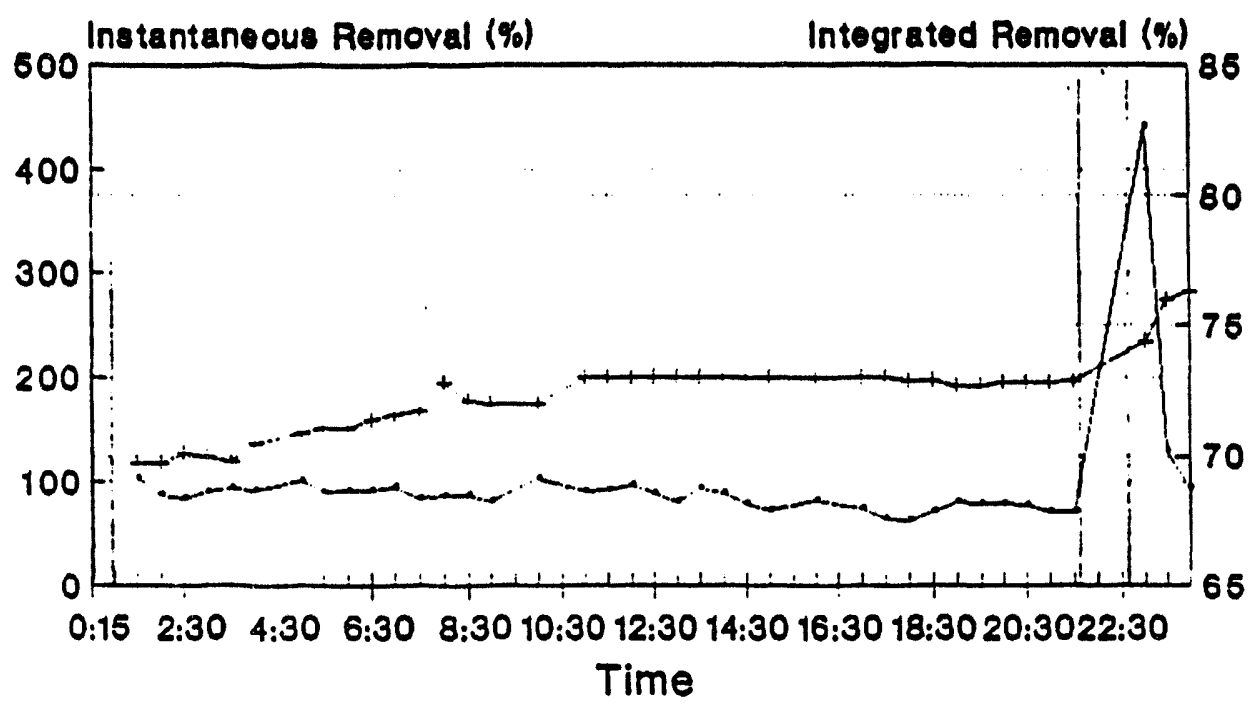

- Instantaneous rem. - Integrated rem.

Run 932 Salt Removal 8/27/93 00:30-8/28 00:00

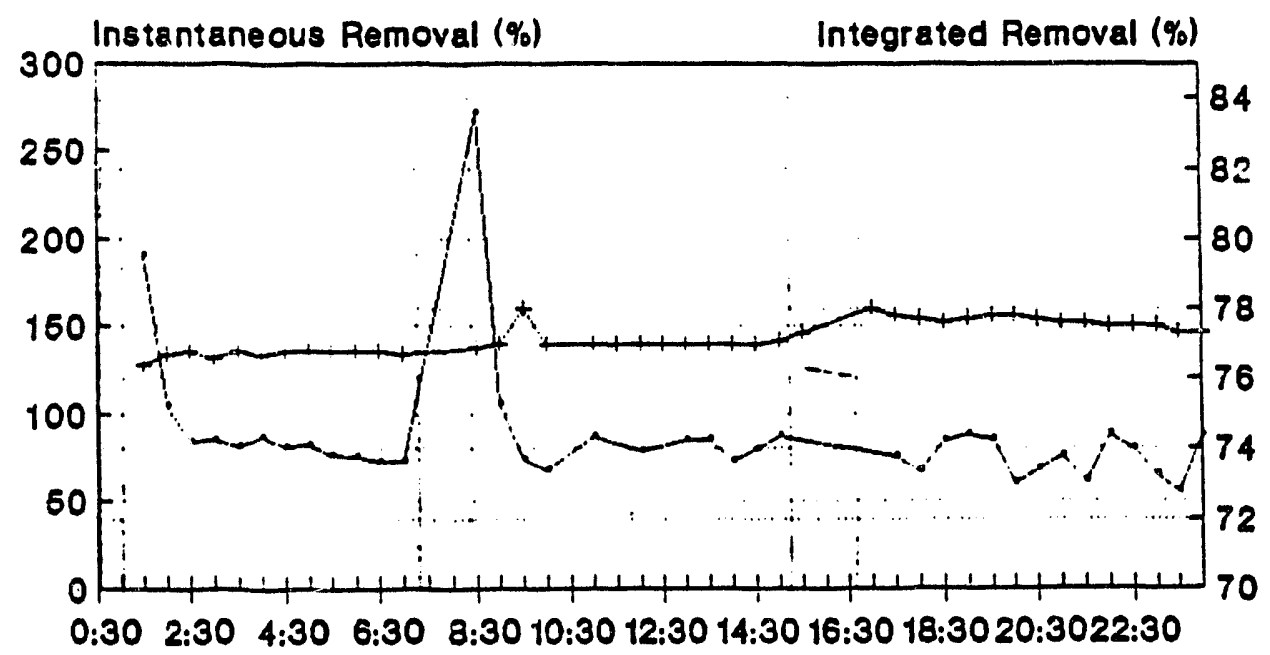

Time

- Instantaneous rem. $\rightarrow$ Integrated rem. 


\section{Run 932 Salt Removal}

\section{8/28/93 00:30-10:45}

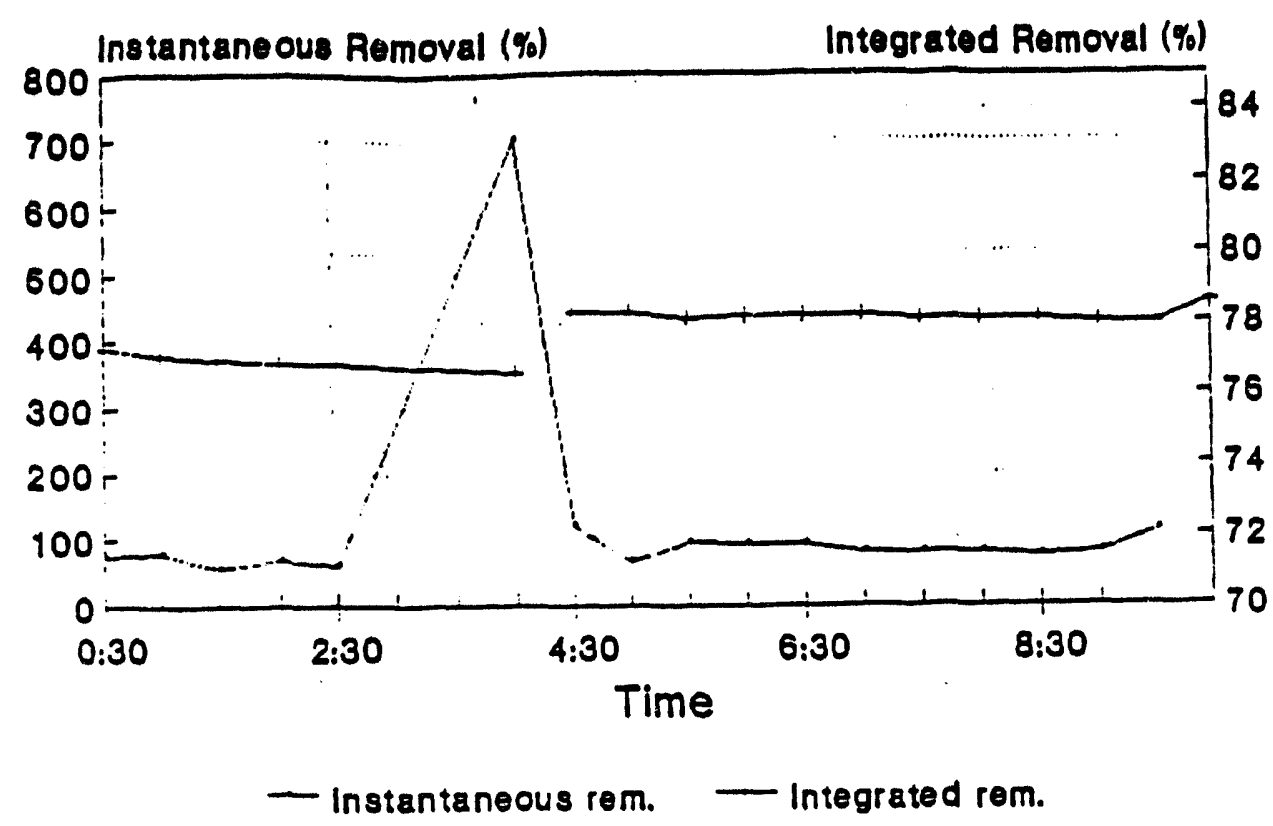




\begin{tabular}{|c|c|c|c|c|c|c|c|}
\hline & \multicolumn{2}{|c|}{ Nameplate } & \multicolumn{2}{|c|}{ Measured } & \multirow[b]{2}{*}{ PF } & \multirow[b]{2}{*}{ fract. on } & \multirow[b]{2}{*}{ Power(KW) } \\
\hline Pumps & $H P$ & $\mathrm{KW}$ & Volts & Amps & & & \\
\hline $\mathrm{C}_{11}$ & 75 & 55.9425 & 478 & 97 & 0.8 & 0.5 & 32.085 \\
\hline P51 & 7.5 & 5.5942 & 477 & 6.9 & 0.786 & 1 & 4.475 \\
\hline P151 & 2 & 1.4918 & 477 & 2.3 & 0.76 & 1 & 1.442 \\
\hline P251 & 3 & 2.2377 & 476 & 3.8 & 0.76 & 1 & 2.378 \\
\hline P351 & 2.0 & 1.4918 & 478 & 1.55 & 0.76 & 1 & 0.974 \\
\hline$P 451$ & & & & & & & 0.000 \\
\hline P551 & 0.03 & 0.02 & 120 & 0.76 & 0.6 & 1 & 0.055 \\
\hline P651 & 2 & 1.4918 & 479 & 2.6 & 0.76 & 1 & 1.637 \\
\hline P751 & 7.5 & 5.5942 & & & 0.786 & 1 & 0.000 \\
\hline P51B & 5 & 3.7295 & 477 & 6.2 & 0.81 & 1 & 4.144 \\
\hline$\overline{\text { Inst Air }}$ & 25 & 18.6475 & 477 & 41 & 0.69 & 0.287 & 6.700 \\
\hline Pump Total & & & & & & & 53.892 \\
\hline \multicolumn{8}{|l|}{\begin{tabular}{|l} 
Pump lotal \\
Heaters \\
\end{tabular}} \\
\hline \multicolumn{8}{|l|}{ Hot Box } \\
\hline 220 & & & 478 & 54.4 & 1 & 0.43 & 19.344 \\
\hline 320 & & & 477 & 103 & 1 & 0.31 & 26.349 \\
\hline \multicolumn{8}{|l|}{ Arms } \\
\hline $4040 A$ & & 1 & 10 fff & & & & \\
\hline 40408 & & & loff & & & & \\
\hline \multicolumn{8}{|l|}{ Hubs } \\
\hline $4050 \mathrm{~A}$ & & & 207 & 3.5 & 1 & 0.74 & 0.928 \\
\hline $4050 B$ & & & 207 & 3.7 & 1 & 0.71 & 0.941 \\
\hline \multicolumn{8}{|l|}{\begin{tabular}{|l} 
Fitting \\
\end{tabular}} \\
\hline $4070 \mathrm{~A}$ & & & 208 & 1.7 & 1 & 1 & 0.612 \\
\hline $4070 B$ & & & loff & & & & \\
\hline \multicolumn{8}{|l|}{ 2nd Stage } \\
\hline 411 & & & 207 & 21 & 1 & 0.31 & 2.331 \\
\hline 412 & & & 207 & 21 & 1 & 0.2 & 1.504 \\
\hline AV410AHIr & & & off & & & & \\
\hline AV410BHtr & & & off & & & & \\
\hline Heater Total & & & & & & & 52.008 \\
\hline \multicolumn{8}{|l|}{ L\&N } \\
\hline LPUS & & & & & & & 0.800 \\
\hline Mgmt Sta & & & & & & & 0.900 \\
\hline
\end{tabular}




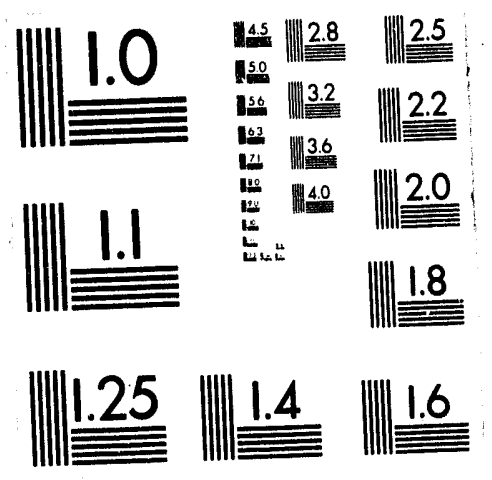



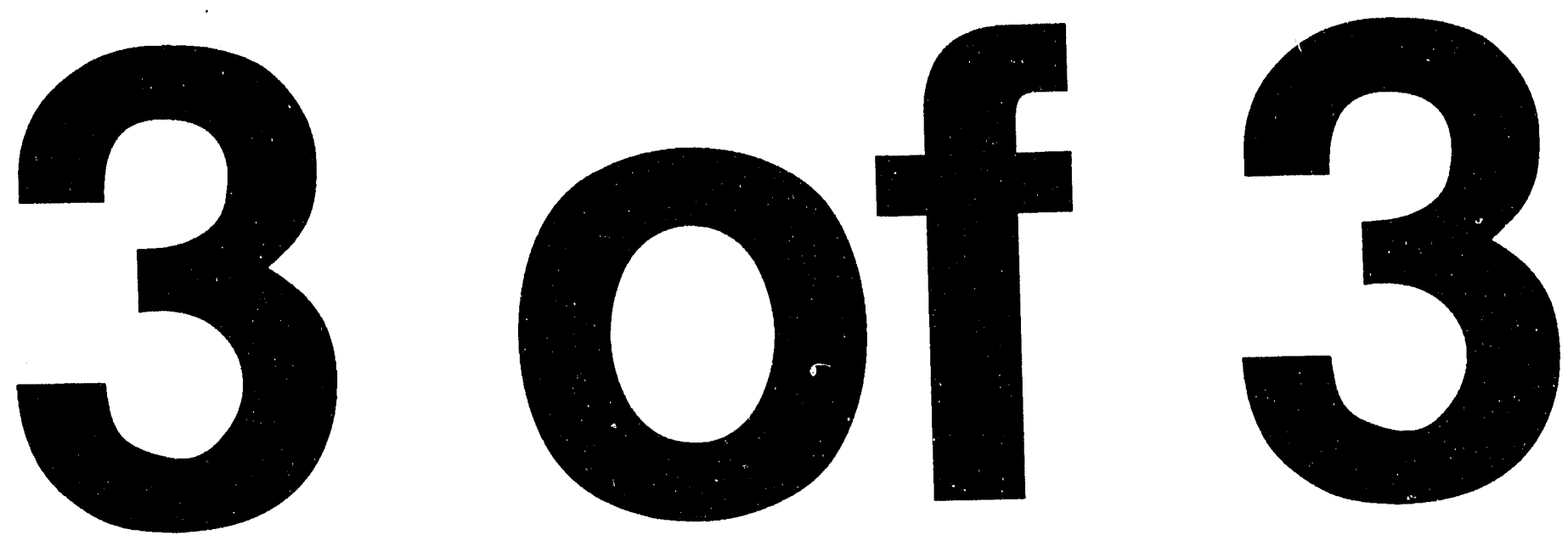


\section{Run 932: Energy Balance}

\begin{tabular}{|c|c|c|c|c|c|c|c|}
\hline & \multicolumn{2}{|c|}{ Nameplate } & \multicolumn{2}{|c|}{ Measured } & \multirow[b]{2}{*}{ PF } & \multirow[b]{2}{*}{ SCR } & \multirow[b]{2}{*}{ Power(KW) } \\
\hline Pumps & IHP & Watts & Volts & Amps & & & \\
\hline C11 & 75 & 55942.5 & 478 & 97 & 0.8 & 0.5 & 32.085 \\
\hline P51 & 7.5 & 5594.2 & 477 & 7 & 0.786 & 1 & 4.540 \\
\hline P151 & 3 & 1491.8 & 476 & 2.3 & 0.76 & 1 & 1.439 \\
\hline P251 & 2 & 2237.7 & 476 & 3.8 & 0.76 & 1 & 2.378 \\
\hline P351 & 2.0 & 1491.8 & 477 & 1.54 & 0.76 & 1 & 0.966 \\
\hline P451 & & & & & & & 0.000 \\
\hline P551 & 0.03 & 24.86 & 120 & 0.77 & 0.6 & 1 & 0.055 \\
\hline$P 651$ & 2 & 1491.8 & 479 & 2.7 & 0.76 & 1 & 1.700 \\
\hline P751 & 7.5 & 5594.2 & & & 0.786 & 1 & 0.000 \\
\hline P51B & 5 & 3729.5 & 477 & 6.1 & 0.81 & 1 & 4.077 \\
\hline Inst Air & 25 & 18647.5 & 476 & 41 & 0.69 & 0.277 & 6.453 \\
\hline Pump Total & & & & & & & 53.695 \\
\hline \multicolumn{8}{|l|}{\begin{tabular}{|l} 
Pump Total \\
Heaters \\
\end{tabular}} \\
\hline \multicolumn{8}{|l|}{\begin{tabular}{|l|} 
Heaters \\
Hot Box \\
\end{tabular}} \\
\hline 220 & & & 478 & 54.5 & 1 & 0.43 & 19.379 \\
\hline 320 & & & 478 & 102 & 1 & 0.31 & 26.148 \\
\hline \multicolumn{8}{|l|}{ Arms } \\
\hline $4040 \mathrm{~A}$ & & & loff & & & & \\
\hline $4040 B$ & ! & & Toff & & & & \\
\hline \multicolumn{8}{|l|}{$\begin{array}{l}4040 B \\
\text { Hubs }\end{array}$} \\
\hline $4050 \mathrm{~A}$ & & 1 & 207 & 3.5 & 1 & 0.74 & 0.928 \\
\hline $4050 B$ & & & 207 & 3.7 & 1 & 0.71 & 0.941 \\
\hline \multicolumn{8}{|l|}{ Fitting } \\
\hline $4070 \mathrm{~A}$ & & & 208 & 1.8 & 1 & 1 & 0.648 \\
\hline $4070 B$ & & & off & & & & \\
\hline \multicolumn{8}{|l|}{$\frac{40708}{2 n d \text { Slage }}$} \\
\hline 411 & & & 207 & 21 & 1 & 0.31 & 2.331 \\
\hline 412 & & & 207 & 20.5 & 1 & 0.2 & 1.468 \\
\hline AV410AHtr & & & off & & & & \\
\hline AV410BHIT & & & Toff & & & & \\
\hline Heater Total & & & & & & & 51.843 \\
\hline \multicolumn{8}{|l|}{\begin{tabular}{|l} 
Heater Total \\
L\&N
\end{tabular}} \\
\hline LPUS & & & & & & & 0.800 \\
\hline Mgmt Sta & & & & & & & 0.900 \\
\hline
\end{tabular}


Run 932 Reactor Temperatures

8/19/93 22:38 - 8/20/93 8:28

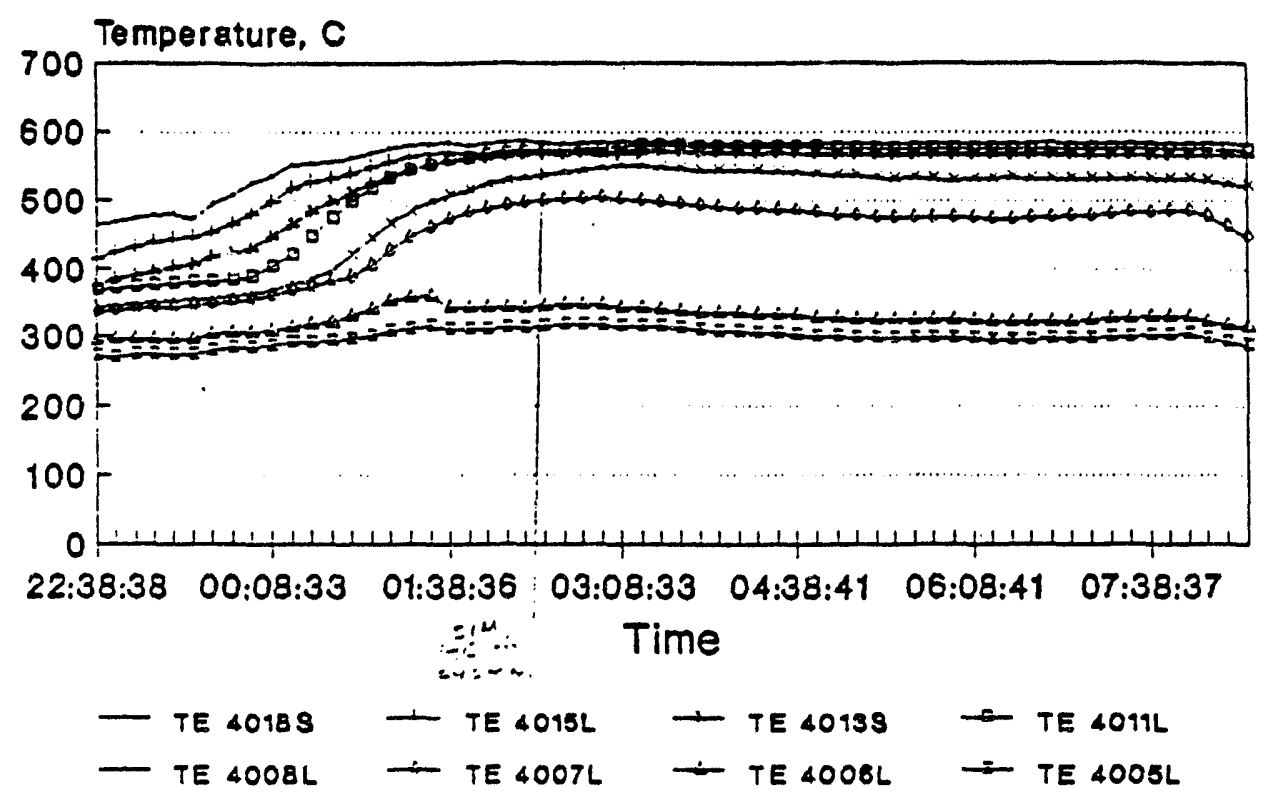

Run 932: Flows and $C O$

\section{8/19/93 22:38-8/20/93 8:28}

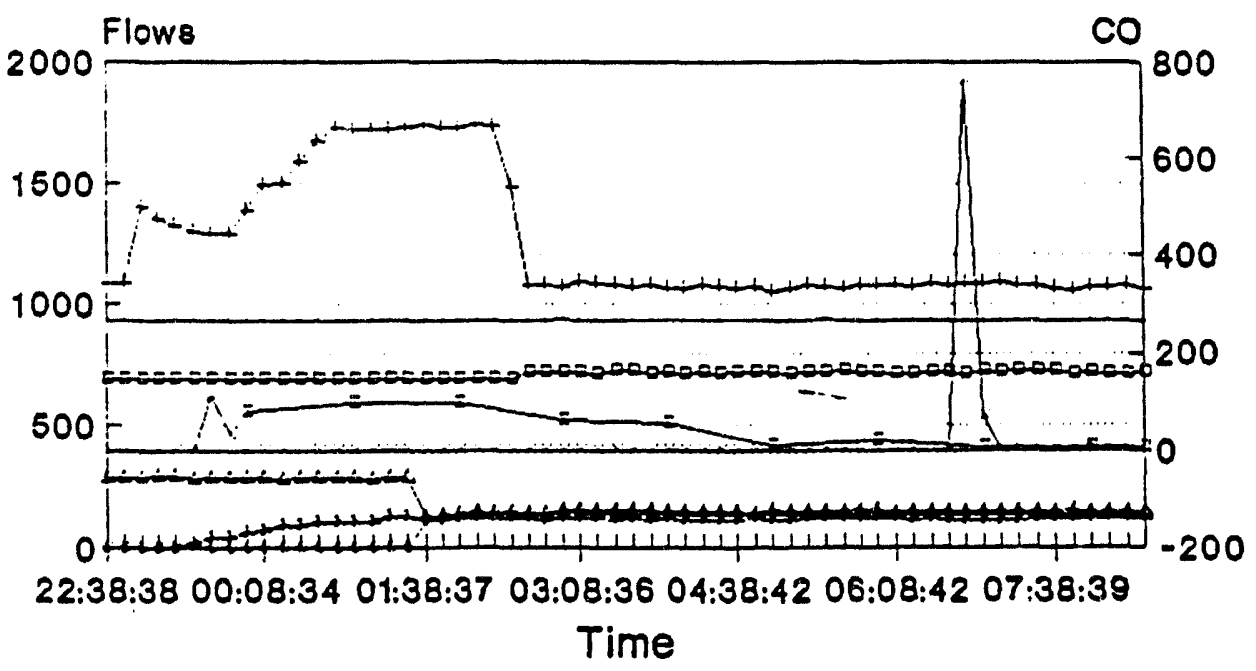

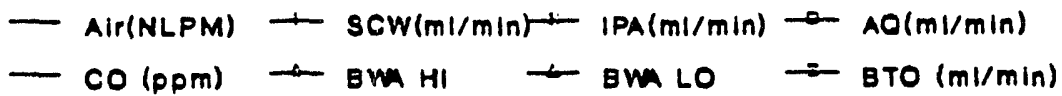




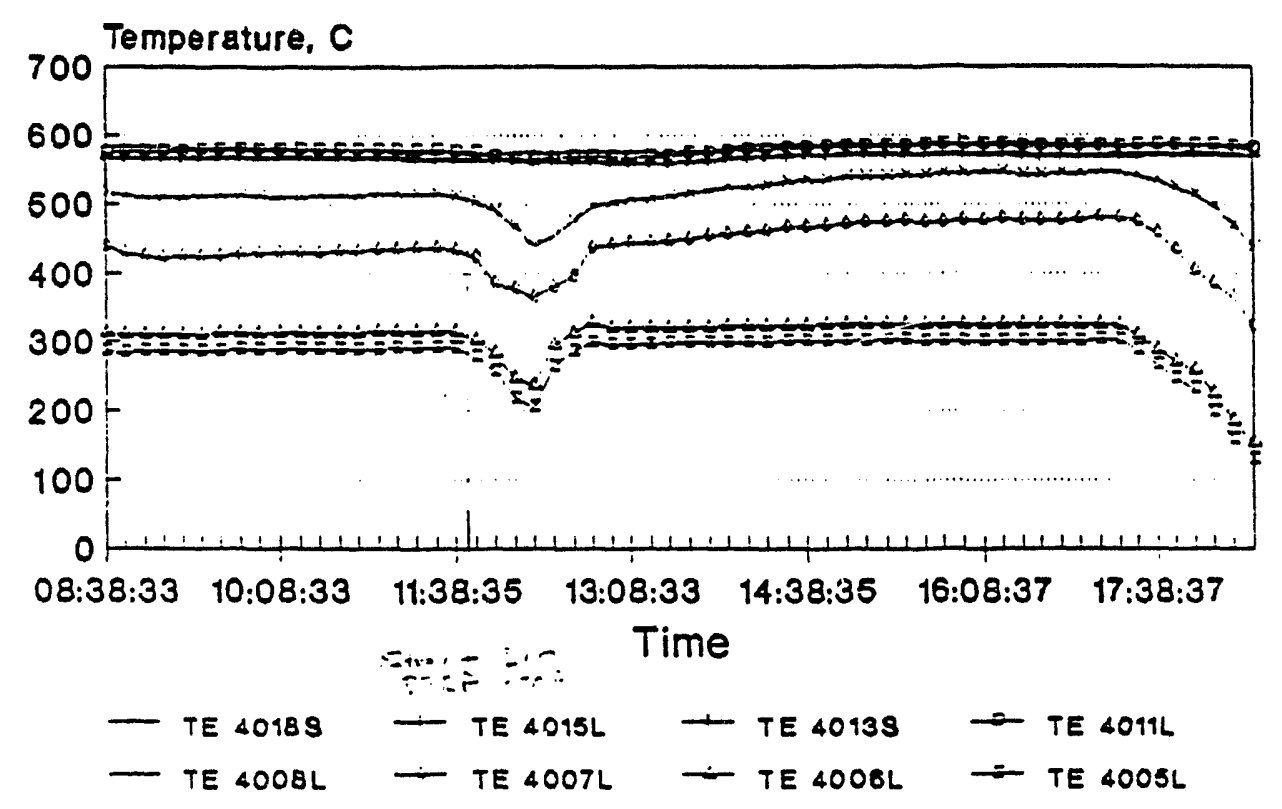

Run 932: Flows and $\mathrm{CO}$

8/20/93 8:38-8/20/93 18:28

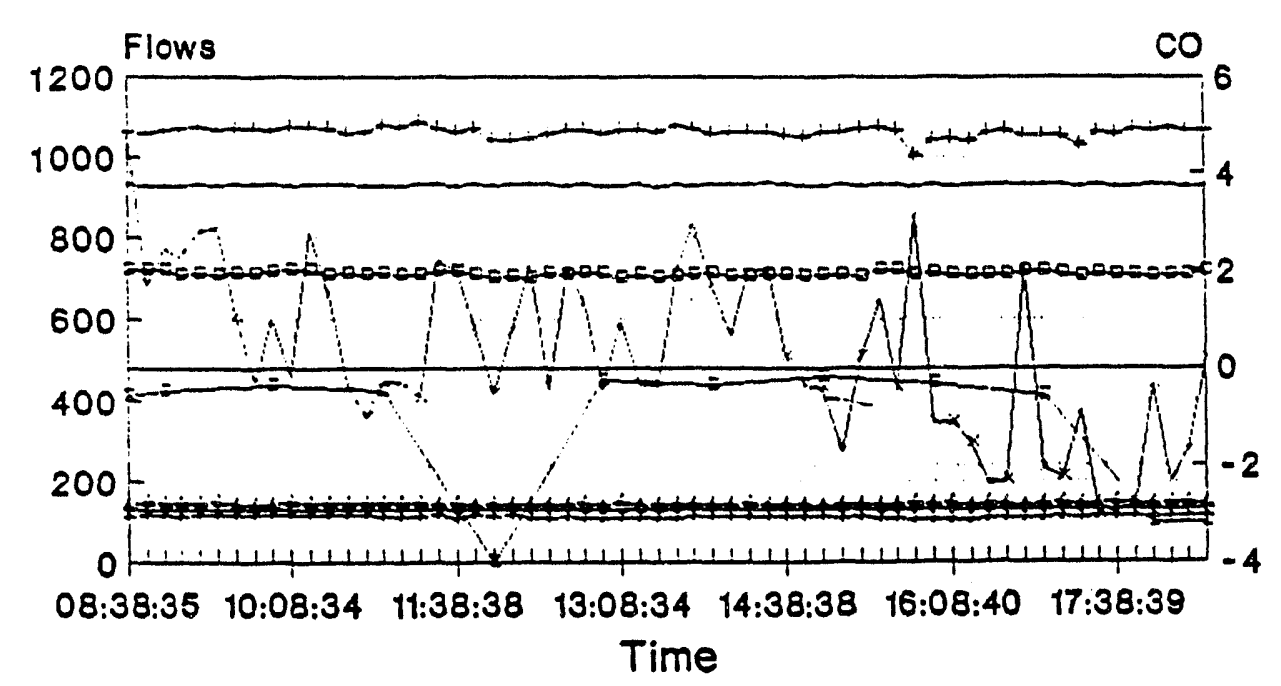

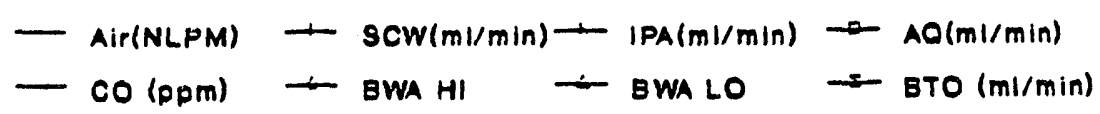

BWA HI and LO oro in $(\mathrm{ml} / \mathrm{min})$ 


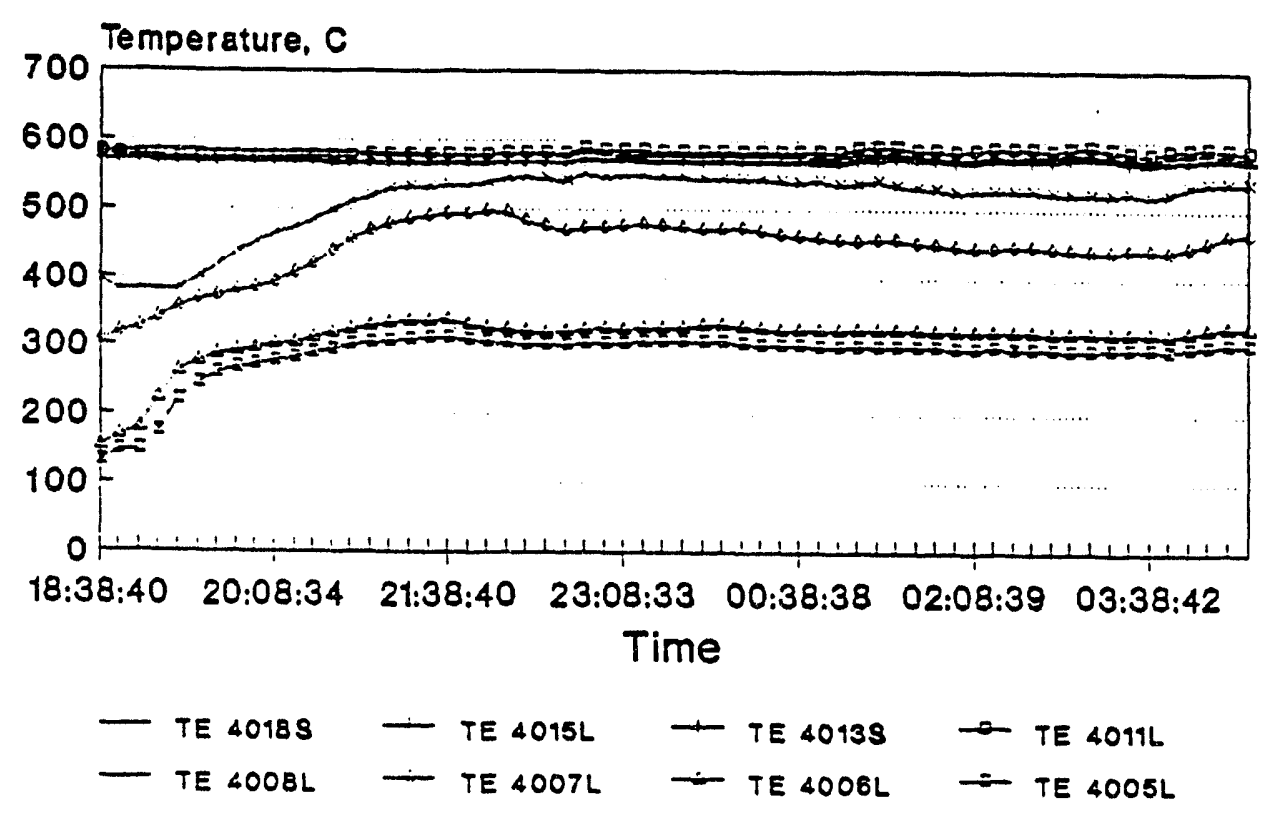

Run 932: Flows and $C O$

8/20/93 18:38-8/21/93 4:28

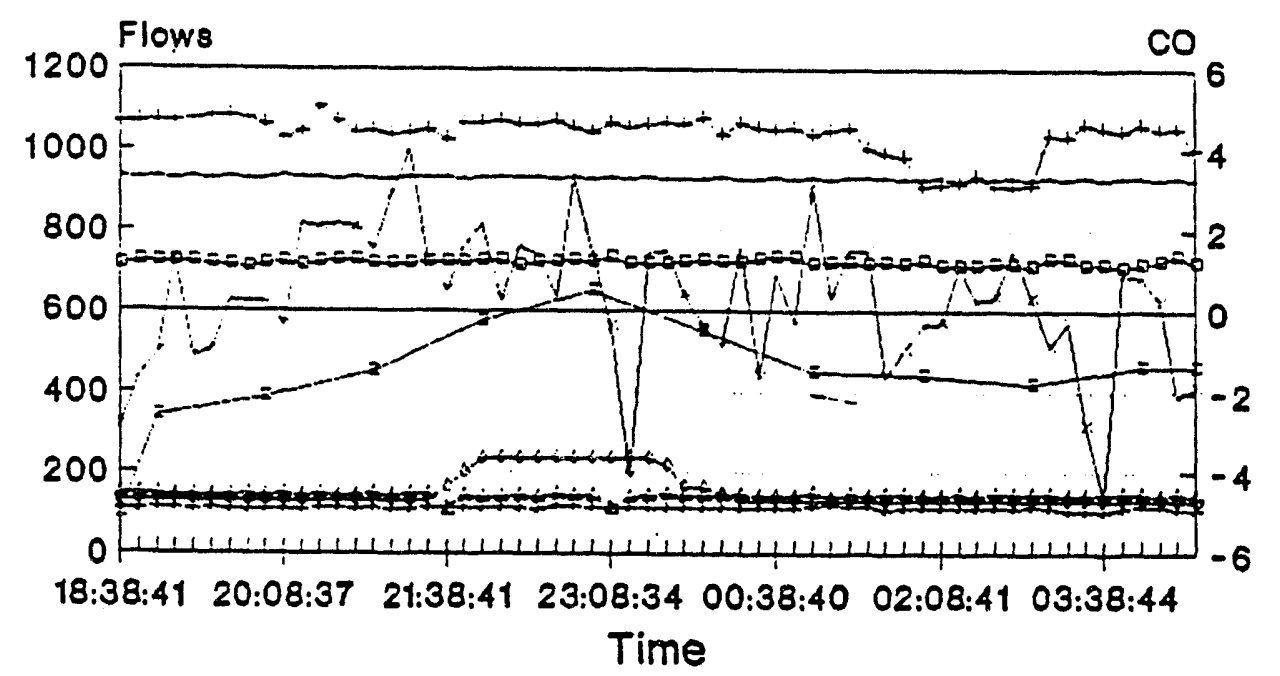

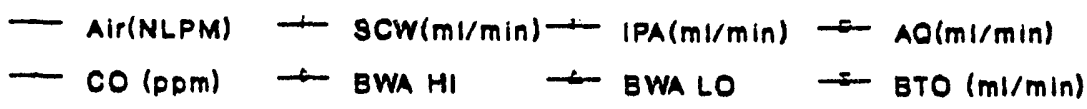




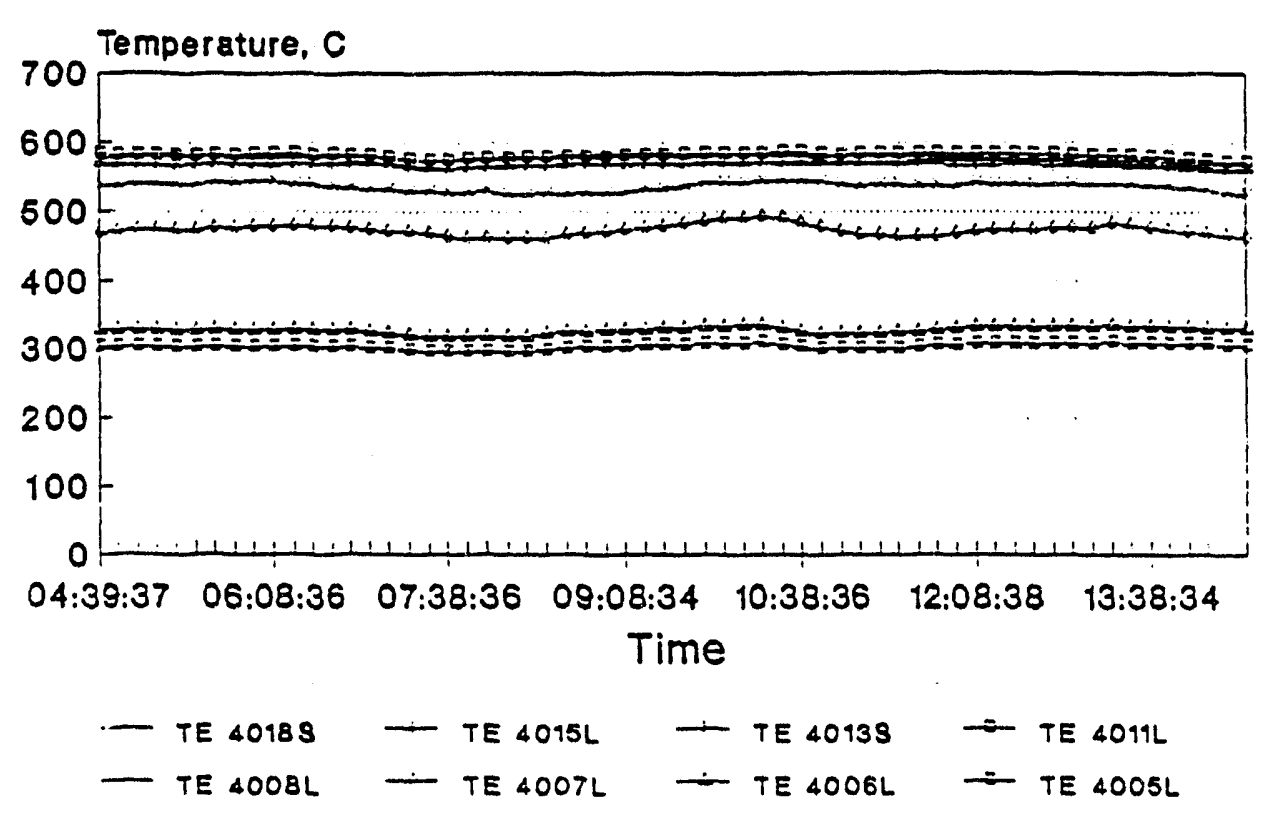

Run 932: Flows and $\mathrm{CO}$

$8 / 21 / 93$ 4:39-8/21/93 14:28

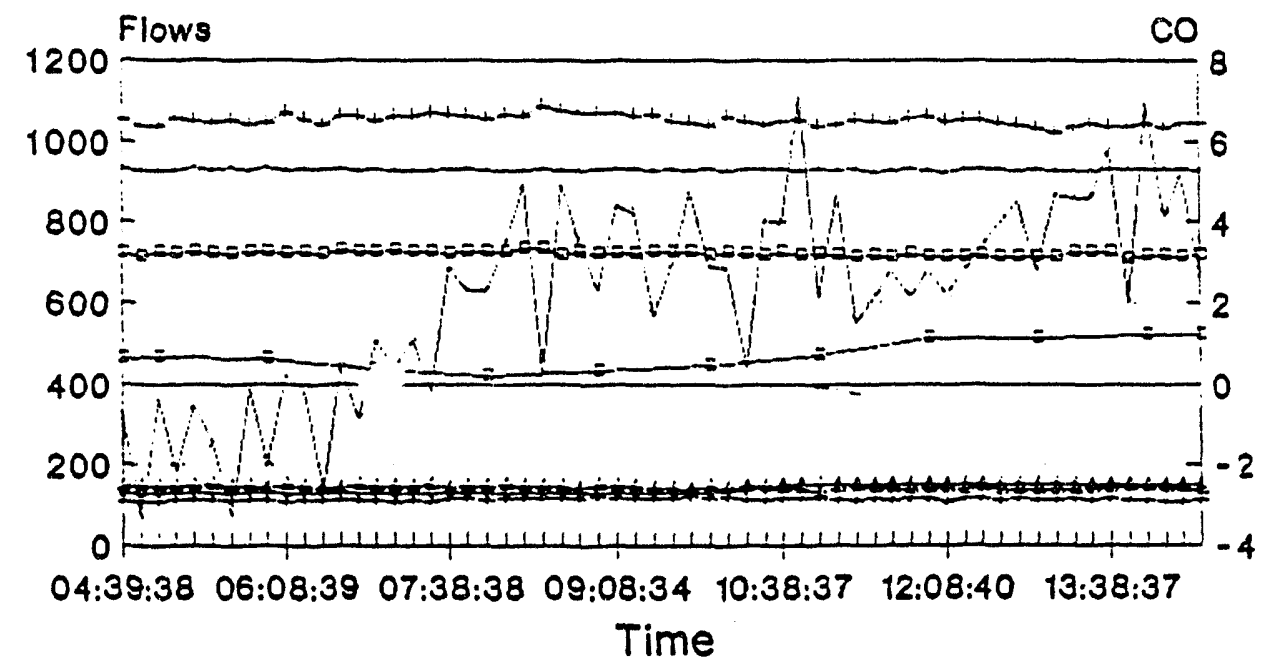

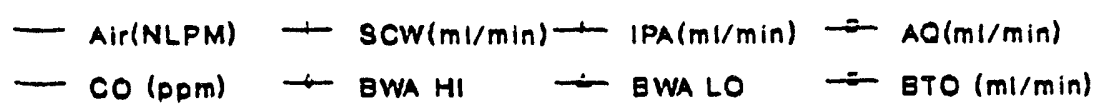


Run 932 Reactor Temperatures

$8 / 21 / 9314: 39-8 / 22 / 93$ 00:28

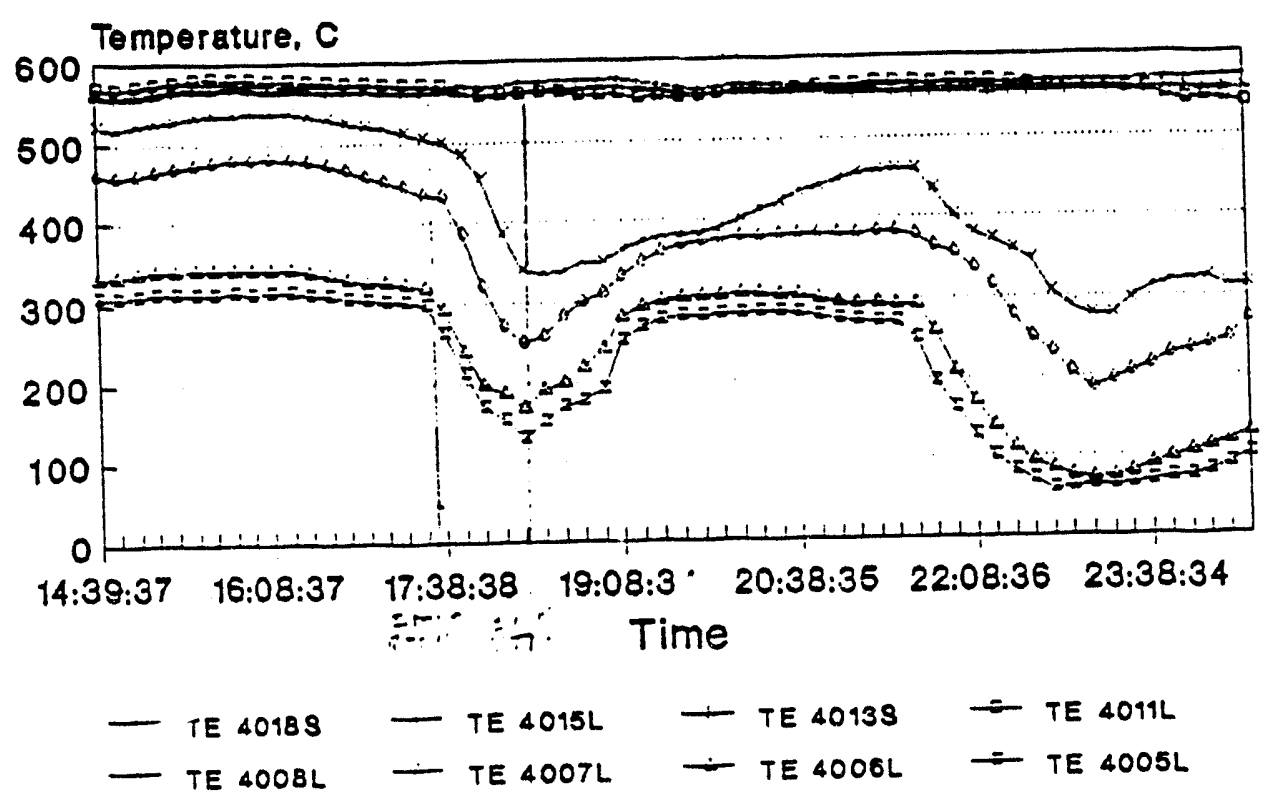

Run 932: Flows and $C O$

$8 / 21 / 93$ 14:39-8/22/93 00:28

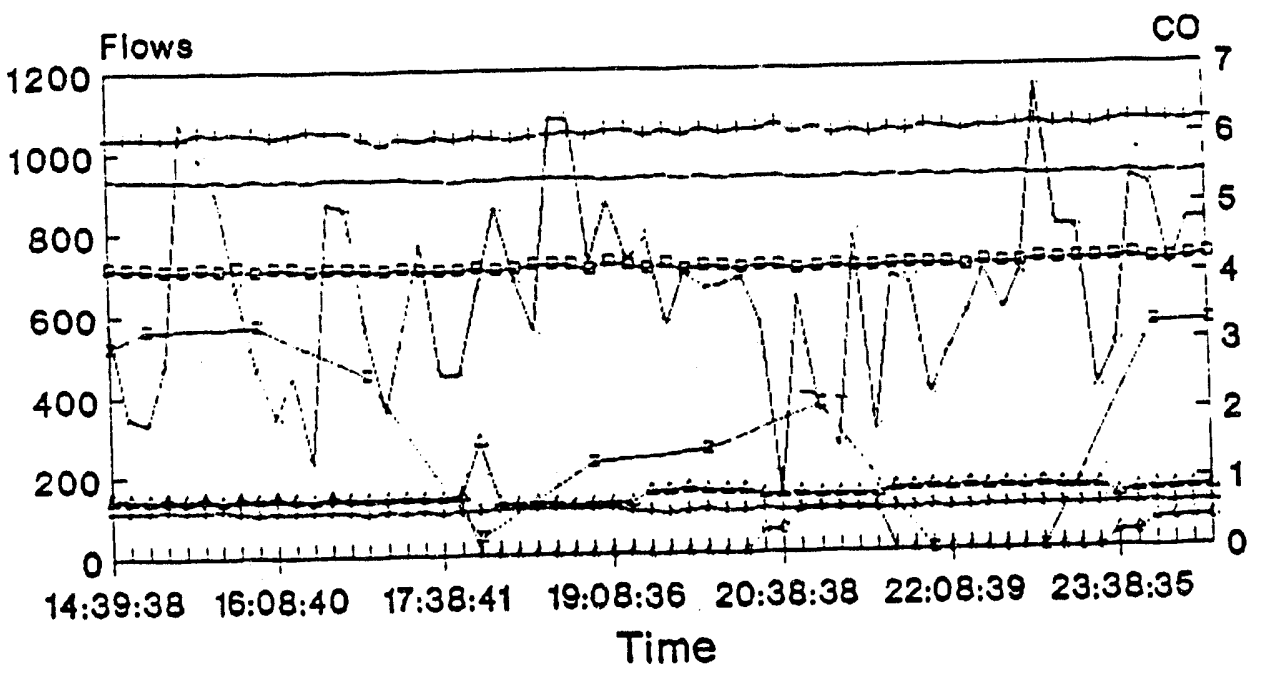

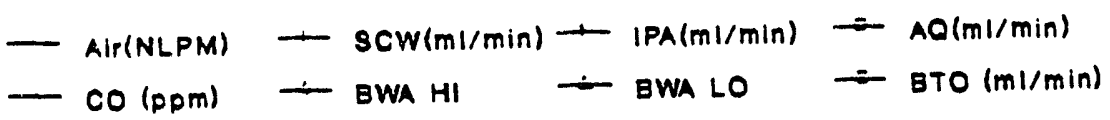


Run 932 Reactor Temperatures

8/22/93 00:39 - 8/22/93 10:28

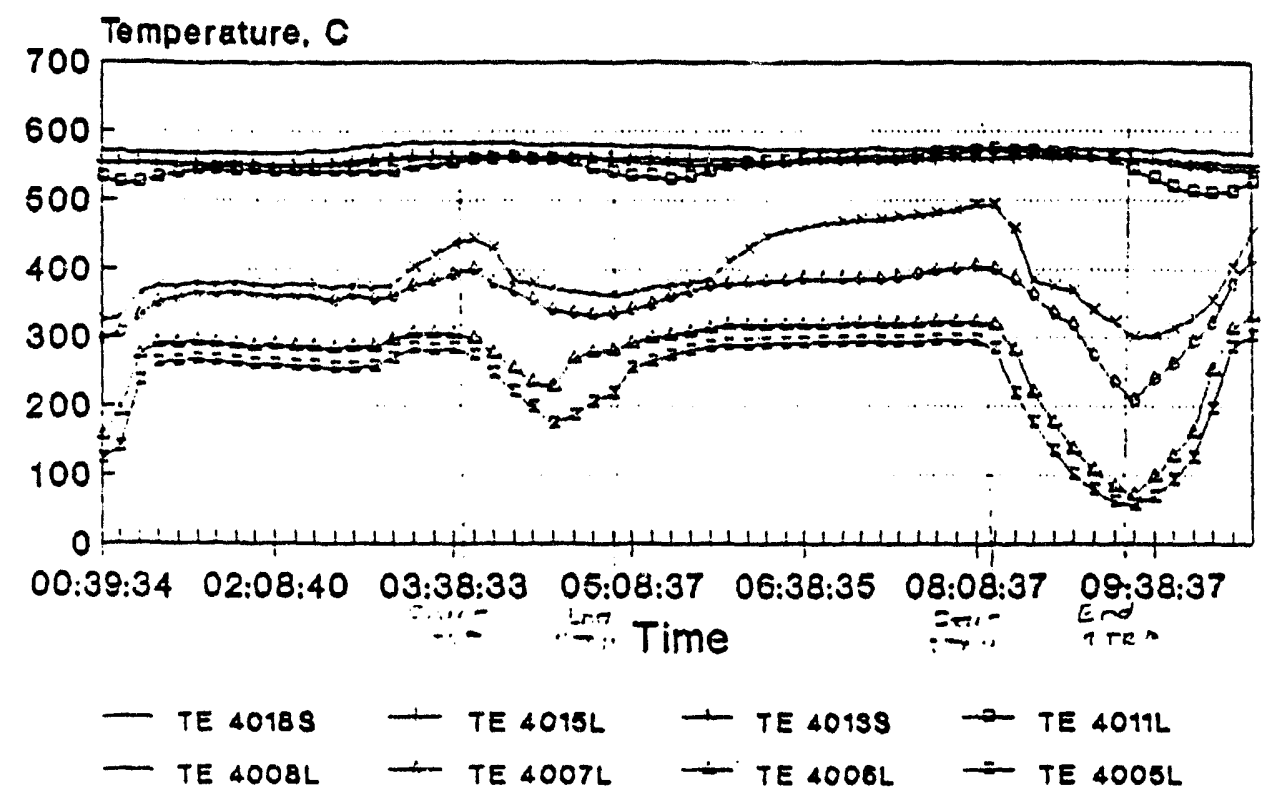

Run 932: Flows and $\mathrm{CO}$

$8 / 22 / 93$ 00:39-8/22/93 10:28

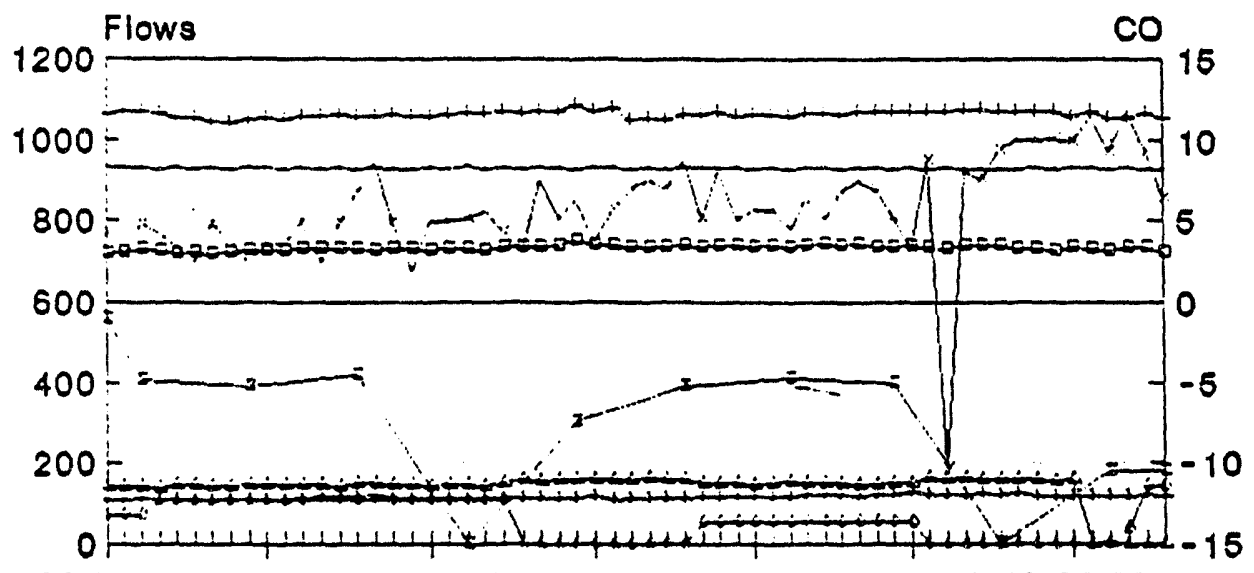

00:39:34 02:08:43 03:38:35 05:08:40 06:38:38 08:08:40 09:38:39

Time

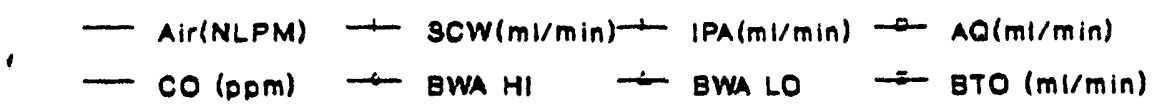


Run 932 Reactor Temperatures

$8 / 22 / 93$ 10:39 - 8/22/93 20:28

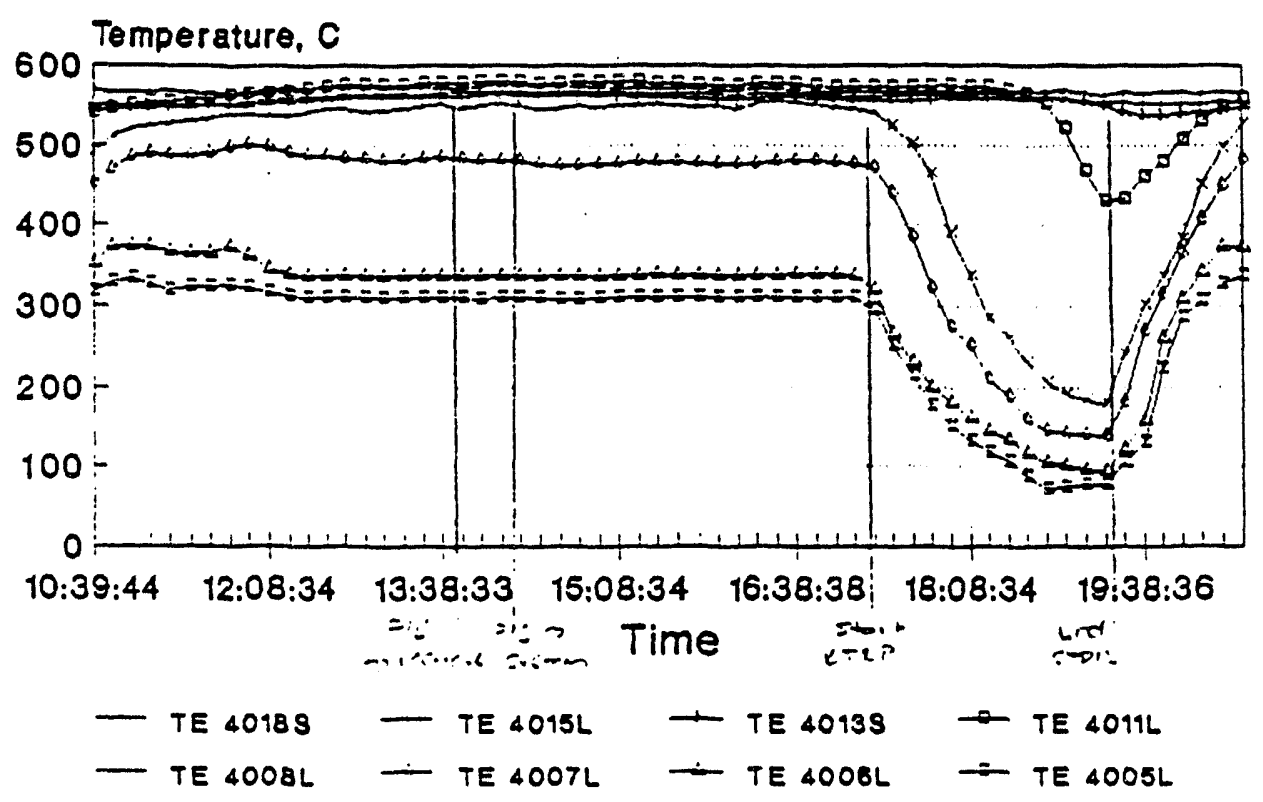

Run 932: Flows and $C O$

$8 / 22 / 93$ 10:39-8/22/93 20:28

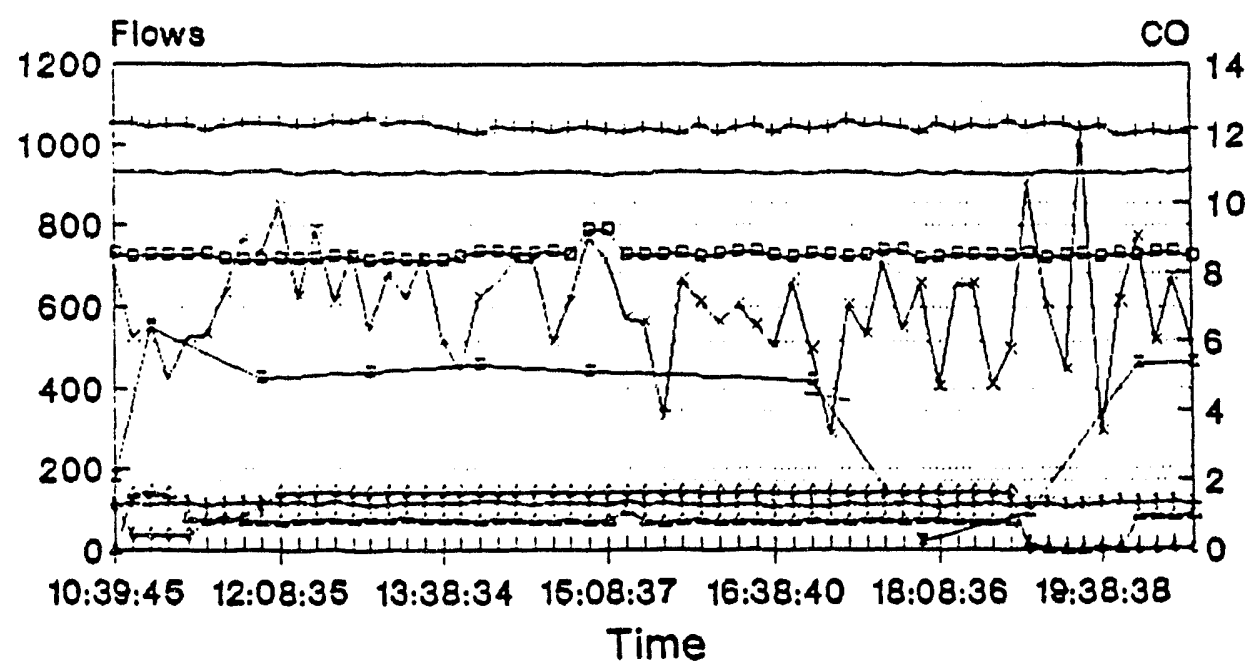

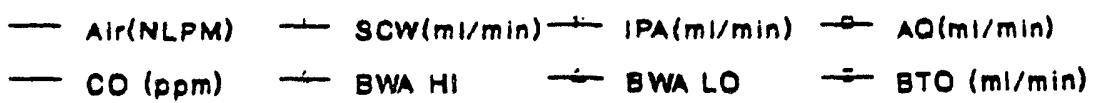


Run 932 Reactor Temperatures

$8 / 22 / 93$ 20:39 - 8/23/93 6:28

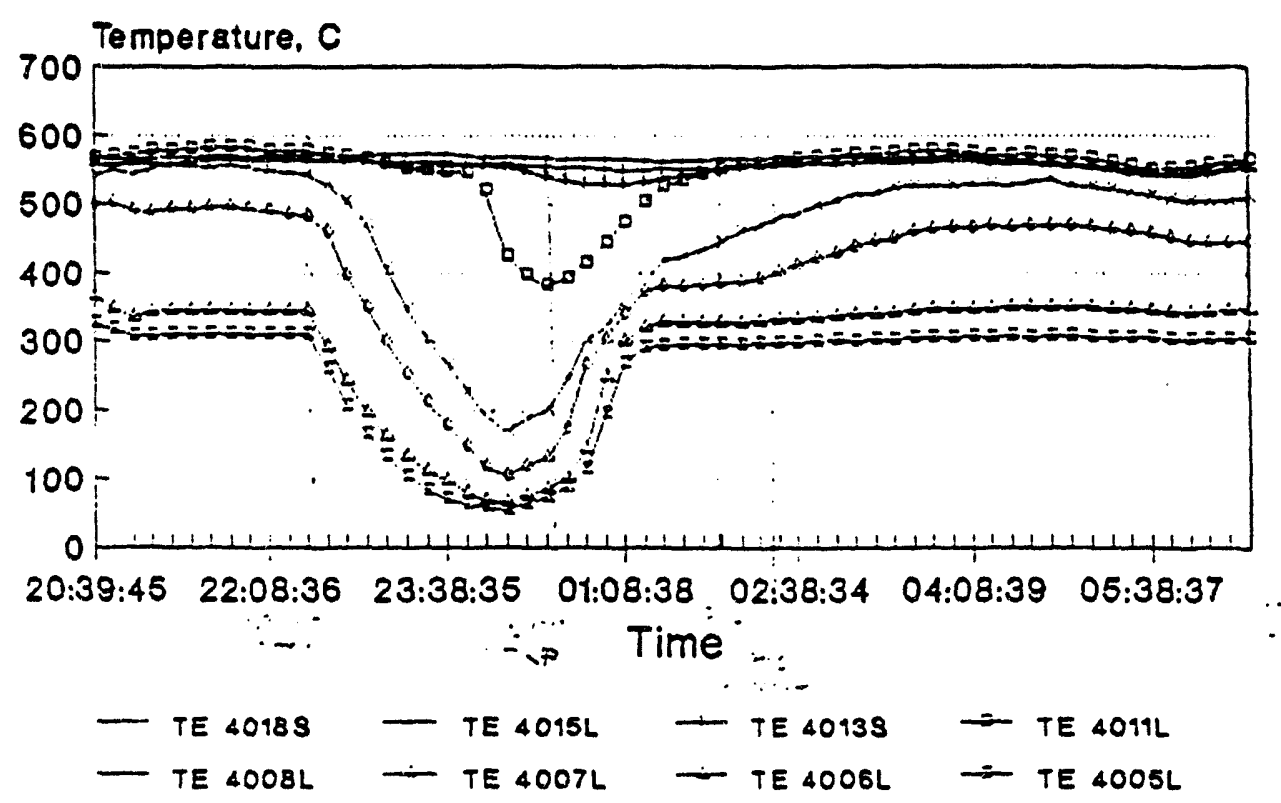

Run 932: Flows and $C O$

8/22/93 20:39-8/23/93 6:28

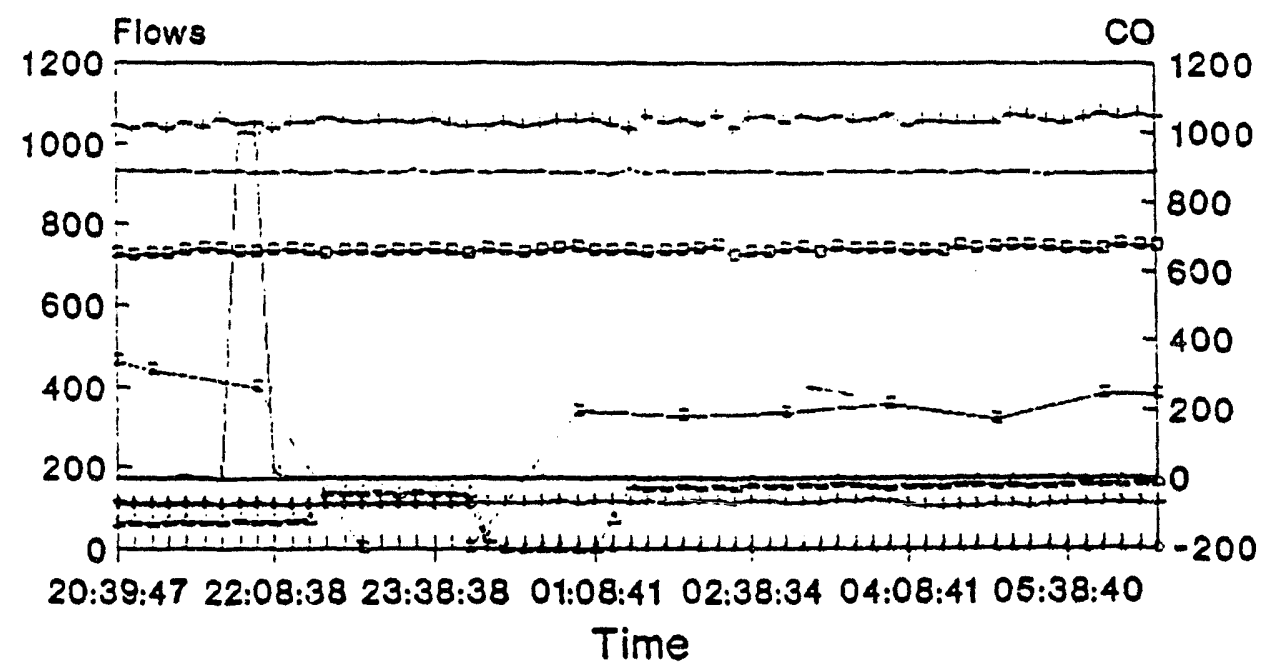

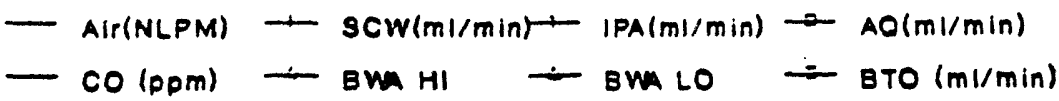


Run 932 Reactor Temperatures

$8 / 23 / 936: 39-8 / 23 / 93$ 11:21

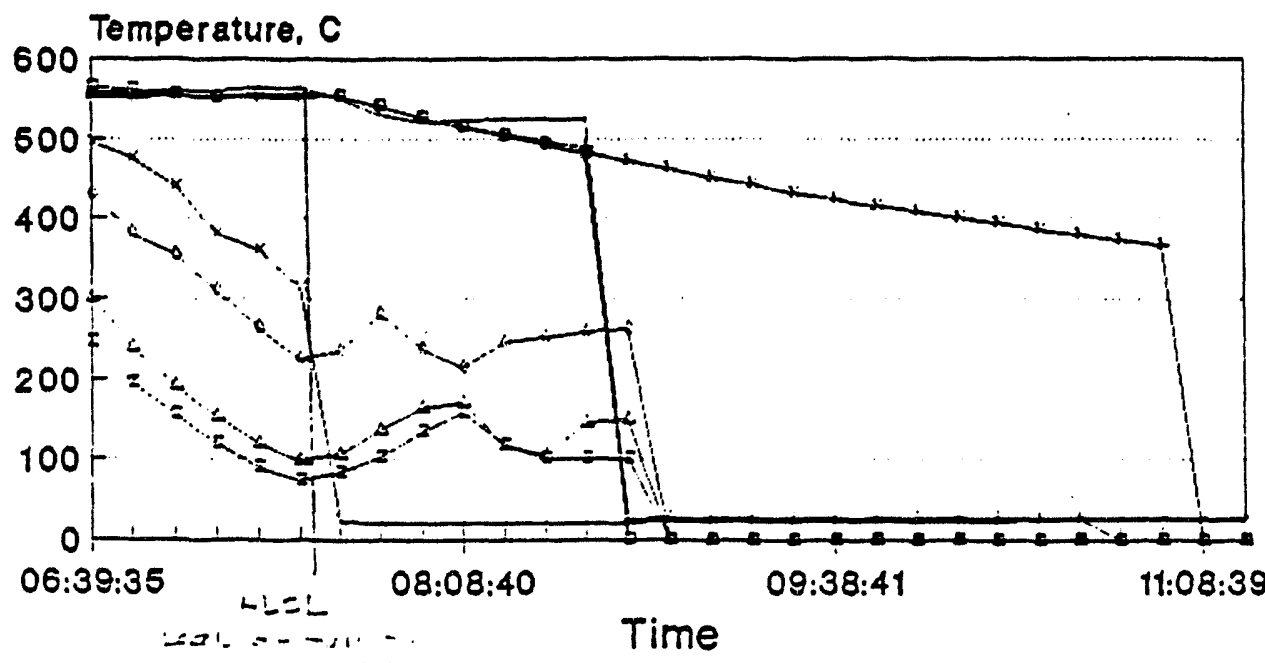

- TE $4018 \mathrm{~S}$ - TE 4015L - TE 40139 - TE 4011L
- TE 4008L TE 4007L - TE 4006L

Run 932: Flows and $\mathrm{CO}$

$8 / 23 / 93$ 6:39-8/23/93 11:20

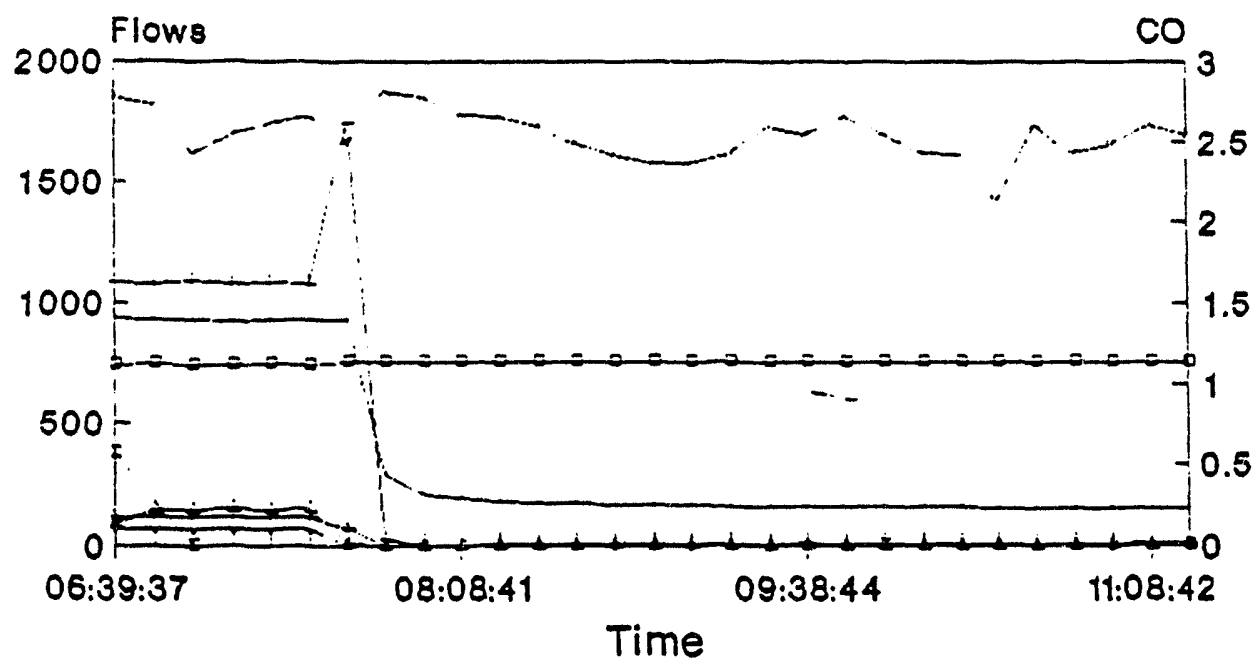

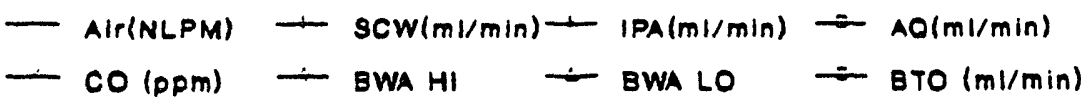

BWA $H I$ and LO are in $(\mathrm{m} / / \mathrm{min})$ 
Run 932 Reactor Temperatures

$8 / 23 / 9315: 22-8 / 23 / 93$ 21:22

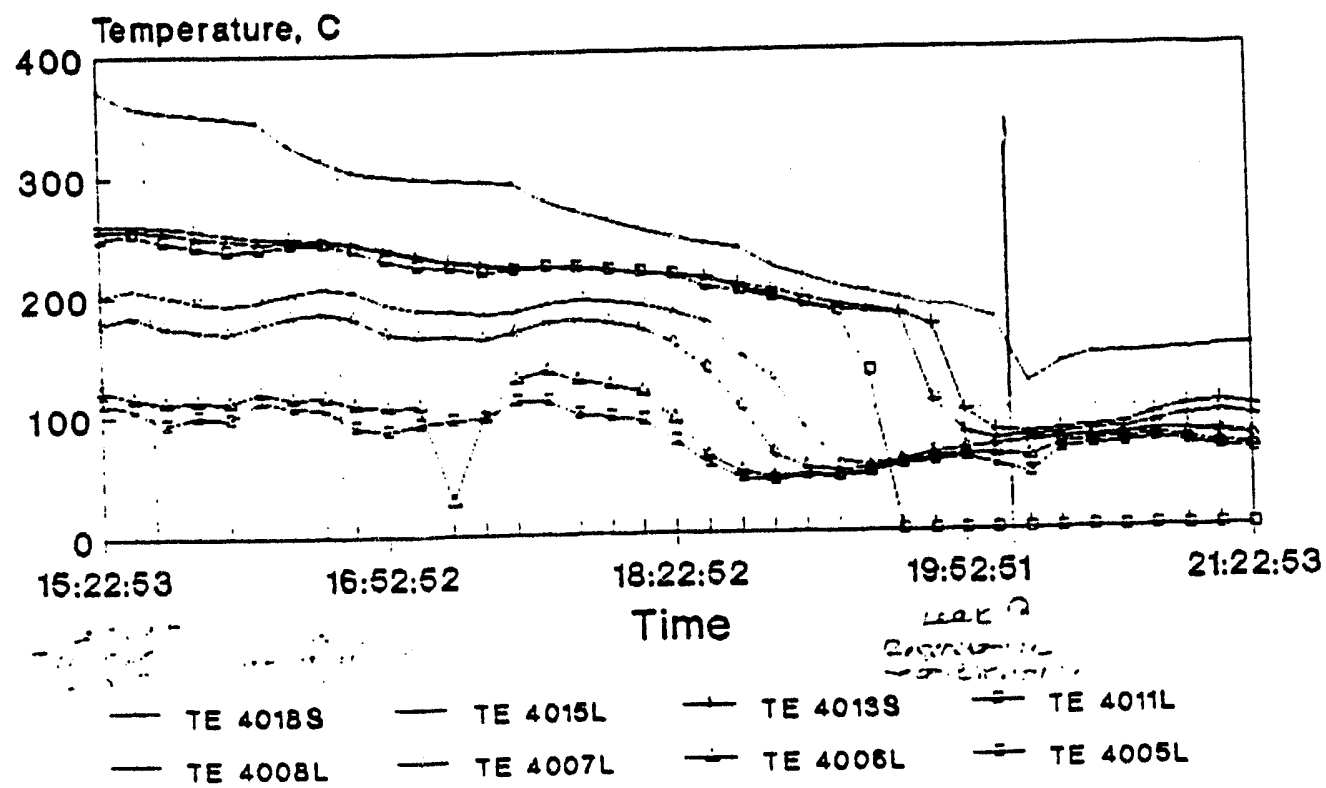

Run 932: Flows and $\mathrm{CO}$

$8 / 23 / 93$ 15:22-8/23/93 21:22

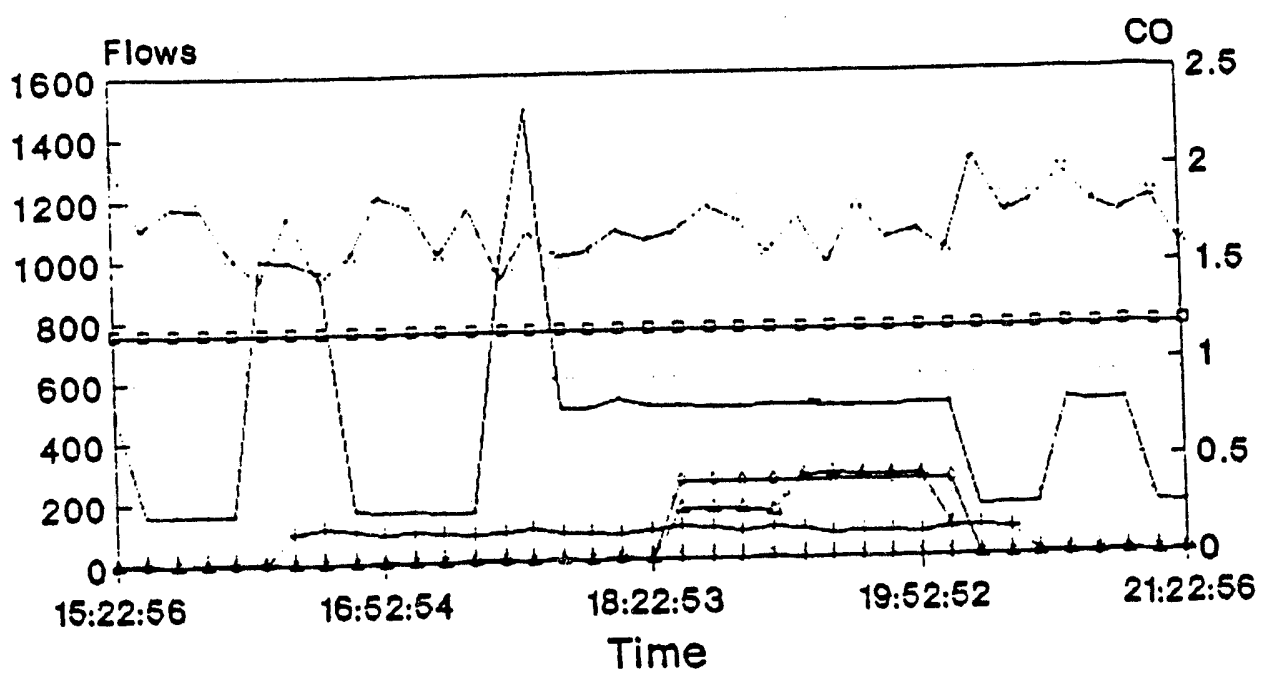

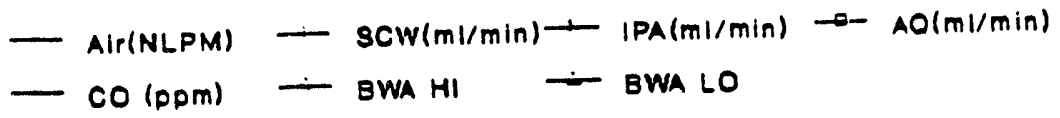


Run 932 Reactor Temperatures

8/24/93 6:01 - 8/24/93 15:51

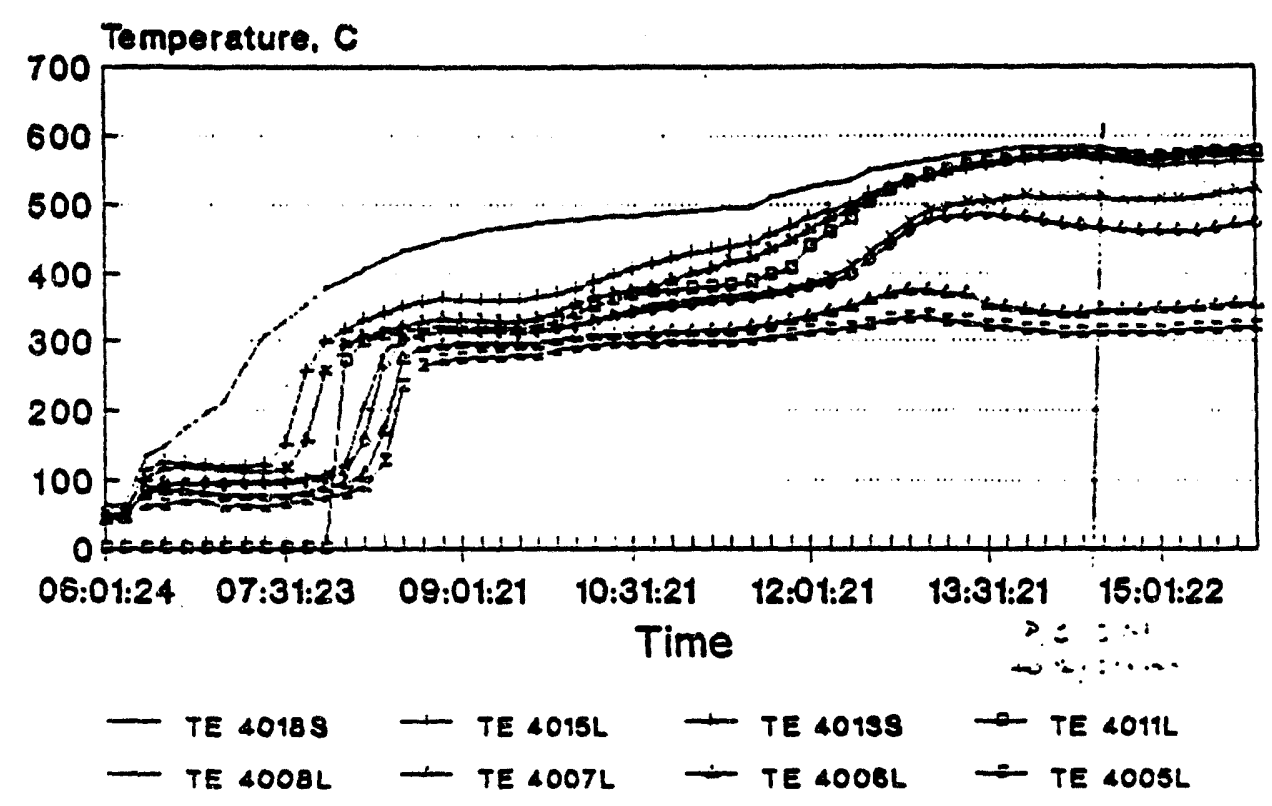

Run 932: Flows and $C O$

8/24/93 6:01-8/24/93 15:51

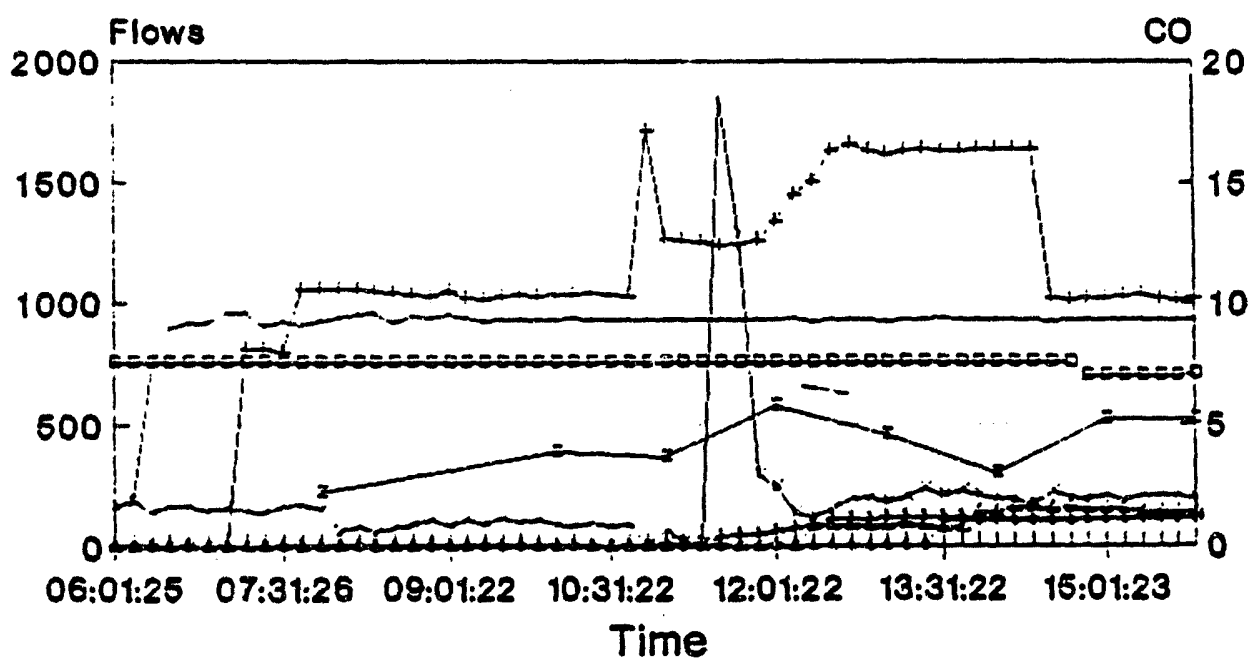

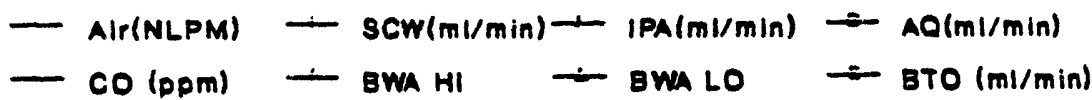

BWA $H I$ and LO ape in $(\mathrm{ml} / \mathrm{min})$ 
Run 932 Reactor Temperatures

$8 / 24 / 93$ 16:01 - 8/25/93 1:51

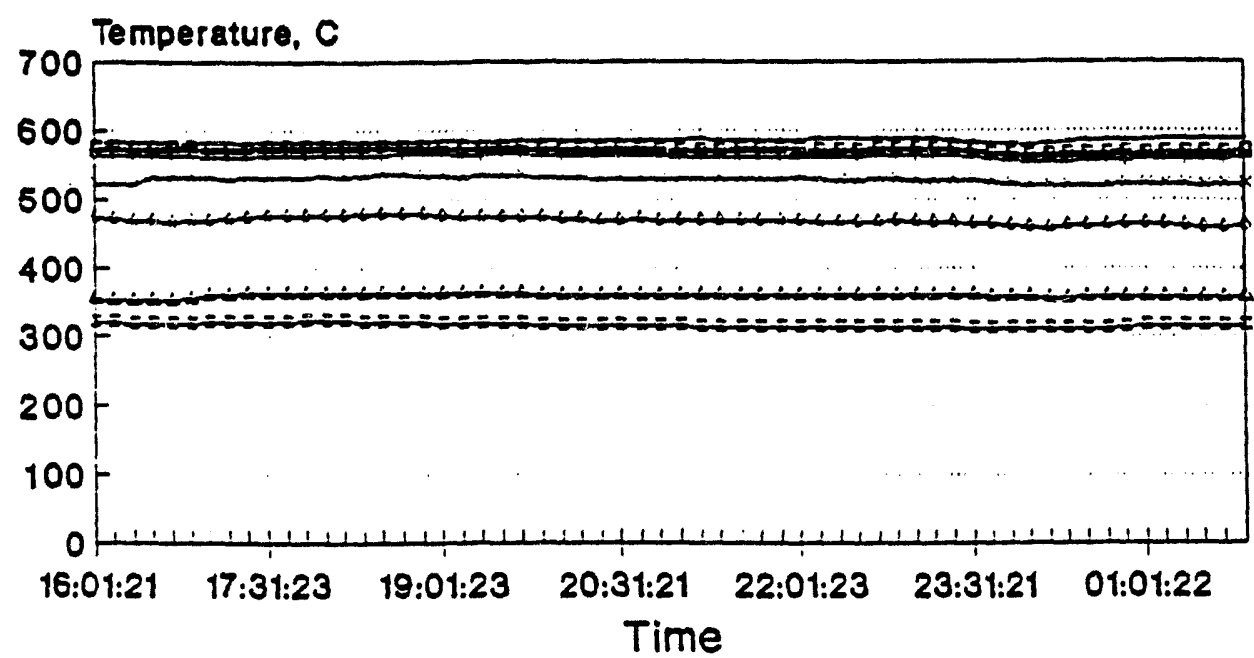

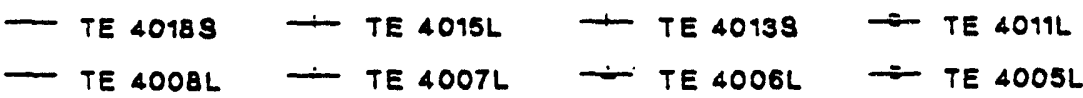

Run 932: Flows and $\mathrm{CO}$

$8 / 24 / 93$ 16:01-8/25/93 1:51

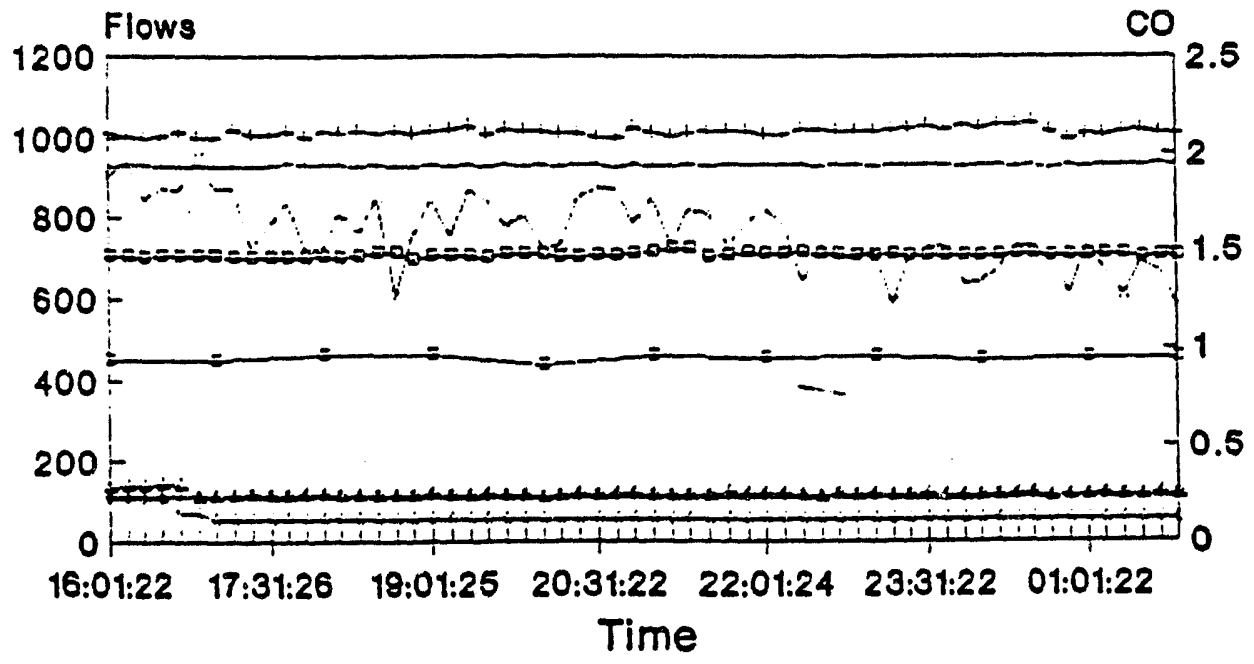

$-\operatorname{Air}(N L P M)-\operatorname{SCW}(\mathrm{ml} / \mathrm{min})+\operatorname{PA}(\mathrm{ml} / \mathrm{min})-{ }_{A O}(\mathrm{ml} / \mathrm{min})$
$-\operatorname{CO}($ PPm)

BWA HI snd LO Gro in (m//min) 
Run 932 Reactor Temperatures

$8 / 25 / 93$ 2:01 - 8/25/93 11:51

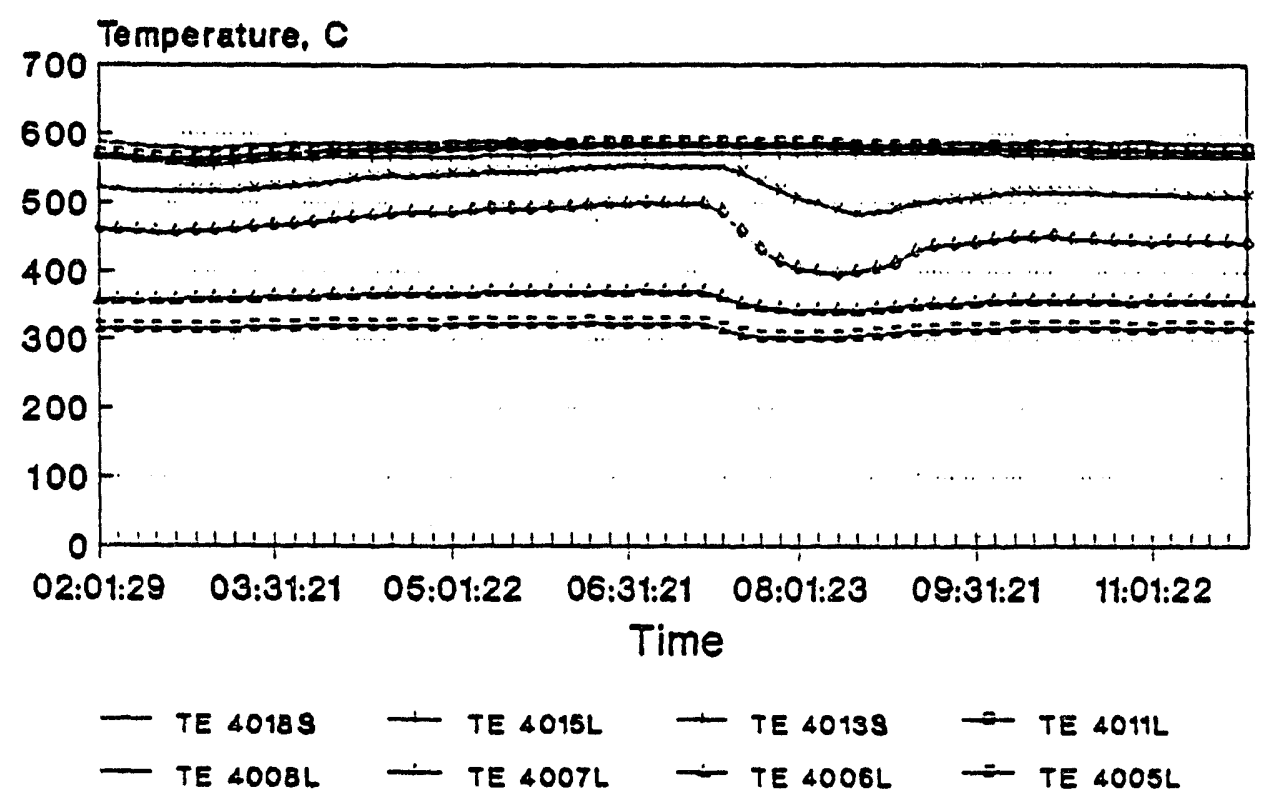

Run 932: Flows and $\mathrm{CO}$

$8 / 25 / 93$ 2:01-8/25/93 11:51

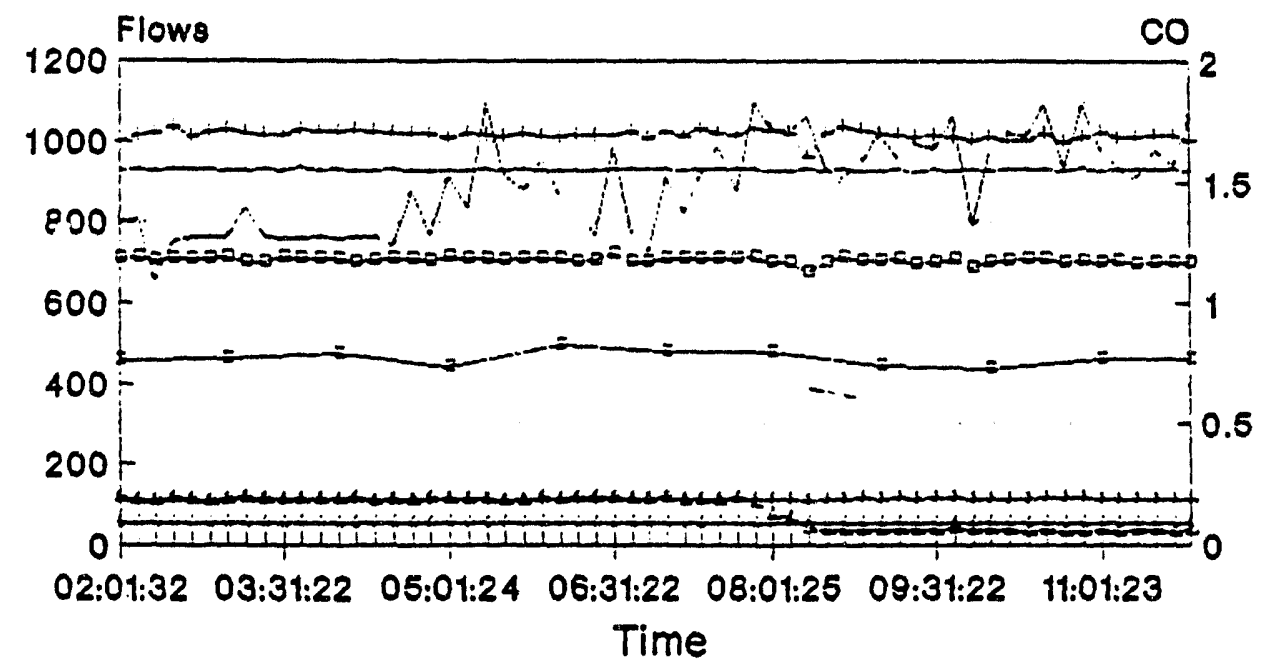

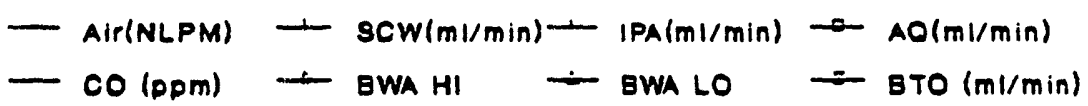

BWA HI end LO aro in $(\mathrm{ml} / \mathrm{min})$ 
Run 932 Reactor Temperatures

$8 / 25 / 9312: 01$ - 8/25/93 21:51

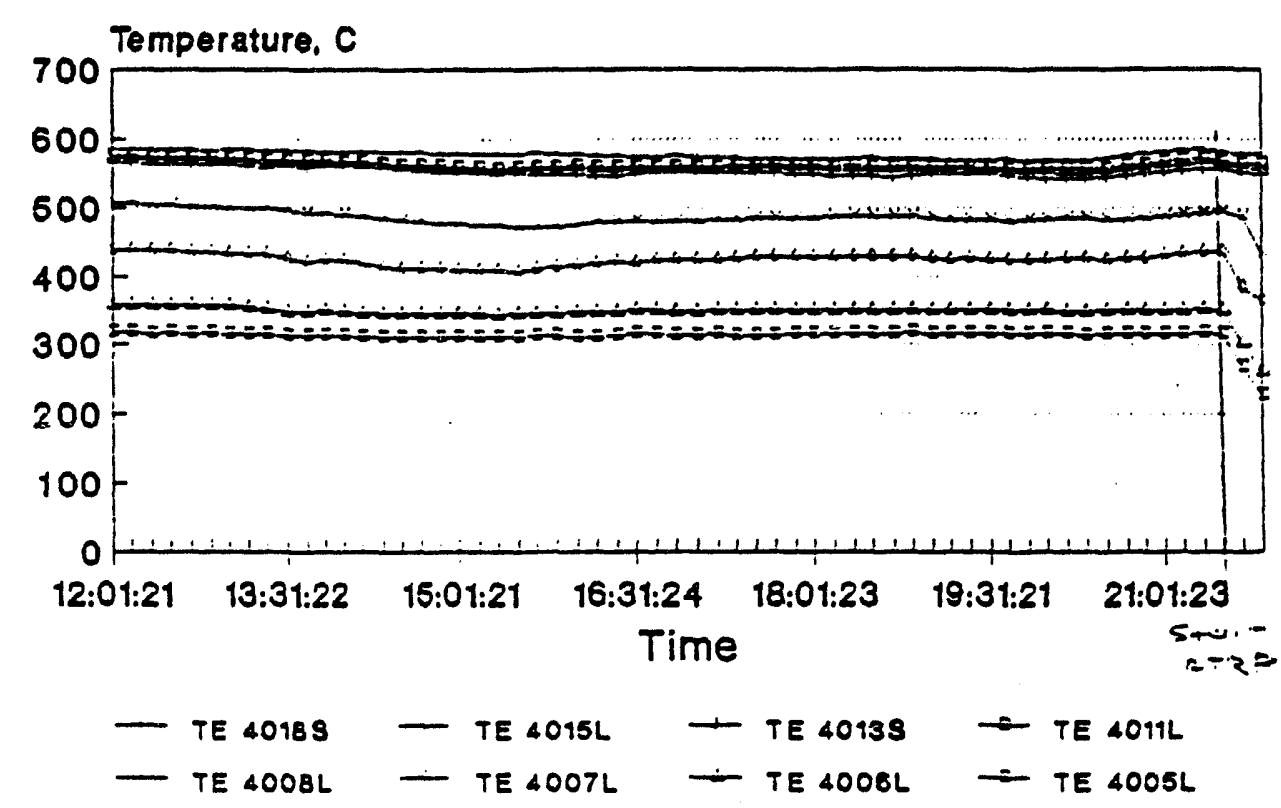

Run 932: Flows and $\mathrm{CO}$

$8 / 25 / 93$ 12:01-8/25/93 21:51

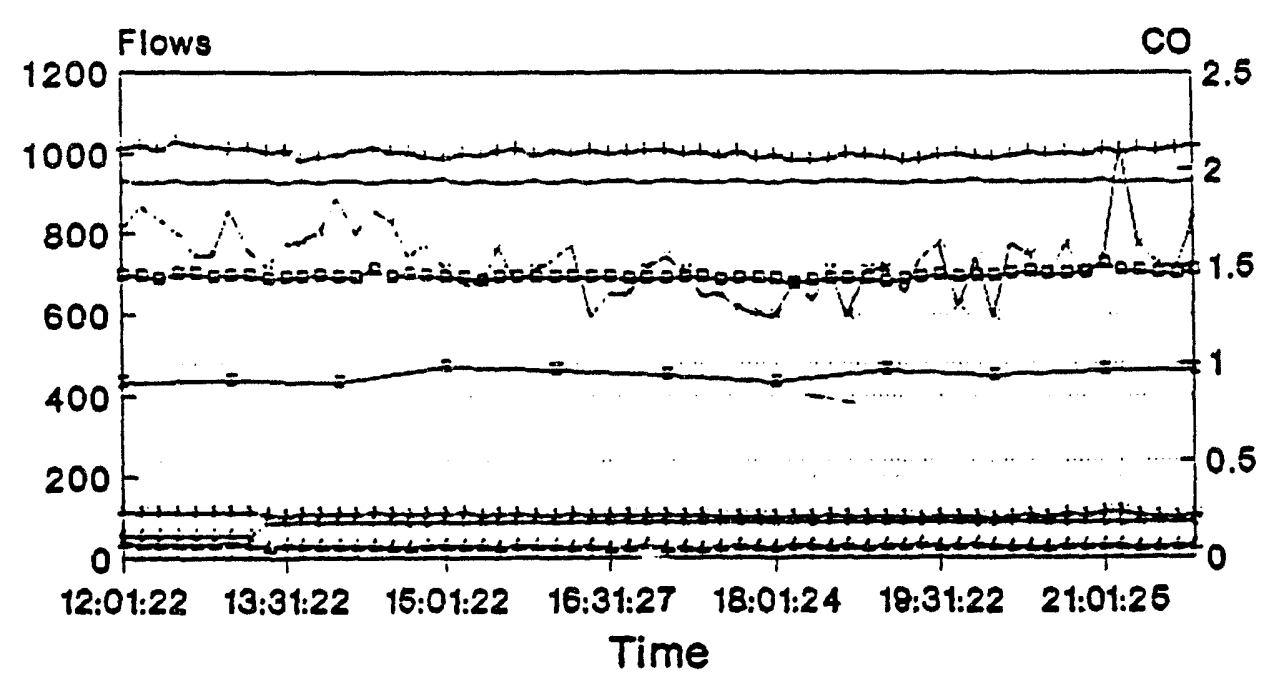

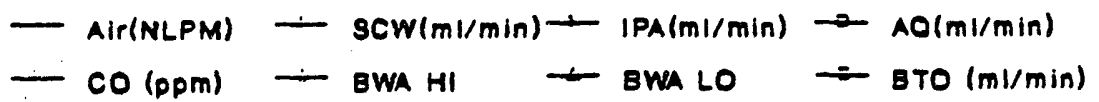

EWA HI and LO ere in $(\mathrm{ml} / \mathrm{min})$ 
Run 932 Reactor Temperatures

8/25/93 22:01 - 8/26/93 7:51

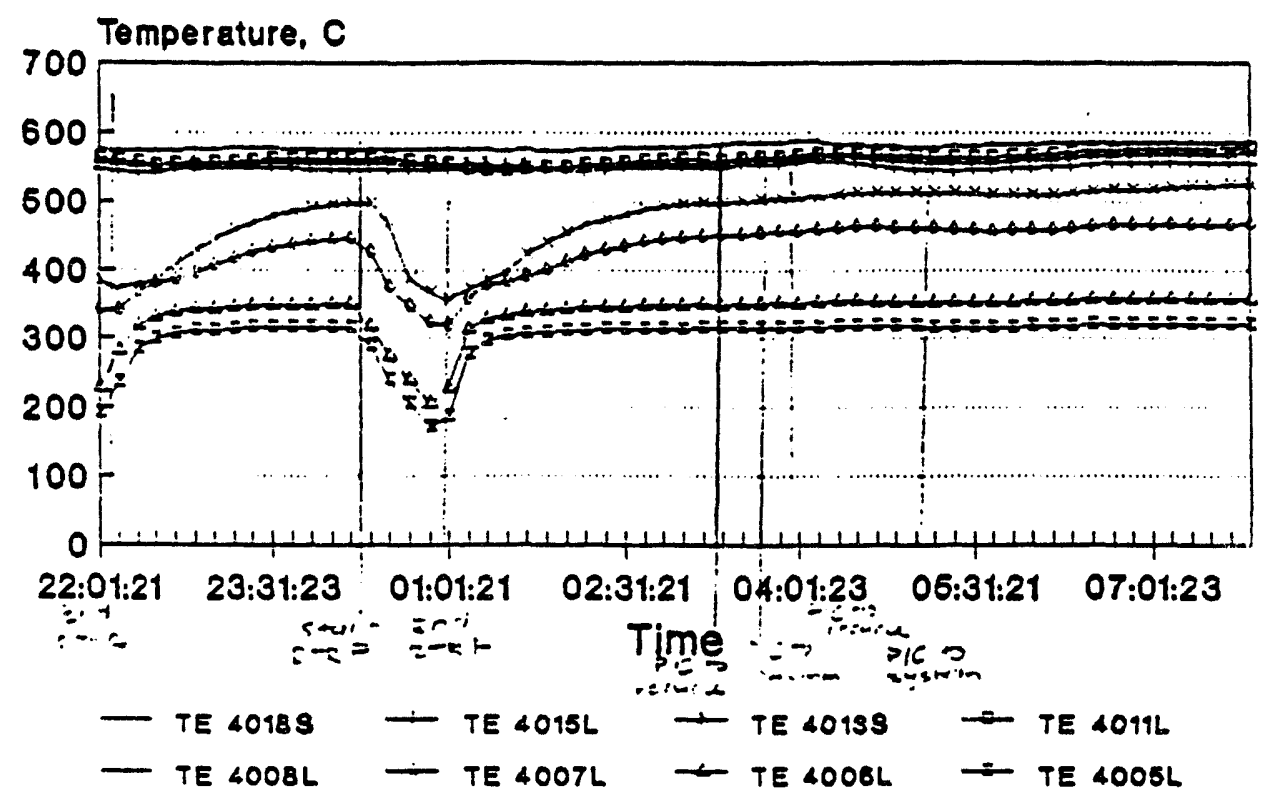

Run 932: Flows and $C O$

$8 / 25 / 93$ 22:01-8/26/93 7:51

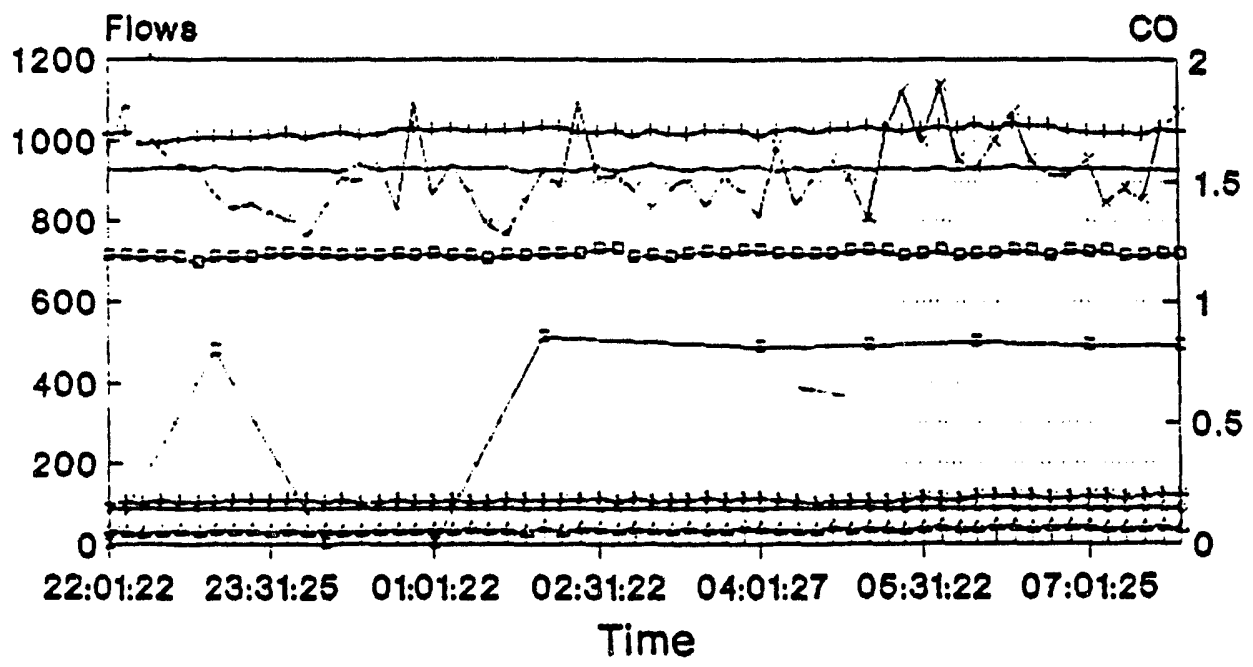

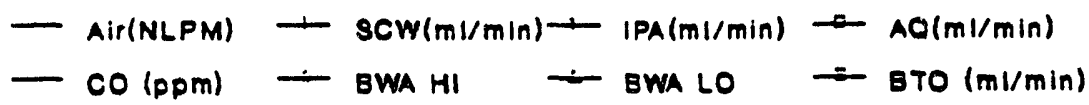

BWA HI and LO are in $(\mathrm{ml} / \mathrm{min})$ 
Run 932 Reactor Temperatures

8/26/93 8:01 - 8/26/93 17:51

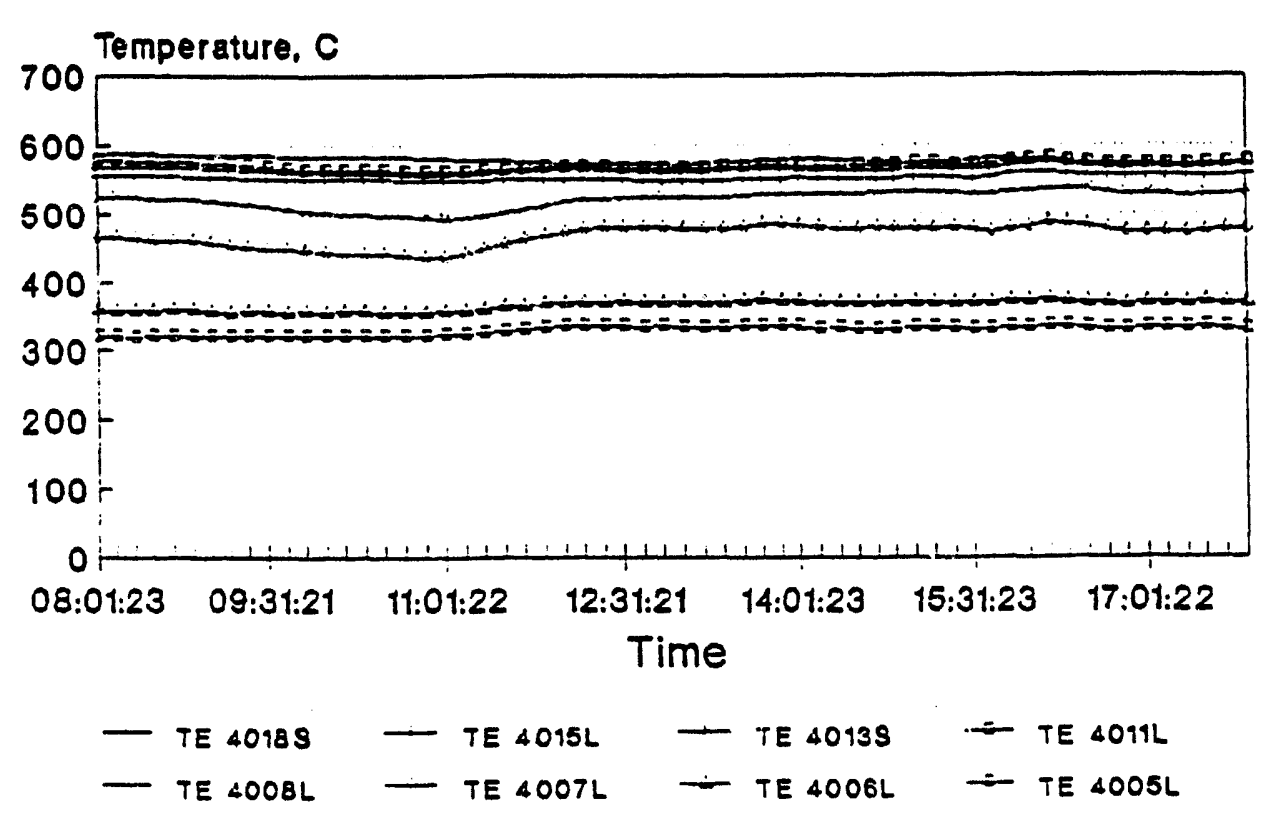

Run 932: Flows and $\mathrm{CO}$

8/26/93 8:01-8/26/93 17:51

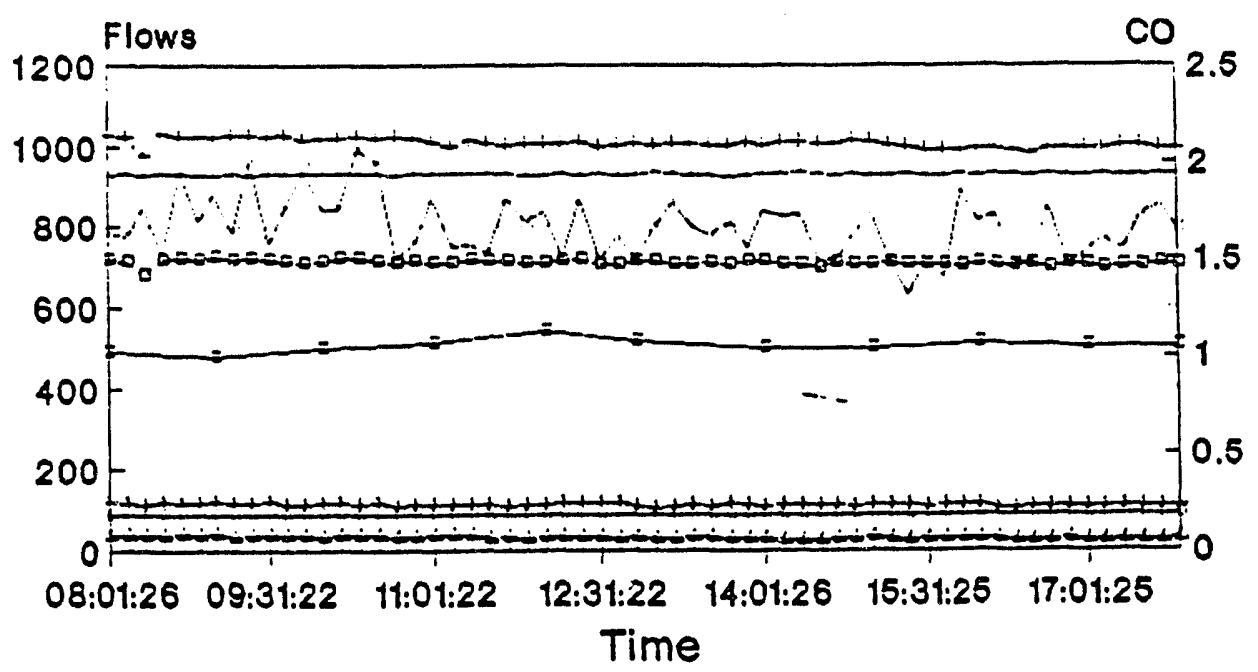

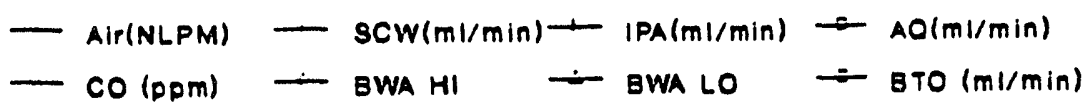


Run 932 Reactor Temperatures

8/26/93 18:01 - 8/27/93 3:51

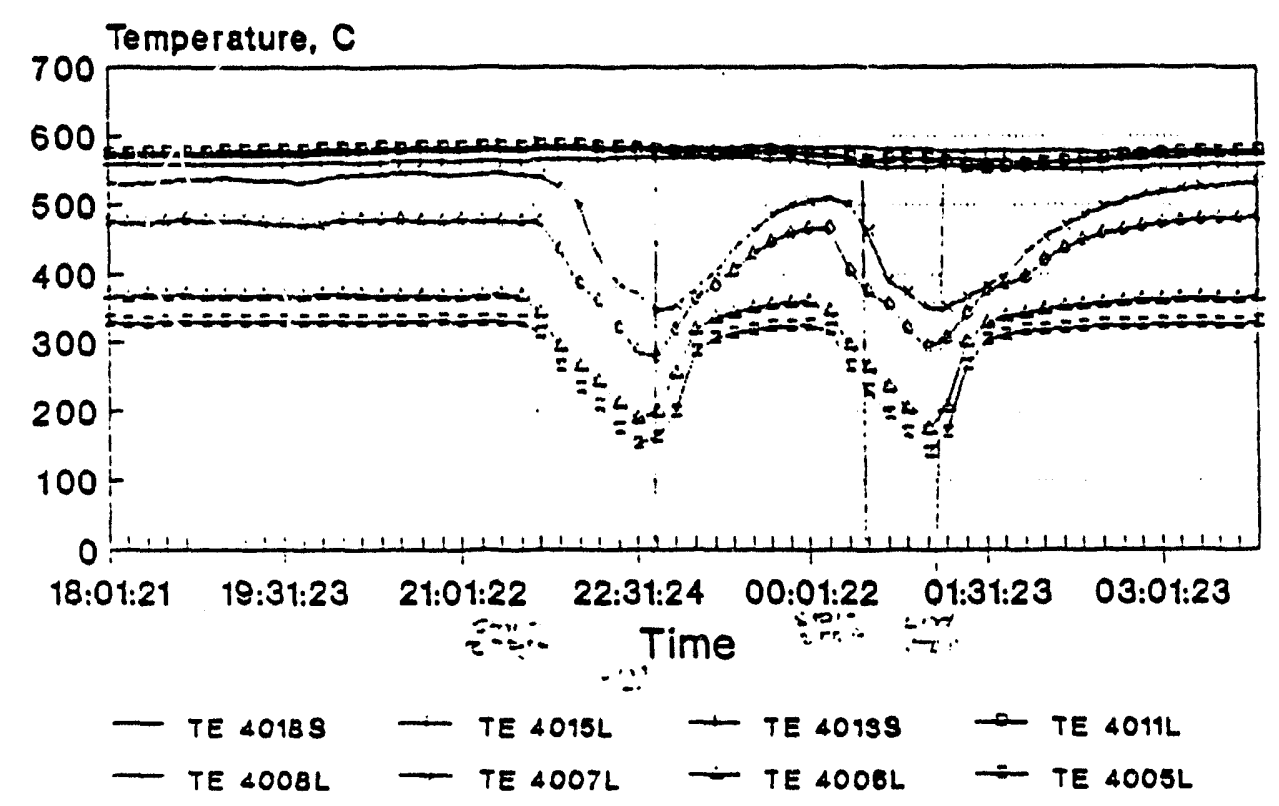

Run 932: Flows and $C O$

8/26/93 18:01-8/27/93 3:51

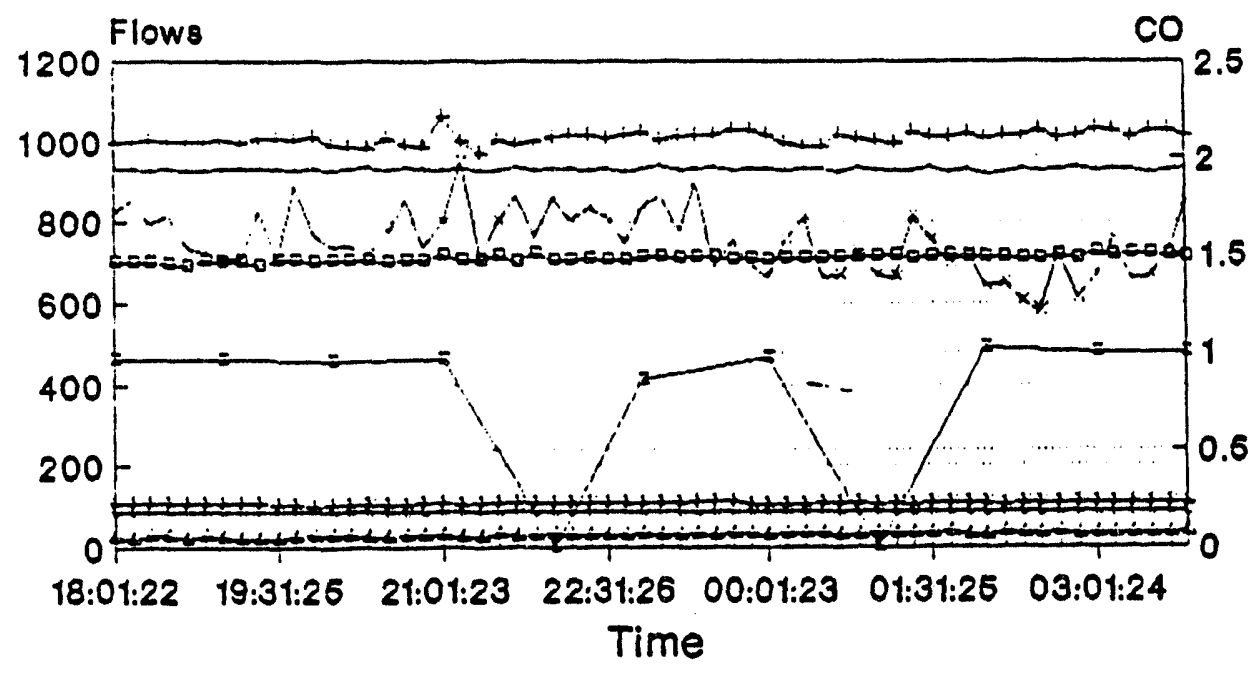

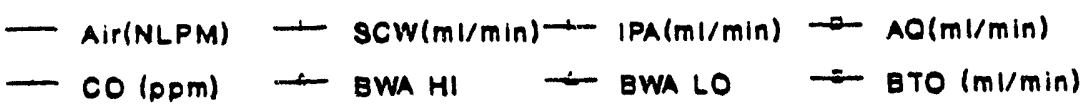


Run 932 Reactor Temperatures

8/27/93 4:01 - 8/27/93 13:51

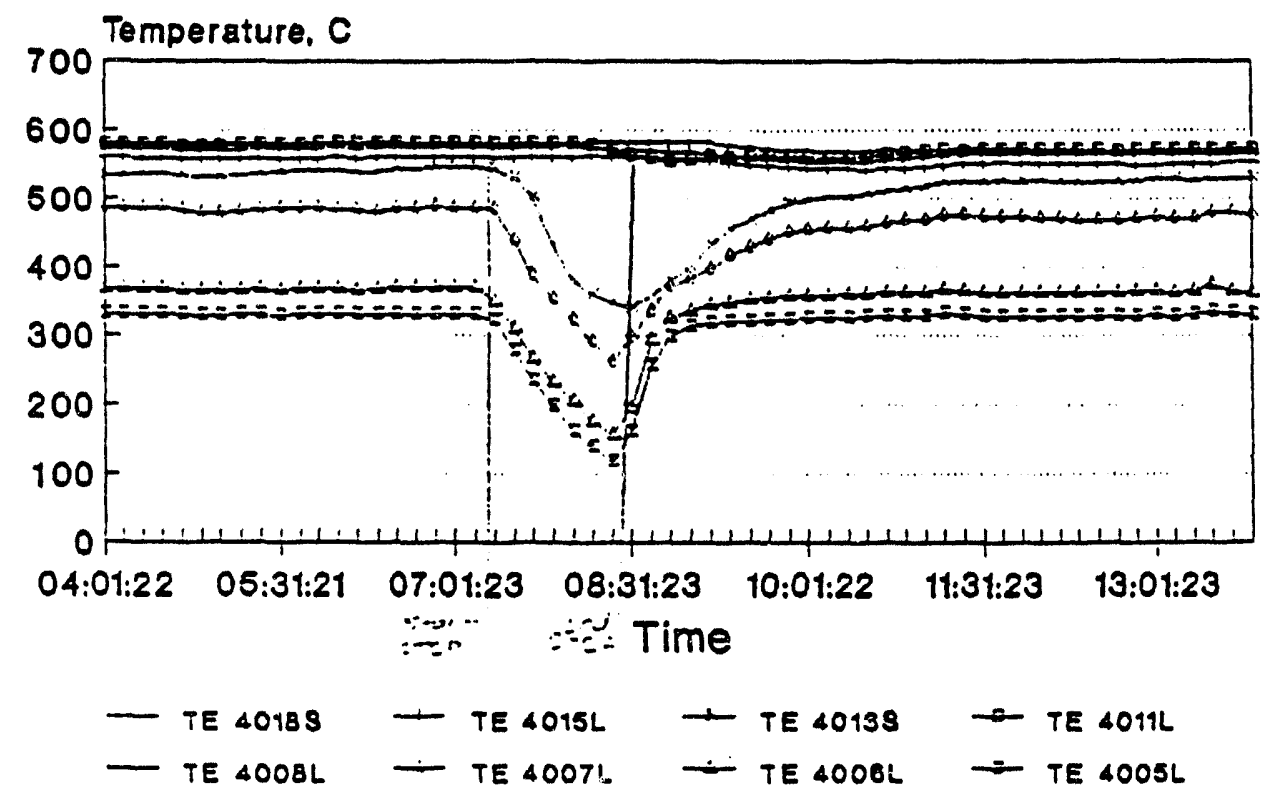

Run 932: Flows and $C O$

$8 / 27 / 93$ 4:01-8/27/93 13:51

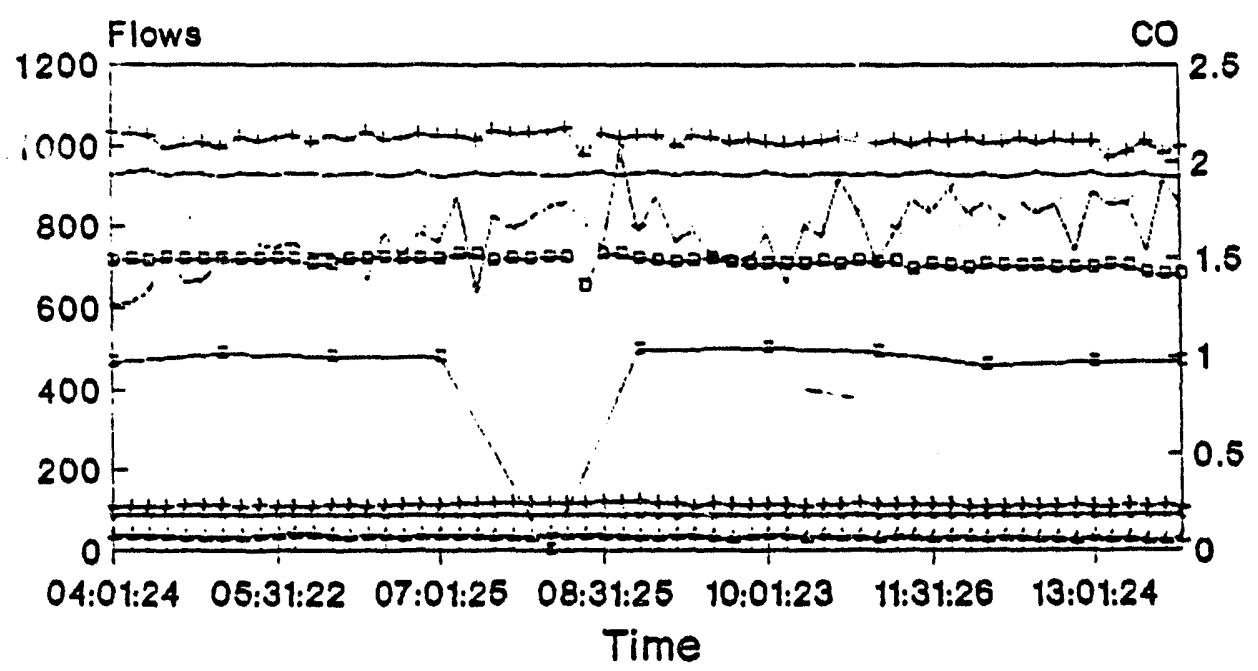

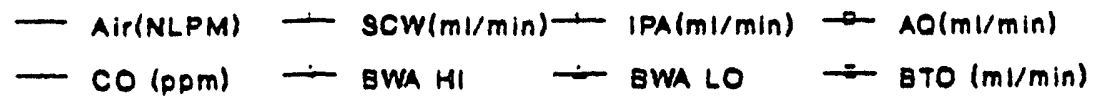

BWA HI and LO spe in $(\mathrm{m} / / \mathrm{min})$ 


\section{Run 932 Reactor Temperatures}

\section{8/27/93 14:01 - 8/27/93 23:51}

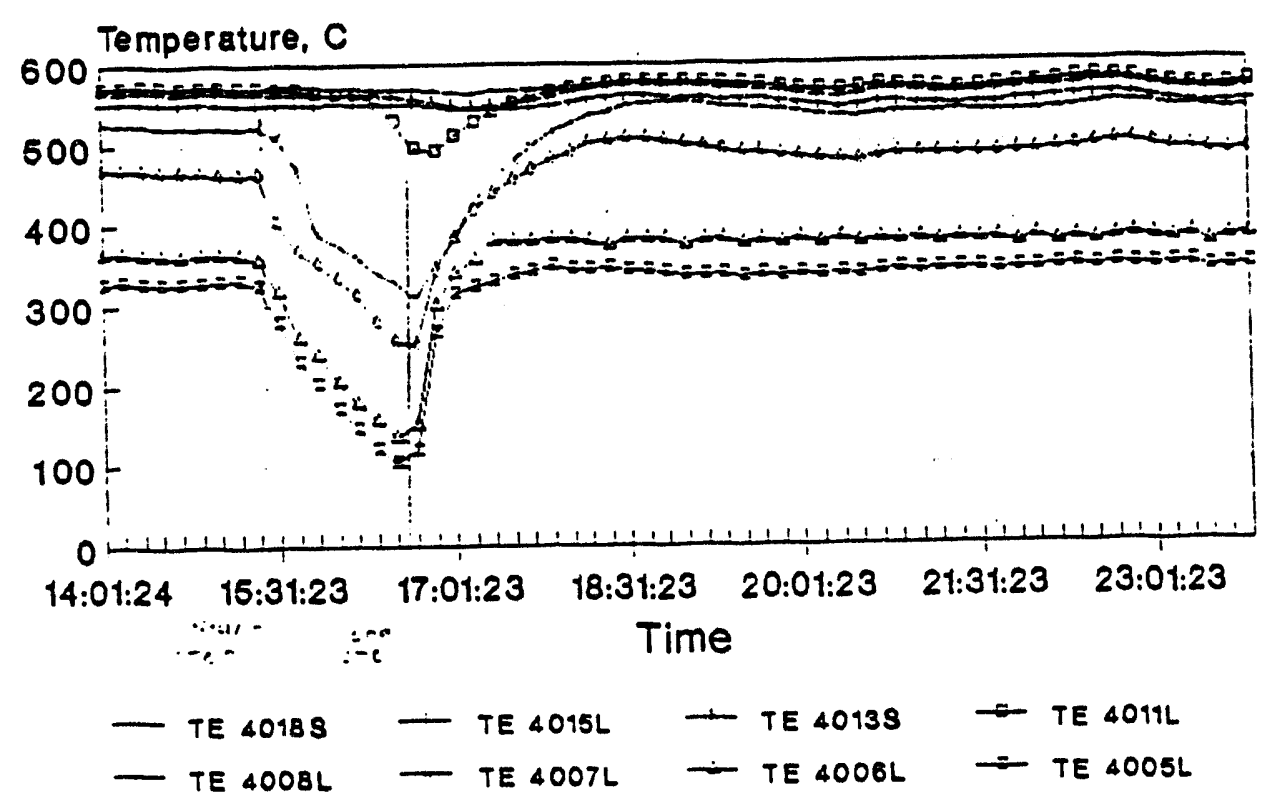

Run 932: Flows and $\mathrm{CO}$

$8 / 27 / 93$ 14:01-8/27/93 23:51

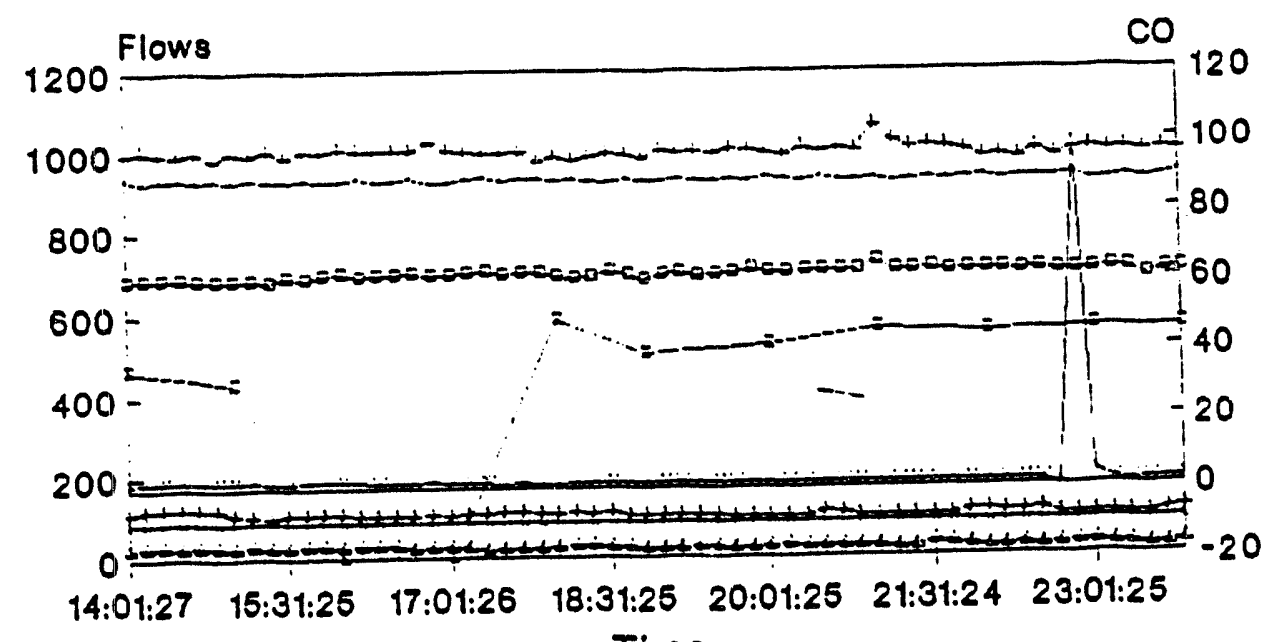

Time

$$
\begin{aligned}
& -\operatorname{Air}(N L P M)+\operatorname{SCW}(\mathrm{ml} / \mathrm{min})+\mathrm{PA}(\mathrm{ml} / \mathrm{min}) \rightarrow A Q(\mathrm{ml} / \mathrm{min}) \\
& -\mathrm{CO}(\mathrm{pPm})-\text { BWA HI } \rightarrow \text { BWA LO }=\text { BTO }(\mathrm{ml} / \mathrm{min})
\end{aligned}
$$


Run 932 Reactor Temperatures

8/28/93 00:01 - 8/27/93 9:51

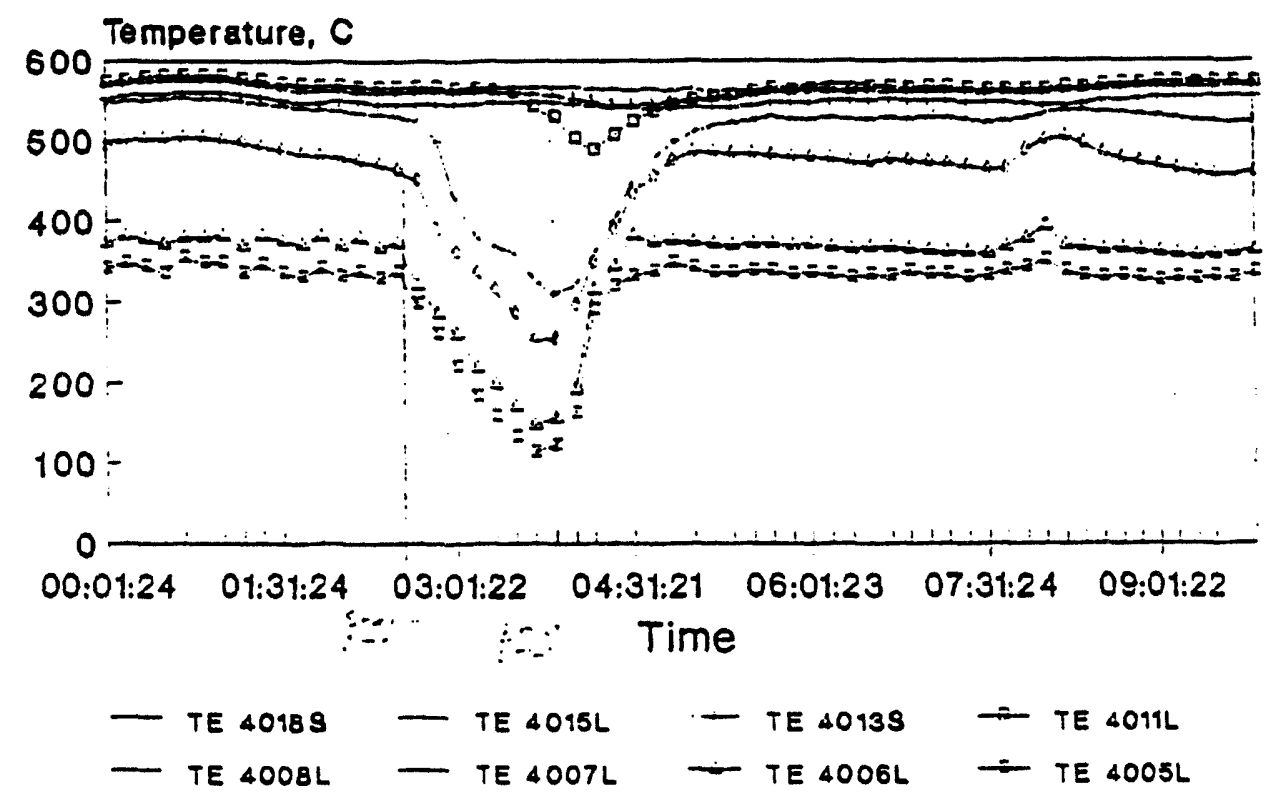

Run 932: Flows and $\mathrm{CO}$

8/28/93 00:01-8/28/93 9:51

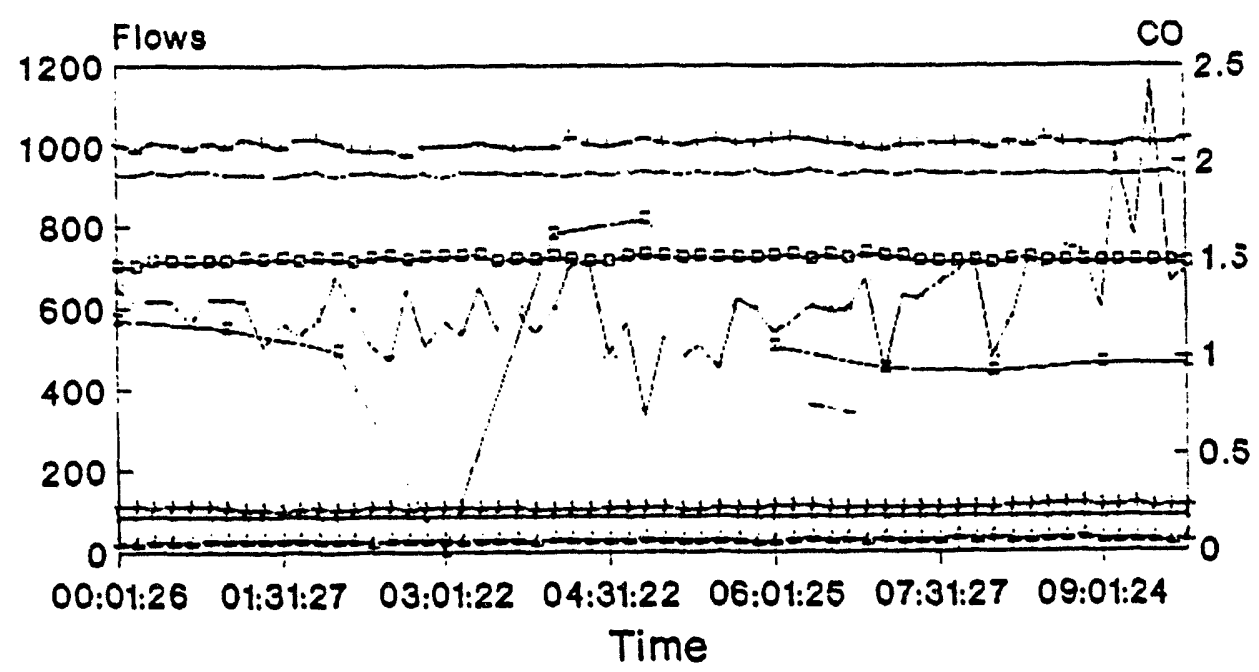

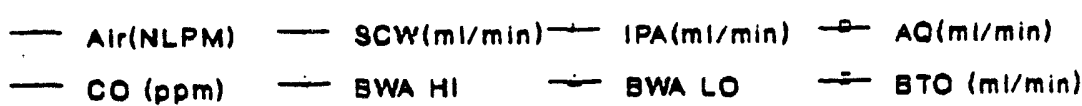

EWA HI and LO are in $(\mathrm{ml} / \mathrm{min})$ 


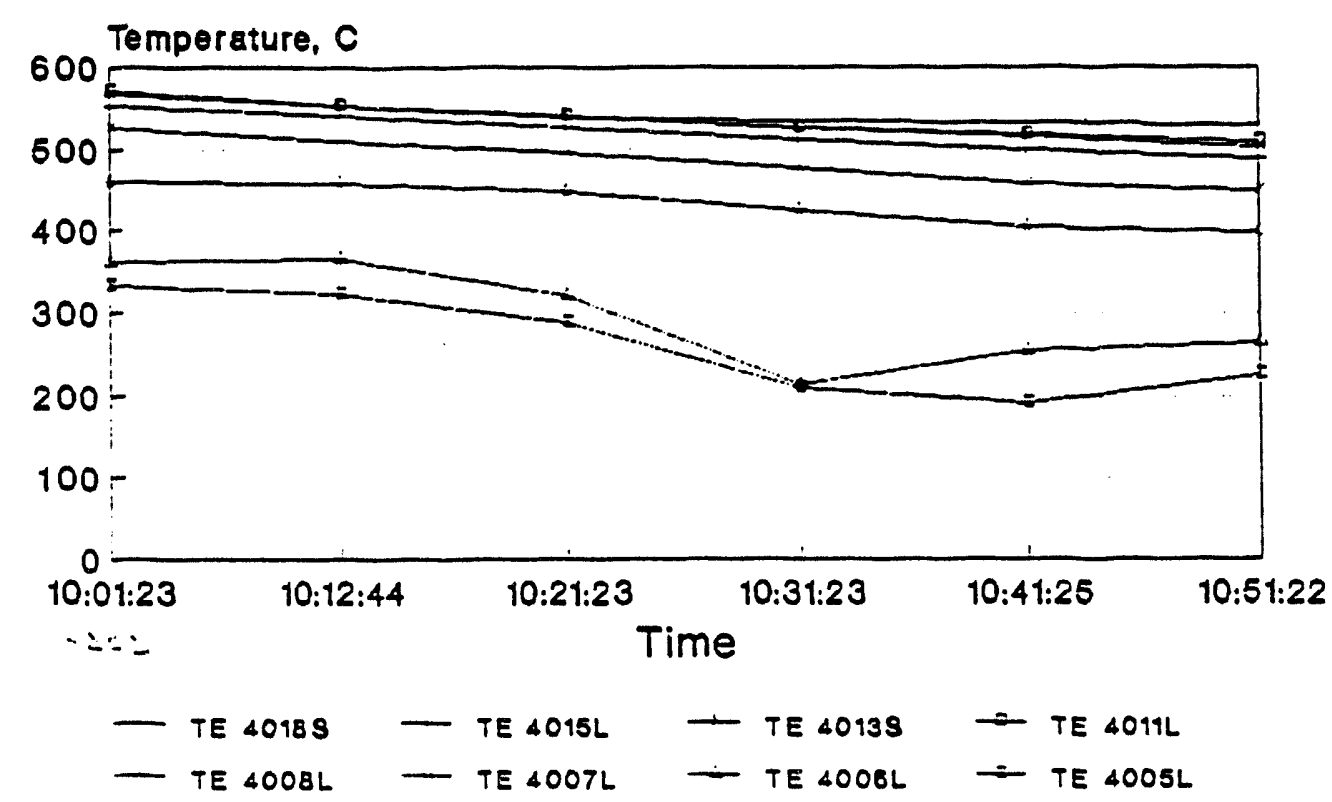

Run 932: Flows and $C O$

$8 / 28 / 93$ 10:01-8/28/93 10:51

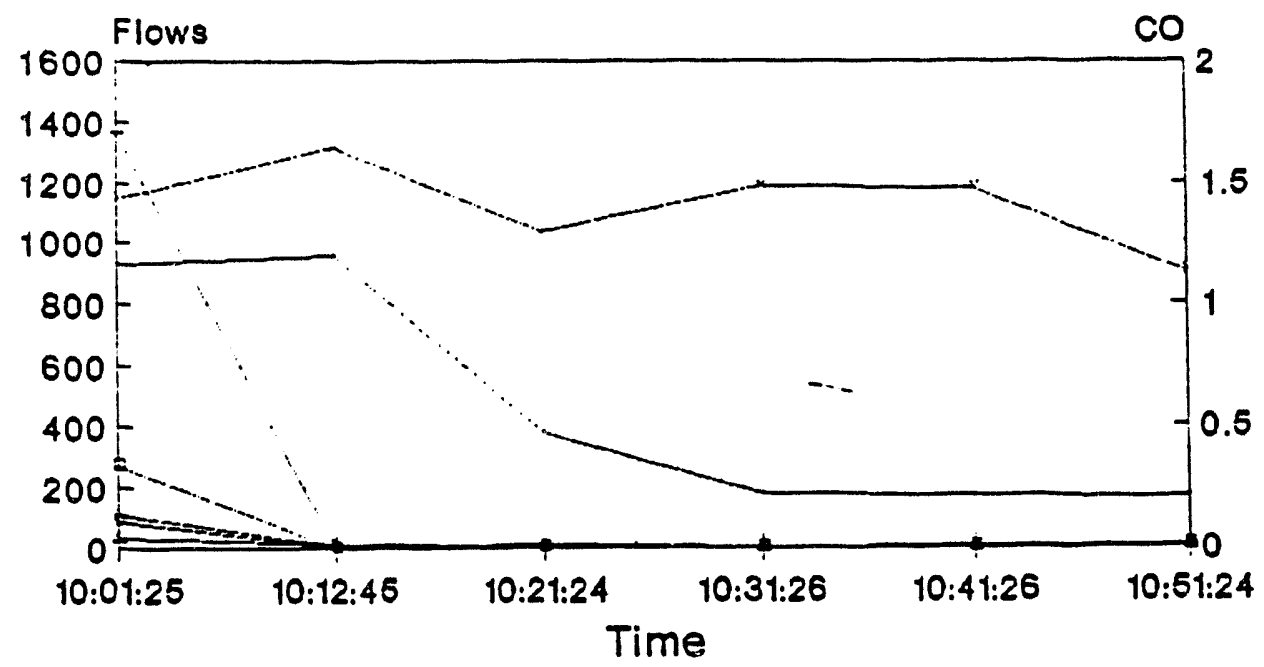

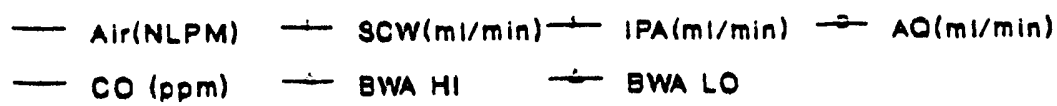



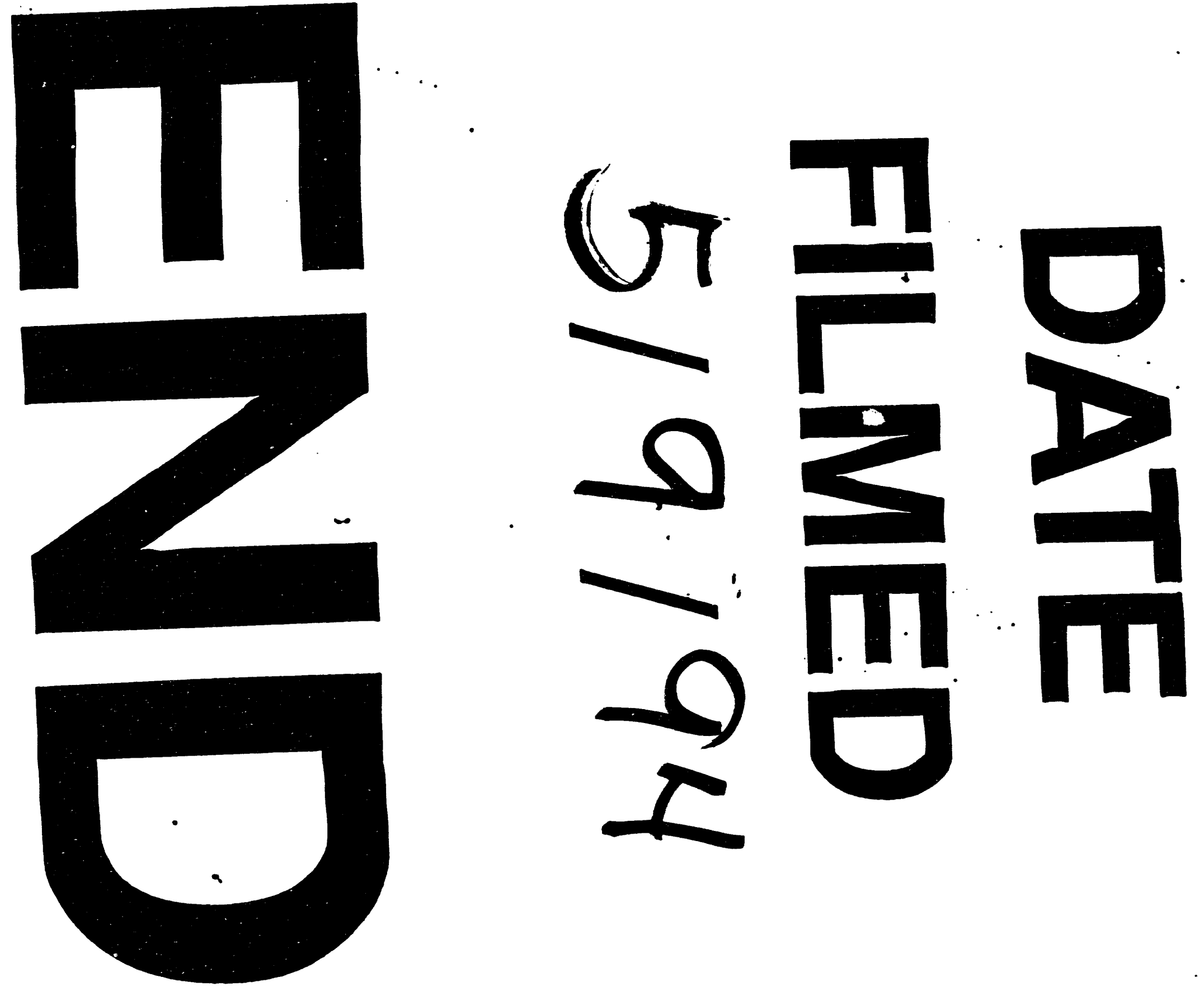
